\title{
WATER AND NUTRIENT RECYCLING BY HIGH RATE ALGAE PONDS FED IN PRIMARY TREATED MUNICIPAL WASTEWATER
}

\author{
A Thesis
}

presented to

the Faculty of California Polytechnic State University,

San Luis Obispo

\author{
In Partial Fulfillment
}

of the Requirements for the Degree

Masters of Science in Civil and Environmental Engineering

by

\section{Michael Field Chang}

June 2013 
(C) 2014

Michael Field Chang

ALL RIGHTS RESERVED 


\section{COMMITTEE MEMBERSHIP}

TITLE: $\quad$ Water and Nutrient Recycling in High Rate Algae Ponds

Fed in Primary Treated Municipal Wastewater

AUTHOR: $\quad$ Michael Field Chang

DATE SUBMITTED: June 2014

COMMITTEE CHAIR: $\quad$ Dr. Tryg Lundquist, Associate Professor

Environmental Engineering Department

COMMITTEE MEMBER: Dr. Greg Schwartz, Assistant Professor

Bio Resources and Agricultural Engineering Department

COMMITTEE MEMBER: $\quad$ Dr. Tracy Thatcher, Associate Professor

Environmental Engineering Department 


\begin{abstract}
Water and Nutrient Recycling by High Rate Algae Ponds Fed In Primary Treated Municipal Wastewater
\end{abstract}

\title{
Michael Field Chang
}

Algal biofuels present a promising future alternative to petroleum based fuels. Water nutrient recycling is a key step to increase the sustainability of algae biofuel production facilities. This thesis discusses the process of nutrient and water recycling in high rate algae raceway ponds (HRAP) fed primary treated municipal wastewater. Research was conducted primarily at the San Luis Obispo Water Resource Reclamation Facility (SLOWRRF). Nine $30 \mathrm{~m}^{2}, 0.3 \mathrm{~m}$ deep HRAP's were operated continuously from June 1, 2013 to April 17, 2014. The ponds were arranged in three sets of triplicate ponds, with two pond sets run on 3-day hydraulic residence time (HRT), and the third on a 2-day HRT. The biomass productivity of the 2-day HRT and 3-day HRT were compared. The two sets of 3-day HRT ponds were run in series to determine the effect on productivity associated with recycling growth media without supplemental nutrient addition. The first pond in series was referred to as round 1 and the second as round 2. Due to solids accumulation in the 2-day HRT ponds in summer proper biomass productivity values could not be determined. 4-inch standpipes were determined to cause the solids accumulation when large flocs were present in ponds. As a possible solution to the solids accumulation issue, a ramped standpipe was designed and installed in one pond per triplicate set. In winter the 2 -day HRT pond was roughly $37 \%$ more productive than the 3 -day HRT. In summer the round 1 (3-day HRT) ponds were roughly $33 \%$ more productive than the round 2 (3-day HRT) ponds. In winter the round 1 (3-day HRT) ponds were roughly $19 \%$ more productive than the round 2 (3-day HRT) ponds. The type of standpipe (ramped or 4-inch) did not cause a significant amount of solids accumulation in either of the 3-day HRT ponds. The type of standpipe did make a difference in the 2-day HRT ponds. On average the 4-inch standpipe pond had 35\% higher TSS than the ramped standpipe ponds. In addition to these field experiments, laboratory aerobic degradation experiments were conducted to determine the nutrient release of previously digested sludge in aerobic ponds. 
Pretreatment of algae sludge did not have a significant effect on nutrient release of previously anaerobically digested algae sludge in aerobic conditions. The maximum soluble nitrogen generated in the aeration reactors was between 56 for the treated sludge, and 66 for the untreated sludge.

Keywords: Nutrient recycling, water recycling, algal productivity, high rate algae ponds, solids accumulation, Aerobic degradation of algae, pretreatment of algae. 


\section{ACKNOWLEDGMENTS}

I would like to express my deepest appreciations to those who supported me throughout my time at Cal Poly.

To my family, all that I have accomplished would not have been possible without your unwavering love and support.

To Dr. Lundquist, every day I am truly amazed by the vast quantity of knowledge you have shared with me. It has been an amazing experience working with you.

To Dr. Thatcher and Schwartz, It has been an absolute honor to work with people as accomplished as you.

To Matt Hutton, Ian Woertz, and Neal Adler, your continual guidance has been instrumental to the success of my research. Your combined knowledge is truly awe inspiring. I hope to live up to the example you have set for me.

To Shelley Blackwell, thank you for your logistical, and biological expertise, and for making the ENVE 405 class the massive interdisciplinary program it has become.

To my fellow grad students, Alex Hill, Justin Kraetsch, Chad Boggess, and Eric Nicolai, thank you for your friendship and support. To Alex specifically, thank you for showing me the awesomeness that is Google Drawing, without it many of the figures in this thesis would have taken hours longer to produce.

To Perry Ng, Hillary Prince, Carter Reiff, Dylan Robertson, Alec Roberts, Brook Favillo, and Chase Perez thank you for sticking with the project for multiple quarters, without your dedication, expertise, and friendship this thesis would not have been possible.

To Amber Hanna thank you for your patience and for re-teaching me all the statistics I had forgotten.

To Matt Rodrigues, Elliot Ripley, and Louis Lefebvre, thank for showing me what it meant to be a grad student and for involving me in your research. The example you set for me was instrumental to the success of my research.

To all the ENVE 400/405 students, there are far too many of you to thank individually, but I am truly grateful for your diligence and dedication to this project.

To the administration and operators of the San Luis Obispo Water Resource Reclamation Facility thank you for providing us with land and wastewater to complete this research.

This project was funded by The Department of Energy. 


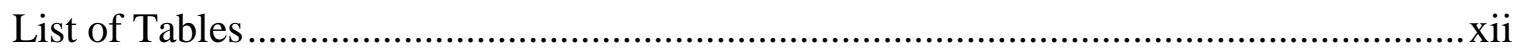

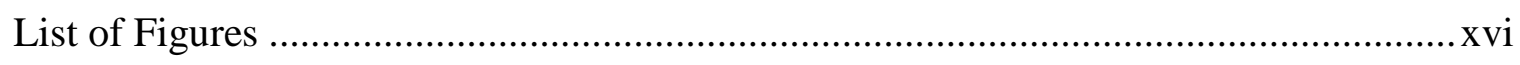

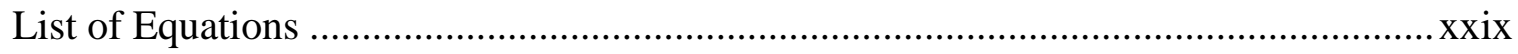

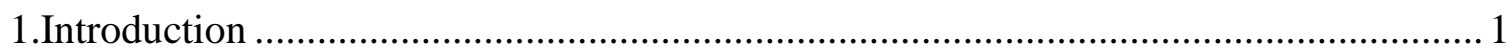

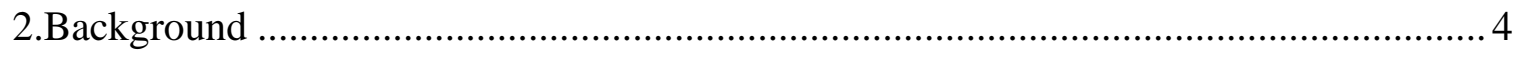

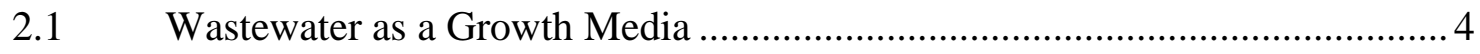

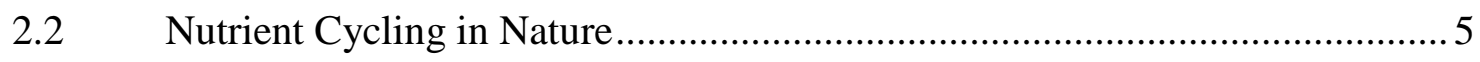

2.3 Aerobic Degradation of Algae …………...................................................

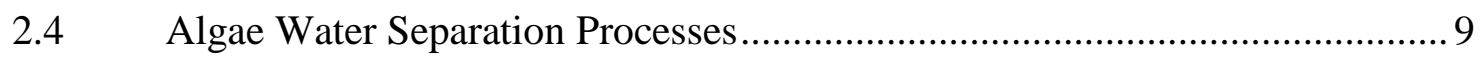

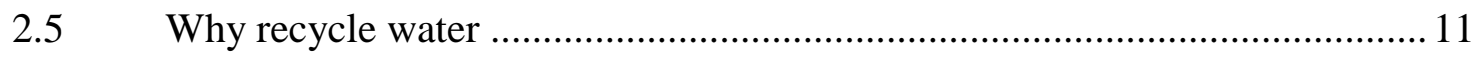

2.6 Factors Effecting Algal Pond Productivity ……......................................... 13

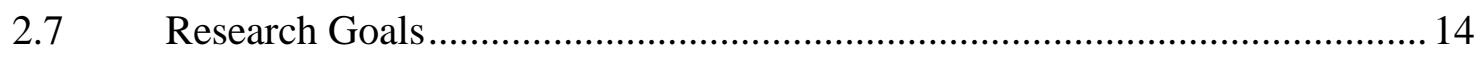

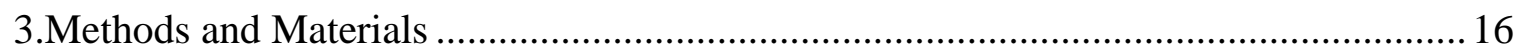

3.1 Algae Field Station: Location Layout ........................................................ 16

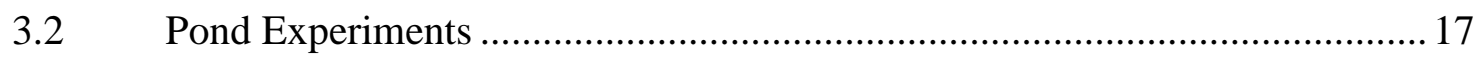

3.2.1 Experimental Concept and Purpose …………………............................ 17

3.2.2 Pond Process Flow ……………....................................................... 18

3.2.2.1 Tube Settler Design and Process Flow ................................................22

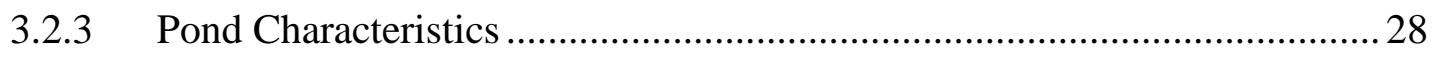

3.2.4 Pond Operations ……………………………........................................2 29 
3.2.3.1 Tube Settler Operations.

3.2.5 Pond Maintenance .................................................................................. 34

3.2.6 Description of Pond Experiments............................................................... 35

3.2.6.1 Two-Day Hydraulic Residence Time Performance …........................... 35

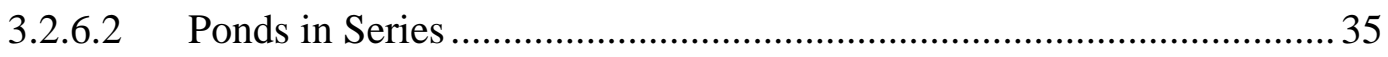

3.2.6.3 Standpipe Development and Performance Evaluation.......................... 37

3.2.7 Pond Sampling Procedures...................................................................... 40

3.2.7.1 Standpipe Testing Sampling Procedures............................................. 42

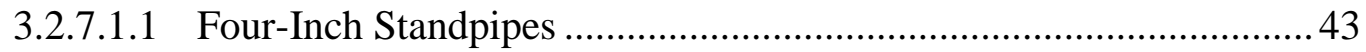

3.2.7.1.2 Ramped Standpipe ………………………................................... 43

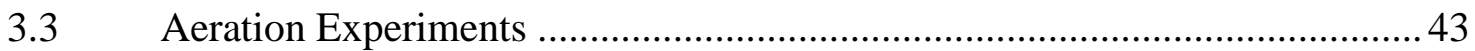

3.3.1 Post Sonication, Post Digestion Aerobic Decay Experiment....................... 44

3.3.2 Post-Homogenization, Post Digestion Aerobic Decay Experiment ............. 46

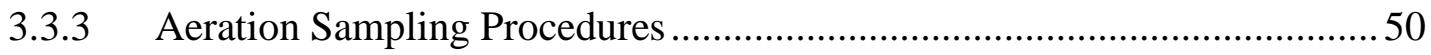

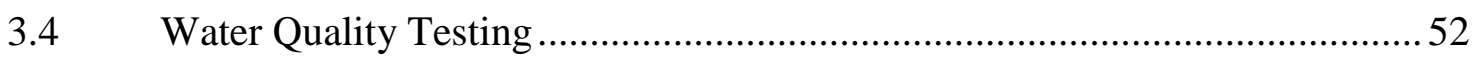

3.4.1 Suspended Solids Testing ........................................................................5

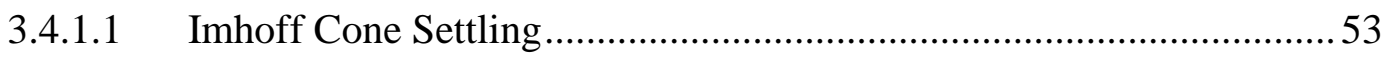

3.4.1.1.1 Sample Homogenization for 0-Hour TSS Samples ............................54

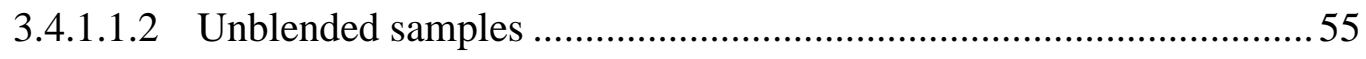

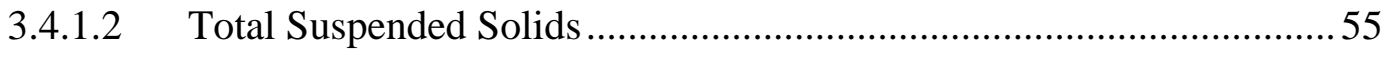

3.4.1.3 Volatile Suspended Solids ..............................................................5

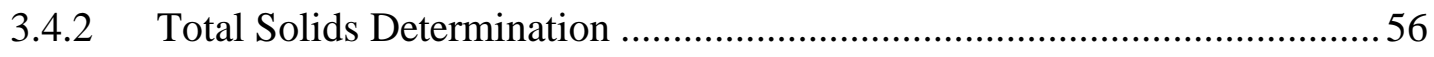

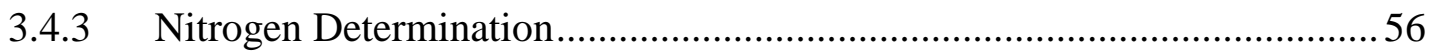


3.4.3.1 Total Ammonia Nitrogen Determination ........................................ 57

3.4.3.2 Total Kjeldahl Nitrogen Determination ........................................ 57

3.4.3.3 Organic Nitrogen Determination .................................................. 58

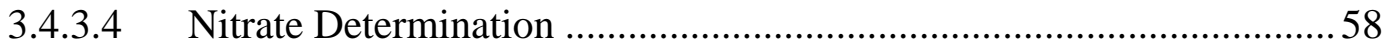

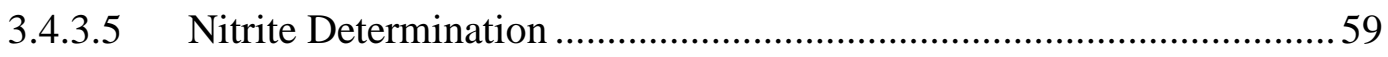

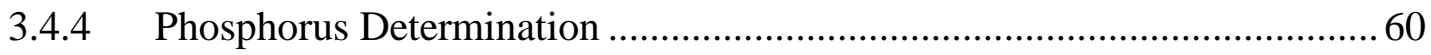

3.4.4.1 Dissolved Reactive Phosphorus Determination ............................... 60

3.4.4.2 Total Phosphorus Determination ............................................... 61

3.4.5 Biochemical Oxygen Demand Determination ..................................... 62

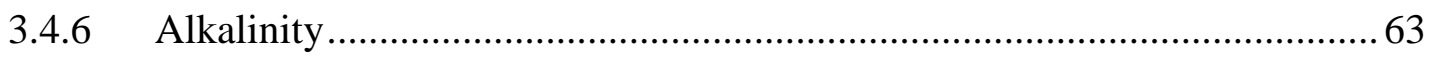

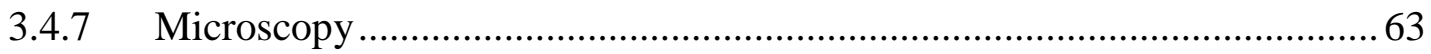

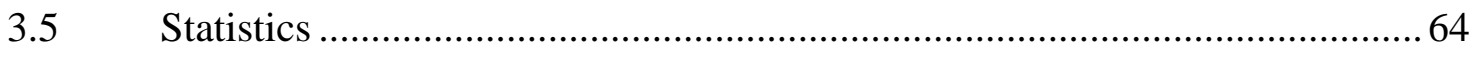

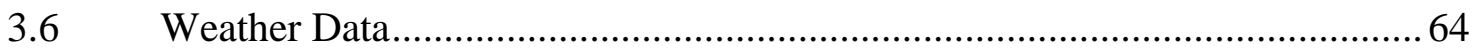

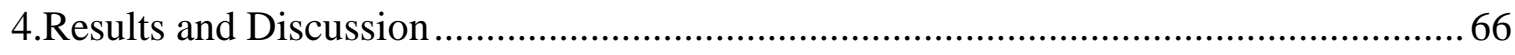

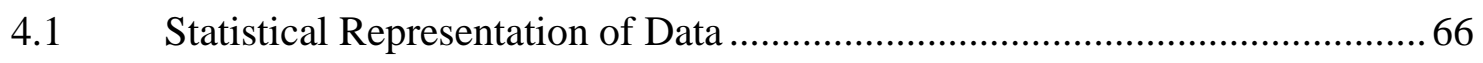

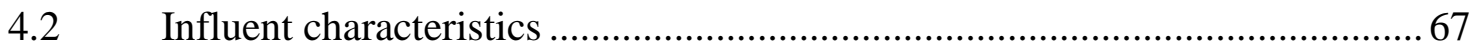

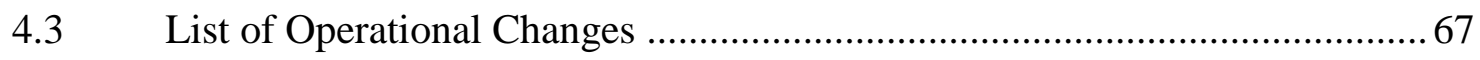

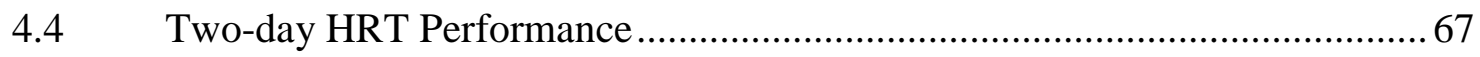

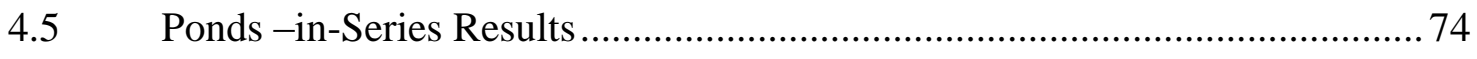

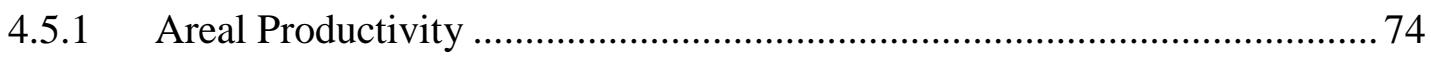

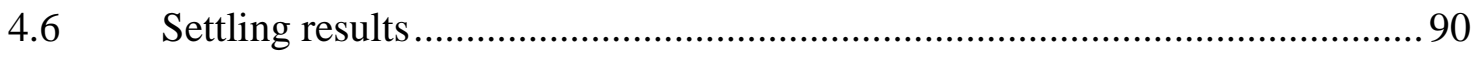

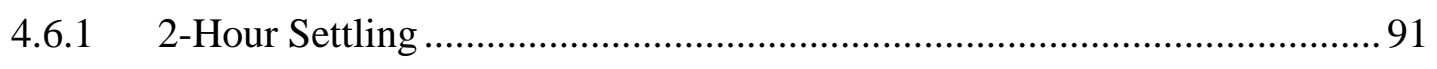

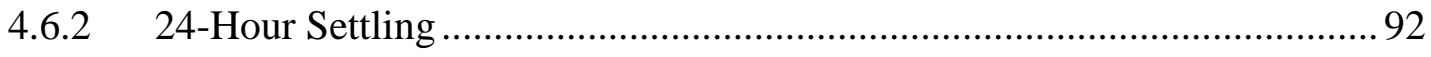




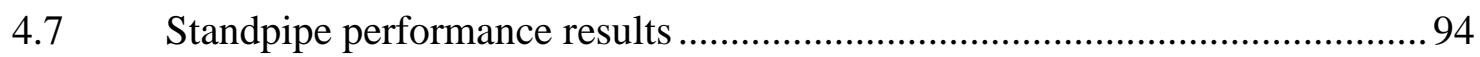

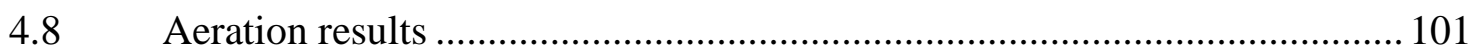

4.8.1 Results of the Aerobic Degradation of Sonicated-Digested Algae

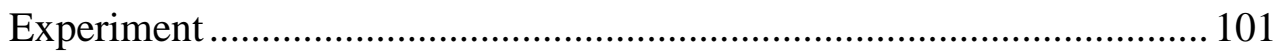

4.8.1.1 Temperature, $\mathrm{pH}$, Dissolved Oxygen................................................ 102

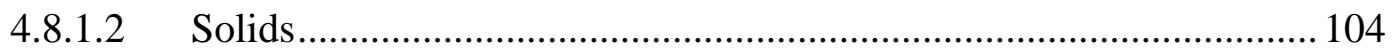

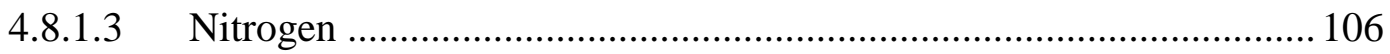

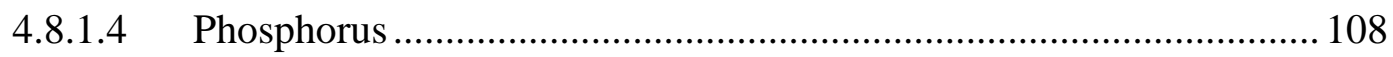

4.8.2 Results of the Aerobic Degradation of Homogenized-Digested Algae

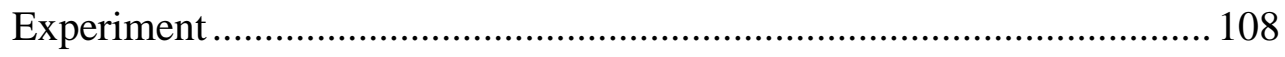

4.8.2.1 Temperature, $\mathrm{pH}$, and Dissolved Oxygen ....................................... 109

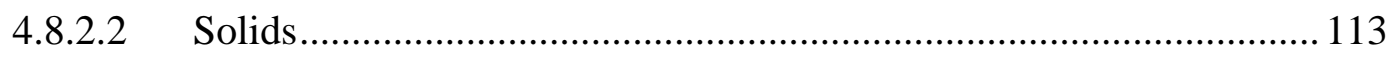

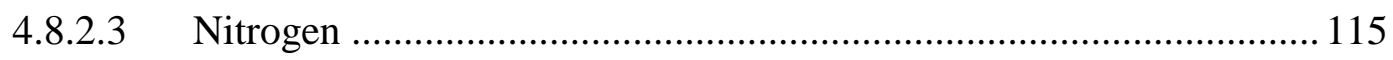

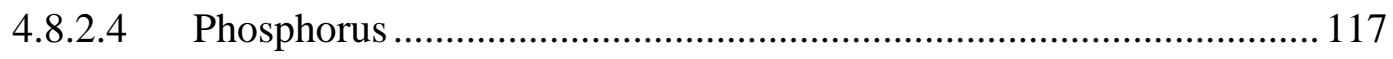

4.8.2.5 Statistical Results .................................................................... 120

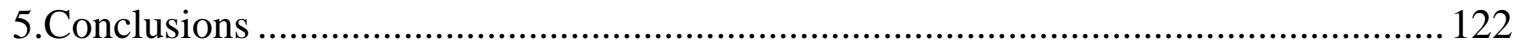

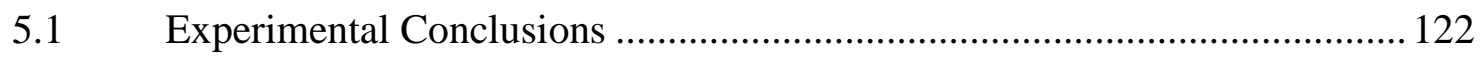

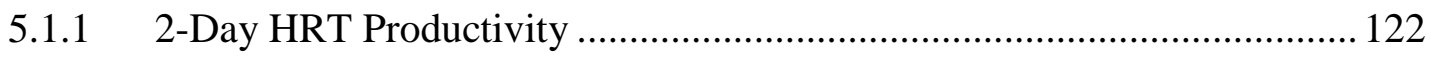

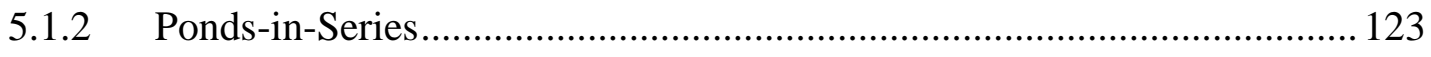

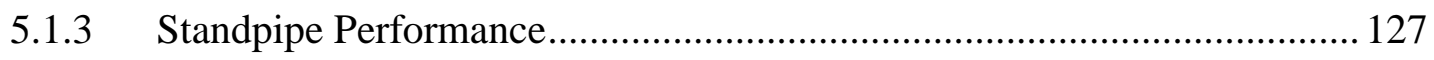

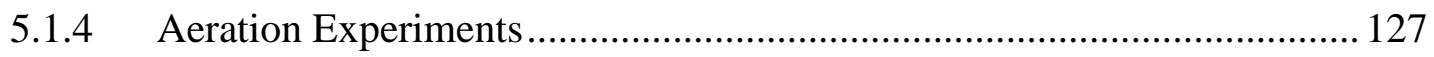

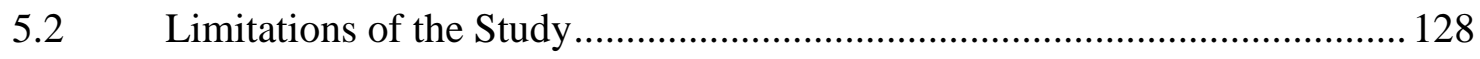

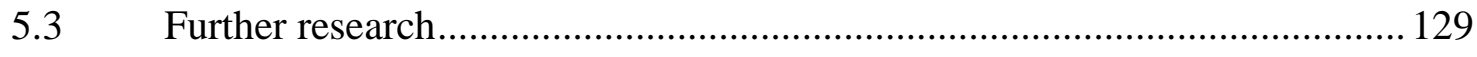




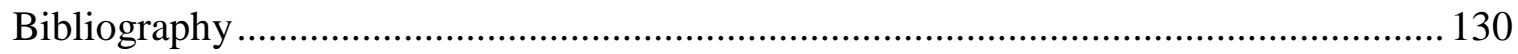

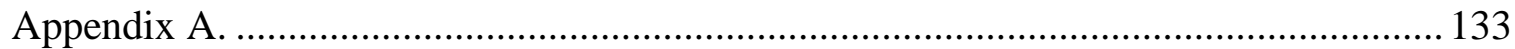

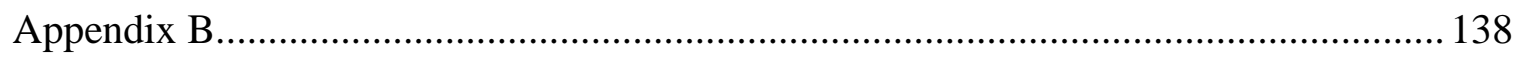

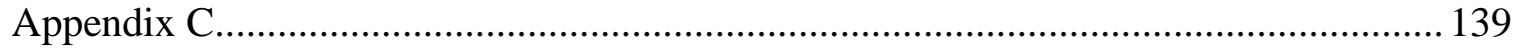

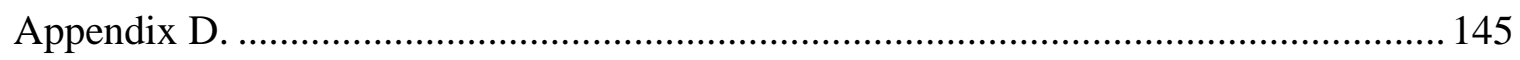

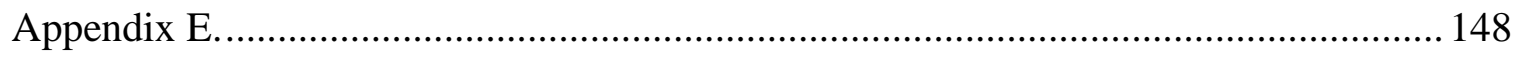

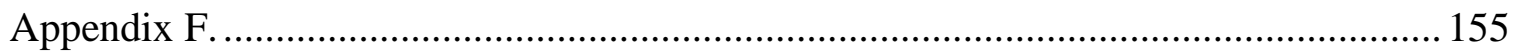




\section{List of Tables}

Table 3-1:Target pond characteristics from June 1, 2012 to July 1,2013 ........................ 28

Table 3-2: Target pond characteristics from July 1, 2013 to April 2014 ........................ 28

Table 3-3: Water quality analyses performed for all sample types. .............................52

Table 4-1: Influent characterization from March 6, 2013 to March 19, 2014 .................67

Table 4-2: Operational Changes for the Algae Field Station. ....................................... 67

Table 4-3: Seasonal variation in productivity for Ponds 7, 8 and 9 in the 2-d HRT

Gamma set. Summer was from March 6 to August 29, 2013, and winter was from September 4, 2013 to February 19, 2014. Note the Pond 7 productivity is presented but was not accurate due to solids accumulation. 69

Table 4-4: Seasonal variation in productivity for Ponds 4, 5, and 6 in the 3-d HRT Alpha set. Summer was from March 6 to August 29, 2013, and winter was from September 4, 2013 to February 19, 2014 69

Table 4-5: Seasonal variation in productivity for Ponds 1, 2, and 3 in the 3-day HRT Alpha set. Summer was from March 6 to August 29, 2013, and winter was from September 4, 2013 to February 19, 2014 
Table 4-6: Summer and winter 2-hour solids percent removal. Summer was from

March 6 to August 29, 2013. Winter was from Sept 4, 2013 to

February 26, 2014

Table 4-7: Summer and winter 24-hour solids percent removal. Summer was from March 6 to August 29, 2013. Winter was from Sept 4, 2013 to

February 26, 2014 .93

Table 4-8: summary of VSS results for the homogenization aeration experiment. 114

Table 4-9: Summary results of oxidized nitrogen for the homogenization aeration experiment.

Table 4-10: DRP released during homogenization experiment. 118

Table 4-11: List of p-values for a series of t-tests done on the homogenization aeration experiment. Red values indicate that there was significant difference between homogenized and untreated. Green values indicate borderline significance, and black values indicate no significant difference 121

Table 5-1: Summer and winter average productivity and percent difference for the 2 and 3-day HRT ponds. 123

Table 5-2: Average seasonal productivity for Round 1 and Round 2 ponds. 124

Table A-1: Summation of results of grab samples and 1 inch standpipe samples for testing the 1 inch standpipe design, samples taken on August 9th, 2013 .... 135 
Table A-2: Summary of results of grab and standpipe samples for samples taken on August 16th, 2013

Table A-3: Summation of results of grab samples and trough samples for testing the ramped standpipe for samples taken on September 4, 2013.

Table C-1: 0-Hour TSS values for the influent and ponds. 140

Table C-2: 0-Hour VSS values for influent and the ponds.

Table C-3: 2-Hour supernatant solids for all ponds. 142

Table C-4: 24-Hour supernatant solids for all ponds. 143

Table C-5: Tube settler supernatant TSS for all ponds.

Table D-1: Standpipe comparison for the Alpha ponds. 145

Table D-2: Standpipe comparison for the Beta ponds. 146

Table D-3: Standpipe comparison for the Gamma ponds. 147

Table E-1: Sonication experiment $\mathrm{pH}$, temperature, and dissolved oxygen 148

Table E-2: Sonication experiment VSS. 148

Table E-3: Sonication experiment TAN 149

Table E-4 Sonication experiment nitrate. 149

Table E-5: Sonication experiment nitrate. 150 
Table E-6: Sonication experiment dissolved reactive phosphorus

Table E-7: Homogenization experiment $\mathrm{pH}$, dissolved oxygen, and temperature

Table E-8: Homogenization experiment VSS

Table E-9: Homogenization experiment TAN

Table E-10: Homogenization experiment nitrite 152

Table E-11: Homogenization experiment nitrate 153

Table E-12: Homogenization experiment dissolved reactive phosphorus 153

Table E-13: Homogenization experiment TKN 154

Table F-1: Soluble nitrogen data for influent and all ponds. 155

Table F-2: Dissolved reactive phosphorus data for influent and all ponds 156 


\section{List of Figures}

Figure 1-1: Process flow for algae production with anaerobic digestion and oil extraction. (Lundquist, Woertz, Quinn, \& Benemann, 2010) 3

Figure 2-1: Algae and bacteria symbiotic relationship in treatment systems.

Soluble oxygen produced by the algae, replaces mechanical aerators.

Source: (Munoz \& Guieysse, 2006) After Oswald 1953 ..............................5

Figure 2-2: Nitrogen cycle. (Robarts \& Wetzel, 2002) ................................................... 6

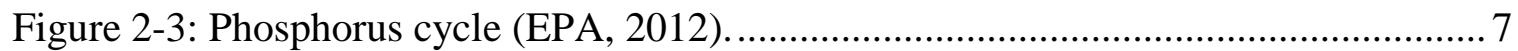

Figure 2-4: Nutrient evolution in DePinto, Verhoff experiments with cultures of

Chlorella and bacteria. The lag phase lasts for roughly 25 days

(DePinto \& Verhoff, 1977) ....................................................................... 8

Figure 2-5: Suspended solids concentration as a function of alum dose. (Golueke \&

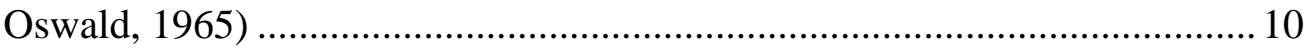

Figure 2-6: Locations of potential ponds sites with cost of water taken into account. (Venteris, Skaggs, Coleman, \& Wignosta, 2013)............................ 12

Figure 2-7: Map of solar insolation in the US. (NREL, 2008)....................................... 12

Figure 2-8: Water consumption and cost increase as oil production increases................. 13

Figure 3-1: Aerial View of AFS indicating the nine 33-m2 raceways, tube settlers, and influent wastewater source. 
Figure 3-2: Influent pump was located in the western primary clarifier.

Figure 3-3: Gamma constant head tank influent pump and distribution system. The water level in the tank is kept constant, and the speed and depth of the scoops is varied to adjust flow into the ponds.

Figure 3-4: Sump of AFS, water that over flows the stand pipe is collected in the sump and pumped back to primary clarifier

Figure 3-5: Raceway effluent was pumped back to the effluent weir of the primary clarifier

Figure 3-6: Alpha constant head tank, and distribution system. The top right photo shows how the tube settler effluent was fed into the head tank. There were six total feed lines, three on the left and three on the right side of the tank. 22

Figure 3-7: Tube settler influent line. Flow enters half way up side of tube settler, bulk water flows up and out of the top of the tube settler, while settled sludge falls to the bottom. 23

Figure 3-8: Bulkhead at the top of the tube settler where the supernatant exits and flows into the Alpha head tank. 24

Figure 3-9: Tube settler underdrain. Sludge is drained through the $3 / 4$ in ball valve. 24

Figure 3-10: Side view of tube settlers showing the $60^{\circ}$ angle of tilt. 25 
Figure 3-11: View from the top of an empty tube settler with tube cassette visible.

Water flows up through the tubes and sludge settles downward. 26

Figure 3-12: View from top of tube settler with perforated backpressure plate in place. 27

Figure 3-13: Side view of scum baffle uninstalled, and installed view of scum baffle. T-fittings prevented floating algae flocs from exiting the tube settler and entering the Alpha pond set 27

Figure 3-14: Neptune PM1 units for $\mathrm{pH}$ and temperature data acquisition. This set up is the same in all pump houses. 29

Figure 3-15: VFD's were used for controlling water and paddle wheel speed. The left most VFD controls the paddle wheel and the right VFD controls the water wheel. This set up is the same in all pump houses. 29

Figure 3-16: Beta pump house with PVC pipes plumbed through each side. 30

Figure 3-17: PVC pipes leaving pump house. Foam insulation was required due to excessive vibration in the lines causing the PVC to wear away. 30

Figure 3-18: Peristaltic pump set up in the Beta pump house. Water enters from the right and flows out the left side. Each pump pulls water from one pond, and feeds it into two tube settlers.

Figure 3-19: Probe stand. The $\mathrm{pH}$ and temperature probes were located in the center of the photo and were submersed in the water. The DO probe is 
held submerged by the blue rod that is held on the side of the stand by a bracket.

Figure 3-20: Left picture, $\mathrm{CO}_{2}$ tank racks located on the outside of the operations shed. Right picture, $\mathrm{CO}_{2}$ solenoid swithces used for distributing $\mathrm{CO}_{2}$ to the ponds 32

Figure 3-21: Sludge being emptied from the tube settlers. The left picture shows green sludge, the right picture shows clear water coming through the underdrain. 33

Figure 3-22: Process flow diagram for the ponds from July 2013 to April 2014 (Ripley 2013). Process flow described in detail in section 3.2.2 36

Figure 3-23: Schematic of solids separation by a standpipe. The small dots represent small flocs and colloidal algae, the larger circles represent large algae flocs, which were concentrated in the pond by the weir action of the standpipes. 37

Figure 3-24: Original four-inch diameter standpipe design installed in Pond 7. 38

Figure 3-25: Side view drawing of the ramped standpipe design. Flow lines were theoretically how water and solids were removed with trough design. Black arrows represent water and solids flow lines.

Figure 3-26: Ramp standpipe design as installed in Pond 7. 39

Figure 3-27: Tube settler supernatant sampling location for Pond 6 tube settler 
Figure 3-28: Sample analysis flow diagram showing subsample volumes reserved for analyses.

Figure 3-29: Sonication aeration batch reactor set up. Reactors were open to the environment; caps were only used to prevent environmental contamination. Mixers and water bath omitted from drawing for clarity. Water bath for this experiment was not temperature controlled. Air lines came in from the top of the reactors and extended to the bottom. Aerators were located at the lowest point that did not interfere with the stir bar mixer.

Figure 3-30: Experimental set up for homogenization experiment, as photographed at start up October 26, 2013.

Figure 3-31: Aeration stone layout for the homogenization aeration experiment. Suction cup was used to secure the aeration stones to the bottom of the reactors. 48

Figure 3-32: Valve at 45 degrees to provide air to reactors 48

Figure 3-33: Activated carbon air filter was used to remove impurities in the air supply 49

Figure 3-34: Typical sample flow for the aeration experiments. Dashed lines signify tests that were not run on every sample event. 
Figure 3-35: Solids adhered to the sides of the reactors as photographed on the final sampling day, February 7th 2014.

Figure 3-36: Imhoff settling cones after 24 hours of settling. Alpha ponds are left most, Beta ponds are in the middle, and Gamma ponds are on the right. Note the floating scum layer in Pond 9. Image taken July 18, 2013 54

Figure 4-1: Average data flow chart for the Alpha ponds. A similar process was used for Beta and Gamma. 66

Figure 4-2: Productivity in the Ponds 8 and 9 in the Gamma set (2-d HRT). Error bars are one standard deviation in the positive and negative direction. 68

Figure 4-3: Productivity in all ponds from March 6, 2013, to April 3, 2014. Error bars removed for clarity.

Figure 4-4: Solar insolation and productivity for the Gamma ponds from March 6, 2013 to April 17, 2014

Figure 4-5: Productivity and soluble nitrogen concentrations for the Gamma ponds. Error bars excluded for clarity. 72

Figure 4-6: Productivity and soluble phosphorus concentrations for the Gamma set ponds. Error bars excluded for clarity 73

Figure 4-7: Percent nitrogen in the biomass in Gamma. 74 
Figure 4-8: Net productivity for the Beta ponds. The mean and standard deviation of triplicates are shown for weekly data. The vertical line represents the shift from 4-d to 3-d HRT in Alpha.

Figure 4-9: Net productivity for the Alpha ponds. The mean and standard deviation of triplicates are shown for weekly data. The vertical line represents the shift from 4-d to 3-d HRT. 77

Figure 4-10: Productivity time series graphs of the Alpha and Beta set ponds. The green line represents the time of the HRT change in Alpha from 4 days to 3 days. Error bars have been removed for clarity. 78

Figure 4-11: VSS concentration of Alpha and influent to Alpha. Notice the two points where the influent VSS exceeds that of the ponds leading to a negative productivity 79

Figure 4-12: VSS of influent and average of Beta pond set. Notice the one point where VSS in the influent exceeds that of the ponds, this leads to the single negative value of productivity in the Beta set

Figure 4-13: Monthly average net productivity in Alpha and Beta set ponds from June 2013 to April 2014 81

Figure 4-14: Alpha productivity and solar insolation for San Luis Obispo. The data points for insolation are not connected for clarity. 82 
Figure 4-15: Beta productivity and solar insolation for San Luis Obispo. The data points for insolation are not connected for clarity.

Figure 4-16: Alpha productivity in and soluble nitrogen concentration. Error bars excluded for clarity. 84

Figure 4-17: Alpha productivity and soluble phosphorus concentrations. Error bars excluded for clarity. 85

Figure 4-18: Organic nitrogen as a percent of VSS for the Alpha ponds. 86

Figure 4-19: Productivity in Alpha ponds. Ponds 1 and 2 declined, while Pond 3 maintained constant. 86

Figure 4-20: Net Productivity and $\mathrm{pH}$ in Pond 1 . The $\mathrm{pH}$ data is taken from alkalinity data collected on the samples once transported back to the laboratory. 87

Figure 4-21: Net Productivity and $\mathrm{pH}$ in Pond 2 . The $\mathrm{pH}$ data is taken from alkalinity data collected on the samples once transported back to the laboratory 88

Figure 4-22: Net Productivity and $\mathrm{pH}$ in Pond 3 . The $\mathrm{pH}$ data is taken from alkalinity data collected on the samples once transported back to the laboratory 88 
Figure 4-23: Beta productivity and soluble nitrogen concentrations. Error bars excluded for clarity. The green line represents the change from a 4 day HRT to a 3 day HRT in Alpha.....

Figure 4-24: Beta productivity and soluble Phosphorus concentrations. Error bars excluded for clarity. The green line represents the change from a 4 day HRT to a 3 day HRT in Alpha. 90

Figure 4-25: 2-hour settling for all pond sets from March 6, 2013 to March 19, 2014 92

Figure 4-26: 24-hour settling for all pond sets from March 6, 2013 to March 19, 2014 93

Figure 4-27: TSS of ramped and 4-inch standpipes for Gamma from October 2, 2013 to April 17, 2014 94

Figure 4-28: TSS of ramped and 4-inch standpipes for Beta from October 2, 2013 to April 17, 2014 95

Figure 4-29: TSS of ramped and 4-inch standpipes for Alpha from October 2, 2013 to April 17, 2014 .95

Figure 4-30: Weekly average TSS for Gamma set ponds with ramped and 4-inch standpipe from October 2013 to April 2014. Error bars are one standard deviation in positive and negative direction. 97 
Figure 4-31: Weekly average TSS for Beta set ponds with ramped and 4-inch standpipe from October 2013 to April 2014. Error bars are one standard deviation in positive and negative direction. 98

Figure 4-32: Weekly average TSS for Alpha set ponds with ramped and 4-inch standpipe from October 2013 to April 2014. Error bars are one standard deviation in positive and negative direction. 99

Figure 4-33: Seasonal floc size variation in all ponds 100

Figure 4-34: Temperature of the reactors for the sonicated algae aeration experiment. 102

Figure 4-35: $\mathrm{pH}$ data for sonication aeration experiment. 103

Figure 4-36: Dissolved oxygen concentration for the sonication aeration experiment. 104

Figure 4-37: VSS concentration data for the sonication aeration experiment. 105

Figure 4-38: TAN data for the sonication aeration experiment. This graph shows up until the point when the TAN concentrations reached zero. The concentration remained at zero until the end of the experiment on September 20, 2013 106

Figure 4-39: Total soluble nitrogen for the sonication aeration experiment. Error bars were omitted from this graph because the standard deviations were too small to be visible 107 
Figure 4-40: Dissolved reactive phosphorus graph for the sonicated aeration experiment 108

Figure 4-41: Temperature for the unhomogenized control samples in the homogenized aeration experiment. Error bars are one standard deviation in the positive and negative direction but are obscured by data points.

Figure 4-42: Temperature for the homogenized samples in the homogenized aeration experiment. Error bars are one standard deviation in the positive and negative direction but are obscured by data points 110

Figure 4-43: pH for the unhomogenized control samples of the homogenized aeration experiment. Error bars are one standard deviation in the positive and negative direction.

Figure 4-44: $\mathrm{pH}$ for the homogenized samples of the homogenized aeration experiment. Error bars are one standard deviation in the positive and negative direction.

Figure 4-45: Dissolved oxygen graphs for the unhomogenized samples of the homogenized aeration experiment. Error bars are one standard deviation in the positive and negative direction.

Figure 4-46: Dissolved oxygen graphs for the homogenized samples of the homogenized aeration experiment. Error bars are one standard deviation in the positive and negative direction. 
Figure 4-47: VSS graph of both the homogenized and unhomogenized samples from the homogenized experiment. Error bars are one standard deviation in the positive and negative direction.

Figure 4-48: Normalized VSS for both the homogenized and unhomogenized samples of the homogenization experiment. Values were normalized by the initial VSS concentration of the samples. Error bars removed for clarity

Figure 4-49: Nitrogen evolution graph for unhomogenized samples from homogenization aeration experiment. Error bars are one standard deviation in the positive and negative directions. Data points are the mean values of triplicate reactors. 115

Figure 4-50: Nitrogen evolution graph for homogenized samples from homogenization aeration experiment. Error bars are one standard deviation in the positive and negative directions. Data points are mean values from triplicate reactors.

Figure 4-51: DRP for the homogenized aeration experiment. 118

Figure 4-52: Homogenized DRP graphed with VSS degradation. Error bars were excluded for clarity.

Figure 4-53: Unhomogenized DRP graphed with VSS degradation. Error bars were excluded for clarity. 120 
Figure 5-1: Summer and winter average productivity for the 2 and 3-day HRT

$$
\text { ponds. }
$$

Figure 5-2: Seasonal productivity for Round 1 and Round 2 ponds.............................. 124

Figure 5-3: Possible two pond production schematic 126

Figure A-1: Finned standpipe design, the fins were meant to allow the water to well up behind the standpipe and create a deeper wave. 


\section{List of Equations}

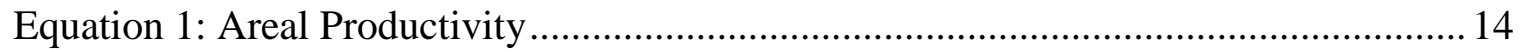

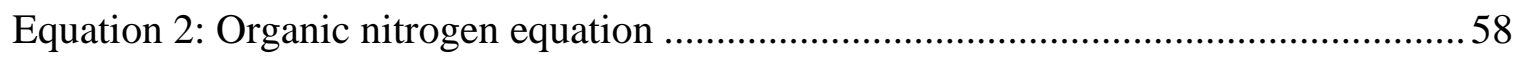

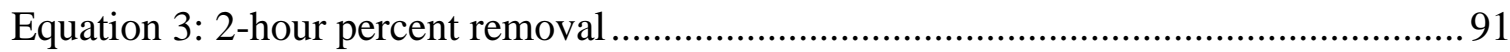




\section{Introduction}

Increased awareness of the global energy crisis has spurred the Department of Energy's (DOE) Office of Energy Efficiency and Renewable Energy, (EERE) Office of the Biomass Program (OBP) to explore possible alternative fuels (U.S. Department of Energy, 2012). Biofuels are one such alternative. Biofuels are fuels that are directly derived from biological material (National Renewable Energy Laboratory, 2014). Crops commonly used for biofuels included, corn, sugar cane, soybeans, palm, mustard, and microalgae.

The biofuel potential of micro algae is much higher compared to terrestrial feedstocks. Microalgae are aquatic organisms that can be grown in areas with poor soil characteristics that would be unacceptable for land based feedstocks. Algae do not have to exert energy to grow dense root structures, which allows them to reproduce much faster than other feedstocks. Algae produce biomass anywhere from ten to 15 percent faster than the fastest land growing biofuel feedstocks (Cellana Inc., 2013) (Huntley \& G.Redalje, 2007).

Microalgae are commonly used to produce two different types of biofuels. The first is biogas which is produced during anaerobic digestion. Biogas is a combination of methane, carbon dioxide and various other gases. For more information on biogas production refer to Hill, 2014.

Biodiesel is another biofuel commonly derived from microalgae. Under stressful conditions, such as nitrogen starvation, algae store energy in the form of lipids. These 
lipids can be extracted with solvents and converted to biodiesel through a transesterification reaction. (Kelley, 2013).

To increase the sustainability of algal biofuels and make them a competitive alternative to petroleum fuels, the production of the algae must be as efficient as possible. Reusing water and nutrients as much as possible is one way of achieving this goal. Water recycling is the process of growing algae on water that has already been used to grow algae. There are several issues with water recycling. One such issue is that in order to grow new algae on recycled media, the algae must first be separated from the water. Traditionally removal of algae from water has involved expensive chemical additions or dissolved air flotation (Golueke \& Oswald, 1965). Another issue is that when the density of algal cultures increase, algae can release inhibitory chemicals designed to reduce competition from other organisms. These compounds are called allelopathic chemicals. For more on inhibition and allelopathic chemicals refer to Boggess, C.D. (2014).

Nutrient recycling can be achieved by lysing and anaerobically digesting algae sludge. Anaerobic bacteria break down biomass (Kristiensen, Ahmend, \& Devol H, 1995) and release the nutrients trapped within it. The nutrient rich sludge can then be recycled back into the ponds. Nutrient recycling has the potential to greatly reduce algae production dependence on external nutrient sources. Anaerobic digestion has the added benefit of producing energy through the production of biogas. Biogas can be cleaned and combusted to produce energy, heat, and $\mathrm{CO}_{2}$. The $\mathrm{CO}_{2}$ can them be diffused into the ponds to regulate $\mathrm{pH}$ and serve as a carbon source for the algae (Figure 1-1). 


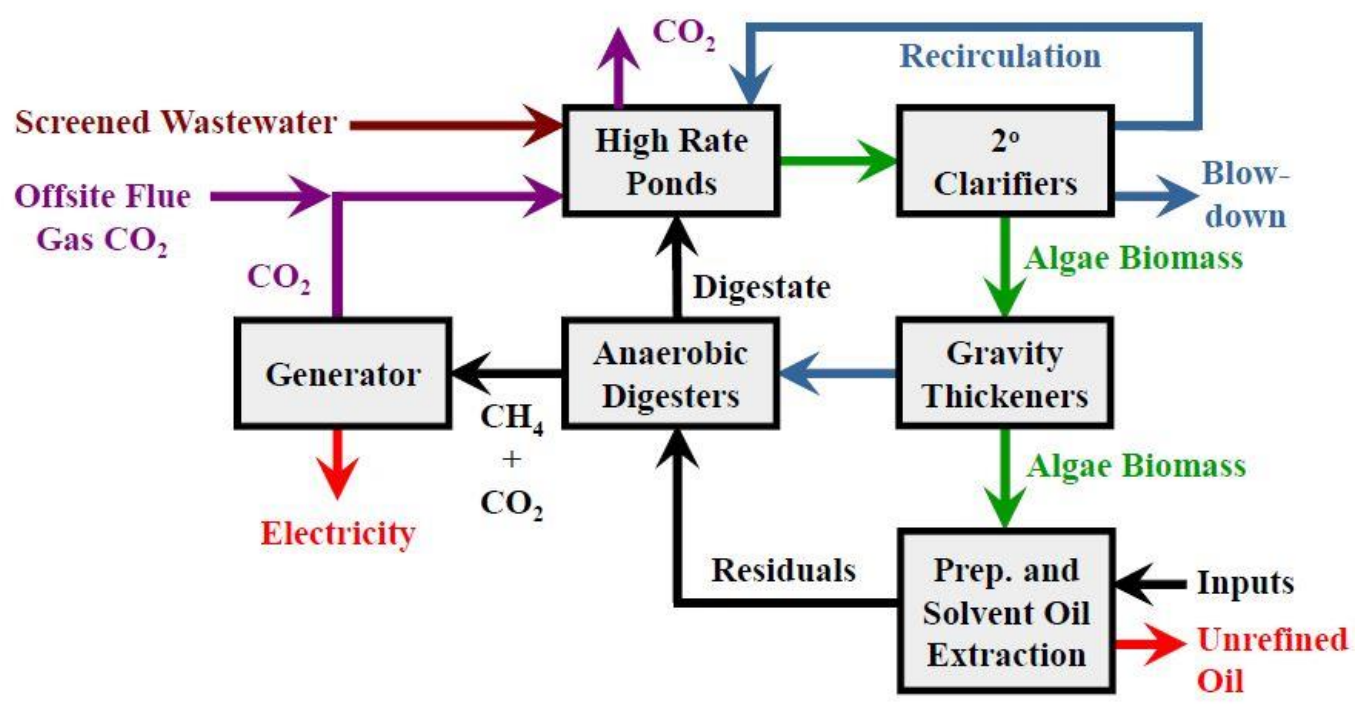

Figure 1-1: Process flow for algae production with anaerobic digestion and oil extraction. (Lundquist, Woertz, Quinn, \& Benemann, 2010)

Nutrient and water recycling will help increase the water and nutrient efficiency of algal production. This thesis focused on comparing productivity of algae grown on fresh primary treated wastewater, and recycled water, as well as how digested sludge degrades in aerobic environments and releases nutrients. 


\section{Background}

This section outlined the significant research previously done in the area of nutrient and water recycling. Previous studies have focused on discerning how algae degrade in natural waters, as opposed to engineered systems.

\subsection{Wastewater as a Growth Media}

As aquatic organisms, Algae require a nutrient rich liquid media to grow. For biofuel purposes, algae must be grown under optimum conditions to achieve the highest possible biomass yield.

There are numerous methods used to cultivate algae. Like plants algae require sun, water, and nutrients to grow. Unlike terrestrial plants algae must be grown in a liquid media, because of this water is more important than with other biofuel feedstocks.

Several options are currently used for cultivating algae. One option is to grow algae on freshwater supplemented with chemical fertilizers. This method is most commonly used for food grade algae production. Freshwater cultivation is undesirable because it adds unnecessary stress on municipal water supplies and purchasing it can be expensive.

Another option is salt or brackish water. Saltwater cultivation requires algae strains that are suited for high salt concentrations. Unlike freshwater, saltwater has the advantage of not interfering with freshwater supplies; however fertilizers are still needed to add nutrients. Because saltwater is cheaper it is one of the most common growth media used for algae cultivation. 
Wastewater is currently an underutilized growth media. Wastewater is ideal for mixed culture algae production. Wastewater is easily and cheaply available in most areas. It is full of nitrogen, and phosphorus, the two main nutrients needed for algal growth. As a non-potable source of water wastewater does not interfere with municipal or agricultural water supplies.

Growing algae in wastewater has the added benefit of treating the water. Algal wastewater systems take advantage of the symbiotic relationship between algae and bacteria. Algae produce oxygen, which bacteria need to remove soluble pollutants, and the bacteria produce $\mathrm{CO}_{2}$ which the algae use as a carbon source for photosynthesis (Figure 2-1) (Oswald, 1990).

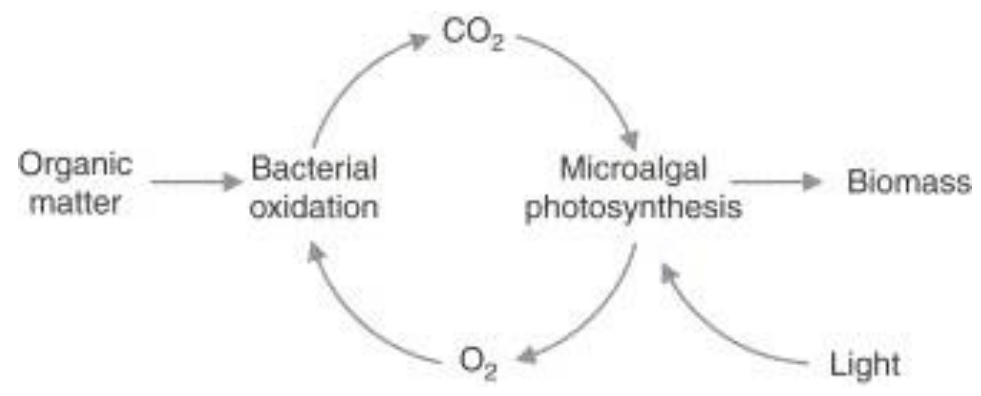

Figure 2-1: Algae and bacteria symbiotic relationship in treatment systems. Soluble oxygen produced by the algae, replaces mechanical aerators. Source: (Munoz \& Guieysse, 2006) After Oswald 1953

Algae treatment systems have been in use since the mid 1950's, however because of the large amount of space required for them they have not caught on as a popular treatment technology. This area of study was pioneered by Dr. William Oswald.

\subsection{Nutrient Cycling in Nature}

Nutrients are constantly recycled in natural water bodies when cellular debris decomposes in the sediments and water column. Recycling can be achieved either 
aerobically or anaerobically. The nitrogen and phosphorus cycles (Figure 2-2, Figure 2-3) are examples of nutrient recycling processes in nature.

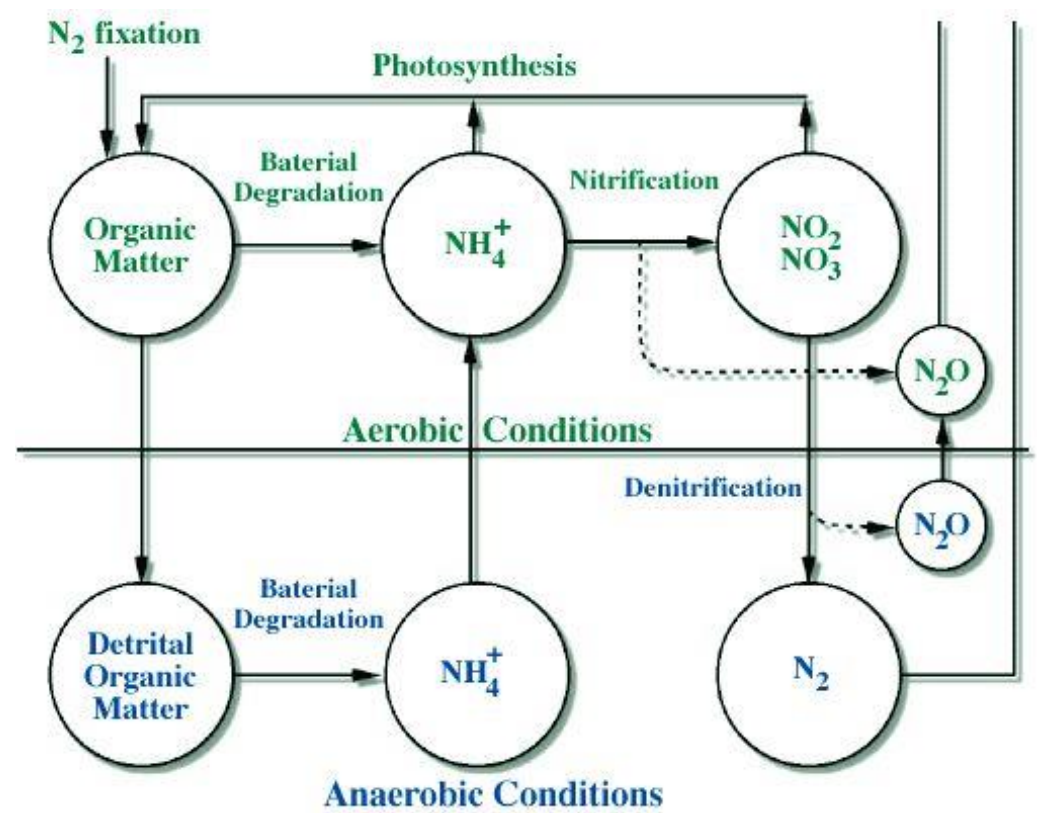

Figure 2-2: Nitrogen cycle. (Robarts \& Wetzel, 2002)

In the nitrogen cycle bacteria, plants, and algae cycle ammonia between decaying and living biomass, and the environment. 


\section{The Phosphorus Cycle}

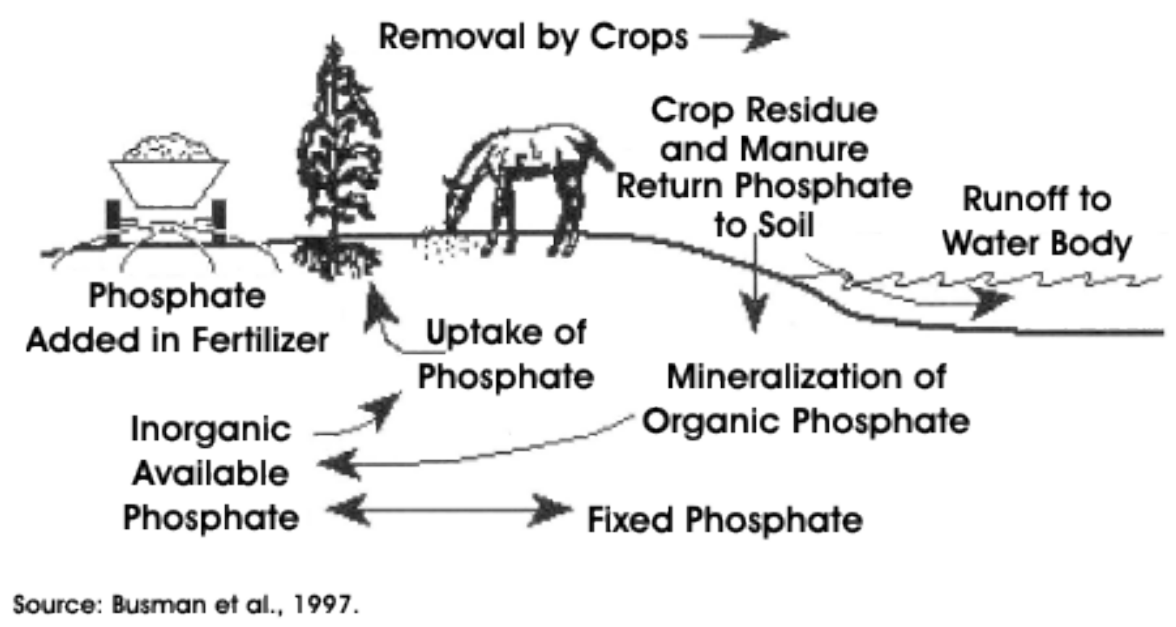

Figure 2-3: Phosphorus cycle (EPA, 2012).

Phosphorus is a mineral that is mined from underground rock deposits. It is an essential nutrient for many forms of life. In nature phosphorus is cycled between being taken up by plants and animals to soluble and mineralized forms.

\subsection{Aerobic Degradation of Algae}

There have been several attempts to quantify the rate and extent of nutrient regeneration from decomposing algal biomass in natural waters. Initially naturally occurring mixed cultures of lake algae were studied (Jewell \& McCarty, 1971) followed later by pure cultures (DePinto \& Verhoff, 1977). Both of these studies the algae used grown in the laboratory conditions under artificial lighting. Neither study made any attempt to lyse the cells prior to decomposition. They both found that in cultures inoculated with degrading bacteria, there was a short initial lag phase where the bacteria grew in number, followed by a simultaneous decrease in solids, and increase in soluble nutrient concentrations (Figure 2-4). 

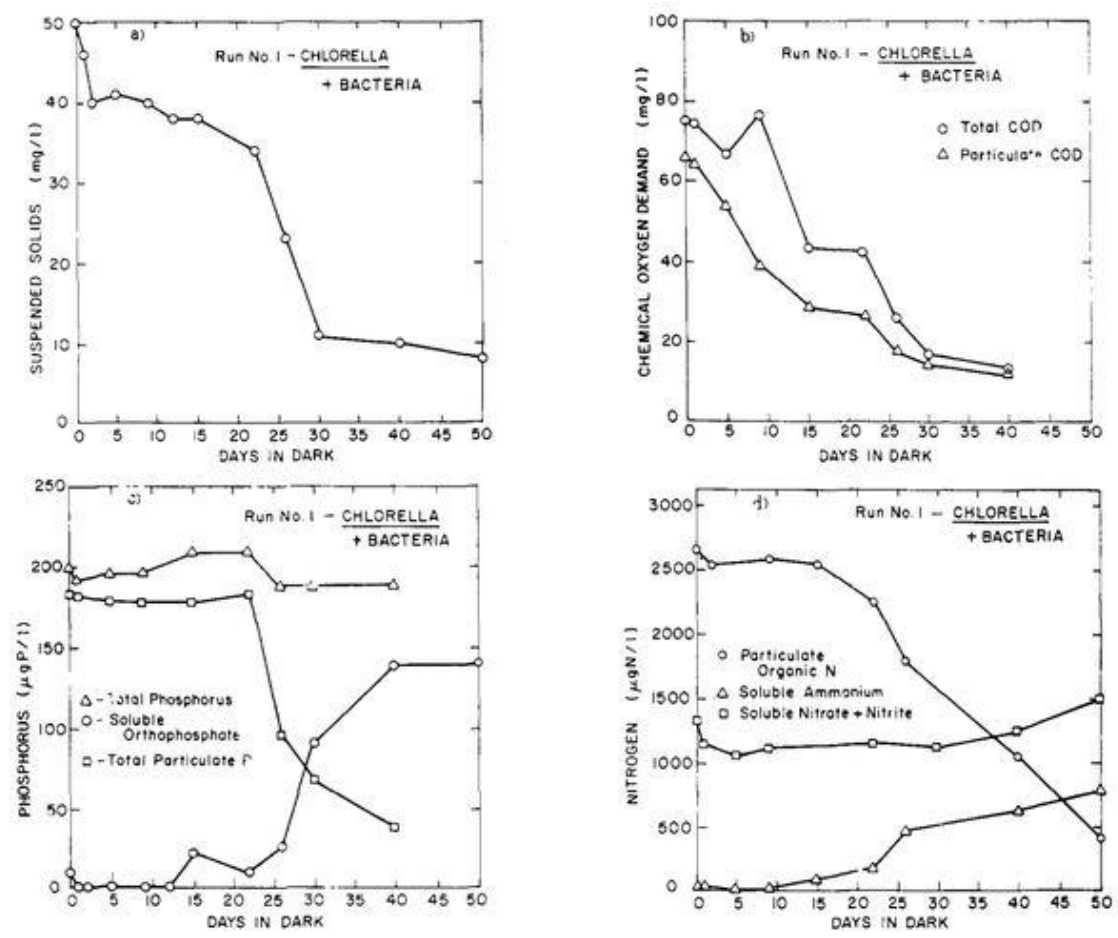

Figure 2-4: Nutrient evolution in DePinto, Verhoff experiments with cultures of Chlorella and bacteria. The lag phase lasts for roughly 25 days (DePinto \& Verhoff, 1977)

Decay followed first order kinetics with reaction constants $(\mathrm{k})$ ranging from 0.01 to 0.06 for young cultures (less than 30 days) (Jewell \& McCarty, 1971).Nutrient regeneration, specifically phosphorus occurred in three stages. The first being release of phosphorus from the cells due to endogenous respiration. Followed by lag period where no phosphorus is released. Lastly bacteria concentrations are great enough that they start breaking down algal cells and releasing soluble forms of Phosphorus (DePinto \& Verhoff, 1977). Nitrogen release from algal cells is directly related to the extent of organic decomposition. Not all nutrients within algal cells are available for regeneration. The non-bioavailable fraction of algal cells was found to be around $40 \%$ with some variability depending on cell age (Jewell \& McCarty, 1971). Younger cells have a higher non-bioavailable fraction; which is unfortunate because the younger cell cultures yielded higher degradation coefficients. 


\subsection{Algae Water Separation Processes}

Removal of algae from water is a top priority for algal wastewater treatment and biofuels. For wastewater it is important to remove the algae because colloidal algae reduce water clarity. For biofuels it is important to recover as much biomass possible to achieve the highest yield.

Studies have been done on the most effective method of removing algae from water. Biomass harvesting is achieved in three main steps, primary concentration, dewatering, and drying (Golueke \& Oswald, 1965). The tube settlers studied for this thesis, fall under the primary concentration category.

From their report Golueke and Oswald determined the most promising methods of primary concentration to be centrifugation, and chemical coagulation. High algae removal was achieved with both of these techniques. In the field study centrifugation was able to achieve best results of 80 to 90 percent removal with a throughput of 100 gallons per minute and a $3000 \mathrm{rpm}$ rotor speed.

Chemical precipitation with high doses of alum $\left(\mathrm{Al}_{2}\left(\mathrm{SO}_{4}\right)_{3} \cdot 18 \mathrm{H}_{2} \mathrm{O}\right)$ successfully remove algae from water, suspended solids concentrations in supernatant dropped to below 30 $\mathrm{mg} / \mathrm{L}$ 


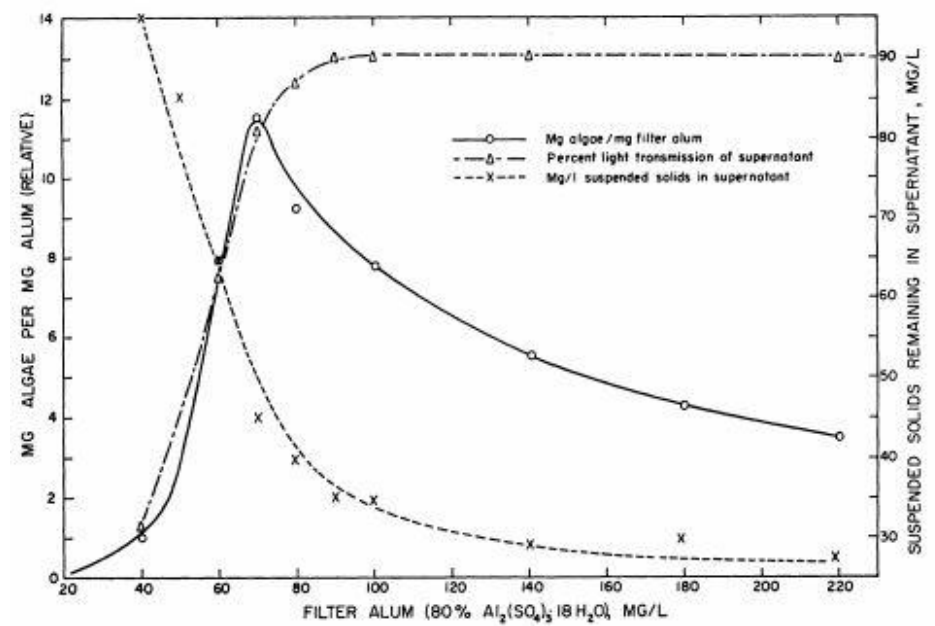

Figure 2-5: Suspended solids concentration as a function of alum dose. (Golueke \& Oswald, 1965)

Organic polymers are another popular method of settling small solids in water. These polymers are long carbon chains with many charged branches which attach to coagulated solids and bind them together. The charged branches can be either positive or negative. Polymer can work in conjunction with coagulants to achieve maximum settling

Centrifugation, chemical coagulation, and flocculation require external inputs to concentrate algae, electricity and chemicals. These inputs make centrifugation, coagulation, and flocculation not ideal for algae biofuel production. Bioflocculation and gravitational settling of algae presents the best possible case for algae production.

Bioflocculation is the process by which bacteria and algae clump together and form large flocs that settle out of water by gravity. Bioflocculation is believed to be causes by extracellular polysaccharides (EPS) excreted by the bacteria under certain conditions. The exact conditions which EPS is excreted are not fully understood.

Activated sludge is an example of a current technology that employs bioflocculation and sedimentation. The ability to easily separate biomass from treated water is important for 
the success of activated sludge. Activated sludge requires a thick layer of sludge to recycle to the front of the reactors to adjust solids retention time. (Metcalf \&Eddy, Inc., 2003).

Previous research into algal settling has focused on bioflocculant algae as a method to remove TSS from algae treated wastewater to within regulatory limits. Higher organic loading rates into the ponds led to better algal settling performance (Frost, 2008). Adding recycled activated sludge (RAS) to the ponds has been contributed to better settling performance as well (Lefebvre, 2012).

\subsection{Why recycle water}

Reducing costs where ever possible is an ever present goal in the biofuel industry. Most areas of the United States with high solar insolation do not have adequate access to water. Lack of local water availability in areas with high solar potential increases production cost. Costs associated with importing water would be transferred to the cost of the fuel increasing the price and making it undesirable to consumers.

Figure 2-6 and Figure 2-7 show the locations in the United States with water available for algae production and the average annual solar insolation in the US. The areas in red receive the most solar radiation which means they are ideal for algae growth however within this area there are few potential pond sites. Water recycling would reduce the demand for water in algae systems, and reduce the cost associated with it. 


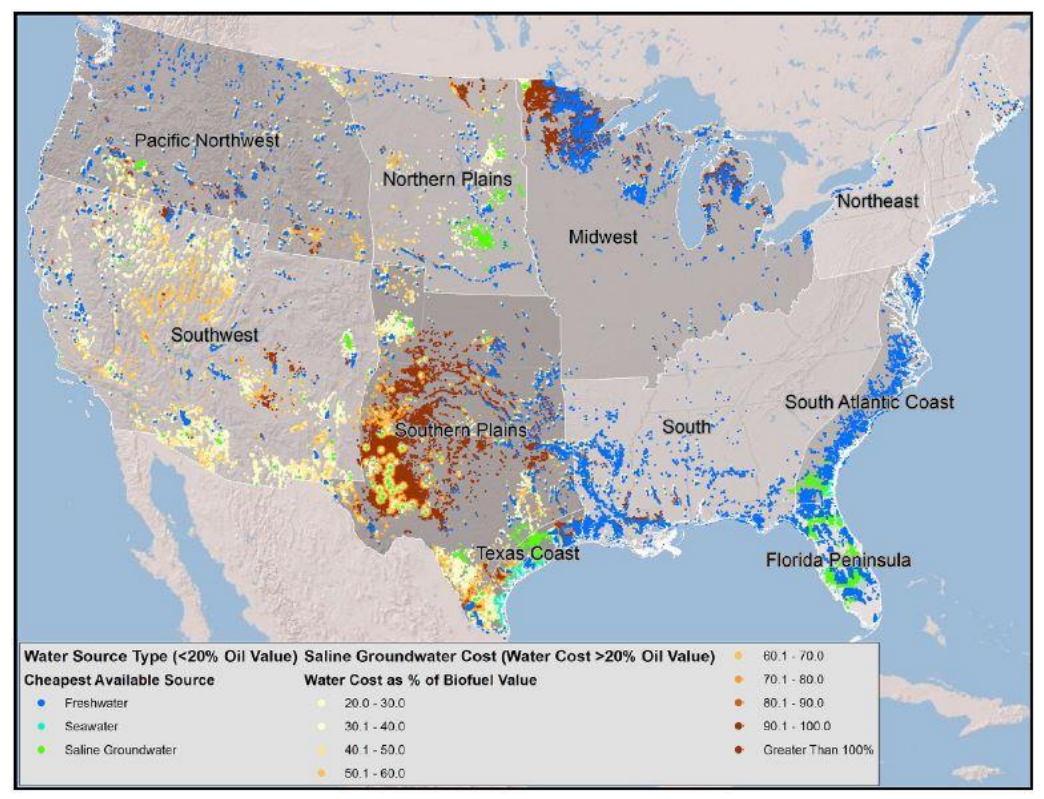

Figure 2-6: Locations of potential ponds sites with cost of water taken into account. (Venteris, Skaggs, Coleman, \& Wignosta, 2013)

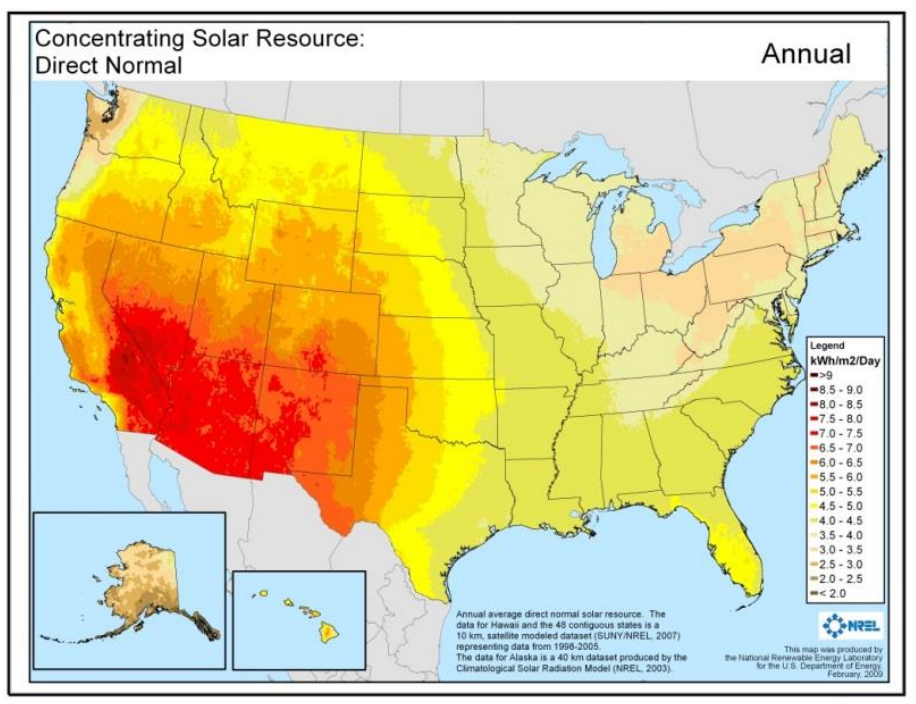

Figure 2-7: Map of solar insolation in the US. (NREL, 2008) 
To have any effect on transportation fuel usage, algae biofuels will need to provide millions of gallons of fuel. In order to produce on this scale, production facilities would have to be very large. As the size of a system increases so does the potential oil production, and water usage (Figure 2-8). Water recycling on a large scale could reduce the cost and consumption of water.

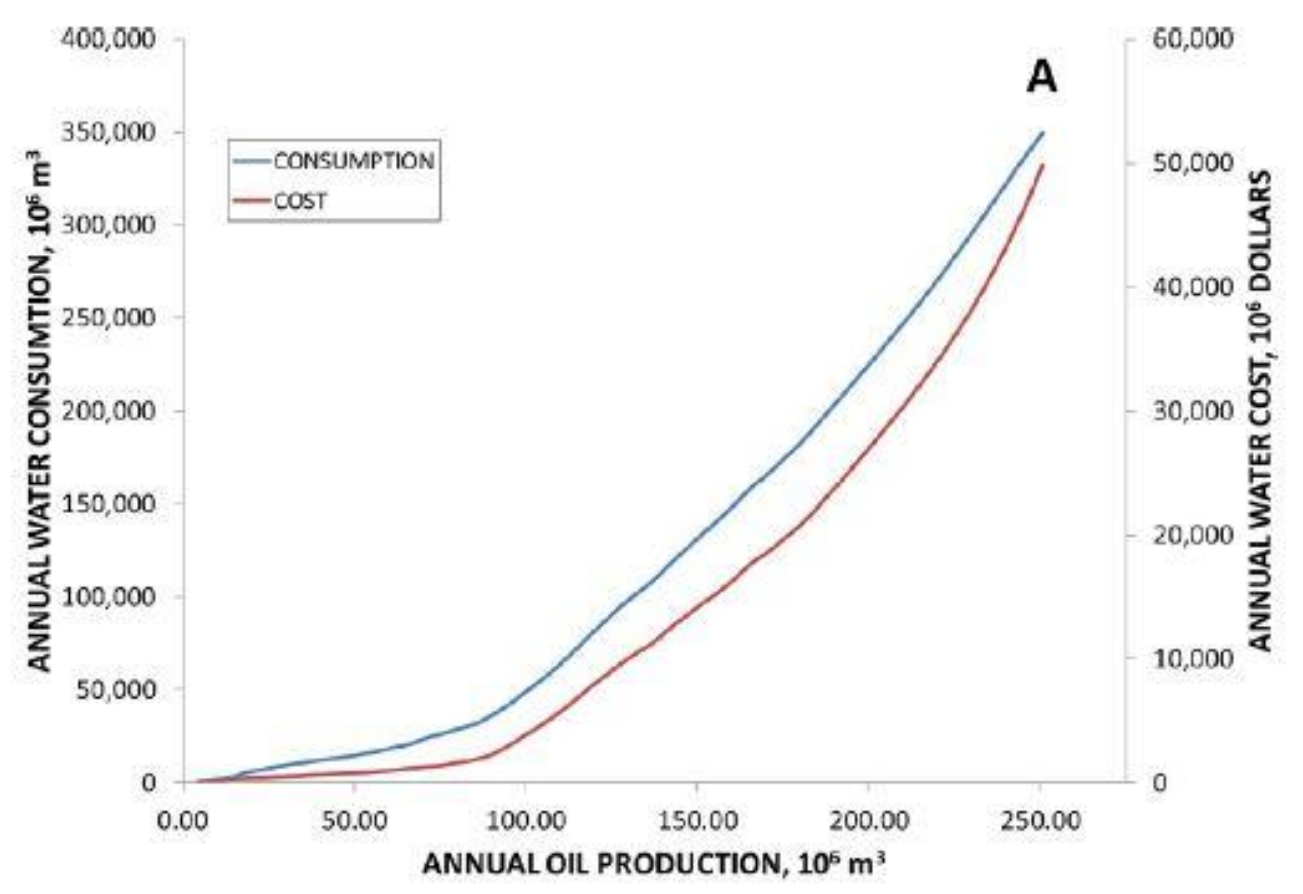

Figure 2-8: Water consumption and cost increase as oil production increases

If water recycling were put in place on large scale the slope of the lines in Figure 2-8 could be reduced.

\subsection{Factors Effecting Algal Pond Productivity}

Pond productivity is the amount of biomass produced in the ponds per area per day. Pond productivity can be calculated according to Equation 1. 
Equation 1: Areal Productivity

$$
\text { Productivity }=\frac{\left(\left(V S S_{\text {Pond }}-V S S_{\text {Inf }}\right) *\right. \text { Depth }}{H R T}
$$

Where the variables have the following units:

Productivity: $\frac{g V S S}{m^{2}-d a y}$

VSS: $\mathrm{mg} / \mathrm{L}$

Depth: $m$

HRT: days

Net areal productivity was important to monitor because it was an indication of biomass yield a pond system, and was used as a metric to compare growth in recycled and unrecycled pond systems.

There are numerous factors that affect algal productivity. These factors include solar insolation, soluble nutrient concentrations, water temperature, grazer predation, and hydraulic residence time.

\subsection{Research Goals}

Questions investigated in this thesis:

1. What is the difference in net areal productivity between algae grown on primary clarifier effluent, and algae grown on settled algae pond effluent? 
2. Is there a standpipe design that reduces solids accumulation due to large algae flocs?

3. What is the rate and extend to which anaerobically digested sludge further degrades and release nutrients in aerobic conditions?

4. Does pretreatment to lyse cells increase the rate or extent of nutrient release? 


\section{Methods and Materials}

Field experiments were conducted in nine raceway style ponds. These experiments were designed to determine how algae could be grown on settled algae pond effluent water. This chapter discusses the layout, process flow, operations, and maintenance of the Algae Field Station (AFS) where the field experiments occurred. In addition, lab experiments were conducted to determine how nutrients would be released when anaerobically digested sludge degrades in pond conditions. Bench-scale aeration experiments for sonicated and homogenized anaerobically digested sludge are also discussed in this chapter.

\subsection{Algae Field Station: Location Layout}

The AFS became operational in 2012. It was located at the Water Resource Recovery Facility (WRRF) of the City of San Luis Obispo, California. At the time of the testing, the WRRF served a population of roughly 46,000 people and was designed to process 5.2 million gallons per day of wastewater (MGD) (Ripley, 2013). For secondary treatment, the WRRF incorporated both a trickling filter and an activated sludge process. The AFS was located next to the western primary clarifier (Figure 3-1). The AFS consisted of nine $33-\mathrm{m}^{2}$ raceway ponds. The ponds were arranged in three sets of triplicates: Alpha, Beta, and Gamma. 


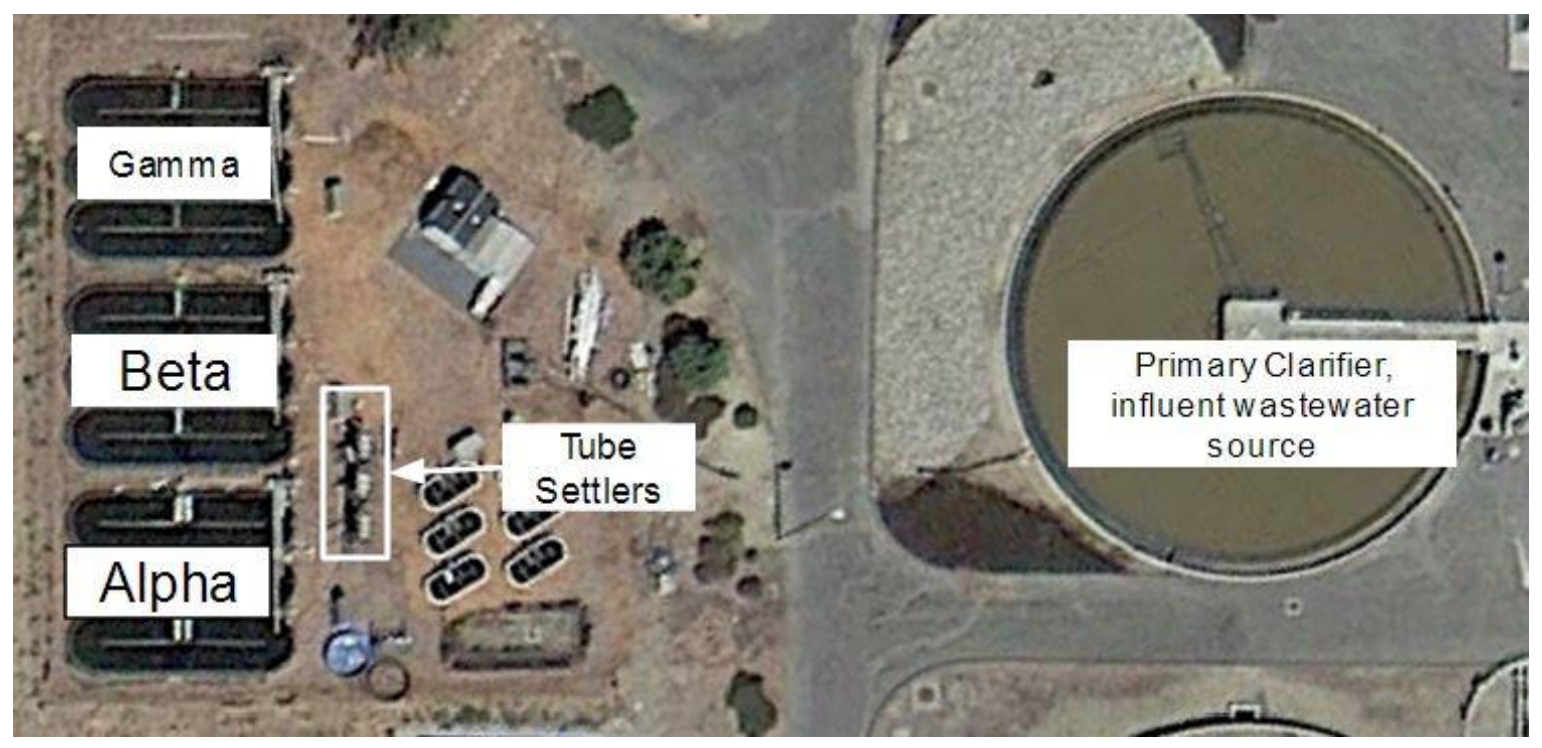

Figure 3-1: Aerial View of AFS indicating the nine 33-m2 raceways, tube settlers, and influent wastewater source.

\subsection{Pond Experiments}

There were four experiments conducted with the ponds: two-day hydraulic residence time (HRT) productivity, ponds-in-series, and standpipe performance evaluation. These experiments were designed to address questions one and two of the research goals.

\subsubsection{Experimental Concept and Purpose}

The purpose of the pond-in-series experiments was to determine whether water can be reused to grow algae in a second round of ponds. Re-using water is a key part of increasing the sustainability of algal biofuels.

There were two rounds of growth for this experiment. Round 1 (Beta) used primary clarifier effluent as a growth media, round 2 (Alpha) used settled pond effluent from the first round. The areal productivity (Equation 1) of the first round ponds were compared to 
that of the second round ponds to determine if productivity was reduced in the recycled ponds.

\subsubsection{Pond Process Flow}

The triplicate sets of raceway ponds were referred to Alpha, Beta, and Gamma; Alpha being Ponds 1-3; Beta being Ponds 4-6; And Gamma being Ponds 7-9.

Influent water to the AFS was drawn from the primary clarifier between the scum baffle and overflow weir (Figure 3-2)

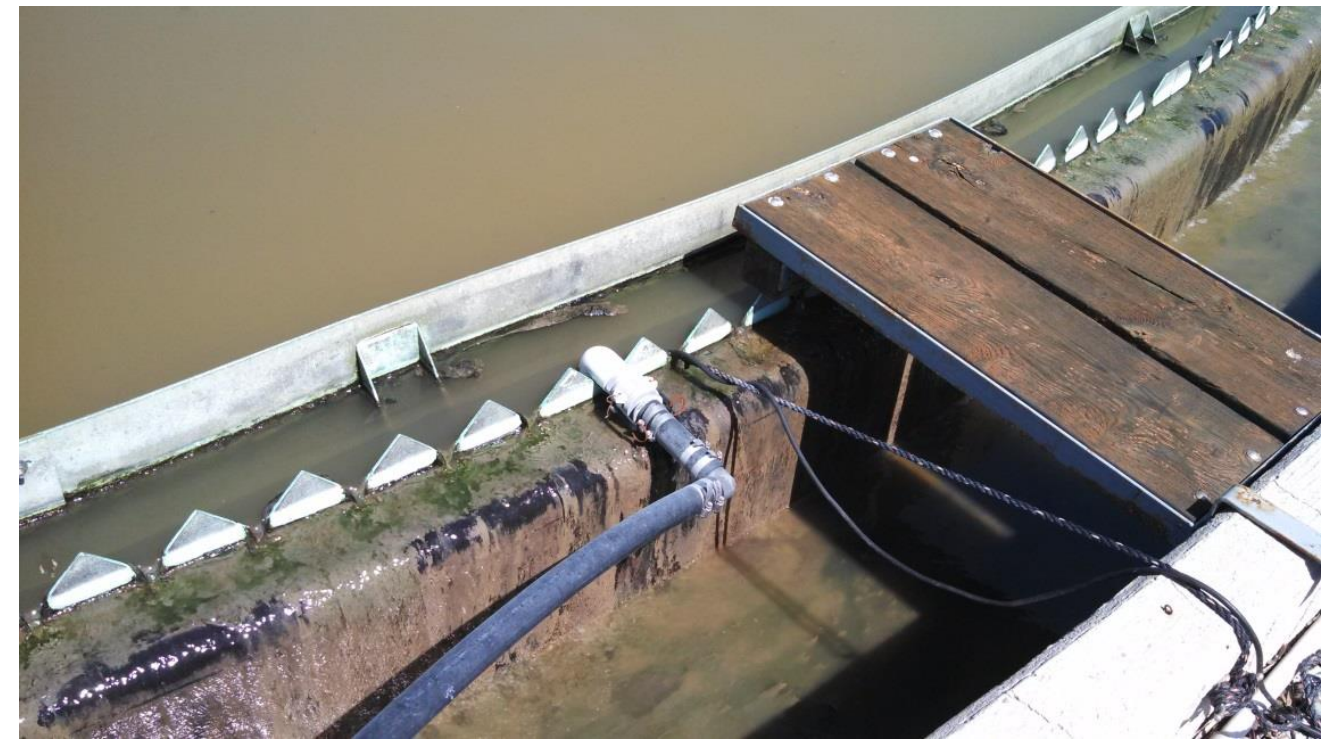

Figure 3-2: Influent pump was located in the western primary clarifier.

The primary effluent was pumped to the Beta and Gamma constant head tanks, where it was distributed to the ponds via a continuously-rotating scoop pump and distribution system (Figure 3-3). 


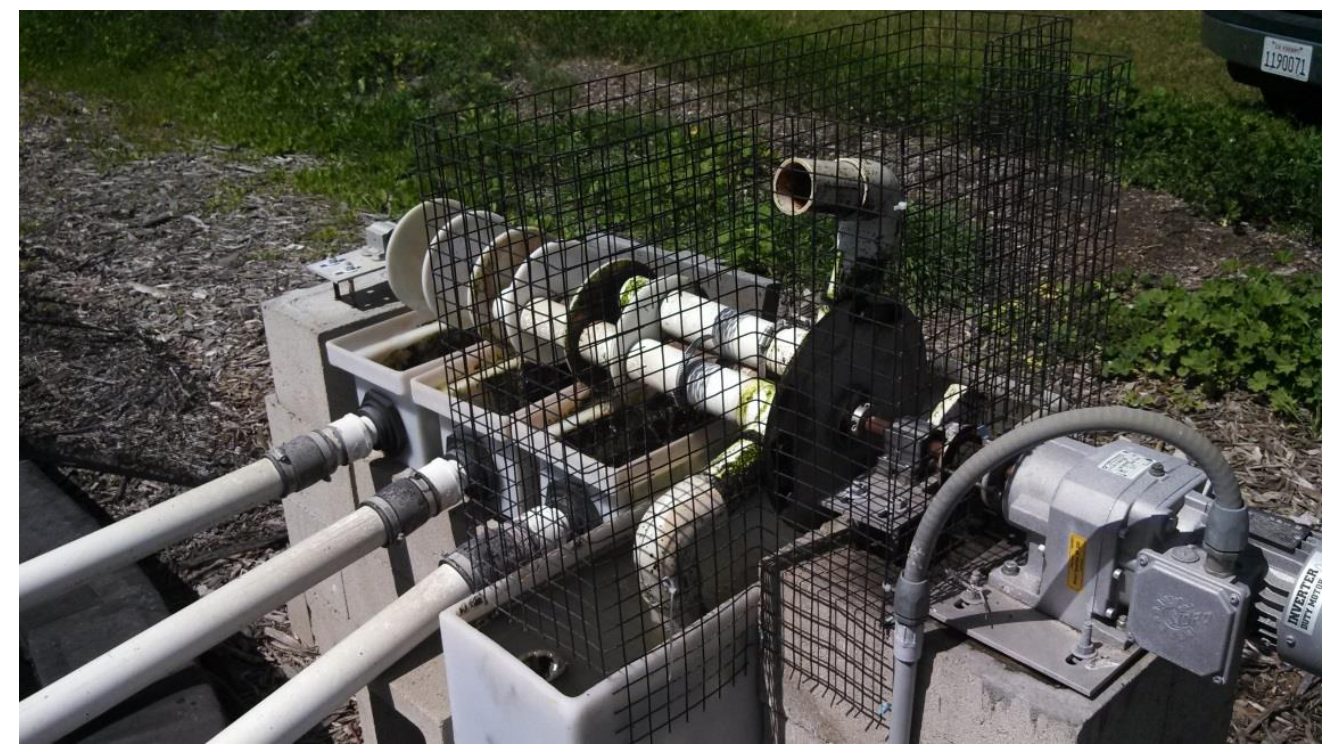

Figure 3-3: Gamma constant head tank influent pump and distribution system. The water level in the tank is kept constant, and the speed and depth of the scoops is varied to adjust flow into the ponds

The water flowed by gravity from the distribution system to the ponds. Each pond was mixed on its northern side by a six-bladed paddle wheel creating a channel velocity of approximately $27 \mathrm{~cm} / \mathrm{s}$ (Ripley, 2013). Water exits Alpha and Gamma sets via a standpipe. The standpipes were also used to control the depth of the ponds. The effluent water was collected in an underground manifold, which flowed to a disposal sump (Figure 3-4). 


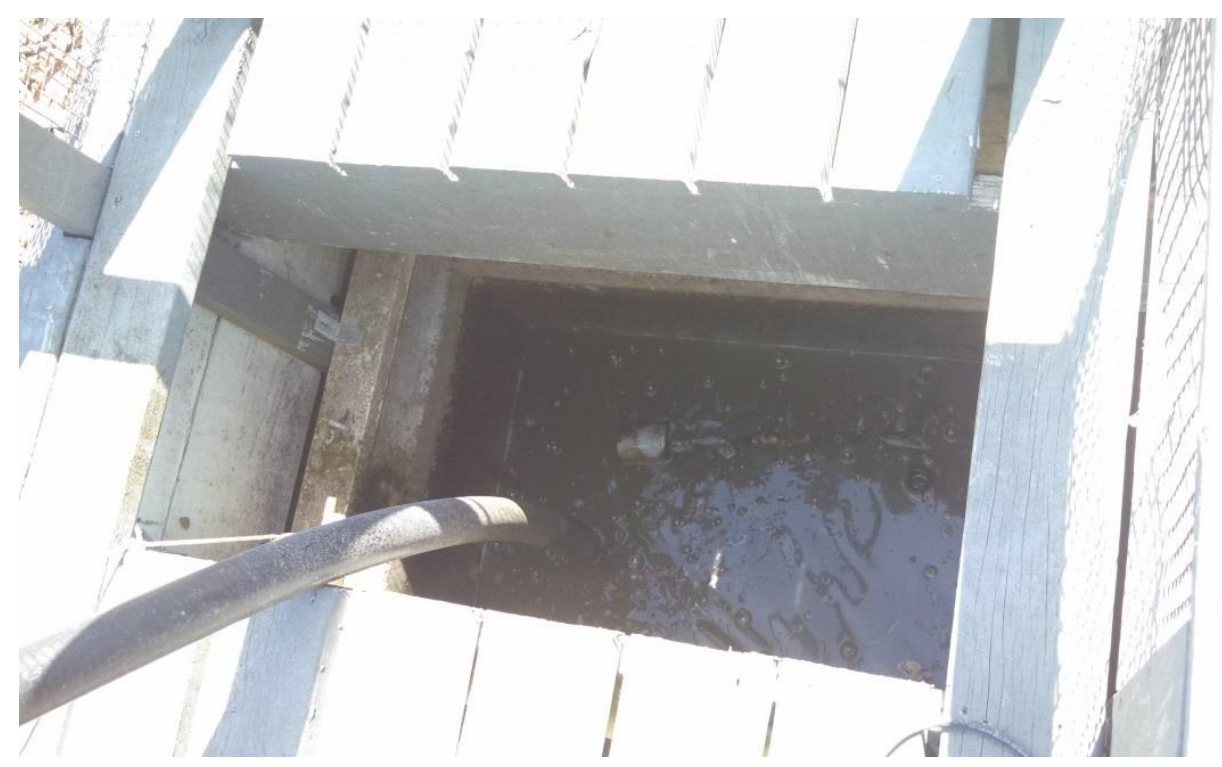

Figure 3-4: Sump of AFS, water that over flows the stand pipe is collected in the sump and pumped back to primary clarifier

The sump was $1.5 \mathrm{~m}$ deep. In the sump there were two float switches that controlled the depth of water in the sump. They turned on when the depth was $1.4 \mathrm{~m}$ deep, and turned off when it was $0.5 \mathrm{~m}$ deep. The water was then pumped back to the effluent weir of the primary clarifier (Figure 3-5). 


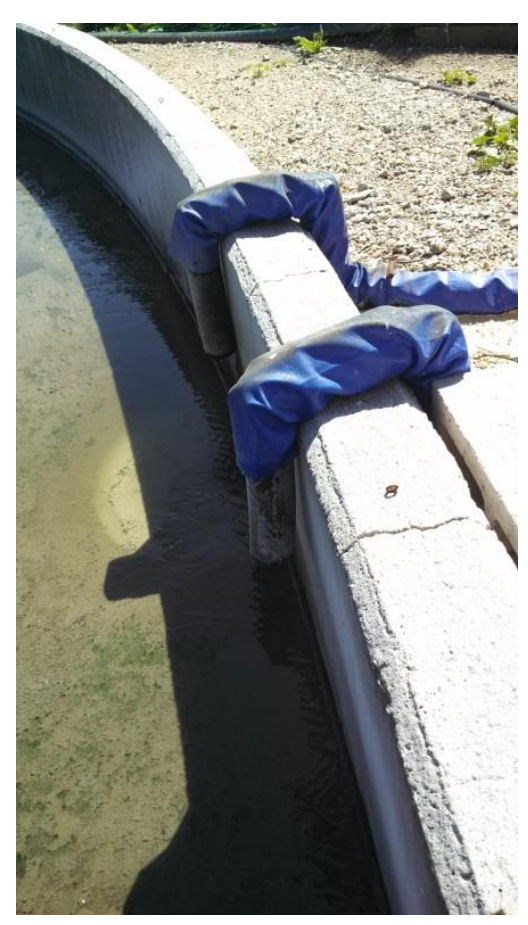

Figure 3-5: Raceway effluent was pumped back to the effluent weir of the primary clarifier

The Beta and Alpha sets were run in series during June 1, 2012 to July 1, 2013.Water from each Beta set pond was settled in tube settlers and the supernatant of the tube settlers was fed into the corresponding Alpha set pond as follows: Supernatant from Pond 4 was fed into Pond 1, Pond 5 into Pond 2, and Pond 6 into Pond 3.

On July 1, 2013 the configuration was changed so that the supernatant from all Beta tube settlers flowed into the Alpha constant head tank. Beta supernatant was then mixed with an aquarium mixer, and pumped into the Alpha ponds by the distribution system (Figure 3-6). 

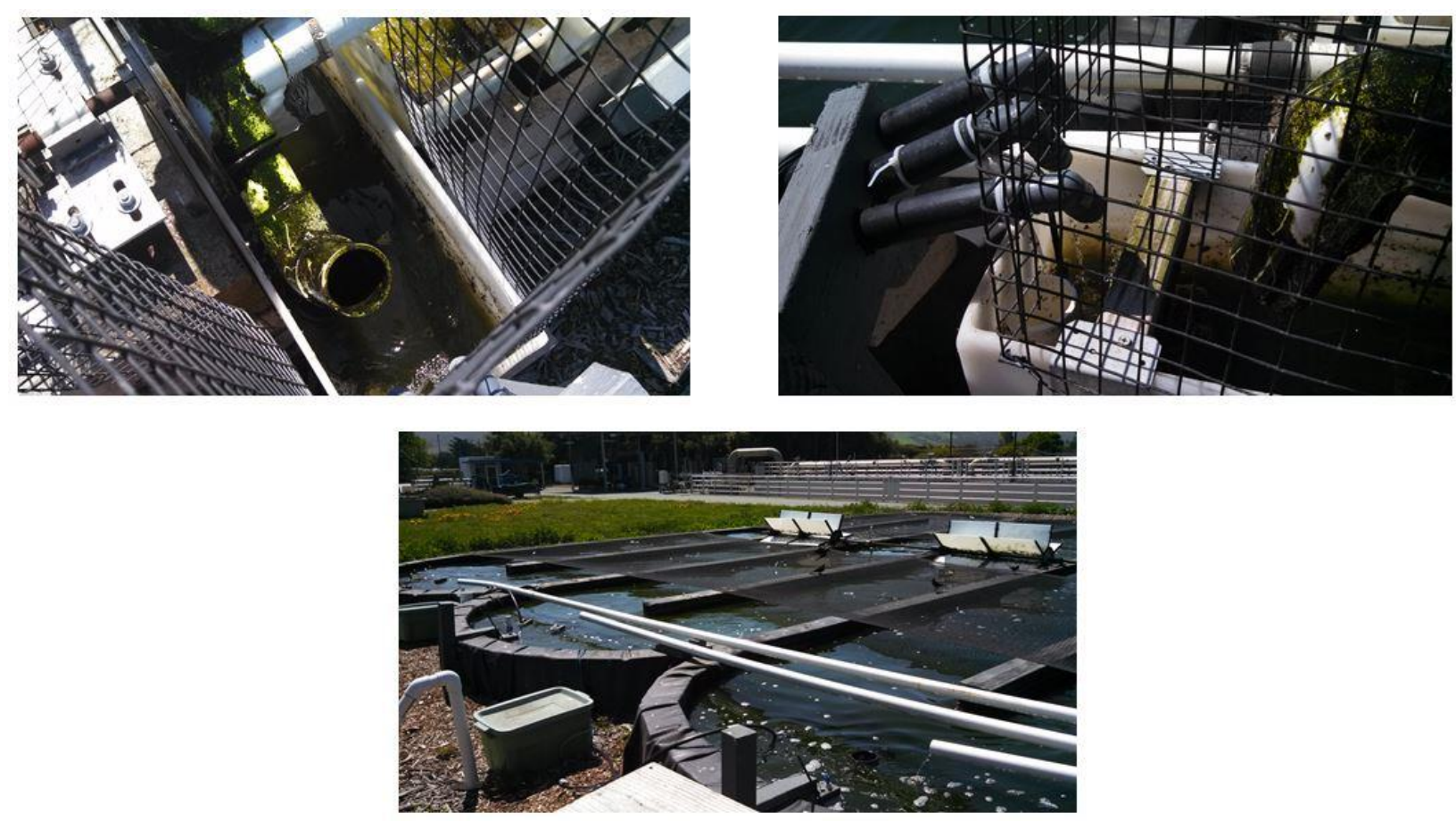

Figure 3-6: Alpha constant head tank, and distribution system. The top right photo shows how the tube settler effluent was fed into the head tank. There were six total feed lines, three on the left and three on the right side of the tank.

In this configuration, all of the water entering the Beta set was fed through the tube settlers and into the Alpha set. From there, half of the water was fed through tube settlers to evaluate settling performance for Alpha, and the rest over flowed standpipes. All water removed from the Alpha set was collected in the underground manifold and flowed to the sump to be pumped back to effluent weir of the primary clarifier.

\subsubsection{Tube Settler Design and Process Flow}

To maximize the amount of new biomass produced in the recycled ponds, it was important to remove as much biomass as possible before recycling the water.

Tube settlers were arranged on three racks, with three settler tanks per rack. The tube settlers were up flow designs. The influent lines were attached at roughly half the length 
of the settler tank (Figure 3-7) and the effluent flowed out the top through a bulkhead (Figure 3-8). Settled sludge was removed from an underdrain located at the bottom of the tube settler (Figure 3-9).

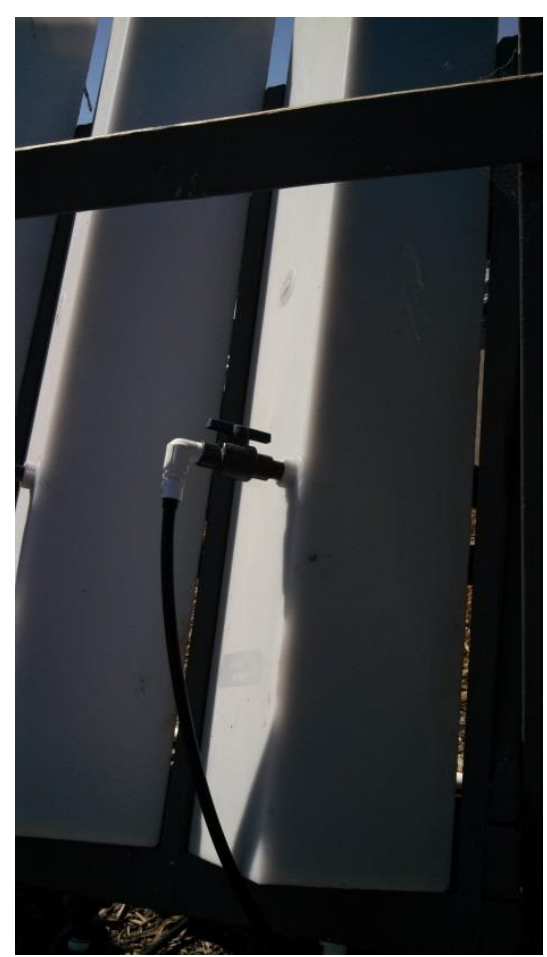

Figure 3-7: Tube settler influent line. Flow enters half way up side of tube settler, bulk water flows up and out of the top of the tube settler, while settled sludge falls to the bottom. 


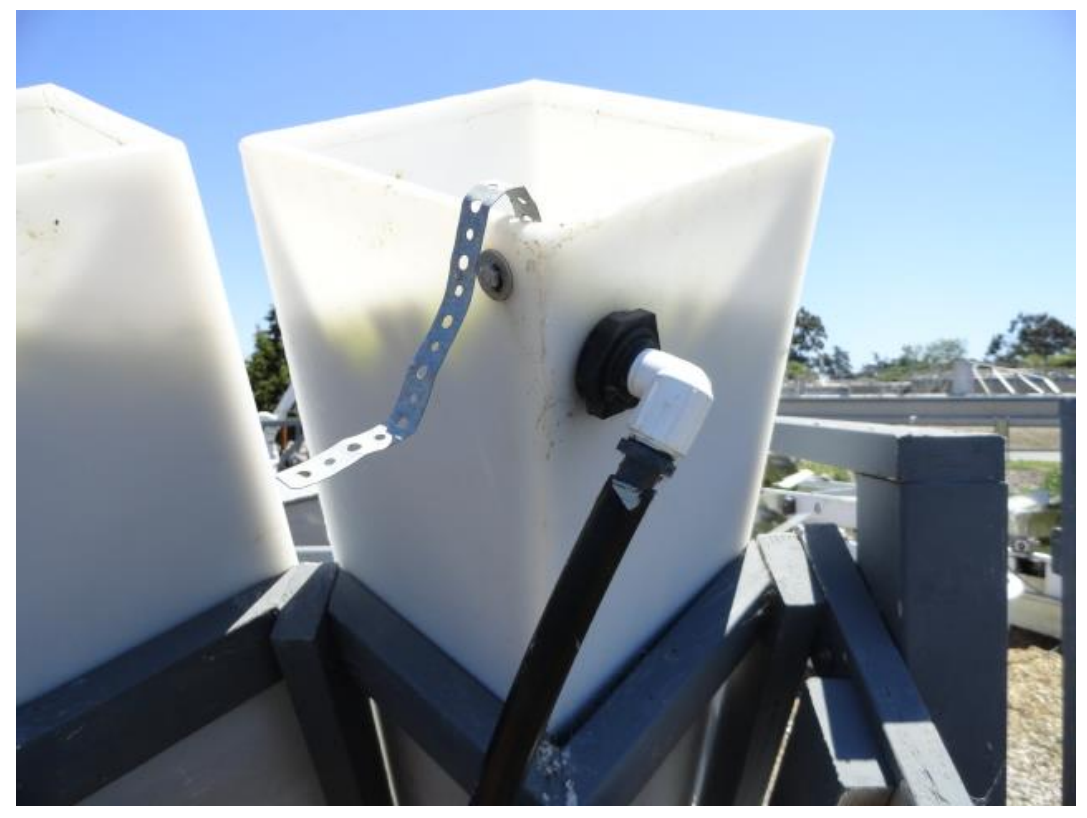

Figure 3-8: Bulkhead at the top of the tube settler where the supernatant exits and flows into the Alpha head tank.

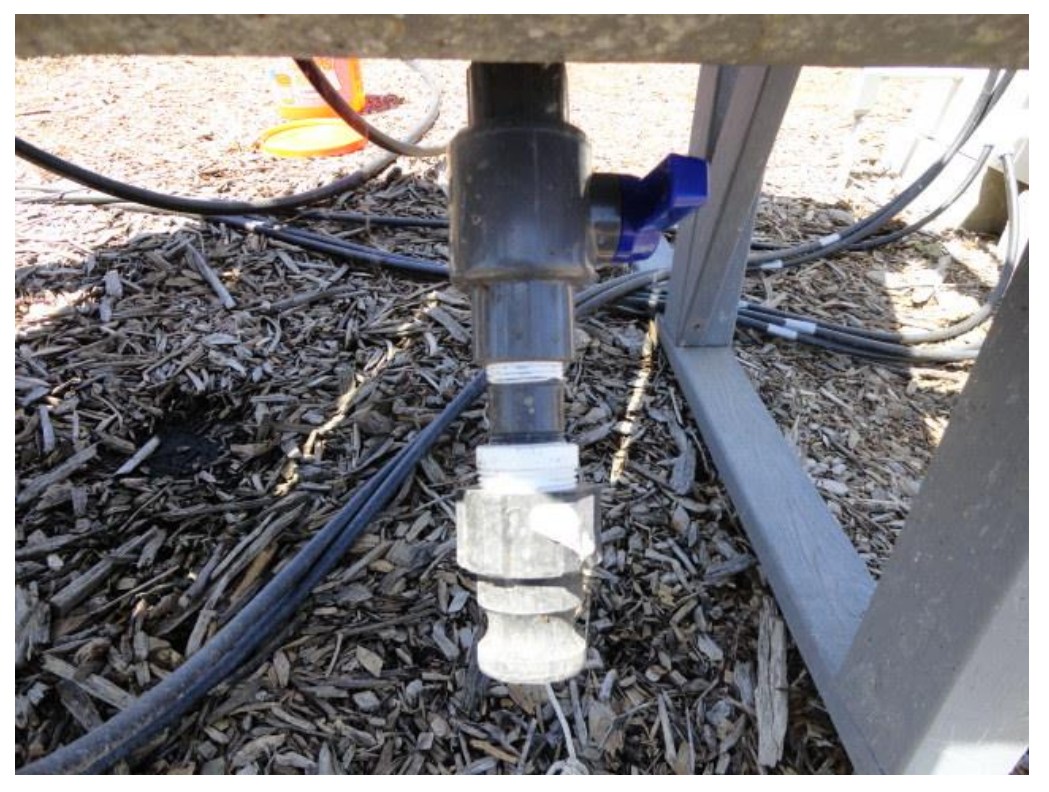

Figure 3-9: Tube settler underdrain. Sludge is drained through the $3 / 4$ in ball valve. 
The influent flow to the tube settlers was metered by peristaltic pumps which were set to the flow rates shown in Table 3-2. All the tube settlers were set at an angle of $60^{\circ}$ (Figure 3-10).

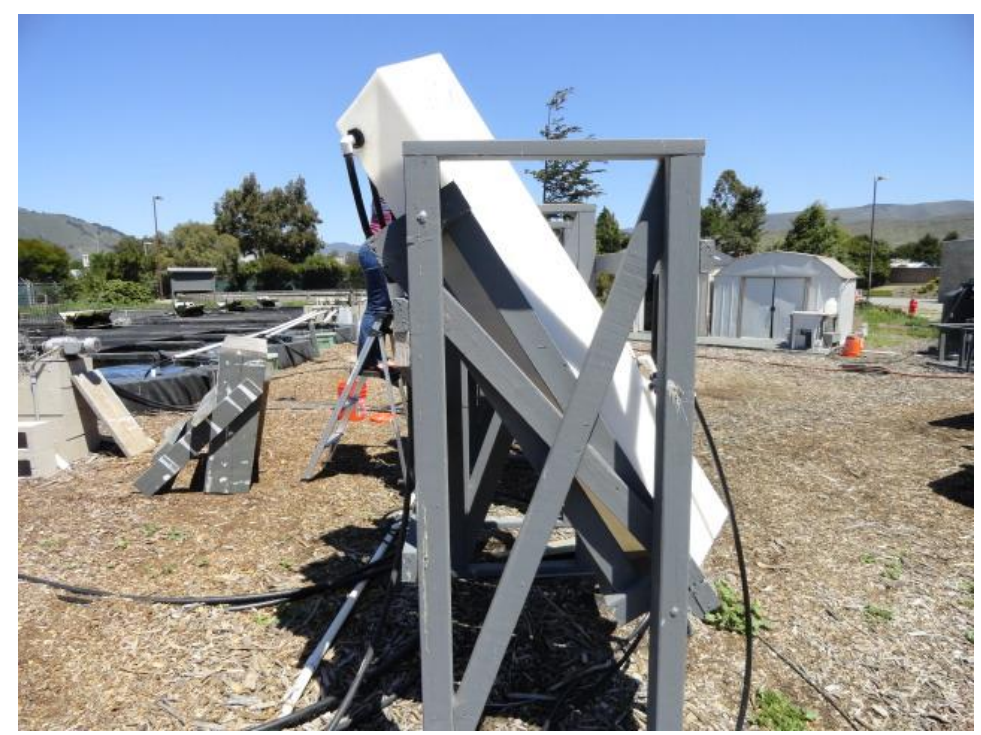

Figure 3-10: Side view of tube settlers showing the $60^{\circ}$ angle of tilt. 
Each tube settler had a removable cassette of tubes that provide the settling surface. Each cassette consisted of nine two-inch diameter $1 / 8^{-i n c h}$ wall thickness tubes arranged in a diamond (Figure 3-11). Roughly half of the depth of the settler was devoted to sludge accumulation.

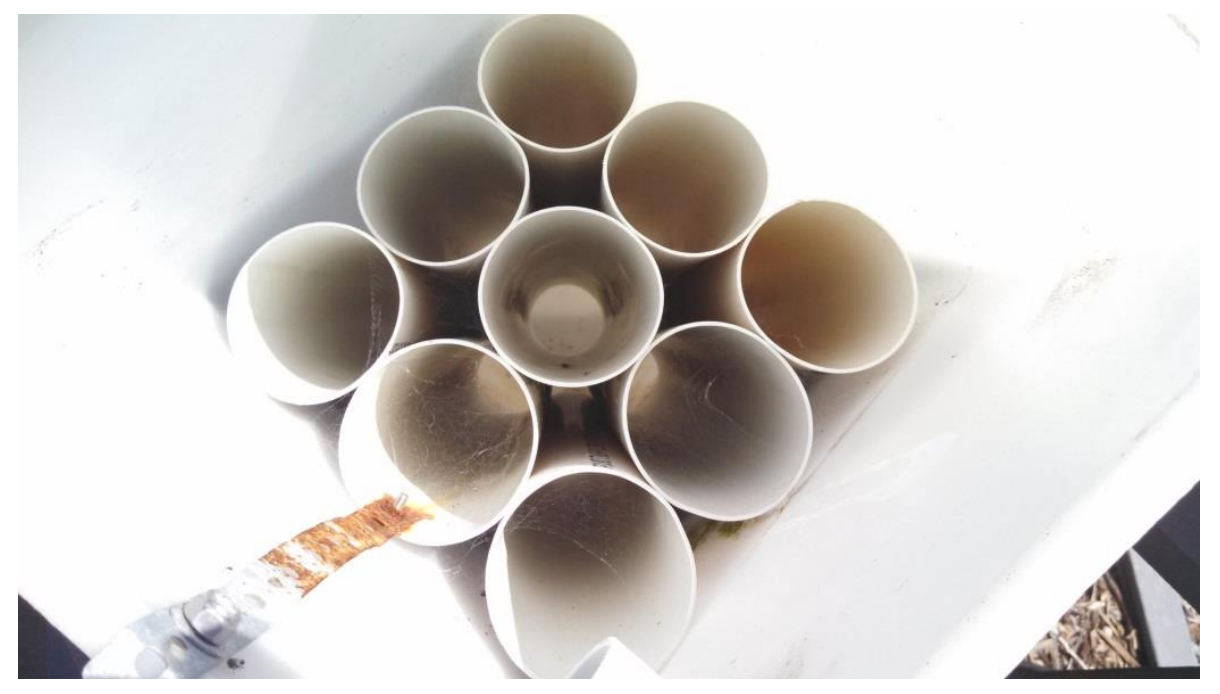

Figure 3-11: View from the top of an empty tube settler with tube cassette visible. Water flows up through the tubes and sludge settles downward.

The tubes were cut off at a slant so that the openings of the tubes were parallel to the ground and not in line with the tilt of the settler. In order to provide some backpressure and prevent short circuiting of the tubes, a perforated plate was placed on top of the tube cassette (Figure 3-12). 


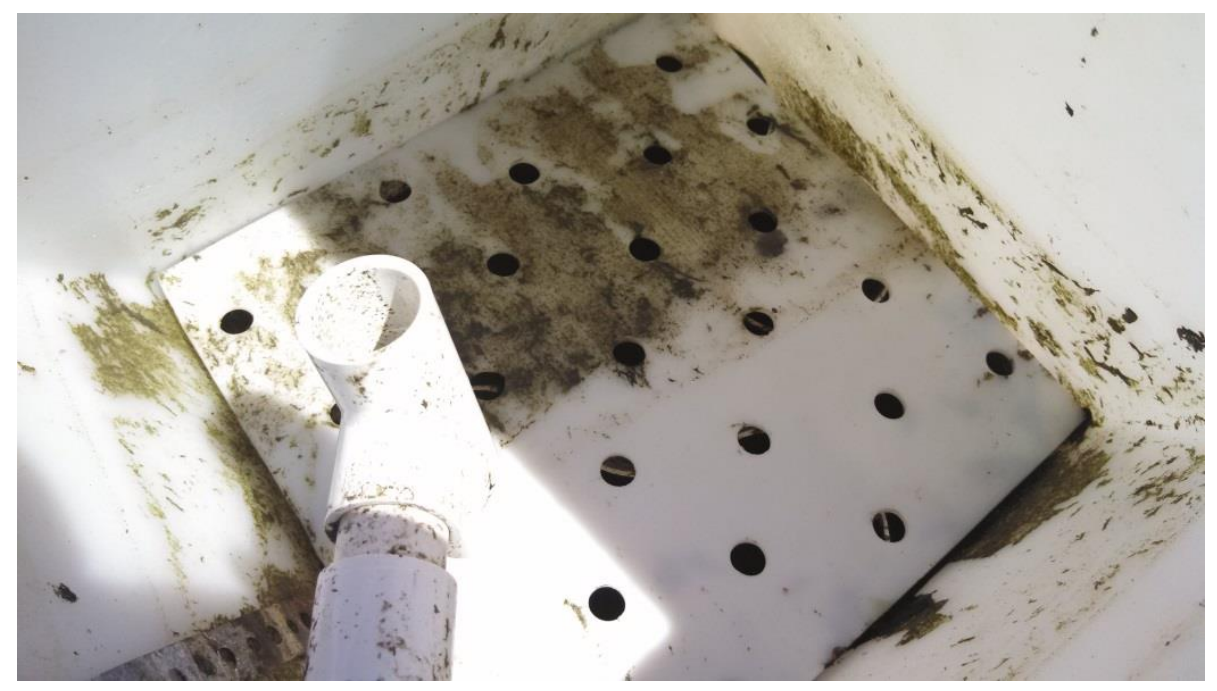

Figure 3-12: View from top of tube settler with perforated backpressure plate in place.

PVC T-fittings were installed in the tube settlers as a scum baffle to prevent large floating flocs of algae from making it into the effluent (Figure 3-13).
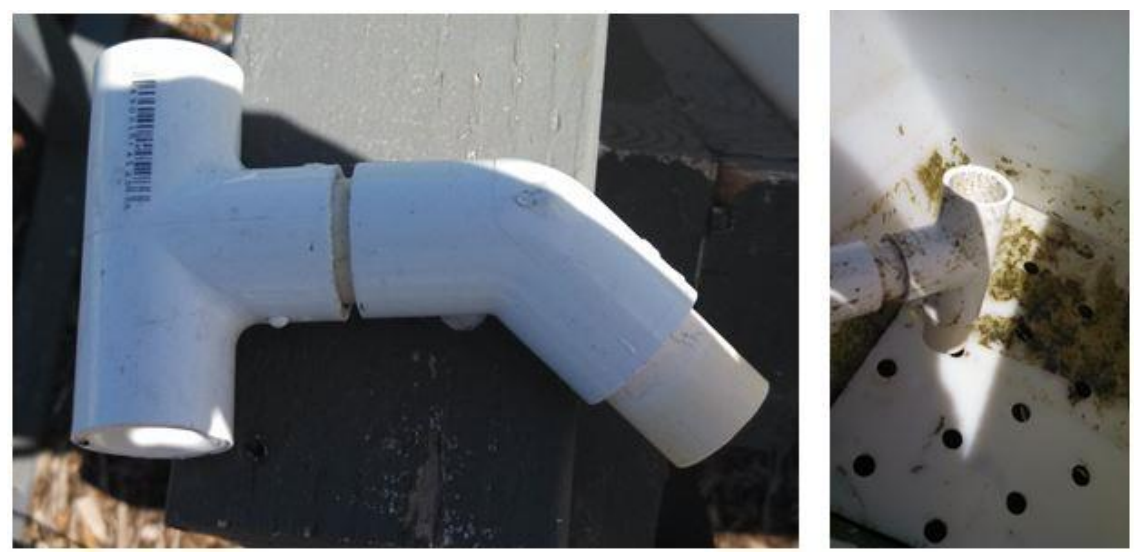

Figure 3-13: Side view of scum baffle uninstalled, and installed view of scum baffle. T-fittings prevented floating algae flocs from exiting the tube settler and entering the Alpha pond set 


\subsubsection{Pond Characteristics}

Pond area, depth and channel velocity remained unchanged during the course of the experiments. The hydraulic residence time (HRT), influent characteristics, and tube settler flow and configuration were changed during the course of the experiments. These specifications are outlined in Table 3-1 and Table 3-2.

Table 3-1:Target pond characteristics from June 1, 2012 to July 1, 2013

\begin{tabular}{cccc} 
& \multicolumn{3}{c}{ Triplicate Set } \\
\cline { 2 - 4 } Specification & Alpha & Beta & Gamma \\
\hline Ponds in Set & $1,2,3$ & $4,5,6$ & $7,8,9$ \\
Depth $(\mathrm{m})$ & 0.30 & 0.30 & 0.30 \\
Channel Velocity (cm/sec) & 25 & 28 & 27 \\
Influent Flow & 1.65 & 2.25 & 3.3 \\
Tube Settler Flow (L/min) & 0.8 & 1.65 & 0.8 \\
HRT (Days) & 4.0 & 3.0 & 2.0 \\
\hline
\end{tabular}

* Channel velocity values from (Ripley, 2013)

Table 3-2: Target pond characteristics from July 1, 2013 to April 2014

\begin{tabular}{cccc} 
& \multicolumn{3}{c}{ Triplicate Set } \\
\cline { 2 - 4 } Specification & Alpha & Beta & Gamma \\
\hline Ponds in Set & $1,2,3$ & $4,5,6$ & $7,8,9$ \\
Depth (m) & 0.30 & 0.30 & 0.30 \\
Channel Velocity (cm/sec)* & 25 & 28 & 27 \\
Influent Flow & 2.25 & 2.25 & 3.30 \\
Tube Settler Flow (L/min) & 2.25 & 2.25 & N/A \\
HRT (Days) & 3.0 & 3.0 & 2.0 \\
\hline
\end{tabular}

* Channel velocity values from (Ripley, 2013) 


\subsubsection{Pond Operations}

Pond Operations were controlled from three pump houses. Equipment common in all pump houses were $\mathrm{pH}$ and temperature control units, and variable frequency drives that control the paddle and water wheel motors (Figure 3-14, Figure 3-15).

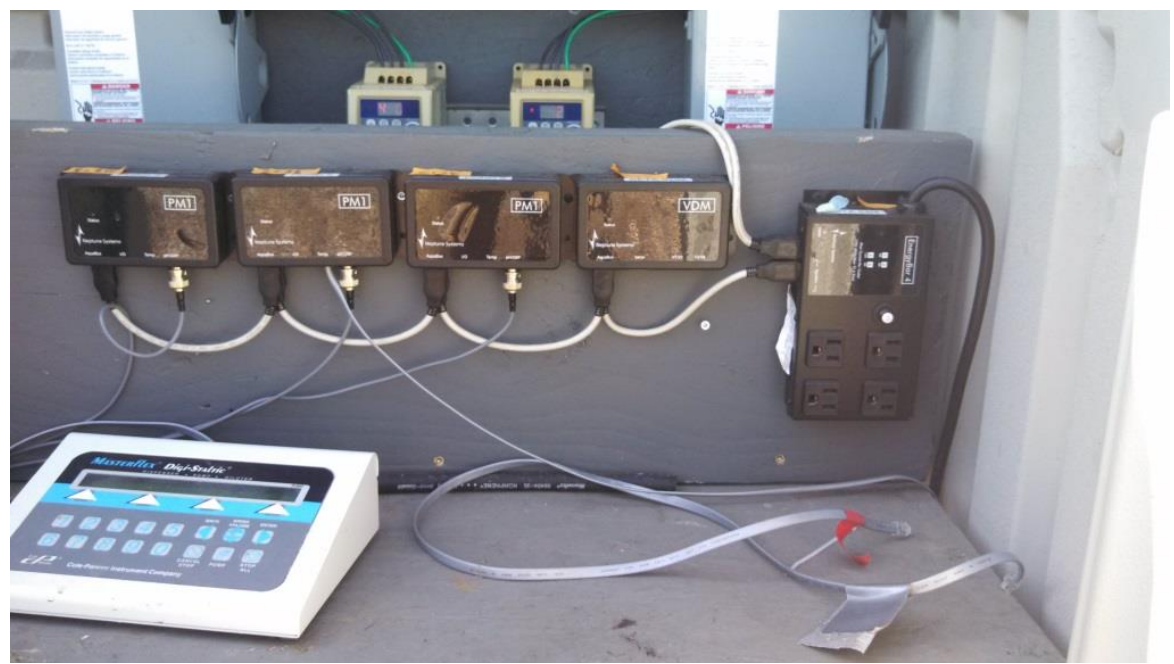

Figure 3-14: Neptune PM1 units for pH and temperature data acquisition. This set up is the same in all pump houses.

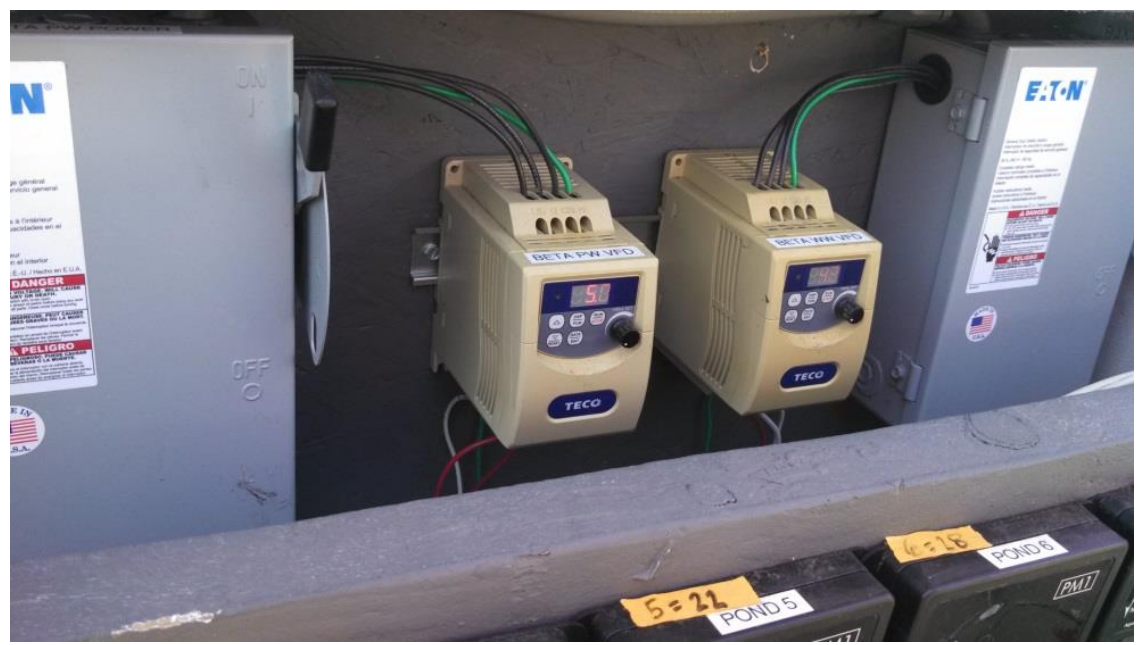

Figure 3-15: VFD's were used for controlling water and paddle wheel speed. The left most VFD controls the paddle wheel and the right VFD controls the water wheel. This set up is the same in all pump houses. 
The Alpha pump house had two peristaltic pumps for the Alpha tube settlers. The Beta pump house contained three peristaltic pumps and rigid PVC pipes for the tube settlers. These rigid pipes (Figure 3-16, Figure 3-17, and Figure 3-18) replaced polyethylene tubing, which tended to kink and interrupt the flow into the tube settlers.

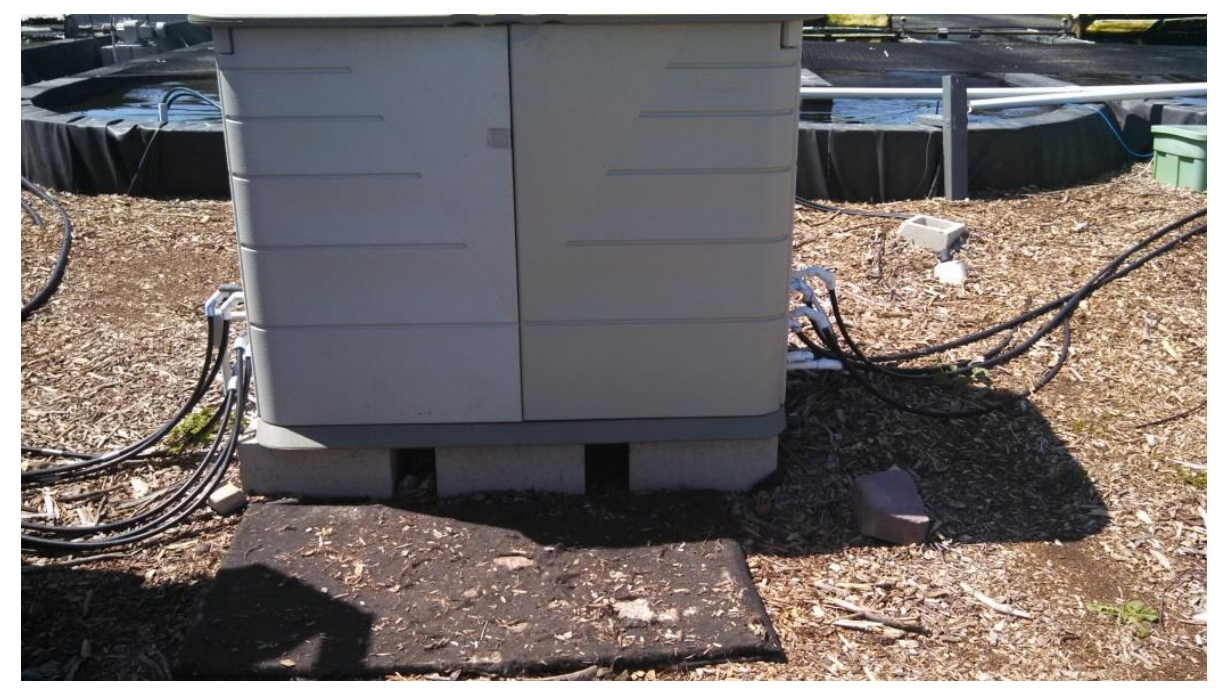

Figure 3-16: Beta pump house with PVC pipes plumbed through each side.

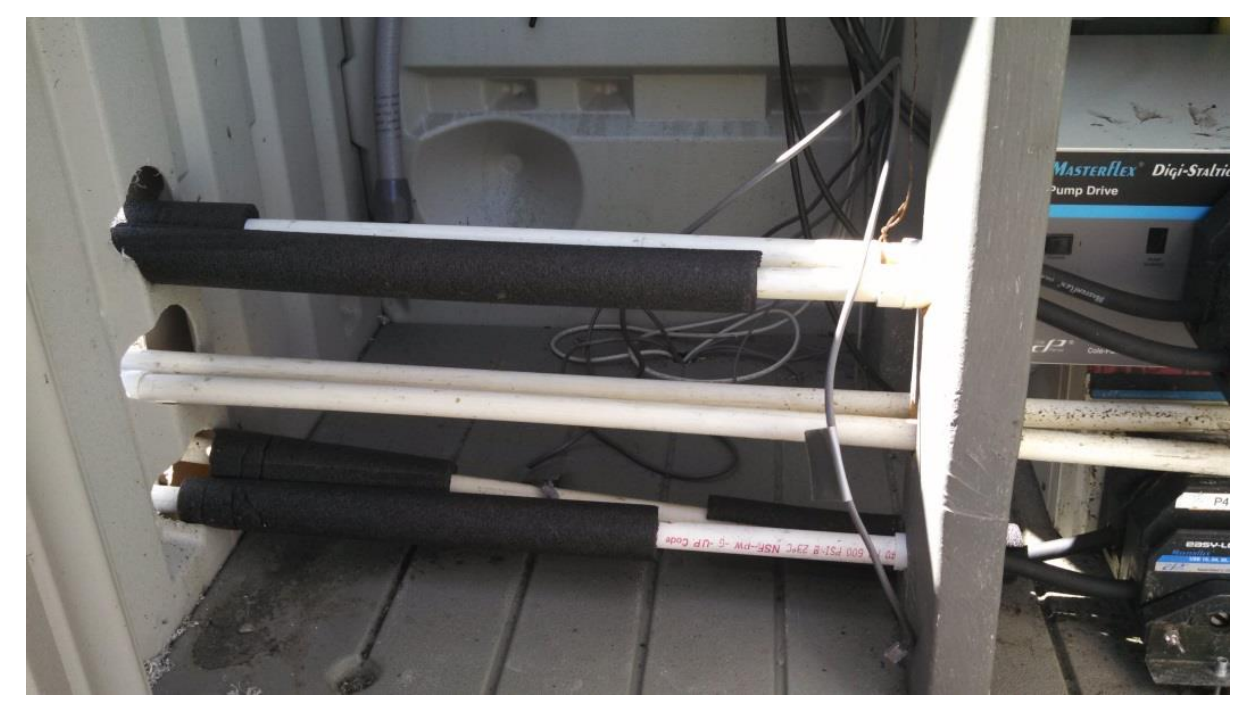

Figure 3-17: PVC pipes leaving pump house. Foam insulation was required due to excessive vibration in the lines causing the PVC to wear away. 


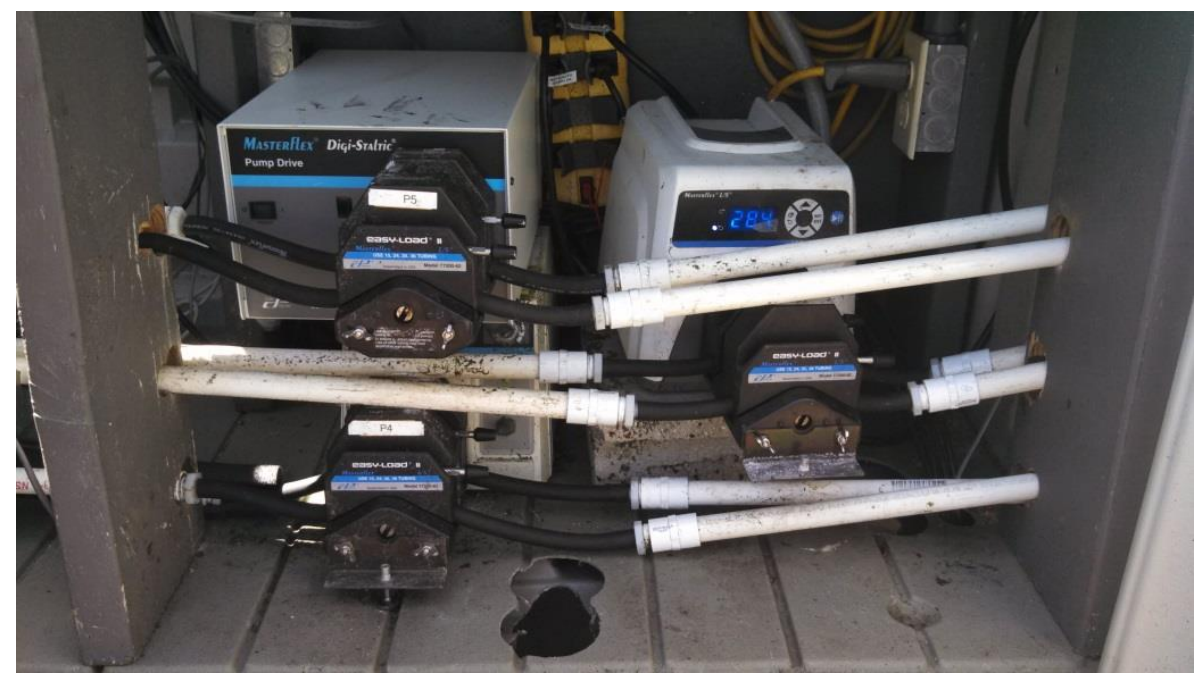

Figure 3-18: Peristaltic pump set up in the Beta pump house. Water enters from the right and flows out the left side. Each pump pulls water from one pond, and feeds it into two tube settlers.

Data loggers were used to record field data until it could be downloaded to an external source. Field data monitored included dissolved oxygen (Neptune Systems, Morgan Hill, California), temperature (Neptune Systems), and pH (Sensorex, Garden Grove California). Data points for $\mathrm{pH}$, temperature, and dissolved oxygen were recorded in 1hour increments. The data were stored in data loggers (Apex AquaControllers, Neptune Systems). The temperature, dissolved oxygen, and $\mathrm{pH}$ probes were located on the eastern most edge of the ponds, just upstream of the influent distribution pipe (Figure 3-19). These probes were cleaned at least three times a week and calibrated weekly. 


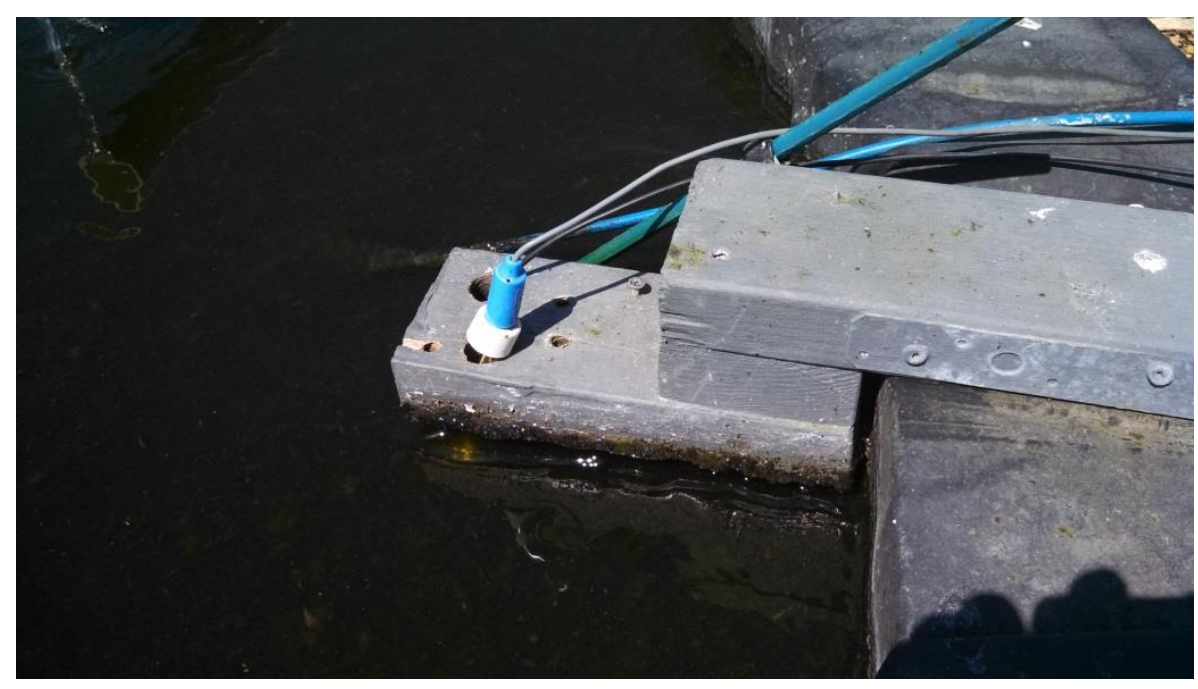

Figure 3-19: Probe stand. The pH and temperature probes were located in the center of the photo and were submersed in the water. The DO probe is held submerged by the blue rod that is held on the side of the stand by a bracket.

The intakes for the tube settlers were located in separate closed bottom standpipes used to control the depth of the ponds.

The Alpha and Beta ponds were $\mathrm{pH}$ controlled by carbon dioxide. Each pond was sparged with $\mathrm{CO}_{2}$ to keep the $\mathrm{pH}$ between 8.3and 8.5. The $\mathrm{CO}_{2}$ was supplied from 50-lbs pressurized cylinders (99.5\% purity, 750 psi, Airgas) (Figure 3-20).
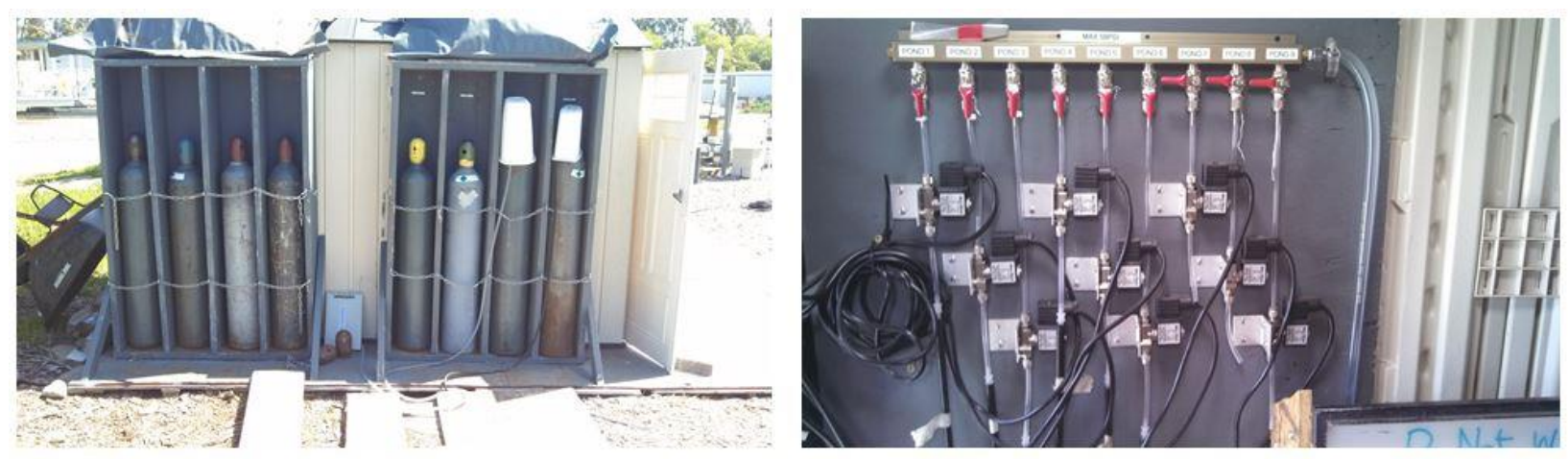

Figure 3-20: Left picture, $\mathrm{CO}_{2}$ tank racks located on the outside of the operations shed. Right picture, $\mathrm{CO}_{2}$ solenoid swithces used for distributing $\mathrm{CO}_{2}$ to the ponds 
The $\mathrm{CO}_{2}$ was dispensed to individual ponds by automated solenoid switches that opened or closed depending on the $\mathrm{pH}$ of the ponds.

All probes were calibrated once per week. The $\mathrm{pH}$ probes were calibrated with a two point calibration using $\mathrm{pH} 10$ and 7 buffers. DO probes were also calibrated with a two point calibration at 0 and $100 \%$ saturation.

\subsubsection{Tube Settler Operations}

To prevent excessive sludge build up, tube settlers were emptied of their sludge five days per week from June 2012 to March 2014. From March 2014 to April 2014, tube settlers were drained seven days per week which lessened the amount of floating sludge in the settlers. Sludge was emptied until the drained water became transparent (Figure 3-21).
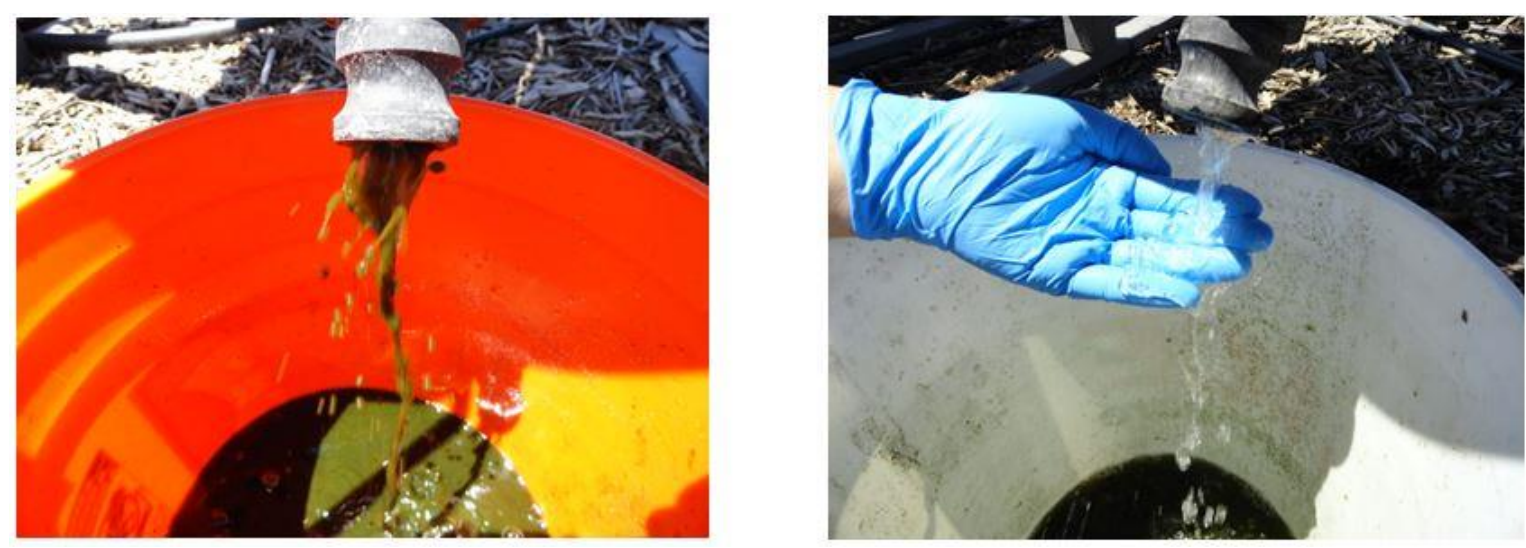

Figure 3-21: Sludge being emptied from the tube settlers. The left picture shows green sludge, the right picture shows clear water coming through the underdrain.

Sludge accumulation was typically around than five gallons per tube settler per day.

Floating flocs accumulated at the top of the tube settlers which were removed daily.

Tube settlers were completely drained once a week and thoroughly cleaned with pressurized water. Thorough cleaning consisted of flushing the tube settler influent lines 
back into the ponds, spraying the cassettes to remove accumulated sludge in the tubes, and flushing the drain lines leading to the Alpha constant head tank to dislodge any algae that may have accumulated.

\subsubsection{Pond Maintenance}

Maintenance was a top priority to prevent degradation of equipment and keep operations running smoothly. Unless otherwise stated daily maintenance tasks were done Monday through Friday. Daily maintenance tasks included emptying the tube settlers of sludge, spraying water and paddle wheels to remove biofilms, checking $\mathrm{CO}_{2}$ tank pressure and changing cylinders when needed, and cleaning off $\mathrm{pH}$, temperature, and DO probes.

Weekly tasks included thorough cleaning of the tube settlers, checking peristaltic pump lines for wear and replacing them when needed, $\mathrm{pH}$ and $\mathrm{DO}$ probe calibration, influent and tube settler flow rate measurements, disposal sump and float switch cleaning. Tube settler cleaning was described in more detail in section 3.2.2.1

Occasional tasks done at 3-6 month intervals included mulch distribution, weed removal, rain water retention basin draining, influent pump cleaning, and switching lead lag float switches in the disposal sump.

The tasks performed as needed tasks included replacing worn-out Teflon paddle wheel pillow blocks, replacing tube settler valves, and repairing tube settler peristaltic pumps. .

As the original Teflon pillow blocks wore, they began to squeak. These pillow blocks were replaced as needed with spring-loaded self-lubricating pillow blocks (Lubesite Systems, Model 305). These pillow blocks temporarily solved the squeaking problem. 
After several months of operation, the spring-loaded grease dispensers became clogged with old grease and stopped working. A two-piece ultra-high-molecular-weight polyethylene (UHMWPE) pillow block (Power Plastics Corp, Portland, Ore.) was then installed in one location for a trial. Squeaking has not been reported herein.

\subsubsection{Description of Pond Experiments}

This section described the pond experiments performed for this thesis. Pond experiments included the two-day hydraulic residence time productivity, ponds-in-series, and standpipe performance.

\subsubsection{Two-Day Hydraulic Residence Time Performance}

Since start up in January of 2012, the Gamma ponds operated with a 2-day nominal hydraulic residence time. Hydraulic residence time was the average amount of time that water remained in the ponds before exiting. Productivity and HRT are inversely related. Low HRT's are necessary to maximize productivity. Algae productivity tends to be high in the summer and low in the winter. Tracking the summer and winter trends of productivity was important to determine the yearly productivity of algae ponds.

\subsubsection{Ponds in Series}

This experiment was designed to address the first question of the research goals. For this experiment the Beta and Alpha pond sets were operated in series, with a nominal HRT of three days for both pond sets. For this experiment round 1 was used refer to the ponds grown with primary clarifier effluent. The recycled water ponds were referred to as round 2. Water was pumped from Beta into Alpha, using peristaltic pumps. Tube settlers were 
installed downstream of the Beta ponds to remove a large fraction of the algal biomass from the water before it flowed into the Alpha set (Figure 3-22). The tube settlers were not designed for a flow rate of $2.2 \mathrm{~L} /$ minute. Two tube settlers per pond were used to make sure that the flow through the tube settlers was low enough to settle properly. The productivity for both pond sets was monitored from March 6, 2013 to April 17, 2014. The ponds were set to the same HRT on June 1, 2013.

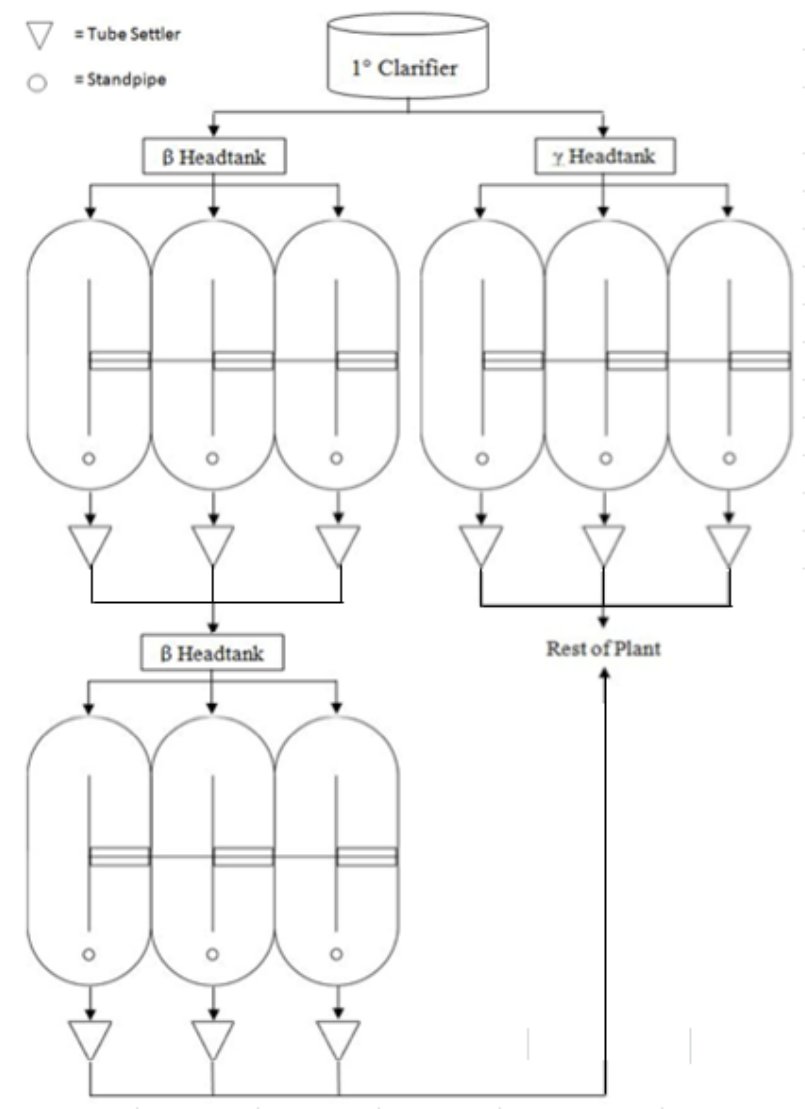

Figure 3-22: Process flow diagram for the ponds from July 2013 to April 2014 (Ripley 2013). Process flow described in detail in section 3.2.2

Data were also collected on water quality in the system to gain insight on wastewater treatment capabilities of this pond configuration. Productivity was the primary output of the pond experiments, the second being settleability, and the third being water quality 
improvement. Productivity for the purposes of this thesis was "areal productivity" or the amount of biomass produced in the ponds per unit area per day. This value was higher than the actual biomass that could be harvested from the pond due to imperfect harvesting techniques.

\subsubsection{Standpipe Development and Performance Evaluation}

Standpipes were vertically oriented cylindrical PVC pipes were used to control the depth of the ponds and to convey effluent water from the ponds. Ripley (2013) showed that in ponds with good bioflocculation, the wave of water exiting over the 4-inch standpipe (Figure 3-23) was shallow and prevented some of the solid mass in the ponds from exiting. As a result solids accumulated in the ponds, and artificially increased the solids concentration of the ponds (Figure 3-24) the productivity of some of the ponds was increased as well.

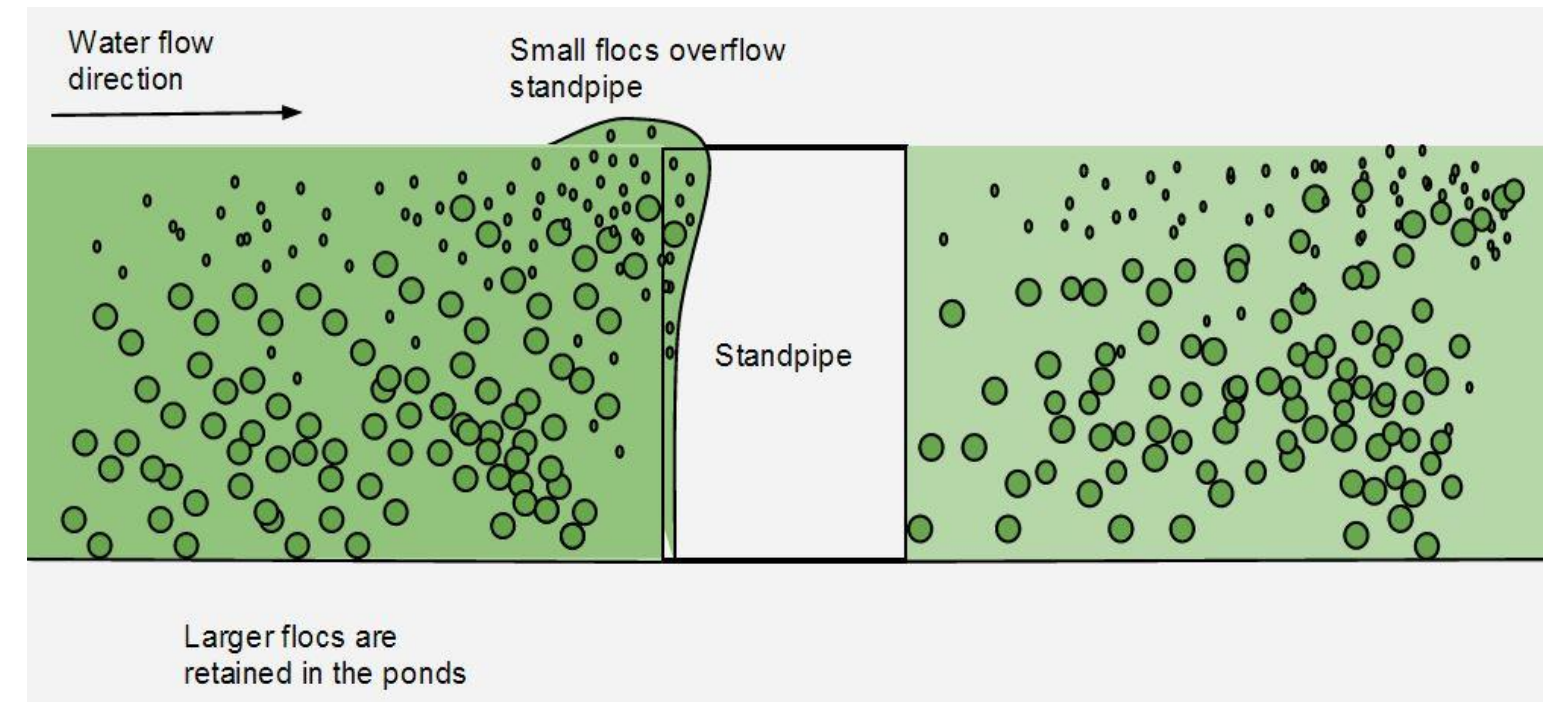

Figure 3-23: Schematic of solids separation by a standpipe. The small dots represent small flocs and colloidal algae, the larger circles represent large algae flocs, which were concentrated in the pond by the weir action of the standpipes. 


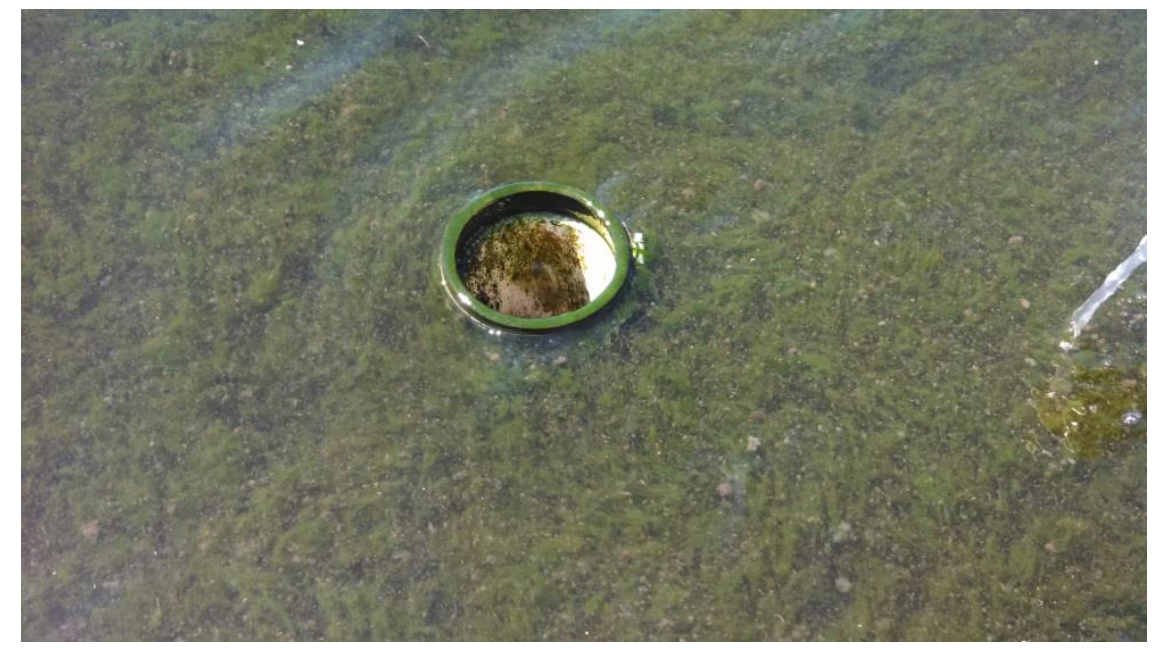

Figure 3-24: Original four-inch diameter standpipe design installed in Pond 7.

An effluent structure which did not concentrate solids was needed, and several alternative standpipe designs were tested.

The one successful design was a two-inch diameter ramp standpipe (Figure 3-25, Figure 3-26). 


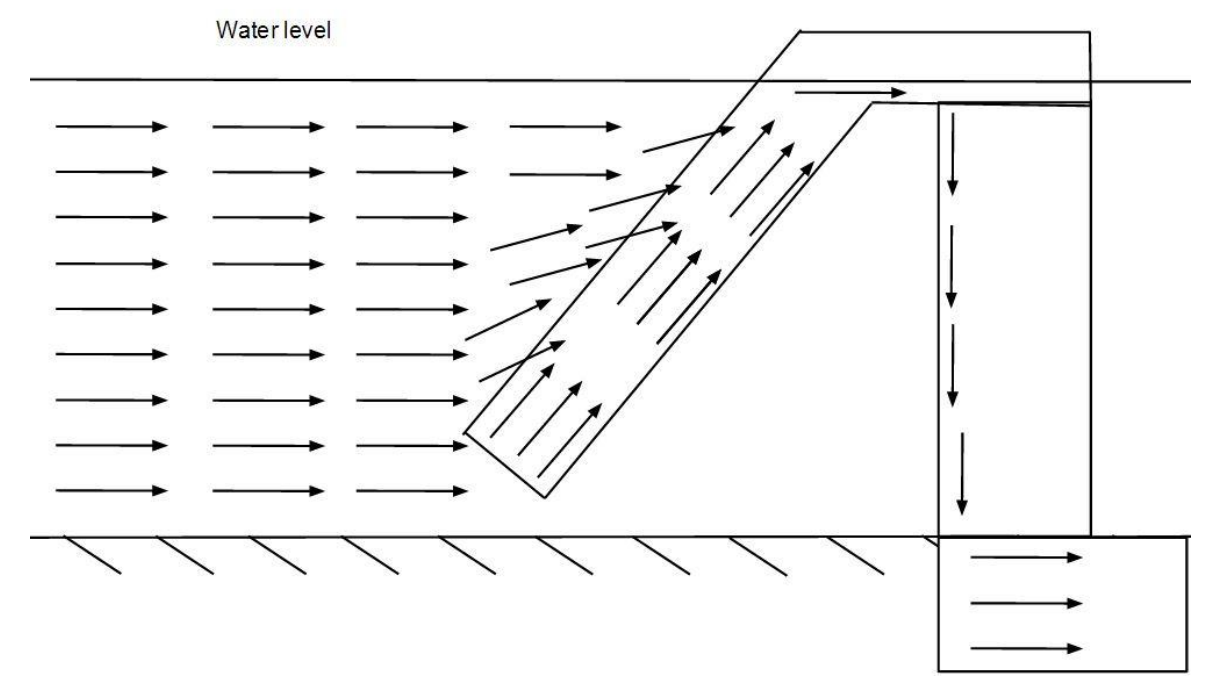

Figure 3-25: Side view drawing of the ramped standpipe design. Flow lines were theoretically how water and solids were removed with trough design. Black arrows represent water and solids flow lines.

The front face of the ramp intersected solids at all depths of the pond and prevent solids from settling and being retained in the ponds.

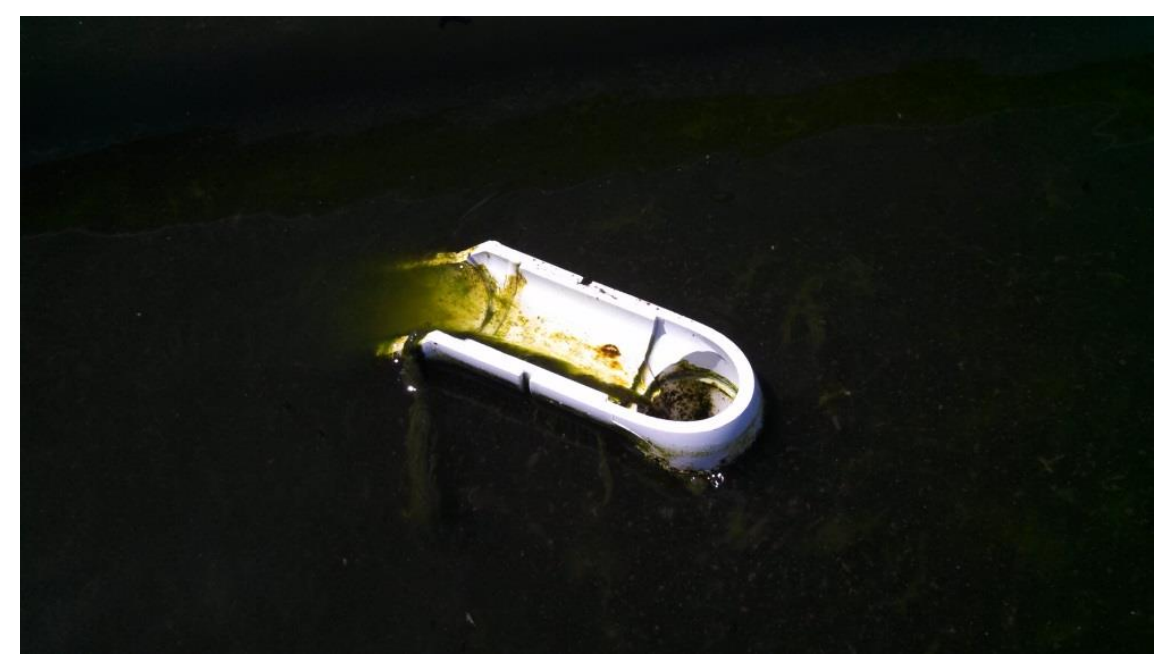

Figure 3-26: Ramp standpipe design as installed in Pond 7.

The ability of the ramped standpipe to discharge water with solids concentrations equal to the bulk pond water was confirmed in grab samples. To explore the effect of the ramped 
standpipes on water treatment performance and nutrient transformations, ramp standpipes were installed in two ponds per pond set, leaving one pond in each set with the 4-inch design. The ponds with the ramps installed in them were Ponds 1, 2, 4, 5, 8, and 9.

\subsubsection{Pond Sampling Procedures}

Weekly grab samples were collected from the ponds for water quality analysis, between 7- 8 am. The sampling location was just upstream of the standpipes at the eastern end of the ponds. Sample bottles were inserted into the ponds upside down and submerged to roughly half the depth of the pond before being turned right side up to let the sample fill the bottle. Because of lab analysis scheduling limitations, no adjustments could be made for day lights savings time. Samples were taken to the Cal Poly lab immediately after being collected and analyzed as soon as possible. All times when samples were not being handled, they were stored in closed coolers, to prevent light from causing algae growth throughout the sample day. A summary of analytical tests and sample volumes is outlined in Figure 3-28.

In addition to sampling from the ponds, tube settler supernatant samples were also collected. Samples from the tube settlers were taken from the down spout at the top of the tube settlers (Figure 3-27) before the effluent flowed into the Alpha head tank. 


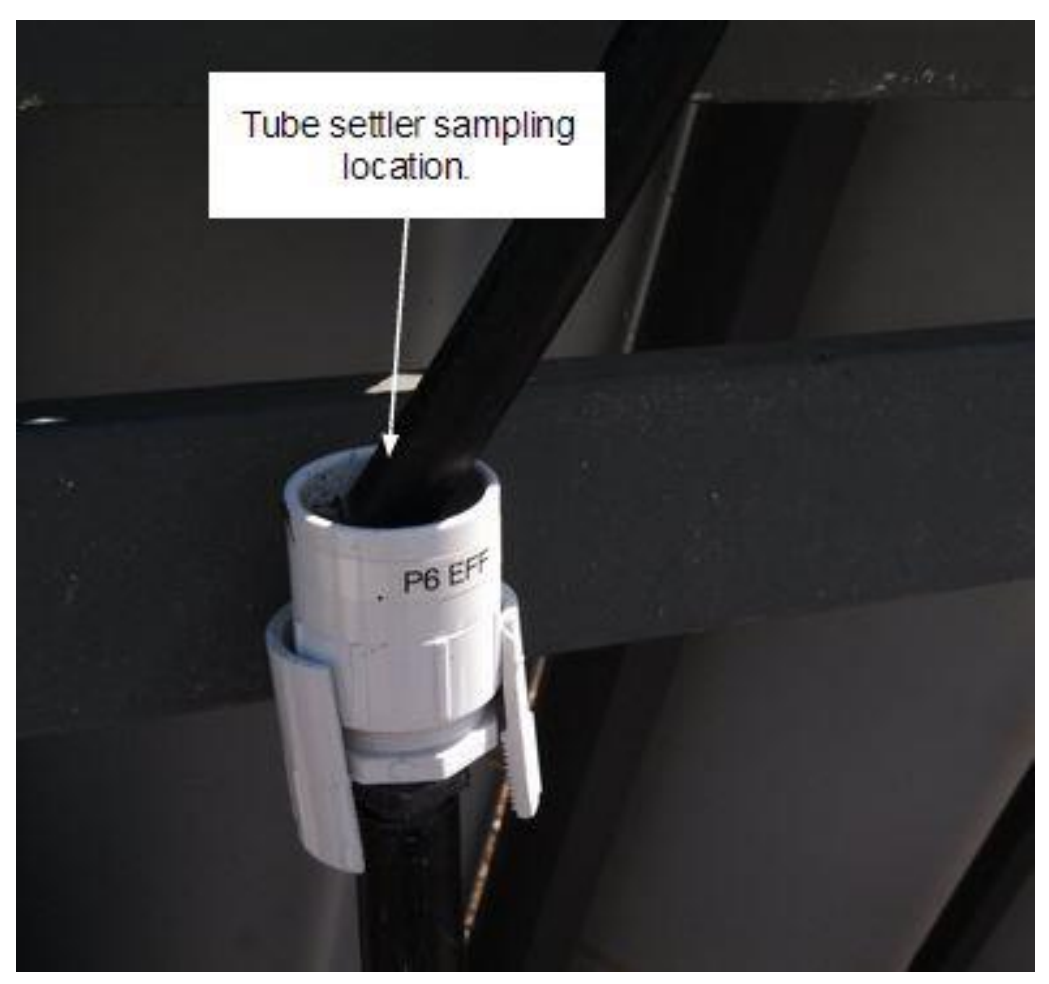

Figure 3-27: Tube settler supernatant sampling location for Pond 6 tube settler

Roughly $1.5 \mathrm{~L}$ of supernatant was collected in 3.78 - $\mathrm{L}$ jugs similar to those used for pond sampling. These samples were used for water quality analyses. Samples used for testing the TSS of the supernatant were collected in 250-mL sample bottles. 


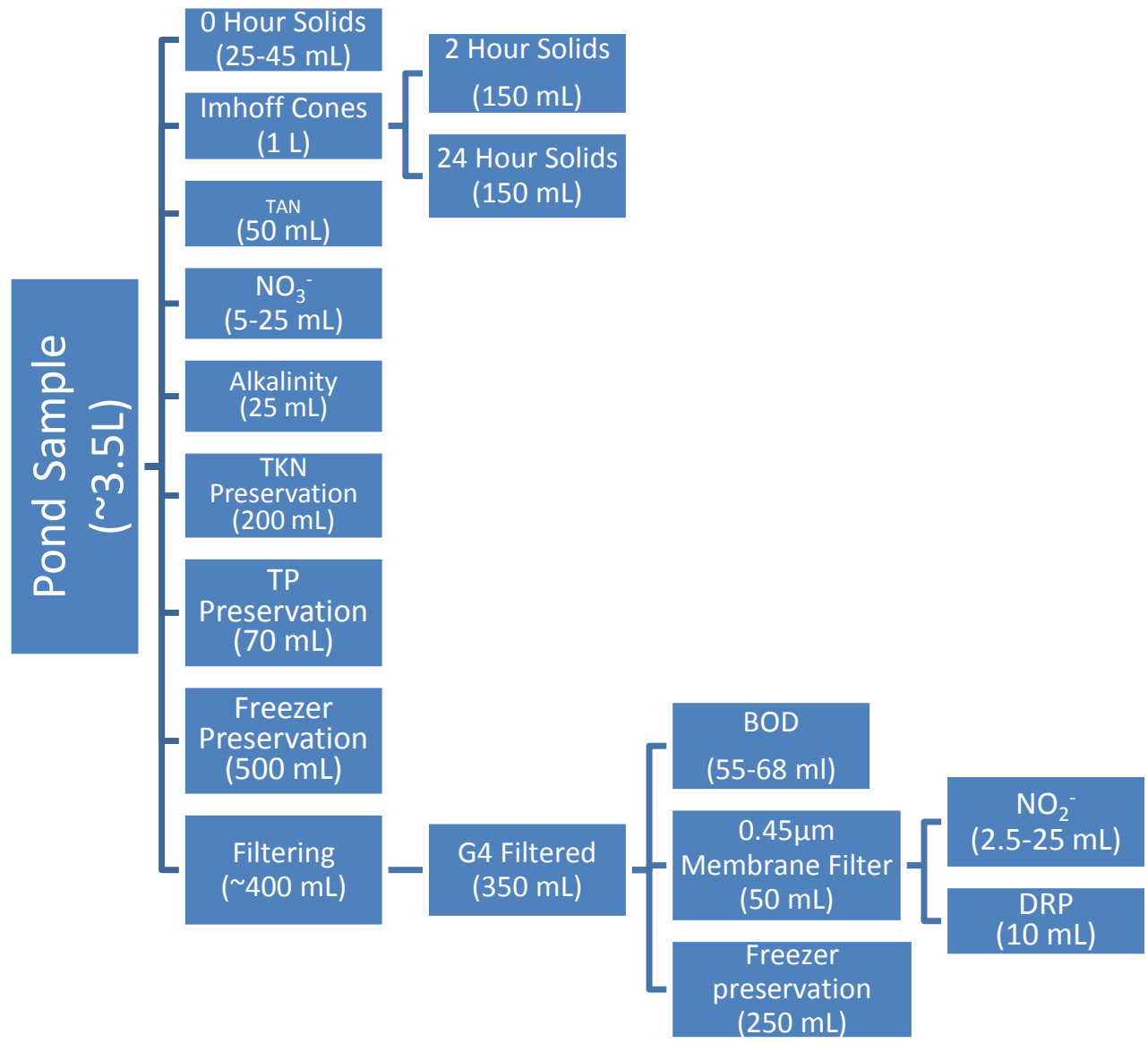

Figure 3-28: Sample analysis flow diagram showing subsample volumes reserved for analyses.

Analytical tests are explained in further detail in Section 3.4

\subsubsection{Standpipe Testing Sampling Procedures}

Standpipes were vertically oriented cylindrical PVC pipes were used to control the depth of the ponds and to convey effluent water from the ponds. It was important to confirm that the water exiting the ponds over the stand pipes were representative of the water in the ponds. Each standpipe tested required unique sampling methods. 


\subsection{Four-Inch Standpipes}

To sample the water entering the four-inch standpipes, a beaker was held along the inner wall of the standpipe so that the water overflowing the standpipe flowed directly into the beaker. A wire basket was used to hold a beaker in place so that the beaker did not fall down the standpipe. Effluent pond water was then transferred to a $250-\mathrm{mL}$ sample bottle to be transported to the lab for solids analysis.

\subsection{Ramped Standpipe}

The ramped standpipes were not installed in all the ponds until after the standpipe sampling experiment. In order to test the ramped standpipe design, a prototype ramp was made to be installed on top of a sample bottle so effluent samples could be collected. The prototype was held in the flow path of the ponds. Water samples were collected after it overflowed the standpipe. The sample bottle was then transported to campus for testing.

\subsection{Aeration Experiments}

In algae biofuels production, after oil is removed from the biomass, solubilization and reuse of nutrients is beneficial in decreasing the costs and greenhouse gas intensity of the process. Anaerobic digestion of the biomass was one such method of nutrient solubilization (Hill, 2014). Once returned to the ponds, the nutrients in the digested sludge became available to support additional algae growth. The aeration experiments were designed to address questions three and four of the research goals. It was important to determine how the digested sludge would degrade further in aerobic environments, and to determine the quantity of nutrients that would be released once in the ponds. 
In an attempt to increase nutrient solubilization, the algae sludge was pretreated by one of four methods: sonication, homogenization, autoclaving, and boiling. (Only sonication and homogenization will be discussed in this thesis because of the delayed sample processing. For information on the other pretreatments, refer to Hill, 2014). After pretreatment, the algae biomass was anaerobically digested for 30-50 days to break-down cells and convert organic nitrogen and phosphorus to soluble forms. After digestion, sludge was aerated to simulate the maximum extent of aerobic degradation that might occur in a raceway if sludge was introduced into the ponds for algae regrowth

\subsubsection{Post Sonication, Post Digestion Aerobic Decay Experiment}

The purpose of this experiment was to determine rate and extend of soluble nutrient regeneration and solids degradation under aerobic conditions. Sonication was used as a benchmark laboratory method against which to compare cell disruption methods more suited to field use. Three aerobic reactors (Figure 3-29) were used in the sonication aeration experiment. 

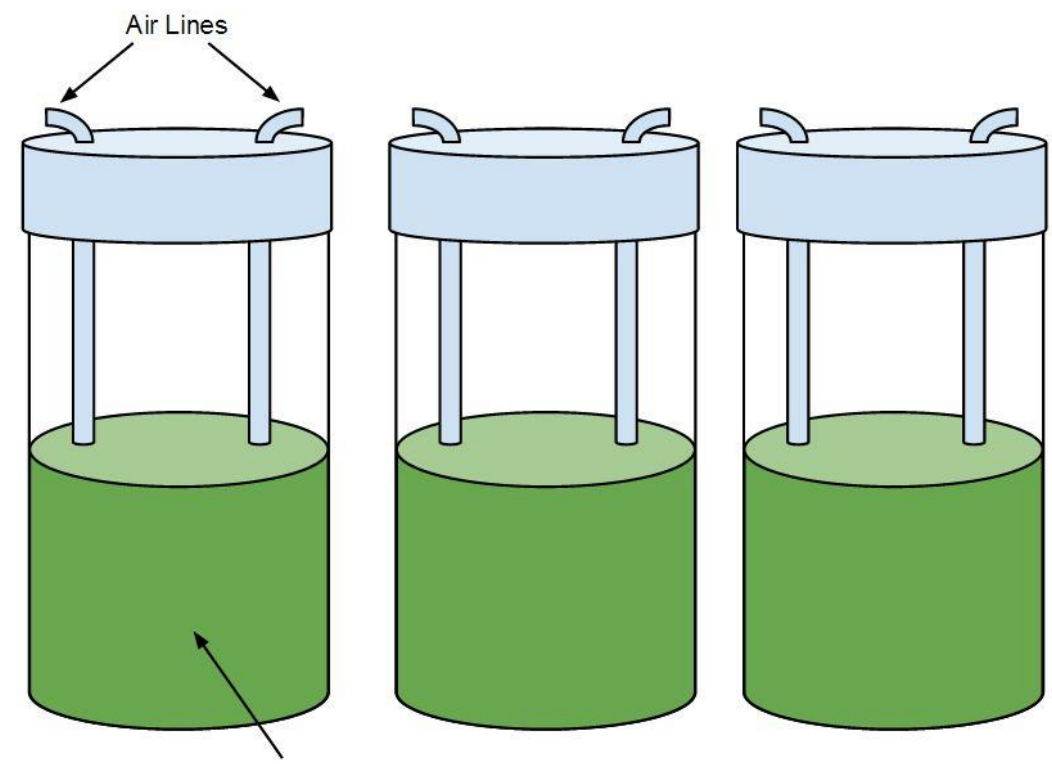

Digested Sludge

Figure 3-29: Sonication aeration batch reactor set up. Reactors were open to the environment; caps were only used to prevent environmental contamination. Mixers and water bath omitted from drawing for clarity. Water bath for this experiment was not temperature controlled. Air lines came in from the top of the reactors and extended to the bottom. Aerators were located at the lowest point that did not interfere with the stir bar mixer.

These reactors were 3.78-L polypropylene juice pitchers (equivalent to beakers). Sludge was aerated and mixed with stir plates (Hanna Instrument, HI 190M). Two fine bubble ceramic diffuser stones (3.5-cm long, 1-cm diameter, commonly used in fish aquaria) per reactor were used to ensure aerobicity. House air was used without filtration in this first experiment. Over the course of the experiment oil present in the house air condensed in the air lines which lead to the development of an air filter for the second aeration experiment.

Algae sludge was collected from the Alpha set tube settlers June 5, 2013, sonicated, and digested (Hill, 2014). The digested sludge was then diluted with dechlorinated tap water and transferred to the anaerobically digested sludge was diluted roughly five-fold to better simulate the dilution that would occur when the sludge was reintroduced into the 
raceway ponds. Dechlorinated tap water was used instead of DI water to prevent osmotic stress. The tap water was declorinated by bubbling compressed air through it overnight.

The diluted sludge was then seeded with $10 \mathrm{~mL}$ of recycled activated sludge (RAS) from the SLO WRRF to provide degrading microbes. This RAS volume of $10 \mathrm{~mL}$ contributed about five percent of the initial volatile solids concentration in the reactors. The diluted and seeded sludge was then mixed and split into three different reactors.

The experiment was conducted for 31 days. Data for VSS, ammonia, nitrate, nitrite, DRP, $\mathrm{pH}$, temperature, and dissolved oxygen were collected. $\mathrm{pH}$ and temperature were measured using a $\mathrm{pH}$ electrode (Oakton waterproof $\mathrm{pH} / \mathrm{mV} /{ }^{\circ} \mathrm{C} /{ }^{\circ} \mathrm{F}$ data meter 310 series, Oakton $\mathrm{pH}$ probe). DO was measured with a calibrated (YSI Digital Professional Series ProODO meter, YSI ProOBOD probe). All other data were collected using methods outlined in section 3.4 .

\subsubsection{Post-Homogenization, Post Digestion Aerobic Decay Experiment}

Similar to the sonication experiment, the purpose of this experiment was to determine if homogenized and digested algae would release more nutrients in an aerobic environment than untreated, digested algae.

Observations from the sonication experiment showed that aeration provided adequate mixing, and that no stir plates were necessary for this experiment. Homogenized and control digested samples were diluted and separated into triplicate aerated reactors. The reactors for this experiment were similar in size and composition to those used in the sonication experiment however the ones used in this experiment had a more uniform 
cross section. Each reactor received roughly 3.2 L of diluted, homogenized, anaerobically-digested sludge. The reactors for homogenized and un-homogenized sludge were placed in separate temperature-controlled water baths (10-gallon fish tanks containing water to a depth nearly equal to that of the sludge solution, and an aquarium heater to maintain constant temperature) (Figure 3-30). Each set of reactors was covered with a cardboard box to exclude light.
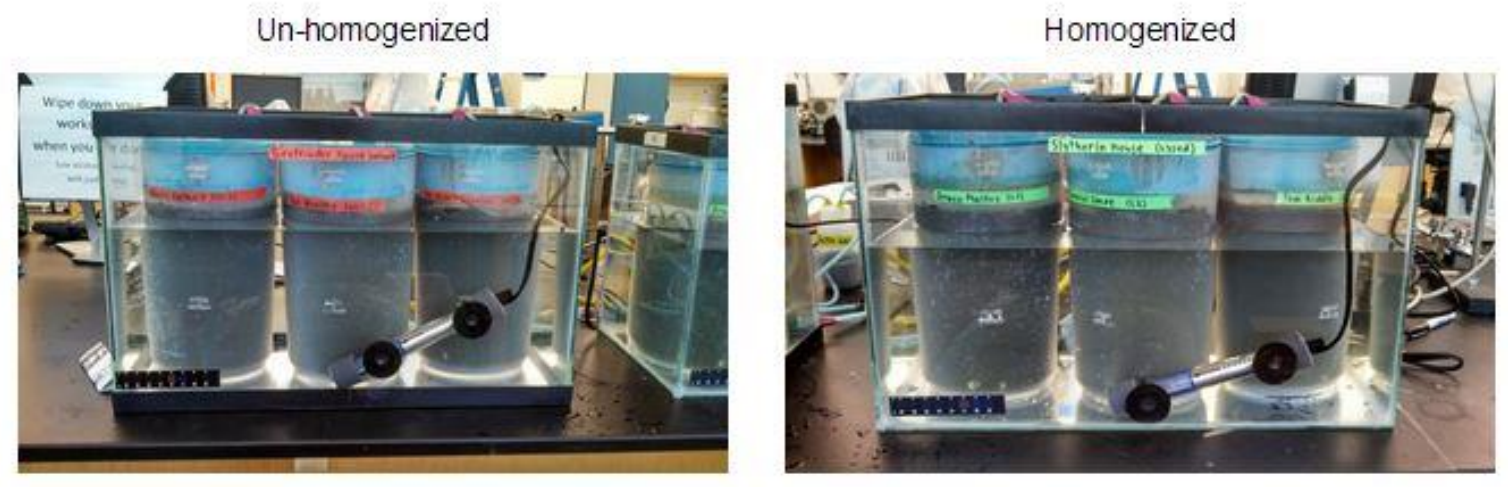

Figure 3-30: Experimental set up for homogenization experiment, as photographed at start up October 26, 2013.

Aeration stones similar to those used in the sonication experiment were secured to the bottom of each reactor with store bought suction cups. To provide both aeration and mixing stones were laid out in an H-pattern (Figure 3-31). 


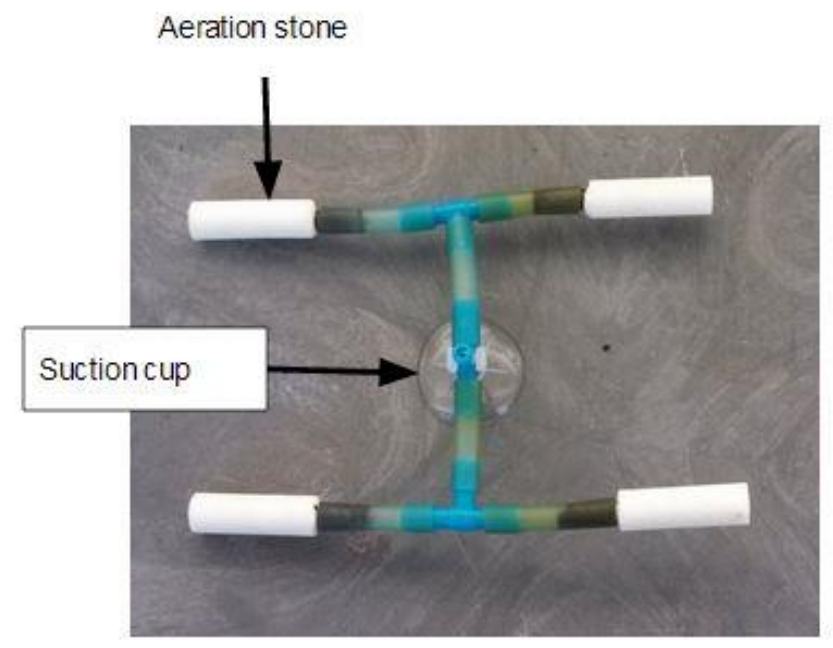

Figure 3-31: Aeration stone layout for the homogenization aeration experiment. Suction cup was used to secure the aeration stones to the bottom of the reactors.

A central air line was used to deliver air to the reactors. The house air valve was maintained at a constant $45^{\circ}$ open (Figure 3-32) to provide an adequate air flow rate into the reactors. An exact air flow rate was not measured, but, by observation, the flow rate was approximately $2 \mathrm{~L}_{\text {air }} / \mathrm{L}_{\text {initial water-sec. }}$

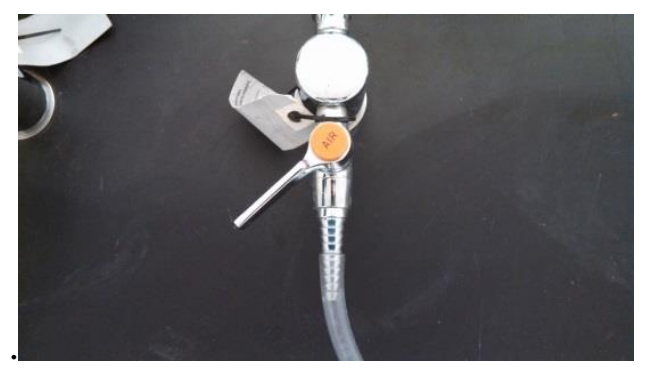

Figure 3-32: Valve at 45 degrees to provide air to reactors

To prevent exposing the reactors to impurities such as vaporized compressor oil, an activated carbon filter was used in the air line (Figure 3-33). The filter was constructed out of a $250-\mathrm{mL}$ plastic bottle filled with activated carbon and cotton balls. The activated carbon was washed first to remove fines. Air flowed into the filter at the bottom of the 
bottle through a tube, passed through the carbon, and out of a line placed just below the cap. The lines were held in place by tape wrapped around the outside of the lines to increase the diameter and prevent the lines from blowing out of the cap.
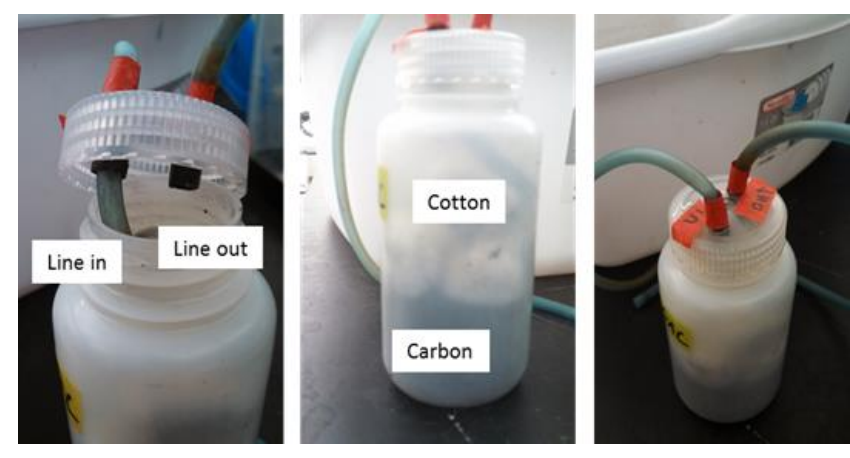

Figure 3-33: Activated carbon air filter was used to remove impurities in the air supply

Sludge with a total solids (TS) concentration of $3.3 \%$ was sieved through a 1 -mm screen and then processed by a bench-scale pneumatic homogenizer (Model M110-L, Microfluidics Corporation, Newton, Mass.). The algae sludge was processed in the homogenizer with a 100-micron ceramic orifice interaction chamber at 20,000 psi pressure drop. The sludge was then anaerobically digested for 43 days before being transferred to the aerobic reactors (Hill, 2014). Unhomogenized algae biomass was digested as a control. The sludge was diluted 6-fold to a starting suspended solids concentration of roughly $2,300 \mathrm{mg} / \mathrm{L}$ for the control and $2000 \mathrm{mg} / \mathrm{L}$ for the homogenized. Reverse osmosis-treated tap water (RO) was used for dilutions. RAS from the SLO WRRF contributed $1 \%$ of the initial VSS for seeding the reactors.

The experiment was initiated on October 26, 2013. Temperature, $\mathrm{pH}$, and dissolved oxygen were monitored each weekday for the first month of aeration, and then periodically after that. 
Data for VSS, ammonia, nitrate, and nitrite were recorded every time samples were taken, based on the rapid changes in VSS and soluble nitrogen in the previous experiment. TKN, COD, DRP, and TP were measured periodically throughout the duration of the experiment. The sampling for these constituents was less frequent than the other constituents to extend the experimental period by minimizing sample collection.

\subsubsection{Aeration Sampling Procedures}

Aeration samples were taken daily for the first week of aeration, and then weekly from then on. Samples were always drawn between 9-10 am. When samples were not being handled, they were stored in the refrigerator at $10^{\circ} \mathrm{C}$. Sample volumes were selected based on anticipated nutrient concentrations and the number of tests to be run on each sample.

In order to draw a representative sample from the reactors, samples were taken with the air flowing. The bubbles prevented solids from settling to the bottom of the reactors. The pipette used to draw the sample was also used to stir the reactors and simultaneously draw sample. A flow diagram of tests and sample volumes is outlined in Figure 3-34. 


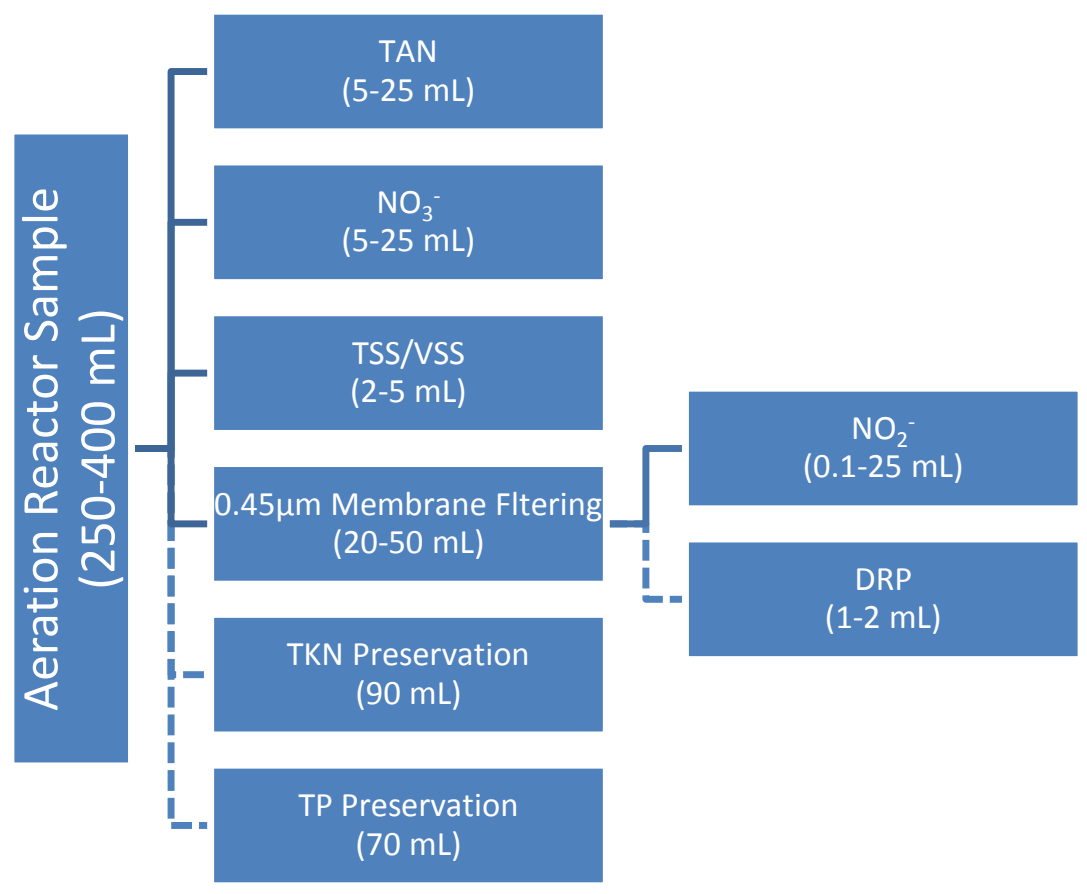

Figure 3-34: Typical sample flow for the aeration experiments. Dashed lines signify tests that were not run on every sample event.

Over the duration of the experiment a small amount of solids adhered to the reactor walls

(Figure 3-35). The total amount of solids adhered to the walls was not measured, but it was estimated to be roughly $10 \%$ of the initial VS of the sample

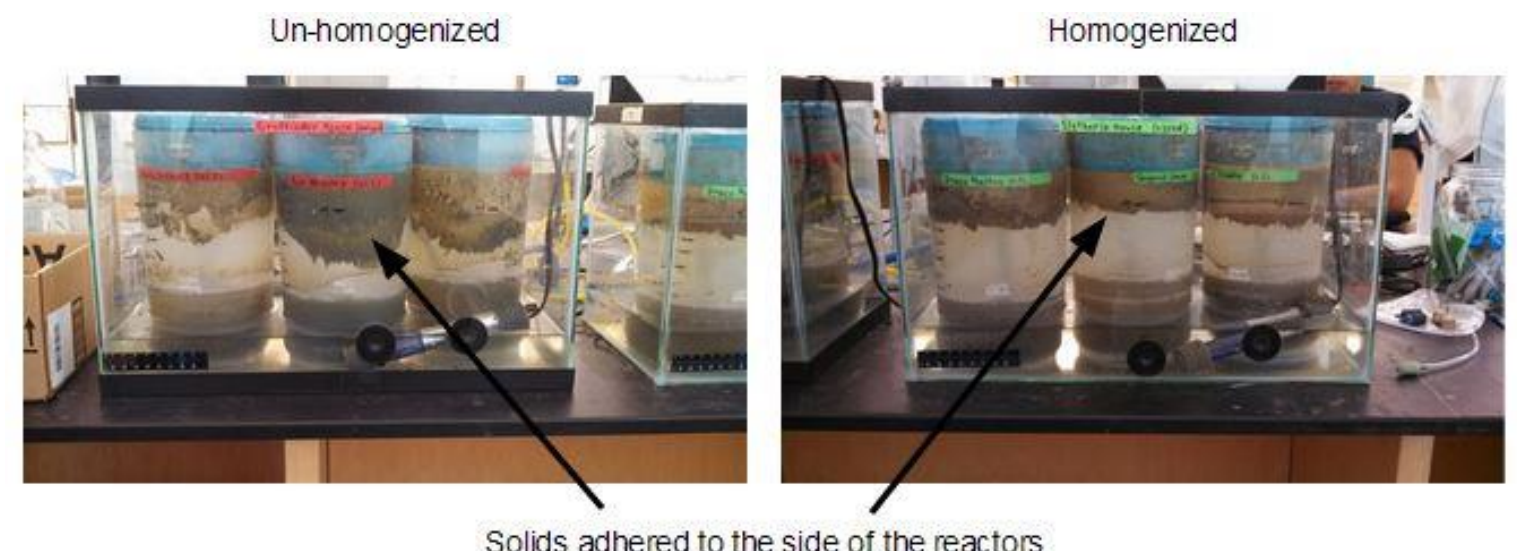

Figure 3-35: Solids adhered to the sides of the reactors as photographed on the final sampling day, February 7th 2014. 


\subsection{Water Quality Testing}

The same water quality tests were performed on both the routine pond and aeration samples. Unless otherwise stated, all tests were performed in accordance with Standard Methods for the Examination of Water and Wastewater1995. Table 3-3 outlines the analytical tests run on each sample types. The meaning of the 0,2 , and 24 hour TSS solids tests will be explained later in the chapter

Table 3-3: Water quality analyses performed for all sample types.

\begin{tabular}{|c|c|c|c|c|c|c|c|c|c|c|c|c|}
\hline Sample Type & $\begin{array}{l}0 \text { Hour } \\
\text { TSS }\end{array}$ & VSS & $\begin{array}{c}2 \text { Hour } \\
\text { TSS }\end{array}$ & $\begin{array}{c}24 \text { Hour } \\
\text { TSS }\end{array}$ & TAN & TKN & $\mathrm{NO}_{3}^{-}$ & $\mathrm{NO}_{2}^{-}$ & DRP & $\mathrm{TP}$ & BOD & Microscopy \\
\hline Influent & $x$ & $x$ & & & $x$ & $x$ & $x$ & $x$ & $x$ & $x$ & $x$ & \\
\hline Alpha Influent & & $x$ & & & & & & & & & & \\
\hline Pond 1 & $x$ & $x$ & $x$ & $x$ & $x$ & $x$ & $x$ & $\mathrm{x}$ & $x$ & $x$ & $x$ & $x$ \\
\hline Pond 2 & $x$ & $x$ & $x$ & $x$ & $x$ & $x$ & $x$ & $x$ & $x$ & $x$ & $x$ & $x$ \\
\hline Pond 3 & $x$ & $x$ & $x$ & $x$ & $x$ & $x$ & $x$ & $x$ & $x$ & $x$ & $x$ & $x$ \\
\hline Pond 4 & $x$ & $x$ & $x$ & $x$ & $x$ & $x$ & $x$ & $\mathrm{x}$ & $x$ & $x$ & $x$ & $x$ \\
\hline Pond 5 & $x$ & $x$ & $x$ & $x$ & $x$ & $x$ & $x$ & $x$ & $x$ & $x$ & $x$ & $x$ \\
\hline Pond 6 & $x$ & $x$ & $x$ & $x$ & $x$ & $x$ & $x$ & $x$ & $x$ & $x$ & $x$ & $x$ \\
\hline Pond 7 & $x$ & $x$ & $x$ & $x$ & $x$ & $x$ & $x$ & $x$ & $x$ & $x$ & $x$ & $x$ \\
\hline Pond 8 & $x$ & $x$ & $x$ & $x$ & $x$ & $x$ & $x$ & $x$ & $x$ & $x$ & $x$ & $x$ \\
\hline Pond 9 & $x$ & $x$ & $x$ & $x$ & $x$ & $x$ & $x$ & $x$ & $x$ & $x$ & $x$ & $x$ \\
\hline Tube Settler 1 & $x$ & & & & & & & & & & & \\
\hline Tube Settler 2 & $x$ & & & & $x$ & $x$ & $x$ & $x$ & $x$ & & & \\
\hline Tube Settler 3 & $x$ & & & & & & & & & & & \\
\hline Tube Settler 4 & $x$ & & & & & & & & & & & \\
\hline Tube Settler 5 & $x$ & & & & $x$ & $x$ & $x$ & $x$ & $x$ & & & \\
\hline Tube Settler 6 & $x$ & & & & & & & & & & & \\
\hline Aeration Samples & & $x$ & & & $x$ & $x$ & $x$ & $x$ & $x$ & $x$ & & $x$ \\
\hline
\end{tabular}

In each analytical batch, at least one of each of the following quality control checks were run: split, matrix spike, blank, and standard check. TSS/VSS and BOD did not have matrix spikes used for $\mathrm{QA} / \mathrm{QC}$; instead all samples were run in duplicate. If a $\mathrm{QC}$ sample failed in a batch, the batch was re-run or removed from the data set.

All samples requiring a dilution (expected concentration outside of calibration curve, or test detection limits) were diluted with deionized water (DI) with the exception of biochemical oxygen demand (BOD) which used standard BOD buffer made with reverse 
osmosis (RO) water. RO water was produced by a Millipore Elix5 unit. DI was produced by a Millipore Milli-Q unit. All reagents and stock solutions were prepared by graduate students or research supervisors.

\subsubsection{Suspended Solids Testing}

This section will outline the different types of suspended solids testing that were done on samples from the ponds, Imhoff cones, standpipes, and aeration tests. All suspended solids samples were run in duplicate, and the results averaged. Suspended solids standards (Ultra Scientific, Kingstown Road Island) were run periodically. The balance (Mettler Toledo AG245) used for suspended solids weight measurements was a set to show $0.00001 \mathrm{~g}$, with the result rounded to $0.0001 \mathrm{~g}$.

\subsubsection{Imhoff Cone Settling}

Laboratory Imhoff cone settling tests were conducted weekly on all ponds. The decrease in supernatant suspended solids used as an indicator of bioflocculation. To conduct this standardized settling, $1 \mathrm{~L}$ of pond sample was poured into an Imhoff cone and allowed to settle. At 2 hours and 24 hours of settling, $150 \mathrm{~mL}$ of supernatant was pipetted out of the Imhoff cones. Before sampling, the Imhoff cone was twisted back and forth several times an eighth of a circle to dislodge any flocs stuck to the side of the cone followed by several minutes for additional settling. The $50-\mathrm{mL}$ sampling pipette was placed $2-4 \mathrm{~cm}$ below the surface of the water to avoid any floating scum. The pipette was rinsed with RO water between drawing additional samples, and when sampling from a different cone. Figure 3-36 shows the arrangement of the Imhoff cones. 

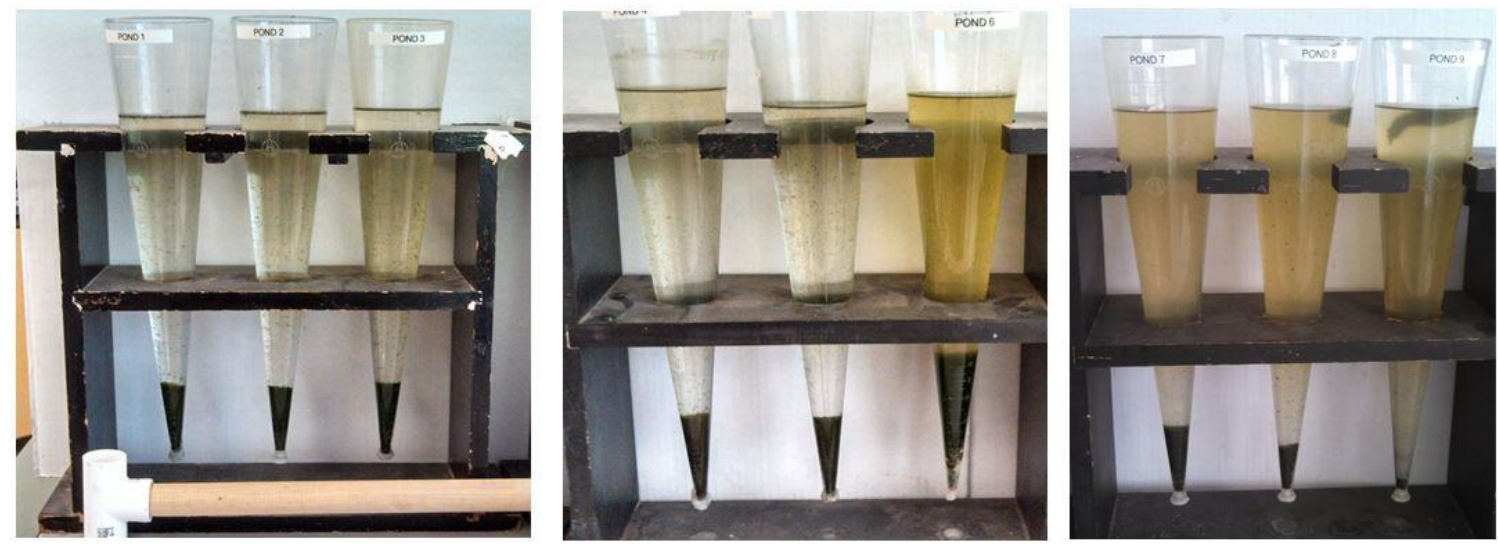

Figure 3-36: Imhoff settling cones after 24 hours of settling. Alpha ponds are left most, Beta ponds are in the middle, and Gamma ponds are on the right. Note the floating scum layer in Pond 9. Image taken July 18, 2013

\subsection{Sample Homogenization for 0-Hour TSS Samples}

Due to the highly flocculent nature of many of the samples, special procedures had to be developed to assure representative aliquots were pipette for suspended solids testing. The samples were first poured into a square beaker (Phipps and Bird Bker ${ }^{2}$ ). Due to large flocs in the ponds, which could be strained by pipetting, homogenization with a 2-speed (high, and low)immersion blender (Proctor Silex, Model No. 59738) was required to break apart the flocs prior to dispensing the sample onto the filter. Samples were blended on the high setting for $15-20$ seconds. The samples were then pipetted out of the beaker with the blender set on low to prevent the samples from settling during sampling. On occasions when samples were not processed immediately samples were stored in 50-mL flat bottom test tubes. Once all samples were pulled they were poured through the filters. The filters and sample were then placed in the oven for two hours. 


\subsection{Unblended samples}

Blending was not required when large flocs were absent from the samples. These samples were poured into a small beaker with a stir bar to provide enough mixing to maintain a homogenous sample while pipetting for filtration.

\subsubsection{Total Suspended Solids}

Total suspended solids (TSS) measurements were performed according to APHA Method 2540 D using glass fiber filters (Fisherbrand G4 filters, Cat No.: 09-804-42C, 1.2 um nominal pore size) previously rinsed with DI water. Because the VSS test was also performed, all filters required 15 minutes in a muffle furnace at $550^{\circ} \mathrm{C}$ prior to determining tare. All filters and filtered solids samples were stored in desiccators with color-indicating desiccant (Agros Organics Drierite). Desiccant was regenerated as needed at $218^{\circ} \mathrm{C}$ for one hour. To keep track of samples, filters were placed aluminum trays (43mm diameter, Fisherbrand) with sample codes etched on the tabs. Fisherbrand trays did not require ashing prior to use. All filtered samples were placed in a gravity convection oven (VWR Symphony, Part No. 414005-110) for at least two hours to remove all moisture from the filters, and then cooled to room temperature in desiccator before being weighed.

\subsubsection{Volatile Suspended Solids}

Volatile suspended solids (VSS) were performed according to APHA Method 2540 E. The same filters used for TSS were used for VSS. After the final weights of the filters and trays were measured for the TSS samples, they were placed in a muffle furnace 
(Fisherbrand Isotemp oven, Model No. 550-58) for 15 minutes at $550^{\circ} \mathrm{C}$ to remove volatile matter. Samples were then allowed to cool to room temperature in a desiccator, before final weights were measured.

\subsubsection{Total Solids Determination}

Total solids determination was performed in according to APHA Method 2540 B. Sludge samples were poured into beakers and stirred with a magnetic stir bar to ensure the sample homogeny. Samples were drawn up using a 5-mL syringe. A syringe was used because the plunger prevented solids from adhering to the sides and artificially reducing the solids concentration. Samples were dispensed directly into a tared and labeled aluminum dishes similar to those used for total suspended solids determination. Samples and trays were placed in the oven for at least two hours to ensure all water was removed. Samples were cooled in desiccators before final weights were measured.

\subsubsection{Nitrogen Determination}

This section describes the nitrogen tests used: total ammonia, nitrate, nitrite, and total Kjeldahl nitrogen (TKN). The first three tests required calibration curves to relate the output to known concentrations. All samples were diluted with DI water so that the concentrations were within the detection limits of the analyses. If samples concentrations fell outside the calibration curve, new samples were diluted and run again. The concentrations of all nitrogen species are reported as $\mathrm{mg} / \mathrm{L}$ as $\mathrm{N}$. 


\subsubsection{Total Ammonia Nitrogen Determination}

Ammonia testing followed APHA Methods 4500-NH3 A and D with an ammonia selective electrode (Thermo Scientific, RS1-12618) and a pH/ion analyzer (Corning Model 355) meter. Ammonia values were reported as total ammoniacal nitrogen (TAN), meaning that it included both $\mathrm{NH}_{3}$ and $\mathrm{NH}_{4}$.

Each time a batch was run, a calibration curve was created by diluting a 2500-ppm stock ammonium chloride standard. The dilutions are outlined in Error! Reference source not found.. All dilutions were done with DI water.

Samples were added to $150-\mathrm{mL}$ beakers and stirred with a magnetic stir bar to ensure the sample touching the electrode membrane was constantly refreshed. Alkaline reagent (Orion 951011) was added one drop at a time until the $\mathrm{pH}$ of the sample exceeded 11. Once a stable mv reading was achieved, it was recorded and compared to the calibration curve to determine the equivalent TAN concentration. For the TAN test, a stable mv reading was considered two consecutive readings within $0.3 \mathrm{mv}$ of each other, and the average value was taken as the result.

\subsubsection{Total Kjeldahl Nitrogen Determination}

Total Kjeldahl Nitrogen (TKN) was run in accordance with APHA Standard Methods 1995 4500-NORG B using round-bottom 800-mL Kjeldahl flasks. There were two stages to the TKN test, the digestion and the distillation. The digestion samples were placed on a heater and boiled with a digestion reagent (sulfuric acid, copper sulfate, potassium sulfate) until 30 minutes after the round-bottomed flasks began to fill with white vapor. 
The distillation step consisted of diluting the digested sample and adding a concentrated solution of sodium hydroxide, sodium thiosulfate. This step was done slowly to prevent a violent acid base reaction. The flasks were added to a distillation apparatus shaken to mix the solution and boiled. The base solution raised the $\mathrm{pH}$ of the sample to above 11, converting the ammonium to ammonia. Once $200 \mathrm{~mL}$ of ammonia distillate had been captured in the boric acid indicator solution, the distillation was halted. The samples were then titrated from green to purple, and the amount of acid required to cause the color change is related to the amount of TKN in the sample.

TKN determinations were performed using an 18-burner combination digestiondistillation fume hood (Labconoco, No. 2117803), which required a major repairs due to the use of a metal blower fan in the acid vapor extraction line and fragile nylon rollers used to support the sliding glass doors.

\subsubsection{Organic Nitrogen Determination}

Organic nitrogen concentrations were calculated using

\section{Equation 2}

$$
\begin{gathered}
\text { Equation 2: Organic nitrogen equation } \\
\text { Organic Nitrogen }=T K N-T A N
\end{gathered}
$$

\subsubsection{Nitrate Determination}

Nitrate determinations were performed in accordance with APHA Standard Methods 1995 sections 4500-NO3- A and D using an nitrate ion selective electrode (Orion, Model RO1-14563) and a pH/ion analyzer meter (Corning, Model 355). Due to the high concentration of interfering ions in wastewater including carbonate, bicarbonate, nitrite, 
and phosphate, Interference Suppression Solution (ISS) was used in a ratio of $10.1 \mathrm{~mL}$ ISS per $90.9 \mathrm{~mL}$ of sample. The ISS was made according to the Orion preparation procedure (Appendix B).

Because of the low levels of nitrate in some ponds, the low calibration curve method was used for nitrate analysis, and consequently some samples had to be diluted. Several volumes of $100 \mathrm{mg} / \mathrm{L}-\mathrm{N}$ standard solution were pipetted into a beaker containing $100 \mathrm{~mL}$ of DI water and $11.1 \mathrm{~mL}$ of ISS to generate the low level calibration curve. The 100 mg/L-N solution was diluted from a $1000 \mathrm{mg} / \mathrm{L}-\mathrm{N}$ sodium nitrate solution.

Samples were diluted with DI water as needed to be within the calibration curve using 50-mL volumetric flasks, which were shaken to ensure complete mixing and poured into $100-\mathrm{mL}$ beakers with magnetic stir bars to maintain a completely mixed sample. The probe was placed in the solution and ISS was added to the sample. When a stable mv reading was attained, it was recorded and compared to the calibration curve to determine the nitrate concentration. For the nitrate test, a stable mv reading was considered two consecutive mv readings of the exact same value to the hundredths of a $\mathrm{mV}$.

\subsubsection{Nitrite Determination}

Nitrite was performed in accordance with APHA Standard Methods 1995 sections 4500NO2 A \& B, which uses a pink color indicator. The coloring reagent was made with $85 \%$ phosphoric acid, sulfanilamide, and N-(1-napthyl)-ethylenediamine. All nitrite samples were filtered through $0.45-\mu \mathrm{m}$ mixed cellulose ester membrane filters (Fisherbrand Cat No. 09-719-2E) to remove interfering solids. Nitrite concentration was determined by the absorbance of the colored sample at 543-nm wavelength. 
The standard curve was made by diluting a $250 \mathrm{mg} / \mathrm{L}-\mathrm{N}$ sodium nitrite solution in 100$\mathrm{mL}$ volumetric flasks.

Samples were diluted in 25-mL volumetric flasks, shaken to ensure complete mixing, and transferred to $40-\mathrm{mL}$ plastic snap top vials. Once in the vials, $1 \mathrm{~mL}$ of coloring reagent was added to each sample and given at least 15 minutes to react. Once samples were stable, the absorbance at $543 \mathrm{~nm}$ was measured on a UV-VIS spectrophotometer (Shimadzu UV-1700 PharmaSpec) using 10-mm path length cuvettes (PLASTIBRAND, Cat No. 759076D). To ensure no water remained in the cuvette after cleaning, samples were poured into the cuvettes and then disposed of, then more sample was poured into the cuvette before finally inserting the cuvette into the spectrophotomer. A stable absorbance value for this test was considered a value that did not change for at least 10 seconds. The absorbance values were related to the calibration curve to determine the nitrite concentrations.

\subsubsection{Phosphorus Determination}

This section described the methods used for determining the phosphorus levels in the ponds and aeration samples.

\subsubsection{Dissolved Reactive Phosphorus Determination}

Dissolved reactive phosphorus (DRP) was performed in accordance with APHA Standard Methods 1995 Sections 4500- P A, B \& E. Similar to the nitrite method, DRP is a colorimetric test requiring all samples be $0.45-\mu \mathrm{m}$ membrane filtered. To reduce phosphorus contamination, all membrane filters were soaked for 24 hours in DI water 
prior to use. This test uses a coloring reagent made with potassium antimonyl tartrate, ammonium molybdate, and ascorbic acid to cause a blue-purple color change in samples. Filtered samples were diluted in 50-mL volumetric flasks, completely mixed, and then added to Erlenmeyer flasks containing $8 \mathrm{~mL}$ of color reagent. The samples and color reagent were given at least 15 minutes to react before being analyzed on the spectrophotometer. The spectrophotometer procedure for DRP was the same as nitrite except the wavelength was $880 \mathrm{~nm}$ instead of $543 \mathrm{~nm}$.

Phosphorus adsorbs to glass which can contaminate samples. All glassware used for phosphorus analysis was acid washed by soaking glassware in $10 \%$ volume/volume sulfuric acid for at least 20 minutes and then soaking in a DI bath for another 20 minutes. Acid washing varied slightly from the standard method, which states to acid wash with hot hydrochloric acid and rinse with DI water. The method was changed for safety and hazardous waste reasons. According to Standard Methods, acid washed glassware had to be acid washed roughly once every three months. The color reagent was added to the flasks first to make sure no residual phosphorus remained from the previous test, which would have been indicated by an immediate color change.

\subsubsection{Total Phosphorus Determination}

Total phosphorus (TP) testing was performed in accordance with APHA 2004-2006 Sections: 4500-P B and $\mathrm{C}$ in which a digestion with nitric and sulfuric acid converts particulate phosphorus to dissolved phosphorus, which is measured calorimetrically. The samples were digested until a brownish orange vapor disappeared and was replaced by white vapor. The appearance of white vapor signified that the nitric acid had boiled away. 
A color reagent made of ammonium molybdate tetra-hydrate, ammonium metavanadate, and hydrochloric acid was added to the samples and given at least 15 minutes to react. The spectrometric finish for total phosphorus was the same as described in the nitrite section. As with DRP, phosphorus contamination was a constant concern. Because of this, all glassware used for TP was acid washed in the same method as described in the dissolved reactive phosphorus section.

\subsubsection{Biochemical Oxygen Demand Determination}

Biochemical oxygen demand (BOD) was performed in accordance with APHA Standard Methods 1995 ed., Sections 5210 A \& B. For this thesis, 5-day carbonaceous BOD $\left(\mathrm{cBOD}_{5}\right)$ and carbonaceous soluble BOD $\left(\mathrm{csBOD}_{5}\right)$ were measured. .

Dilution water was made by adding one BOD nutrient buffer pillow (HACH Cat No. NC9574781) to four liters of RO water. 60-mL (actual volume68-mL) BOD bottles (Wheaton Scientific Products) were used. To ensure all bottles were free of contaminating organisms, they were thoroughly scrubbed with soap and water, and then autoclaved $\left(215^{\circ} \mathrm{C}\right.$ for 15 minutes). All carbonaceous BOD bottles had one "shot" ( 0.08 g) of nitrification inhibitor (HACH formula 2533) added to them. The BOD bottles were filled half way first with sample, or sample and dilution water, shaken to bring the DO of the sample to the saturation point, and then filled with the rest of the sample or dilution water. Any remaining space in the bottles was filled with dilution water to halfway up the bottles' necks. No seed was used for unfiltered samples. When bottles were filled, the initial DO was measured with a calibrated dissolved oxygen electrode (YSI Digital Professional Series, ProODO meter, YSI ProOBOD probe). Calibration was performed 
according to manufacturers' instructions. The BOD bottle stopper was inserted and seated by twisting slightly, and the bottle capped with a plastic cap to prevent the water seal from evaporating in the incubator. After five days at $20^{\circ} \mathrm{C} \pm 5^{\circ} \mathrm{C}$, the samples were removed from the incubator, and the final DO concentrations were measured.

Each pond sample was run in duplicate and averaged. A standard solution made of glucose and glutamic acid (GGA) at a concentration of $300 \mathrm{mg} / \mathrm{L}$ GGA was used to check the accuracy of the method. Unseeded dilution water blanks were run, but often exceeded the recommended limit of $0.2 \mathrm{mg} / \mathrm{L}$ DO drop.

Most samples were tested for soluble BOD, which involved filtering through G4 filters (1.2- $\mu \mathrm{m}$ pore size). Because these samples were filtered, they were seeded with a $0.2 \mathrm{~mL}$ of primary clarifier effluent to provide a sufficient population of bacteria.

\subsubsection{Alkalinity}

Alkalinity was performed in accordance with APHA method 2320 B. Samples were poured into 50-mL beakers and mixed with a magnetic stir bar. A calibrated $\mathrm{pH}$ probe (Corning) was used to check the initial $\mathrm{pH}$ of the samples. Samples were titrated with $0.02 \mathrm{~N}$ sulfuric acid to an endpoint $\mathrm{pH}$ of 4.5 .

\subsubsection{Microscopy}

Microscopy was performed on a weekly basis. Images were taken using Olympus CX 41 (Serial No. 6M10585, 6M12454) microscopes with Olympus Infinity 2 cameras (7A21051, 7A01304). The program used to capture the pictures was Infinity Analyze 
(Lumera Corporation). The program was calibrated using a Fisher Scientific

Hemacytometer.

Each pond sample was poured into a $150-\mathrm{mL}$ beaker and allowed to settle for five minutes. Flocculated samples were drawn out of the bottom of the beaker and one to two drops were placed on a slide. The cover slip was placed over the sample, and it was placed in the microscope for examination. Several pictures were taken at 100x total magnification to estimate the relative algae-to-bacteria ratio. Several more pictures were taken at $1000 x$ total magnification to identify the genera of algae present in the ponds.

\subsection{Statistics}

Statistical analyses were performed on data sets to determine the relative difference or similarity of the pond sets. Statistics performed included averaging split sample concentrations, as well as the corresponding standard deviation. T-tests were used to determine the similarity of sludge pretreatment methods. Unless otherwise stated the null hypothesis for all t-tests was that there was no difference between the treated algae and untreated algae. Unless otherwise stated the p-value cut off was 0.05 for all t-tests. Unless otherwise stated, all error bars are one standard deviation in the positive and negative directions for the three ponds of each triplicate set.

\subsection{Weather Data}

Weather data were downloaded from the California Irrigation Management Information Systems website. The weather station was located at the practice irrigation field on the 
Cal Poly San Luis Obispo campus. The weather station was roughly six kilometers north of the ponds. The main weather data used for this thesis was solar insolation. 


\section{Results and Discussion}

The results for the ponds-in-series experiment are presented first. These results showed the relative differences between the productivity of the Alpha and Beta sets. To evaluate the performance of the ramped standpipes the TSS in the Gamma set was compared to determine if there was a significant difference between the solids in the ponds. Finally the aeration experiment results showed the time series evolution of soluble nitrogen and phosphorus for the sonication and homogenization experiments.

\subsection{Statistical Representation of Data}

Unless otherwise stated, values shown for individual ponds or reactors are the average of results from split samples, when available. (Suspended solids were always determined on splits.) Averages for pond sets (e.g., Alpha, Beta, and Gamma) were calculated by averaging the results from each of the ponds in a pond set. Figure 4-1 shows this process in visual form for the Alpha set, but the process was the same for each pond set.

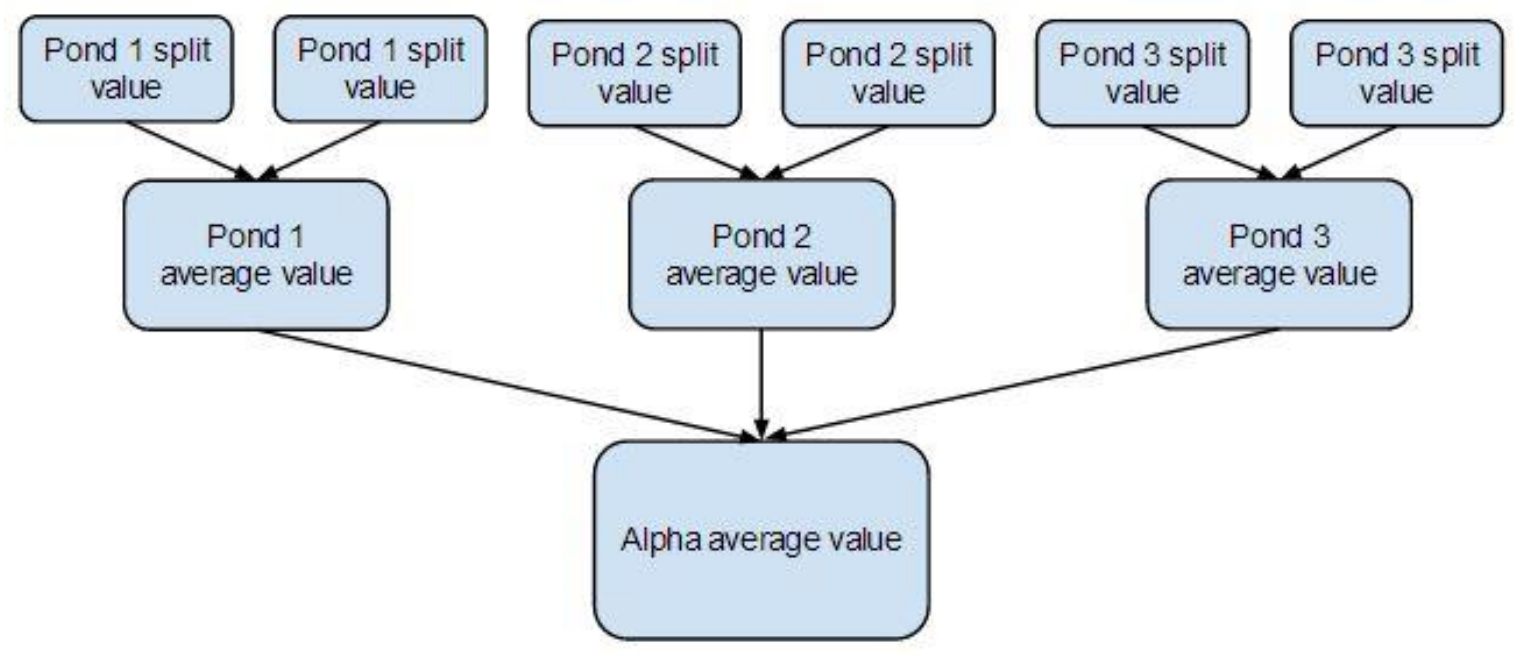

Figure 4-1: Average data flow chart for the Alpha ponds. A similar process was used for Beta and Gamma. 


\subsection{Influent characteristics}

It was important to characterize the influent to know what chemical and physical constituents going into the ponds. Table 4-1outlines the characteristics of the influent for the duration of all experiments.

Table 4-1: Influent characterization from March 6, 2013 to March 19, 2014

\begin{tabular}{ccccccccc} 
& \multicolumn{8}{c}{ Influent Characterization } \\
\cline { 2 - 9 } & TAN & NO3 & NO2 & TKN & TSS & VSS & DRP & TP \\
\cline { 2 - 9 } Max (mg/L) & 53.30 & 4.98 & 0.27 & 59.92 & 182.50 & 172.50 & 4.52 & 8.29 \\
Min (mg/L) & 26.56 & 0.21 & 0.00 & 31.36 & 32.83 & 23.00 & 1.78 & 3.49 \\
Average (mg/L) & 37.42 & 1.15 & 0.04 & 44.87 & 63.52 & 59.82 & 3.62 & 5.72 \\
Standard Deviation & 6.14 & 0.93 & 0.05 & 7.40 & 24.19 & 25.33 & 0.45 & 1.48 \\
Number of Data Ponts & 50.00 & 45.00 & 40.00 & 43.00 & 46.00 & 36.00 & 48.00 & 29.00 \\
\hline
\end{tabular}

\subsection{List of Operational Changes}

There were several operational changes made during the course of the experiments. These changes are outlined in Table 4-2.

Table 4-2: Operational Changes for the Algae Field Station.

\begin{tabular}{l} 
Date Operational Change \\
\hline 3/6/2013 Grab samples start \\
6/1/2013 Alpha HRT changed from 4 days to 3 days \\
6/1/2013 Gamma Tube settlers moved to Beta ponds \\
8/9/2013 1-inch standpipes installed \\
8/16/2013 Single and double fin standpipes installed \\
10/2/2013 Ramped standpipes installed in Ponds 3,6 , and 7 \\
\hline
\end{tabular}

\subsection{Two-day HRT Performance}

The areal biomass productivity in Gamma was highly variable during the course of the year (Figure 4-2). The productivity data prior to the ramp installation was unexpectedly 
high. The high values were most likely due to solids accumulation due to the 4-inch standpipes. This data is mainly included for comparison reasons, but was not included in the analysis of productivity. Ramps were installed in October 2013, therefore productivity data for winter was the only data considered accurate for this study.

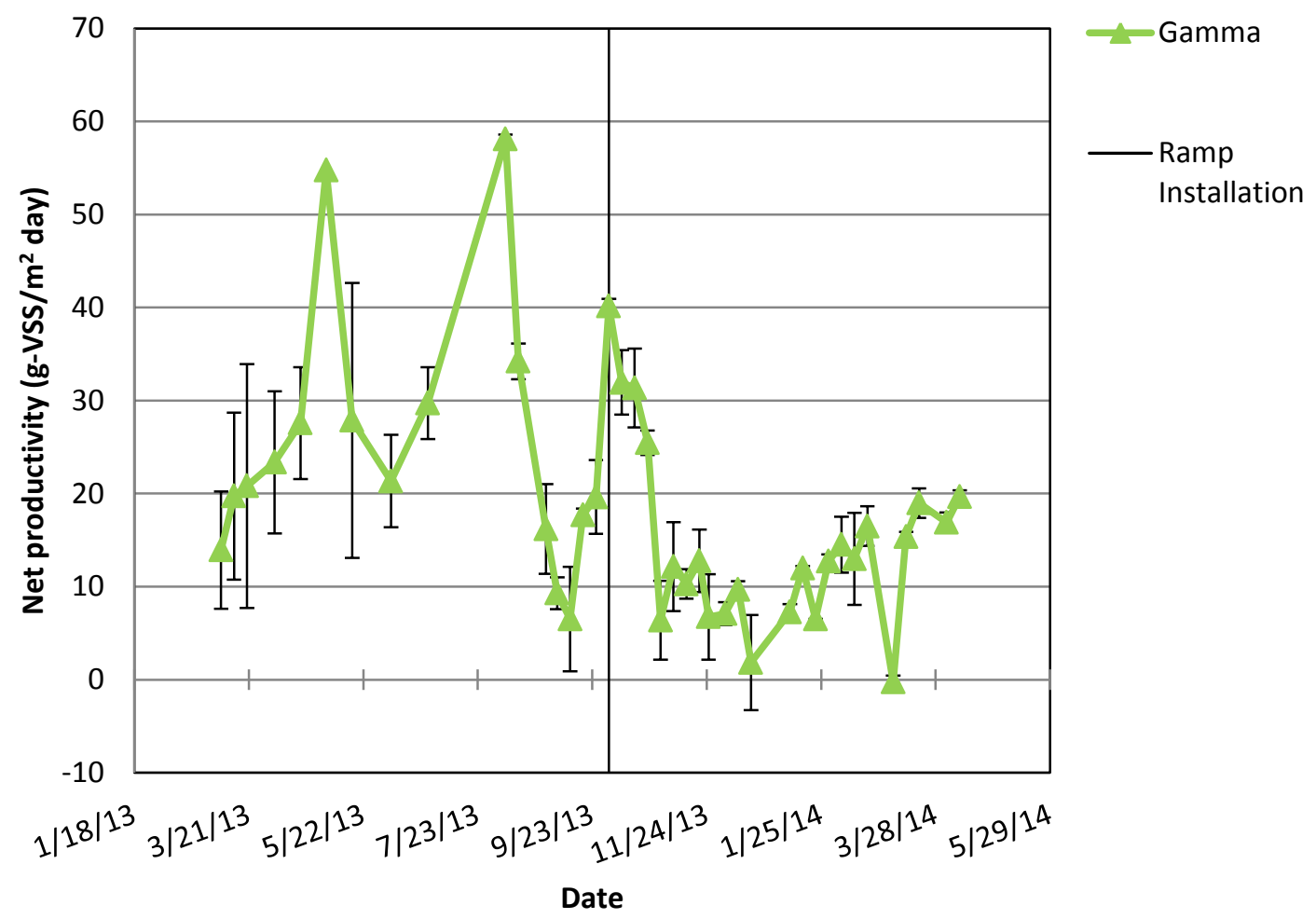

Figure 4-2: Productivity in the Ponds 8 and 9 in the Gamma set (2-d HRT). Error bars are one standard deviation in the positive and negative direction.

Table 4-3 shows the seasonal variation in the Gamma ponds. True Pond 7 productivity values are not available due to absence of sampling of standpipe overflow. Solids accumulation will be discussed further in Chapter 4.7. The average winter productivity in Gamma (Table 4-3) was most likely elevated due to solids accumulation. 
Table 4-3: Seasonal variation in productivity for Ponds 7,8 and 9 in the 2-d HRT Gamma set. Summer was from March 6 to August 29, 2013, and winter was from September 4, 2013 to February 19, 2014. Note the Pond

7 productivity is presented but was not accurate due to solids accumulation.

\begin{tabular}{cccccccc} 
& \multicolumn{7}{c}{ Gamma Productivity } \\
\cline { 2 - 8 } & \multicolumn{2}{c}{ Pond 7 } & \multicolumn{2}{c}{ Pond 8 } & \multicolumn{2}{c}{ Pond 9 } \\
\cline { 2 - 8 } & Summer & Winter & Summer & Winter & Summer & Winter \\
\cline { 2 - 8 } $\begin{array}{c}\text { Max Productivity } \\
\text { (g vss/m2-day) }\end{array}$ & 39.9 & 39.6 & 58.5 & 40.7 & 66.8 & 16.2 \\
$\begin{array}{c}\text { Min Productivity } \\
\text { (g vss/m2-day) }\end{array}$ & 12.4 & -0.4 & 9.5 & -1.8 & 12.8 & 3.4 \\
$\begin{array}{c}\text { Average Productivity } \\
\text { (g vss/m2-day) }\end{array}$ & 26.5 & 20.7 & 25.2 & 13.7 & 33.1 & 15.2 \\
$\begin{array}{c}\text { Standard Deviation } \\
\text { (g vss/m2-day) }\end{array}$ & 8.1 & 8.7 & 14.1 & 10.4 & 16.8 & 9.2 \\
Number of Data Points & 12 & 22 & 11 & 23 & 13 & 23 \\
\hline
\end{tabular}

Compared to Alpha and Beta, the productivity in Gamma is generally higher if only slightly (Table 4-4,

Table 4-5, Figure 4-3).

Table 4-4: Seasonal variation in productivity for Ponds 4, 5, and 6 in the 3-d HRT Alpha set. Summer was from March 6 to August 29, 2013, and winter was from September 4, 2013 to February 19, 2014

\begin{tabular}{|c|c|c|c|c|c|c|}
\hline & \multicolumn{6}{|c|}{ Beta Productivity } \\
\hline & \multicolumn{2}{|c|}{ Pond 4} & \multicolumn{2}{|c|}{ Pond 5} & \multicolumn{2}{|c|}{ Pond 6} \\
\hline & Summer & Winter & Summer & Winter & Summer & Winter \\
\hline $\begin{array}{l}\text { Max Productivity } \\
\text { (g VSS/m2-day) }\end{array}$ & 30.7 & 23.4 & 27.3 & 18.7 & 25.3 & 20.8 \\
\hline $\begin{array}{l}\text { Min Productivity } \\
\text { (g vss/m2-day) }\end{array}$ & 11.4 & -1.0 & 9.2 & -3.8 & 6.6 & -0.7 \\
\hline $\begin{array}{l}\text { Average Productivity } \\
\text { (g vSs/m2-day) }\end{array}$ & 20.9 & 11.5 & 16.7 & 8.6 & 15.8 & 9.8 \\
\hline $\begin{array}{l}\text { Standard Deviation } \\
\text { (g VSS/m2-day) }\end{array}$ & 7.4 & 5.6 & 5.9 & 5.4 & 6.7 & 5.4 \\
\hline Number of Data Points & 14 & 21 & 13 & 22 & 13 & 23 \\
\hline
\end{tabular}


Table 4-5: Seasonal variation in productivity for Ponds 1, 2, and 3 in the 3-day HRT Alpha set. Summer was from March 6 to August 29, 2013, and winter was from September 4, 2013 to February 19, 2014

\begin{tabular}{|c|c|c|c|c|c|c|}
\hline & \multicolumn{6}{|c|}{ Alpha Productivity } \\
\hline & \multicolumn{2}{|c|}{ Pond 1} & \multicolumn{2}{|c|}{ Pond 2} & \multicolumn{2}{|c|}{ Pond 3} \\
\hline & Summer & Winter & Summer & Winter & Summer & Winter \\
\hline $\begin{array}{l}\text { Max Productivity } \\
\text { (g vSS/m2-day) }\end{array}$ & 24.5 & 16.2 & 25.5 & 14.7 & 28.6 & 17.7 \\
\hline $\begin{array}{l}\text { Min Productivity } \\
\text { (g VSS/m2-day) }\end{array}$ & 1.2 & -1.2 & 3.3 & -3.1 & 0.1 & -1.8 \\
\hline $\begin{array}{l}\text { Average Productivity } \\
\text { (g VSS/m2-day }\end{array}$ & y) 12.9 & 8.0 & 13.8 & 7.4 & 11.6 & 9.3 \\
\hline $\begin{array}{l}\text { Standard Deviation } \\
\text { (g VSS/m2-day }\end{array}$ & 7.3 & 4.0 & 5.9 & 4.2 & 7.8 & 4.7 \\
\hline Number of Data Points & 16 & 23 & 18 & 21 & 17 & 22 \\
\hline
\end{tabular}

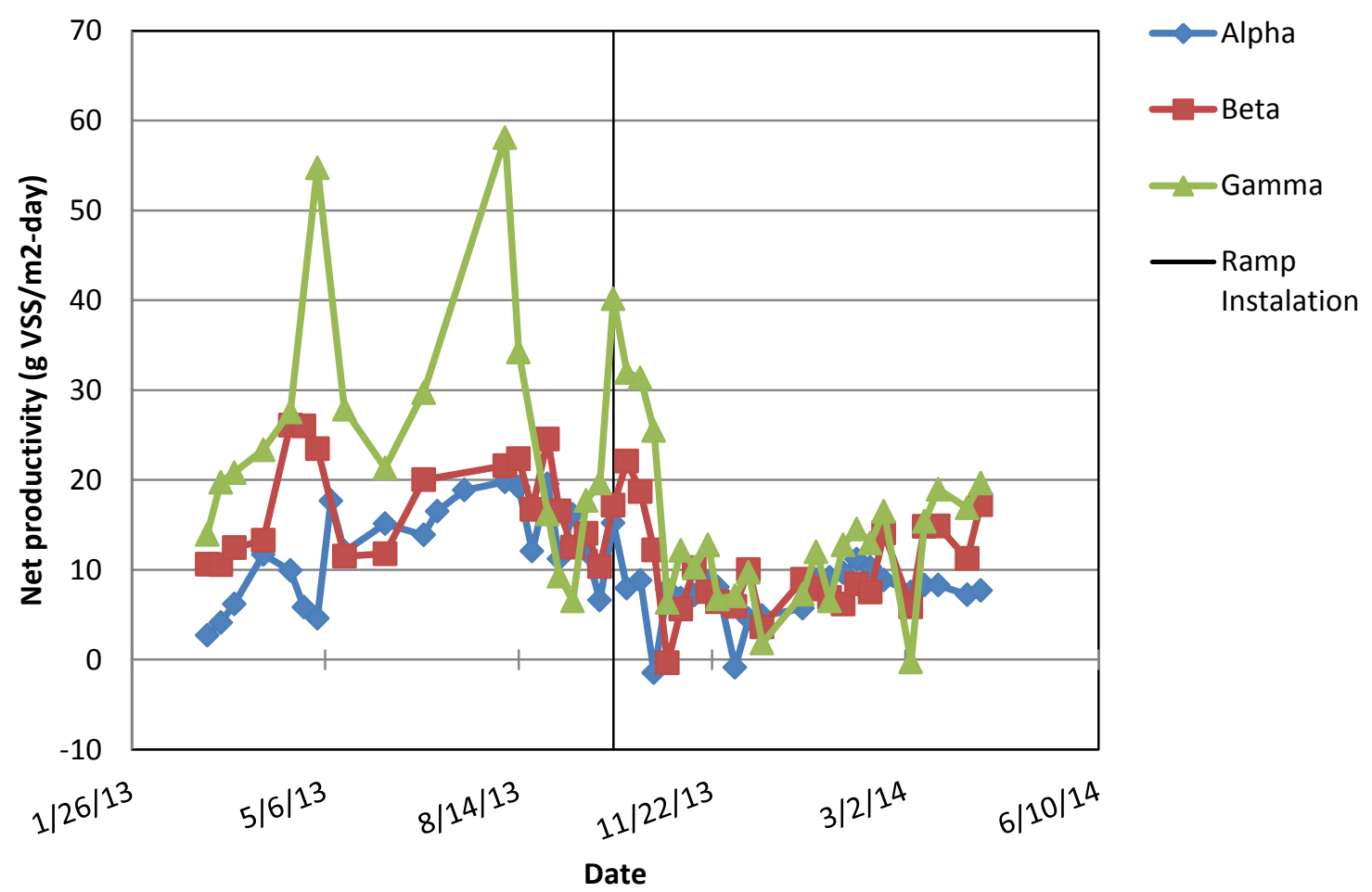

Figure 4-3: Productivity in all ponds from March 6, 2013, to April 3, 2014. Error bars removed for clarity. 
The gamma ponds higher productivity values were likely due to the shorter HRT compared to the other ponds.

The trend of high productivity in the summer and low productivity in the winter was due to more solar insolation in the summer than the winter (Figure 4-4). In ideal operational conditions light would be the only limiting factor.

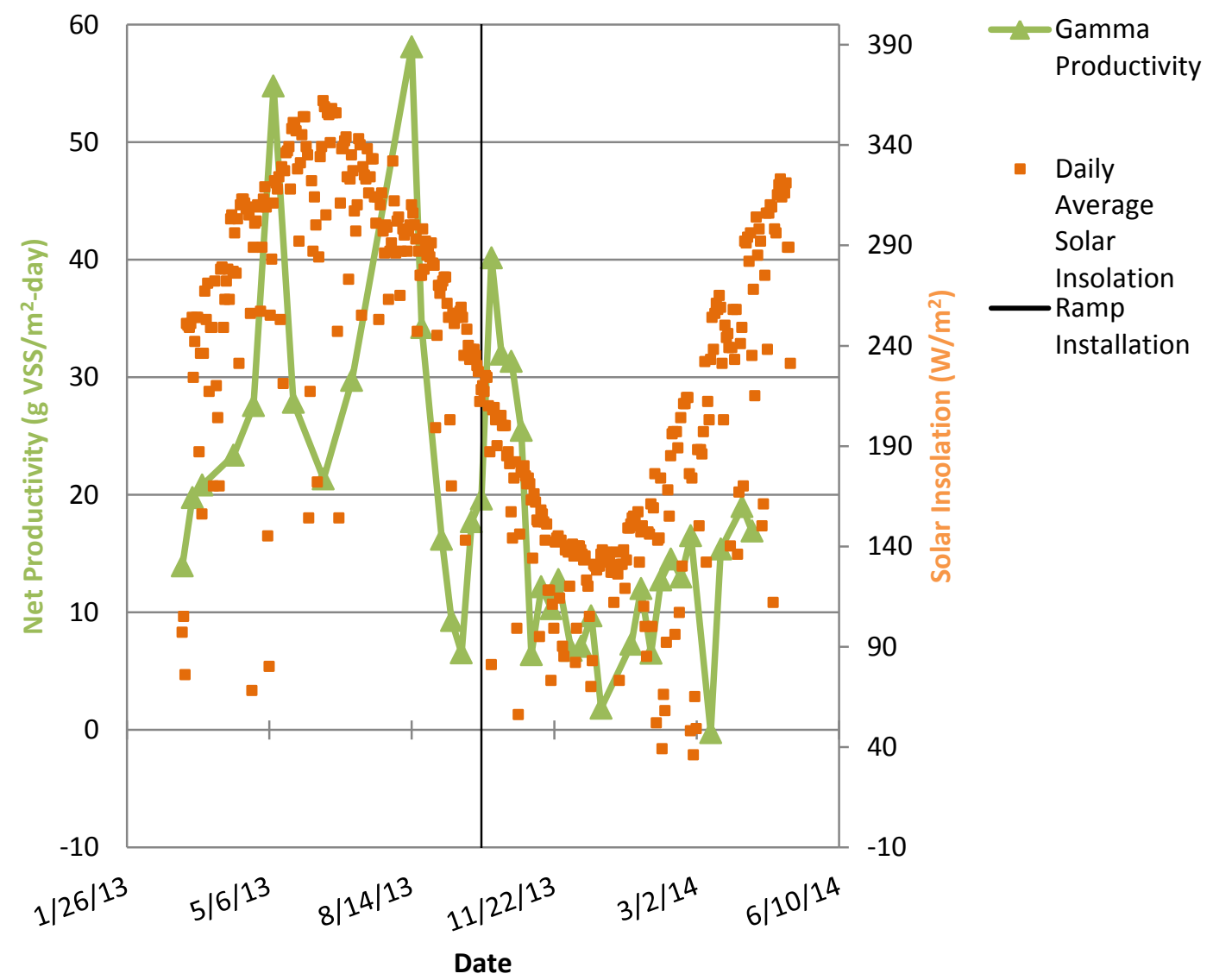

Figure 4-4: Solar insolation and productivity for the Gamma ponds from March 6, 2013 to April 17, 2014 
Figure 4-5, Figure 4-6 show the relationship between nutrients (soluble nitrogen and phosphorus) and productivity in the Gamma ponds.

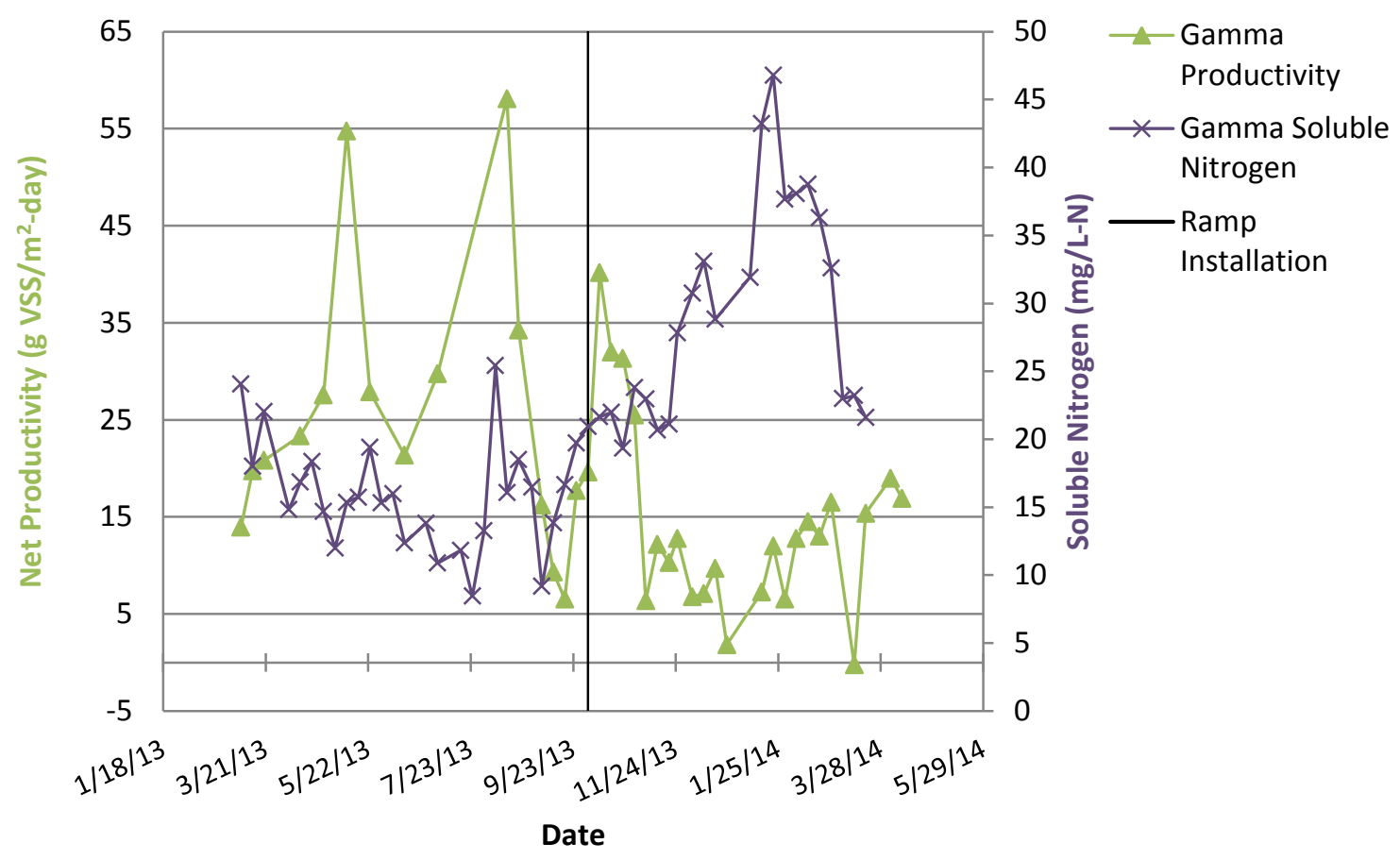

Figure 4-5: Productivity and soluble nitrogen concentrations for the Gamma ponds. Error bars excluded for clarity. 


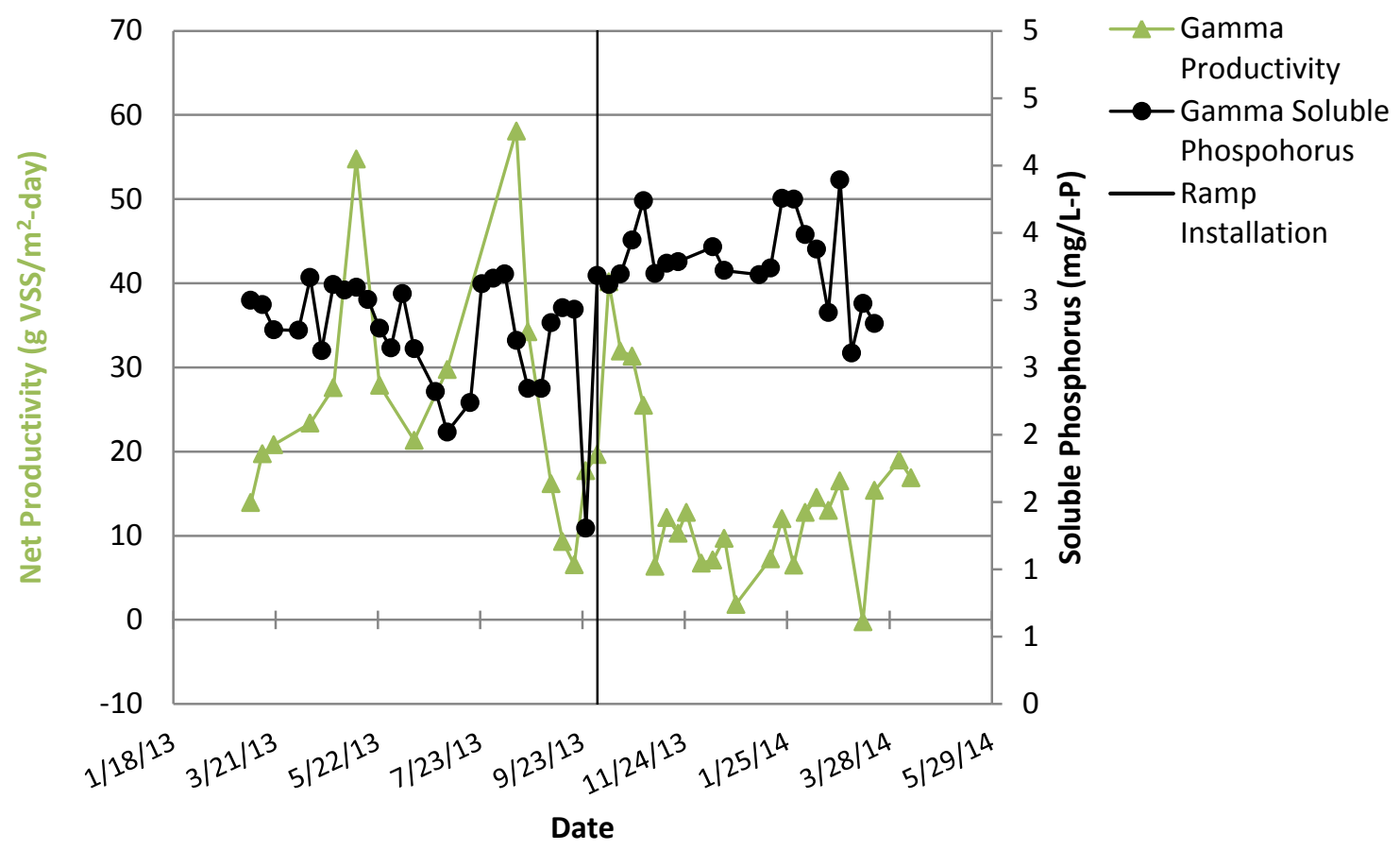

Figure 4-6: Productivity and soluble phosphorus concentrations for the Gamma set ponds. Error bars excluded for clarity

There is a pattern of high productivity, low nitrogen and phosphorus concentration in Gamma.

Growth was considered nitrogen limited when the percent nitrogen in the biomass was less than five percent. Figure 4-7 shows that there were only a few instances when the percent nitrogen in the biomass fell below five percent. 


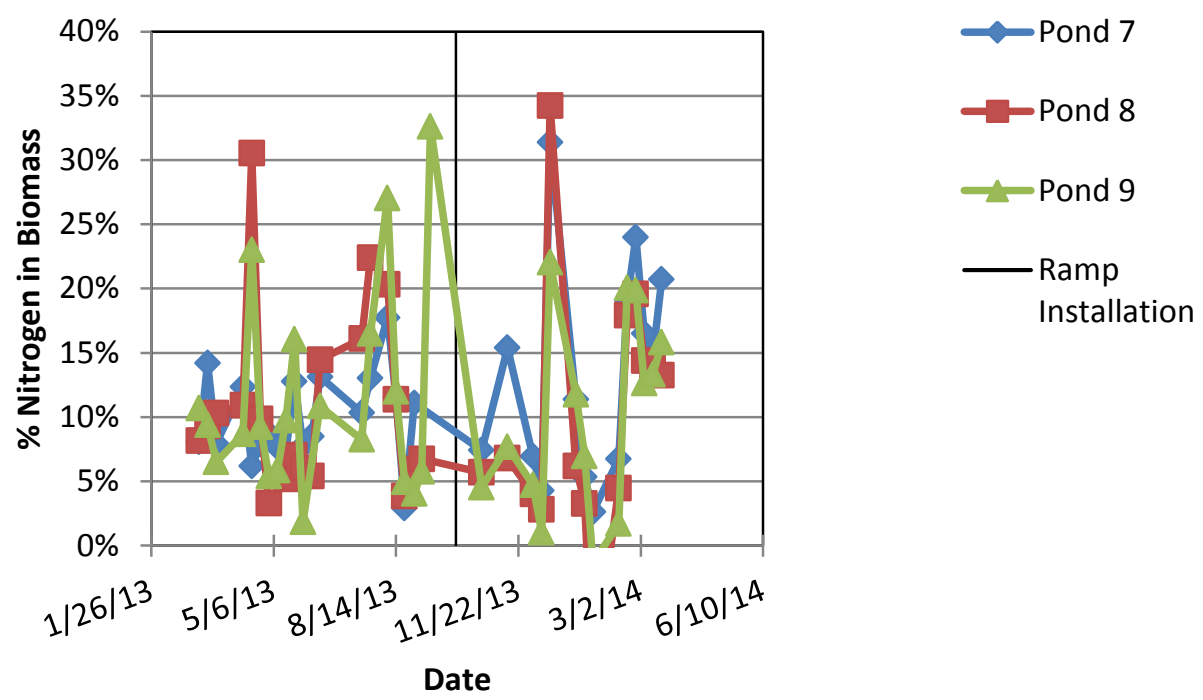

Figure 4-7: Percent nitrogen in the biomass in Gamma.

Nitrogen and phosphorus concentrations in Gamma rarely dropped to low levels, meaning Gamma was most likely not nutrient limited.

\subsection{Ponds -in-Series Results}

The main variable considered in this experiment was influent type: primary clarifier effluent (fresh media) or tube settler effluent (recycled media). Round 1 (Beta) was used when referring to the ponds fed primary clarifier effluent, round 2 (Alpha) was used when referring to ponds fed tube settler effluent.

\subsubsection{Areal Productivity}

Biomass productivity of the ponds was the main output variable monitored in the pondsin-series experiment. Productivity was defined as the net mass of biomass produced in the ponds per unit area per time (g VSS/ $\mathrm{m}^{2}$-day). VSS was used the proxy for biomass (Equation 1). There was no distinction made between algal biomass and bacterial 
biomass. The influent VSS was subtracted so that only the net VSS grown in the ponds was considered.

The VSS ${ }_{\text {inf }}$ for the Beta ponds was the VSS in the primary clarifier effluent. The VSS $\mathrm{Vinf}_{\text {f }}$ for the Alpha ponds was the VSS in the tube settler effluent (settled Beta pond effluent). From March 6, 2013 to August 14, 2013 no data were collected on the influent to Alpha. The influent VSS for Alpha was estimated by averaging the Beta VSS and multiplying it by the average solids removal of the Beta tube settlers.

Figure 4-8, Figure 4-9, and Figure 4-10 show the average productivity for the Alpha and Beta set ponds. The green vertical line in the graphs represented the date when the Alpha ponds were set to the same HRT (3-day) as Beta. The black line represented the date that the ramped standpipes were installed. As stated in section 4.7 no significant accumulation was seen in either Alpha or Beta and thus it was assumed that productivity was not affected by accumulation as in Gamma.

For a majority of the experiment, the productivity of Beta was slightly higher than Alpha. 


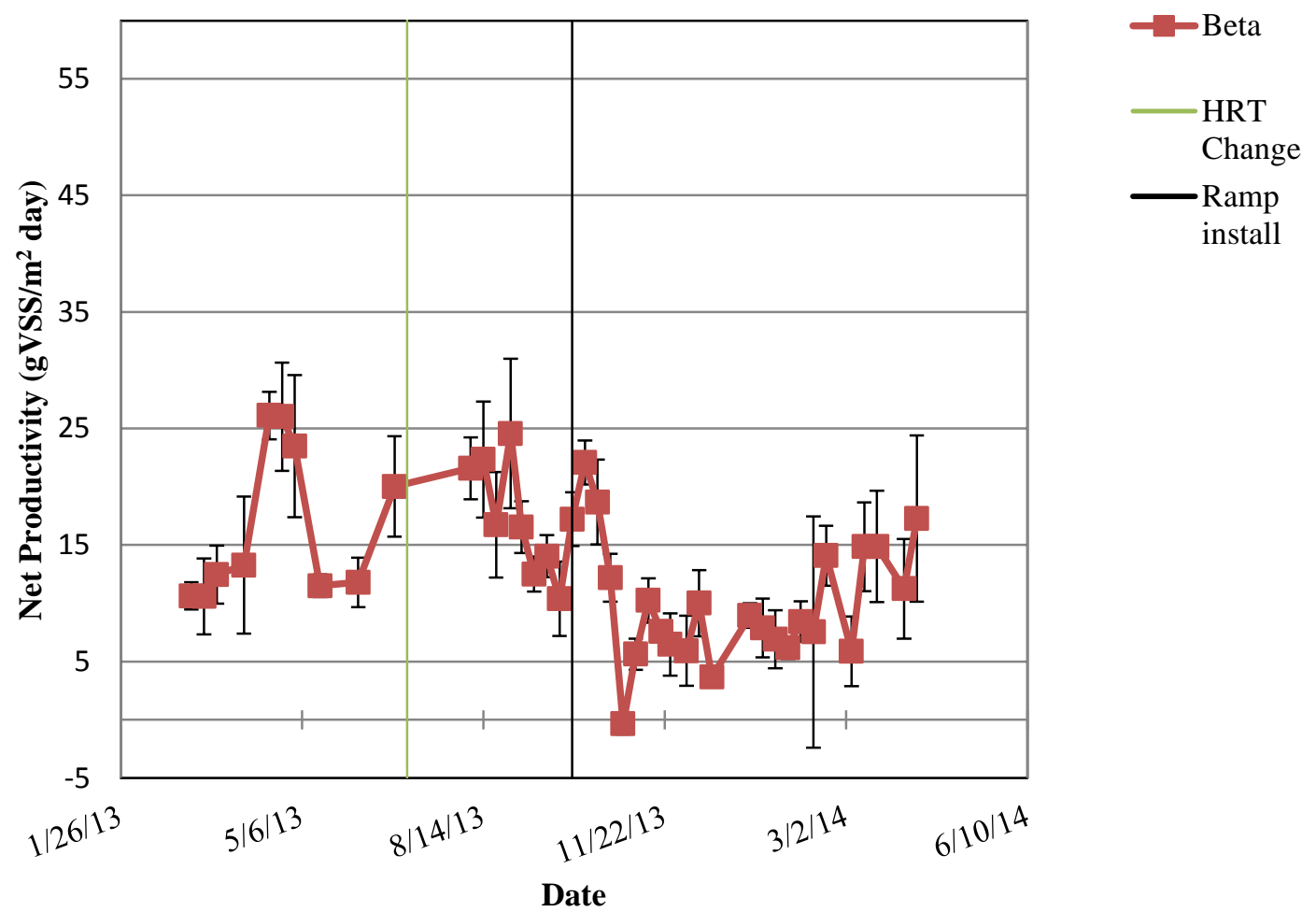

Figure 4-8: Net productivity for the Beta ponds. The mean and standard deviation of triplicates are shown for weekly data. The vertical line represents the shift from 4-d to 3-d HRT in Alpha. 


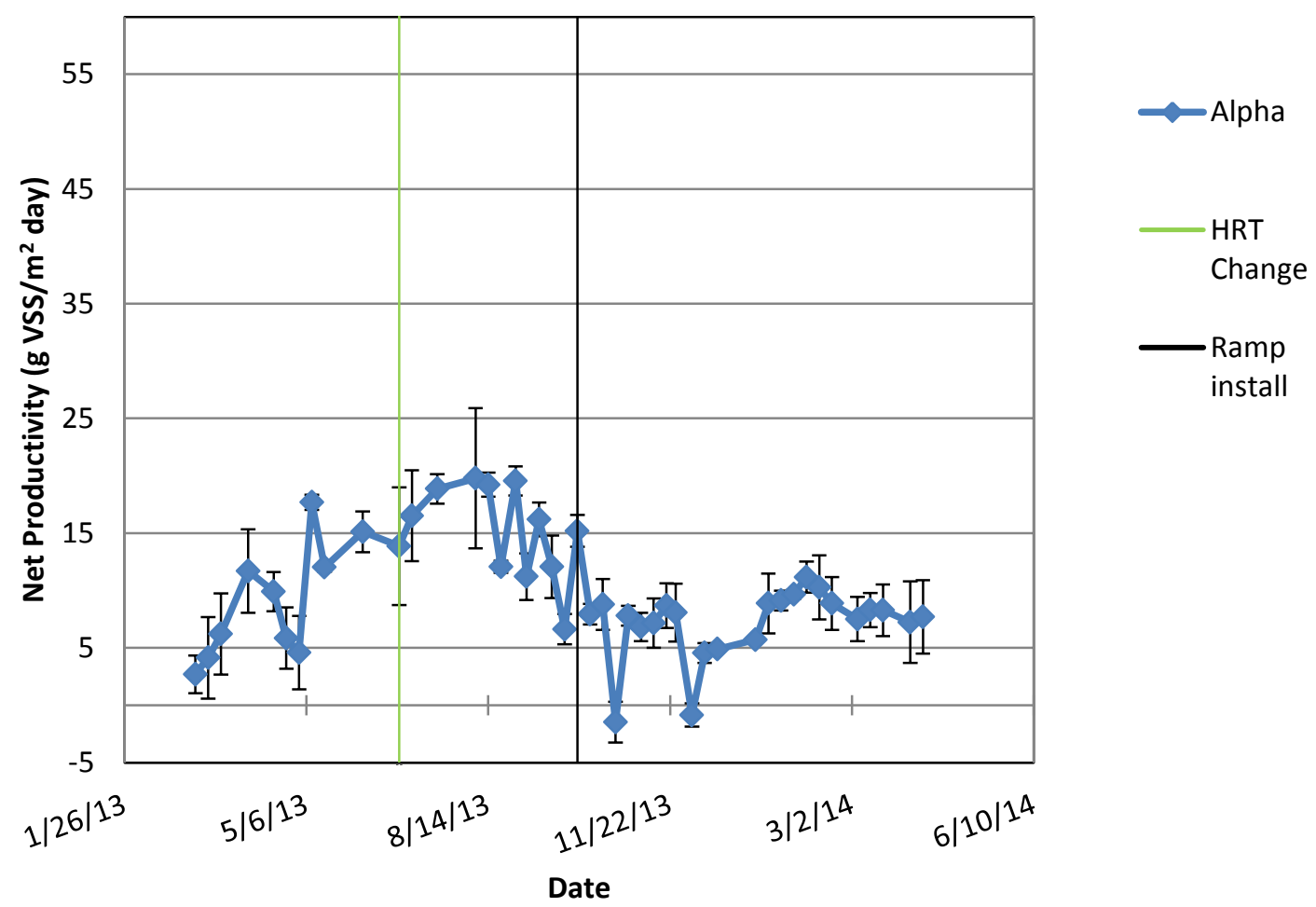

Figure 4-9: Net productivity for the Alpha ponds. The mean and standard deviation of triplicates are shown for weekly data. The vertical line represents the shift from 4-d to 3-d HRT. 


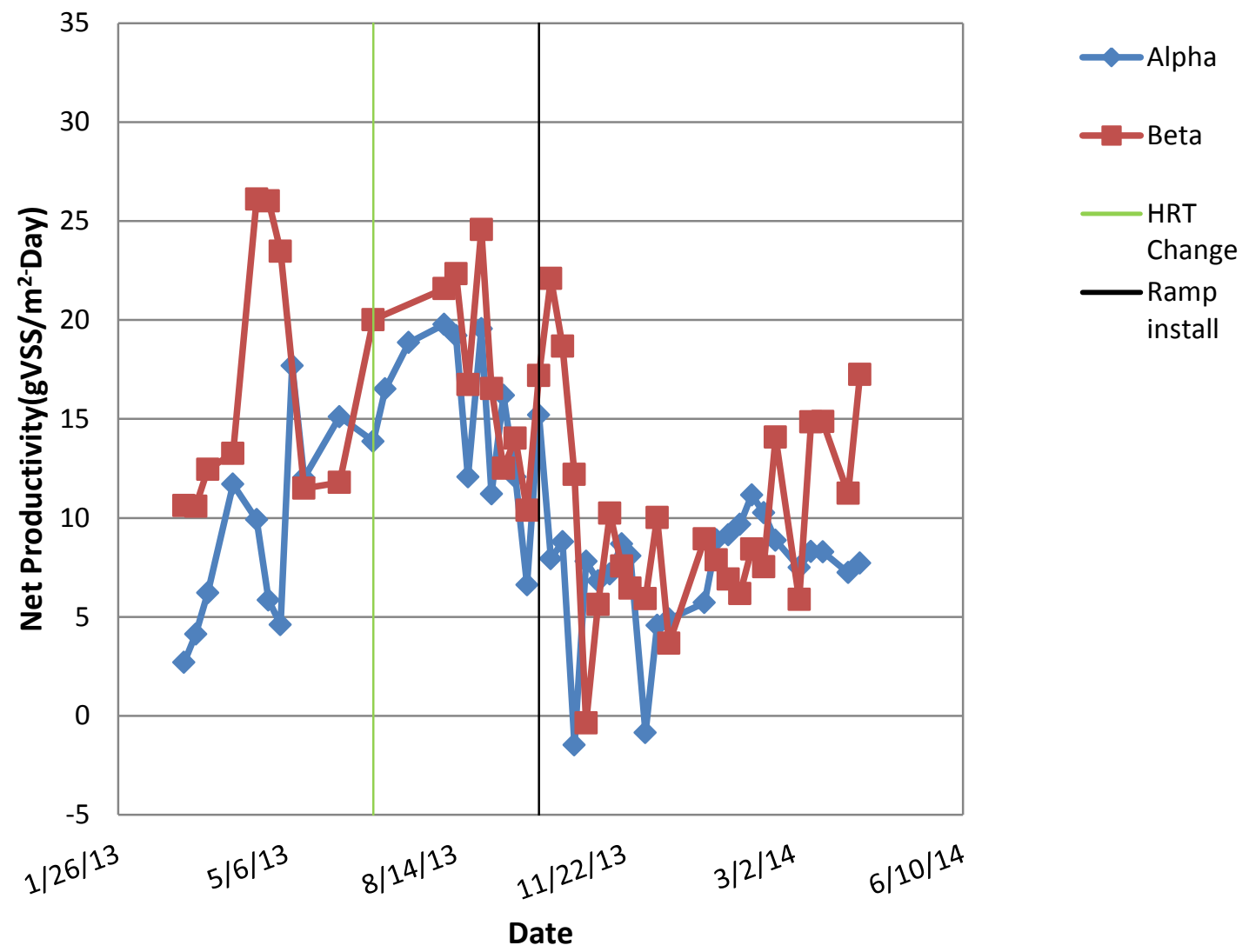

Figure 4-10: Productivity time series graphs of the Alpha and Beta set ponds. The green line represents the time of the HRT change in Alpha from 4 days to 3 days. Error bars have been removed for clarity.

The productivity of the Alpha ponds was negative for the weeks of October 23,

December 4, 2013, and October 30 for the Beta ponds. Recall that productivity was calculated by subtracting the influent VSS from the VSS in the ponds. The negative productivity values were due to an increase of solids concentration in the influent of around four times that of average (Figure 4-11). In the Alpha set, this was caused by poor 
tube settler performance. In the Beta set, it was due to a spike in solids from the clarifier and the declining VSS concentrations in the ponds due to fall and winter (Figure 4-11, Figure 4-12).

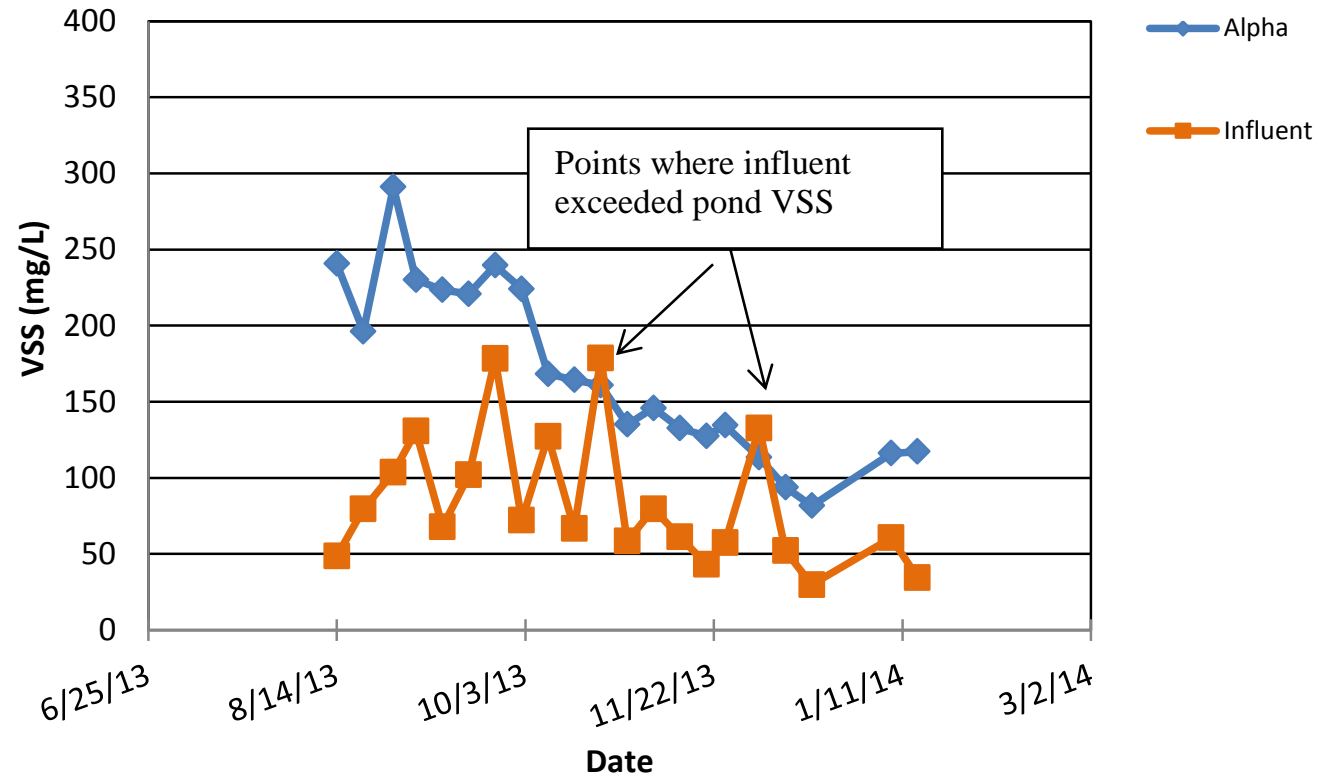

Figure 4-11: VSS concentration of Alpha and influent to Alpha. Notice the two points where the influent VSS exceeds that of the ponds leading to a negative productivity. 


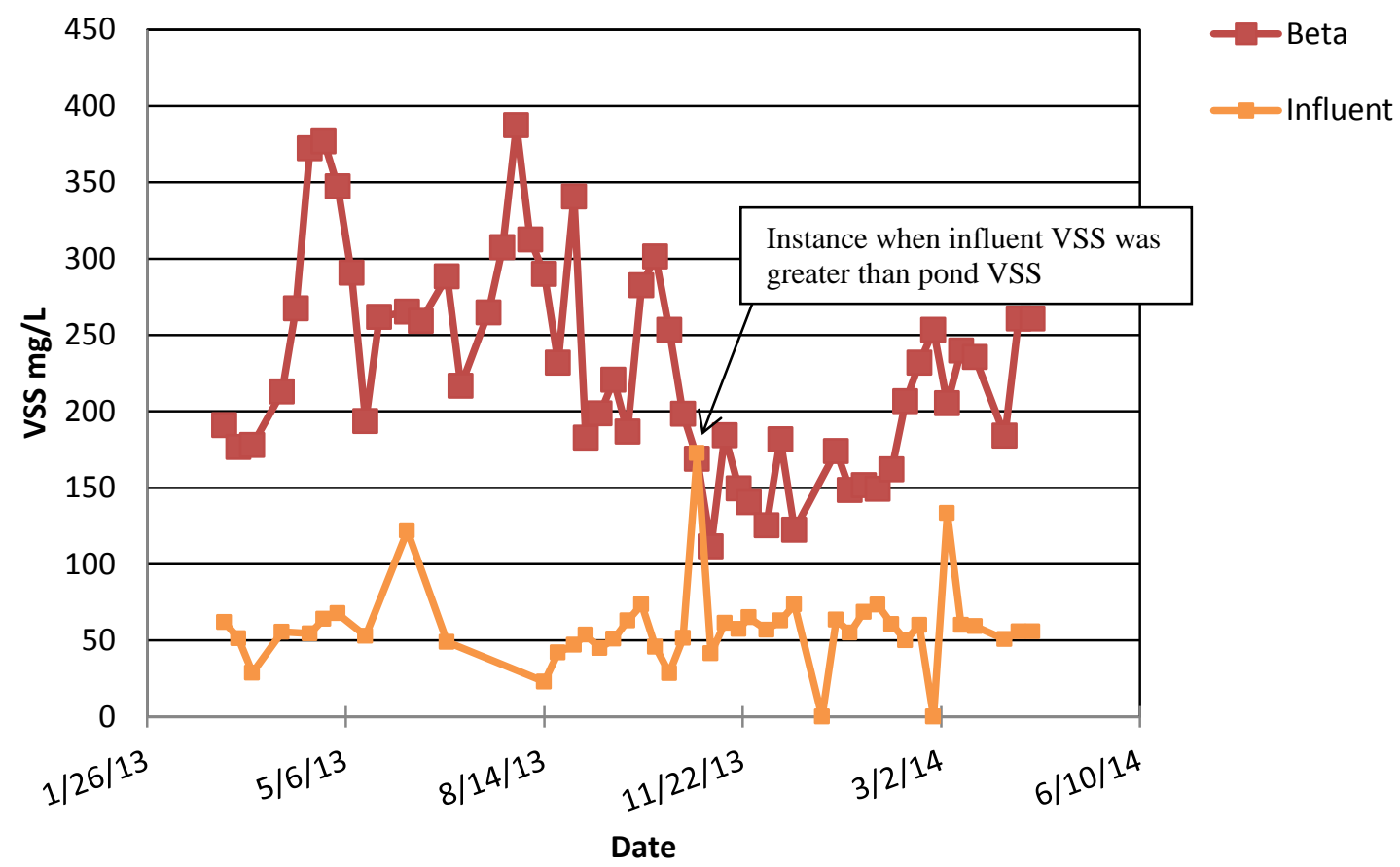

Figure 4-12: VSS of influent and average of Beta pond set. Notice the one point where VSS in the influent exceeds that of the ponds, this leads to the single negative value of productivity in the Beta set

These graphs show the instances when the influent concentration was higher ponds concentrations resulting in a negative productivity. As stated above, this was caused by the downward trend of pond VSS during the fall and winter months and the spikes in influent solids.

Because grab samples were only taken at one time during the day, a spike in solids concentration at the time of sampling would be disproportionately expressed in a grab sample. Because grab samples were the only type of samples taken, there was no way to determine if the spike was momentary or lasted for a longer period of time. Samples were collected between 7-8am, which is at least 10 hours after emptying sludge from the tube 
settlers. It is possible that sludge build up in the tube settlers caused floating flocs that passed through the settler.

Figure 4-13 shows the average monthly productivity in the Alpha and Beta set ponds. This format shows the difference between the Alpha and Beta sets more clearly than weekly time series graphs. During the summer productivity in Beta was on average 33\% higher than Alpha, and in winter Beta was 19\% higher than Alpha.

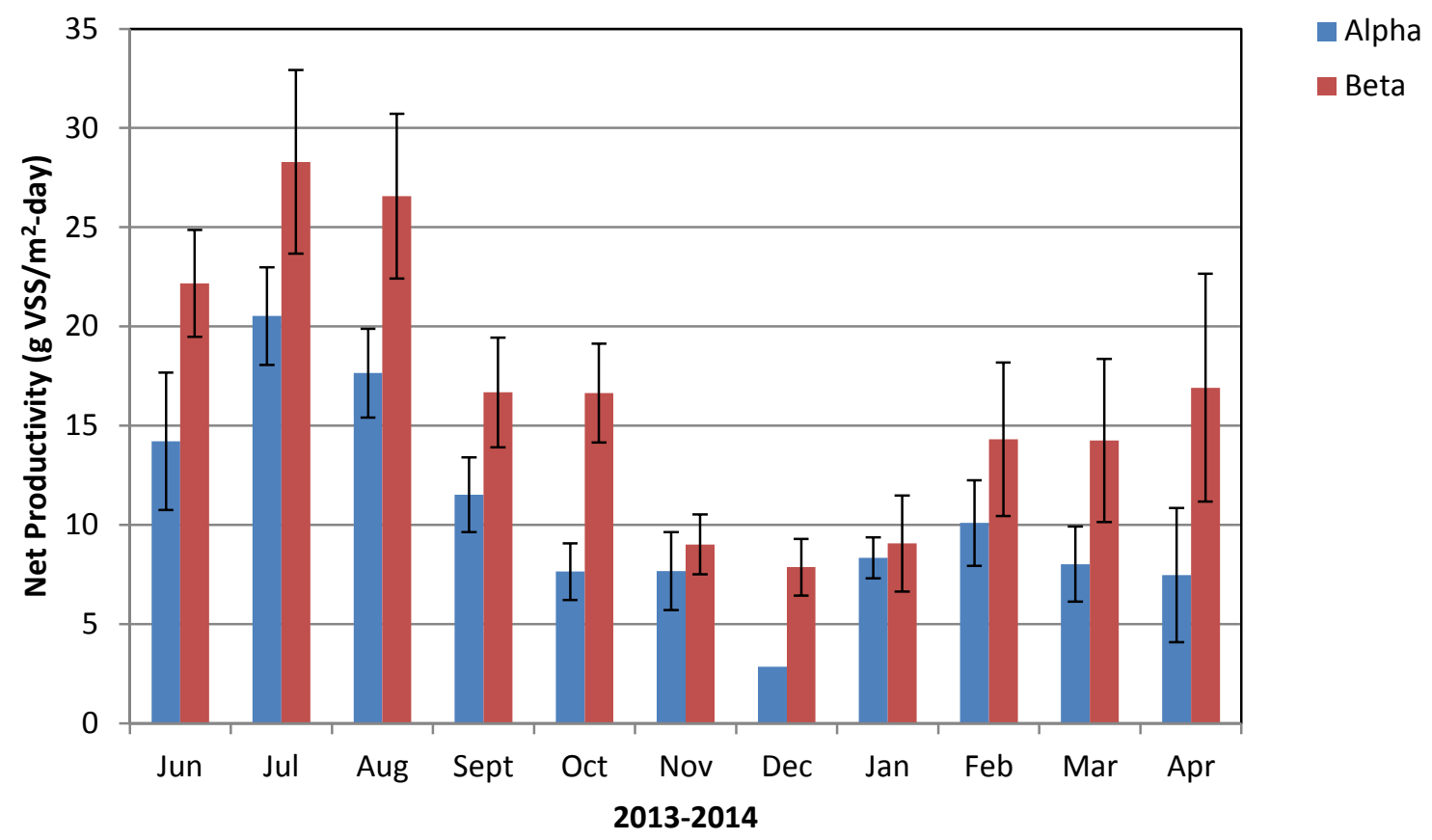

Figure 4-13: Monthly average net productivity in Alpha and Beta set ponds from June 2013 to April 2014 Two weeks of sampling were skipped in December, so no error bars could be generated for that month. Both Alpha and Beta followed roughly the same pattern of high productivity in summer and lower in the winter, but Beta mean productivity was consistently higher than Alpha. 
Several factors likely affected productivity in ponds including nutrient concentration, solar insolation, temperature, HRT, and grazer presence. Variables such as insolation and HRT were the same for the both Alpha and Beta. Nutrient concentrations were monitored over the duration of the experiment.

Figure 4-14 and Figure 4-15 show the direct relationship between solar insolation and productivity.

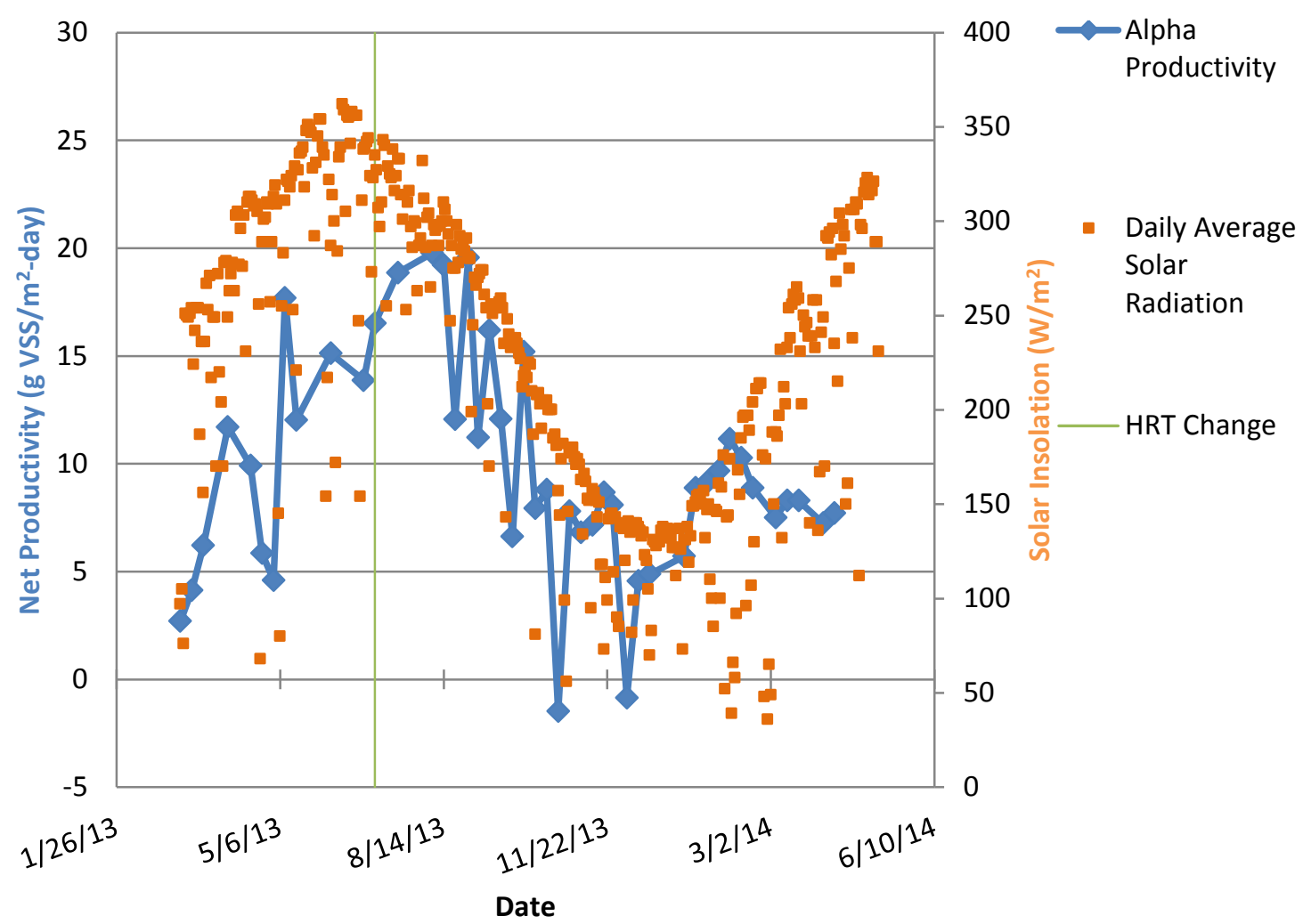

Figure 4-14: Alpha productivity and solar insolation for San Luis Obispo. The data points for insolation are not connected for clarity. 


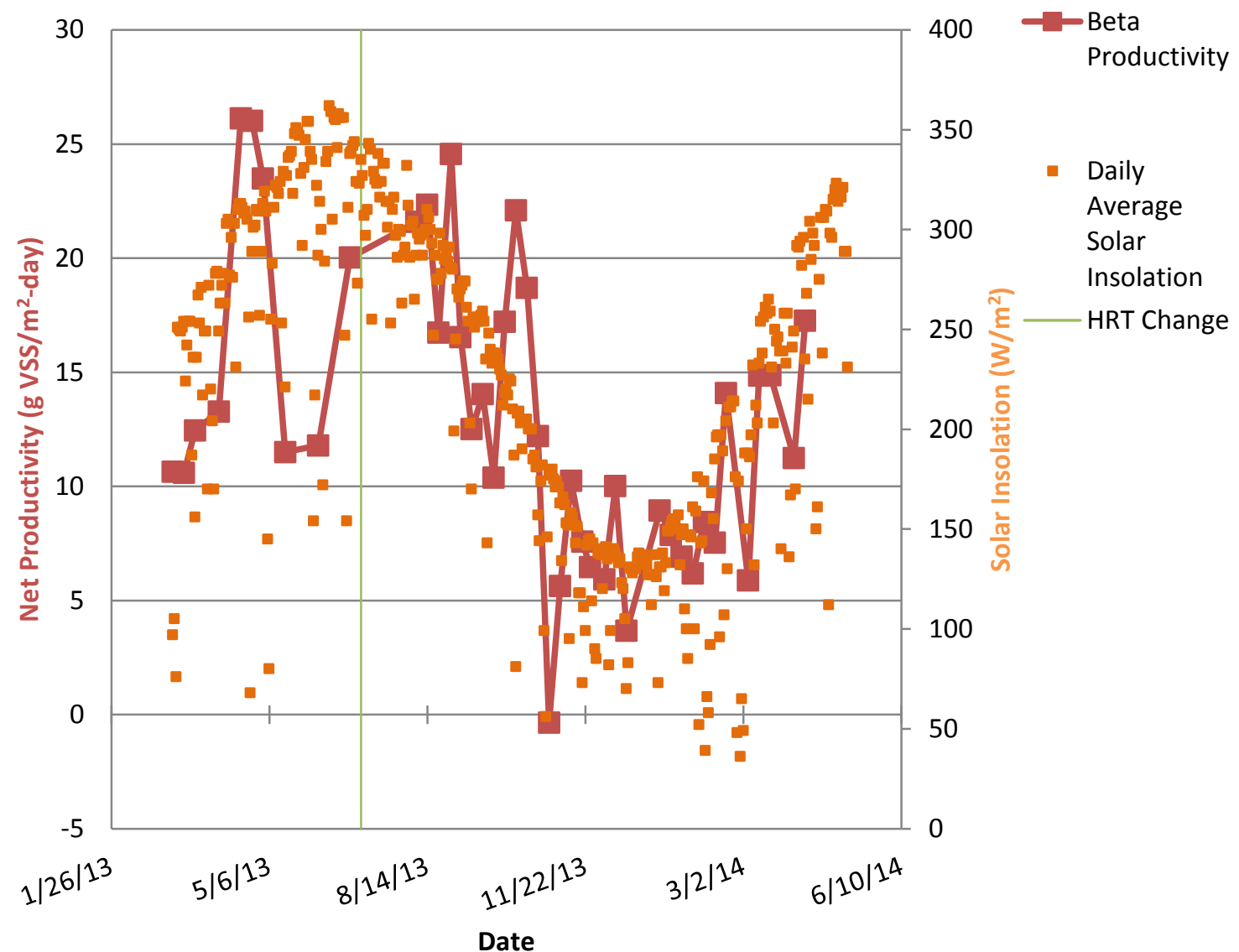

Figure 4-15: Beta productivity and solar insolation for San Luis Obispo. The data points for insolation are not connected for clarity.

High insolation in the summer led to high productivity, the opposite was true in the winter. Solar insolation was assumed to be identical for both Alpha and Beta, and thus should have been equally limiting for both Alpha and Beta. Despite identical solar insolation, the difference in the productivity indicates that some other factor that may have been limiting in Alpha.

Figure 4-16 and Figure 4-17 show an inverse correlation between algae productivity and nutrient concentrations for Alpha. This trend was common between both nitrogen and phosphorus. During summer when productivity was high, the concentrations of both soluble nitrogen and phosphorus were low. Conversely in the winter when the 
productivity was low, the soluble nitrogen and phosphorus concentrations were high.

This trend was expected because higher productivity requires more nutrients to be synthesized into cell material.

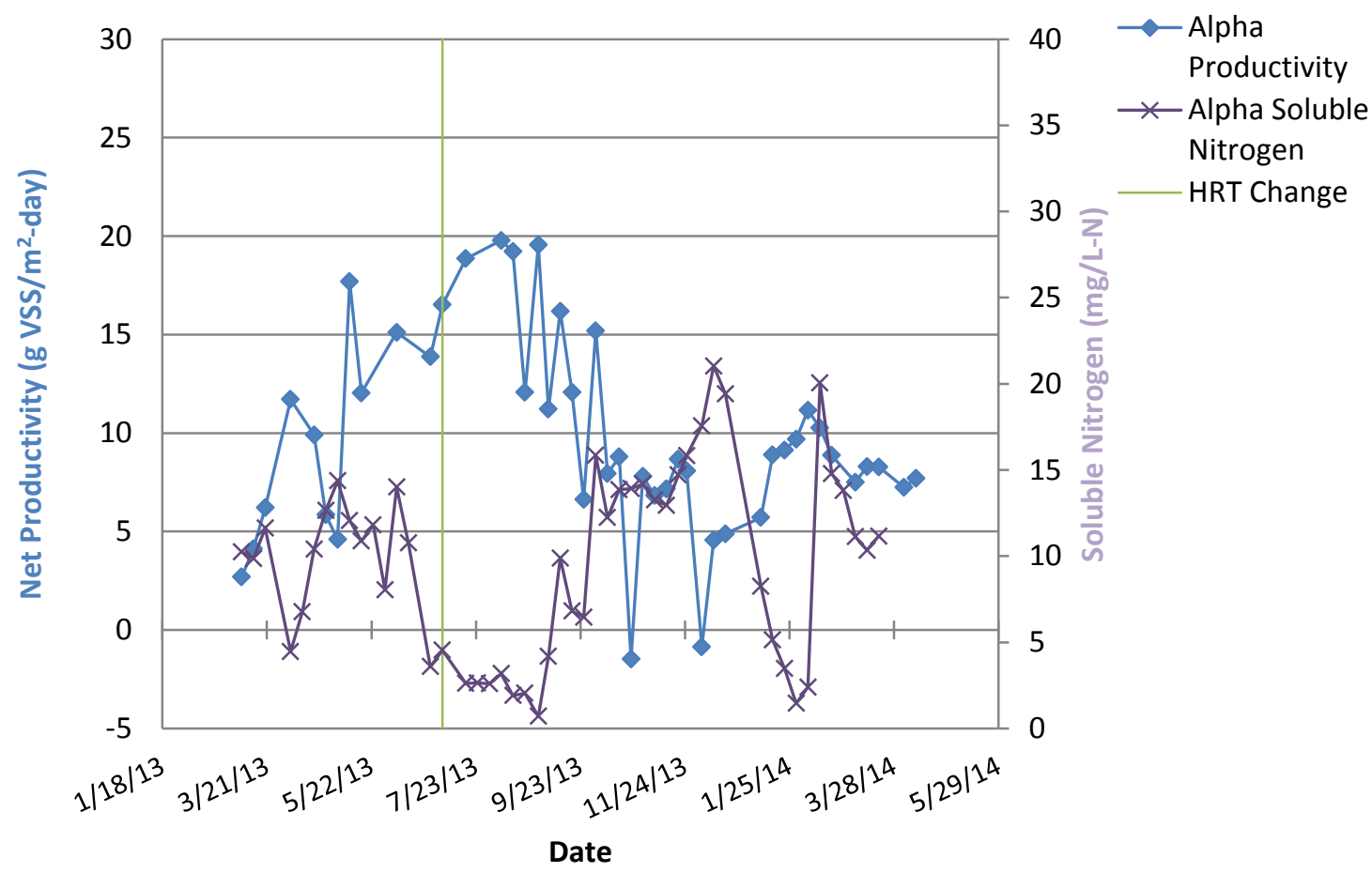

Figure 4-16: Alpha productivity in and soluble nitrogen concentration. Error bars excluded for clarity. 


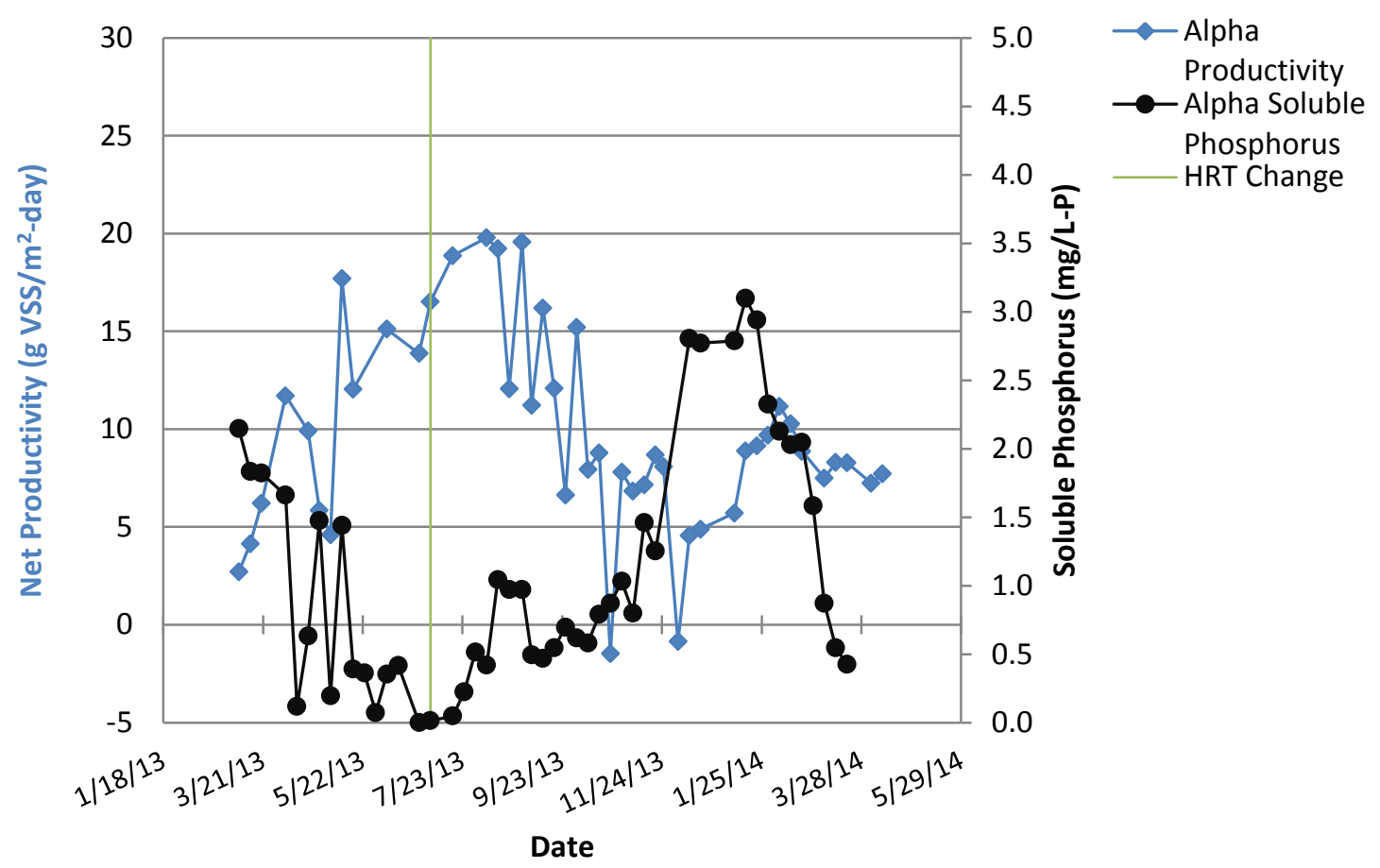

Figure 4-17: Alpha productivity and soluble phosphorus concentrations. Error bars excluded for clarity.

As stated previously, nutrient limitation occurs when the percent nitrogen in the biomass is less than five percent. This only occurred in Ponds 2 and 3 on December 11, 2013. Despite nutrient levels being low during summer, true nutrient limitation is indicated by a percent nitrogen of less than five percent in biomass. Figure 4-18 shows that it is unlikely that the productivity in Alpha was nutrient limited because the percent nitrogen in the biomass only falls below five percent on the week of December 11, 2013. 


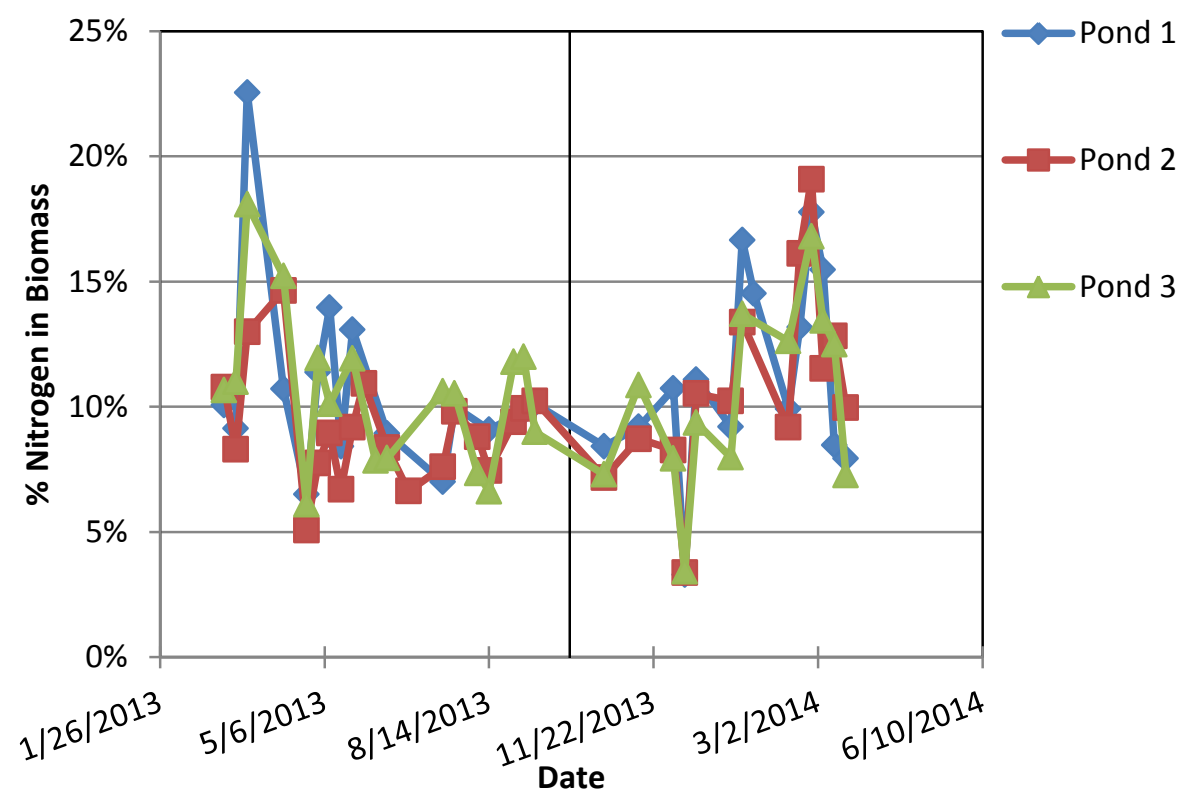

Figure 4-18: Organic nitrogen as a percent of VSS for the Alpha ponds.

Between the end of January and early May the productivity in Alpha declined unexpectedly (Figure 4-9). Figure 4-19 shows a discrepancy of productivity between Ponds 1, 2, and 3.

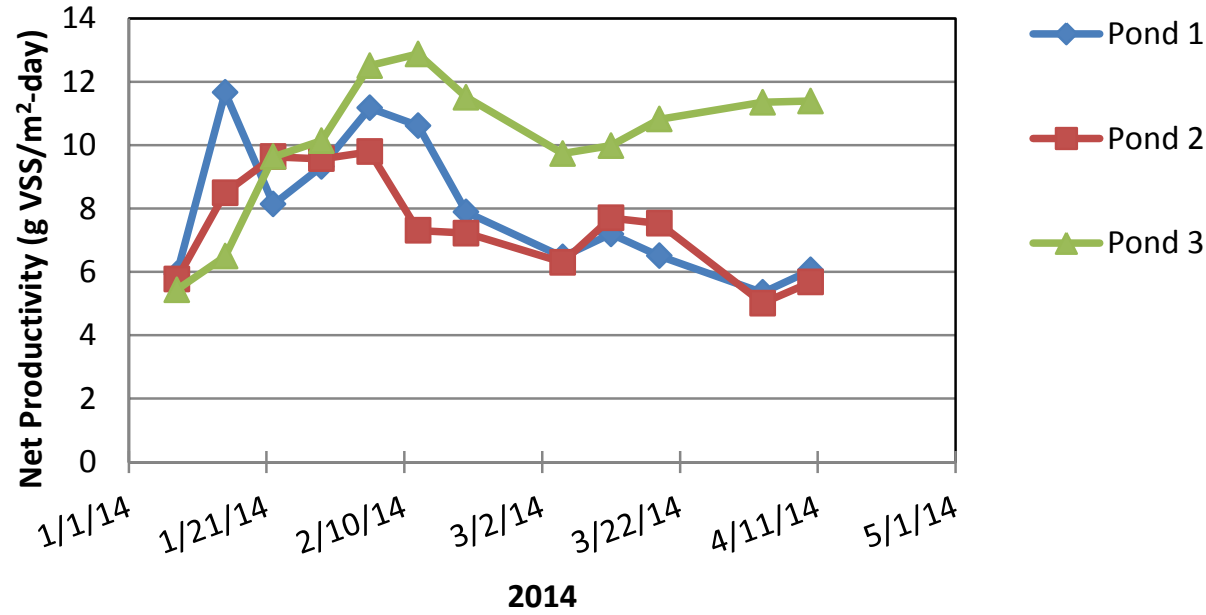

Figure 4-19: Productivity in Alpha ponds. Ponds 1 and 2 declined, while Pond 3 maintained constant. 
In early January 2014 , the Neptune $\mathrm{pH} / \mathrm{CO}_{2}$ control system began to malfunction. As a result Ponds 1, 2, and possibly 3 received unequal amounts of $\mathrm{CO}_{2}$. This may have caused carbon limitation which could have caused the decline in productivity in Alpha.

Ponds 1 and 2 received less $\mathrm{CO}_{2}$ than Pond 3. Because the Neptune system was malfunctioning and not recording correct $\mathrm{pH}$ values, initial $\mathrm{pH}$ values were recorded from alkalinity were used as indicators of $\mathrm{CO}_{2}$ dose. Figure 4-20 and Figure 4-21 show how the $\mathrm{pH}$ in Ponds 1 and 2 steadily increased as the productivity steadily decreased. Figure 4-22 shows that the $\mathrm{pH}$ in Pond 3 stayed lower than Ponds 1 or 2 . This indicated that more $\mathrm{CO}_{2}$ was being provided to Pond 3 , which resulted in a higher productivity than Ponds 1 or 2. The decline in productivity in Ponds 1, 2, and 3 as a result of the carbon limitation most likely was the cause of the downward trend in the productivity data for the Alpha ponds between January and April in Figure 4-9.

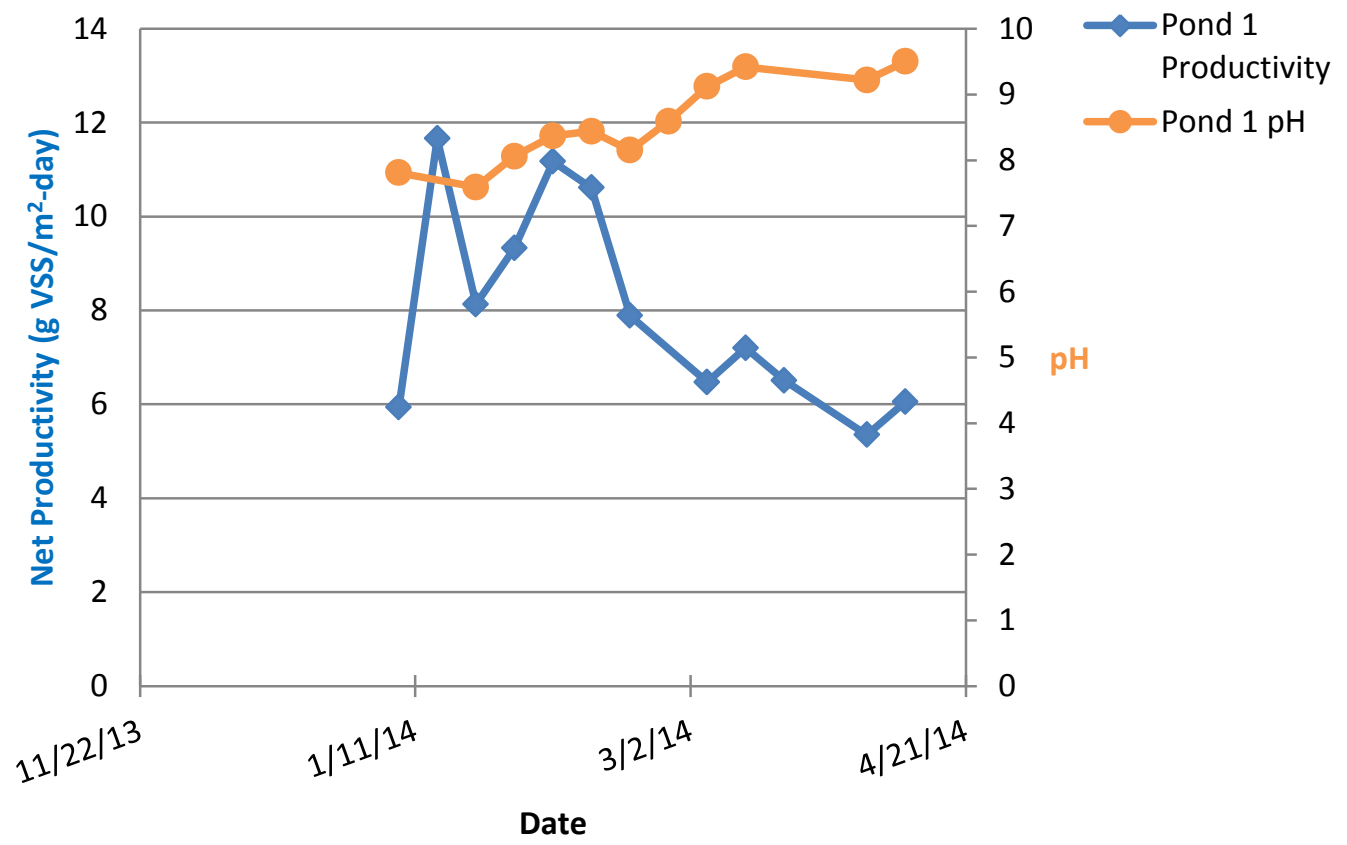

Figure 4-20: Net Productivity and $\mathrm{pH}$ in Pond 1. The pH data is taken from alkalinity data collected on the samples once transported back to the laboratory. 


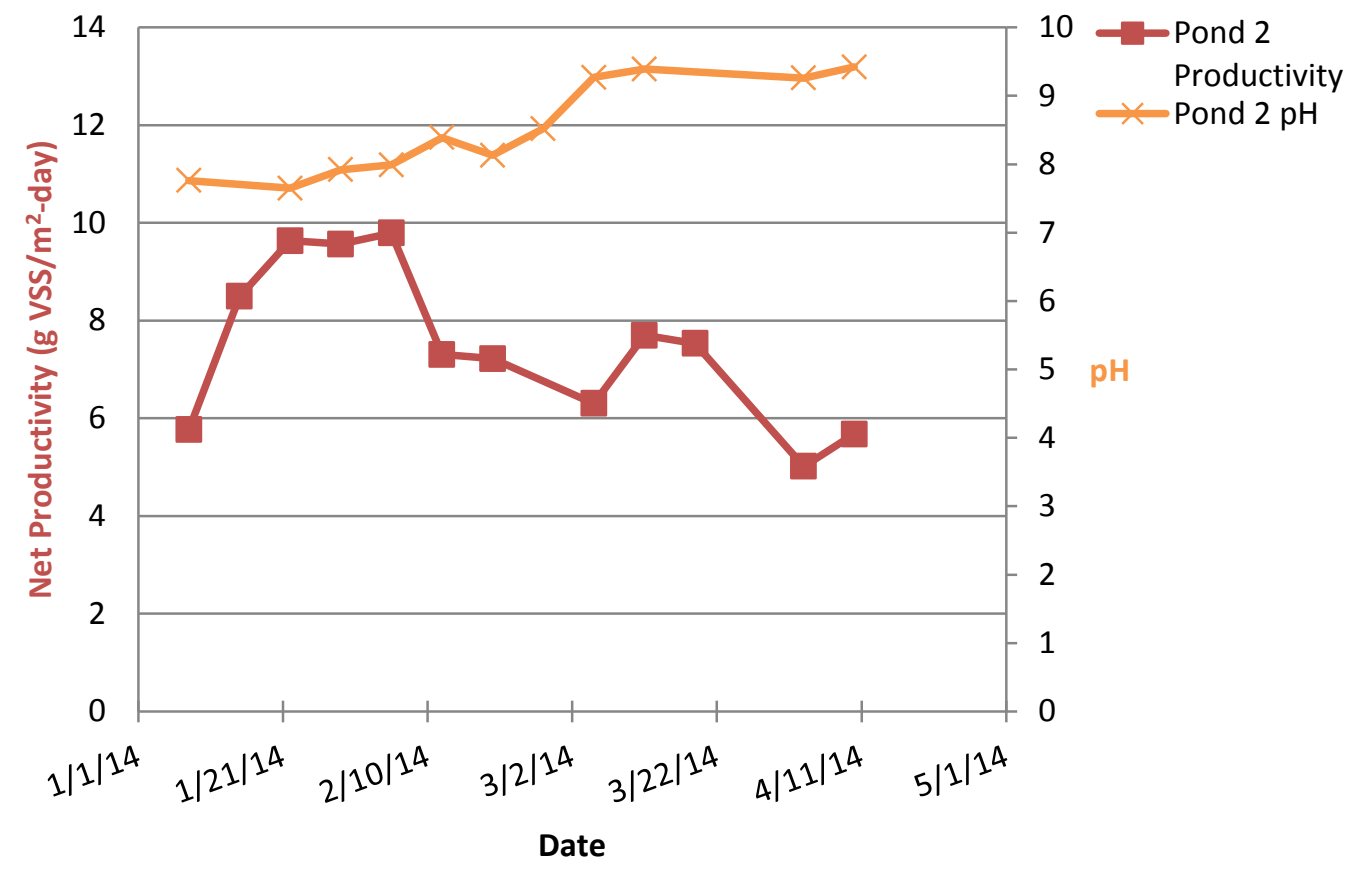

Figure 4-21: Net Productivity and pH in Pond 2. The pH data is taken from alkalinity data collected on the samples once transported back to the laboratory

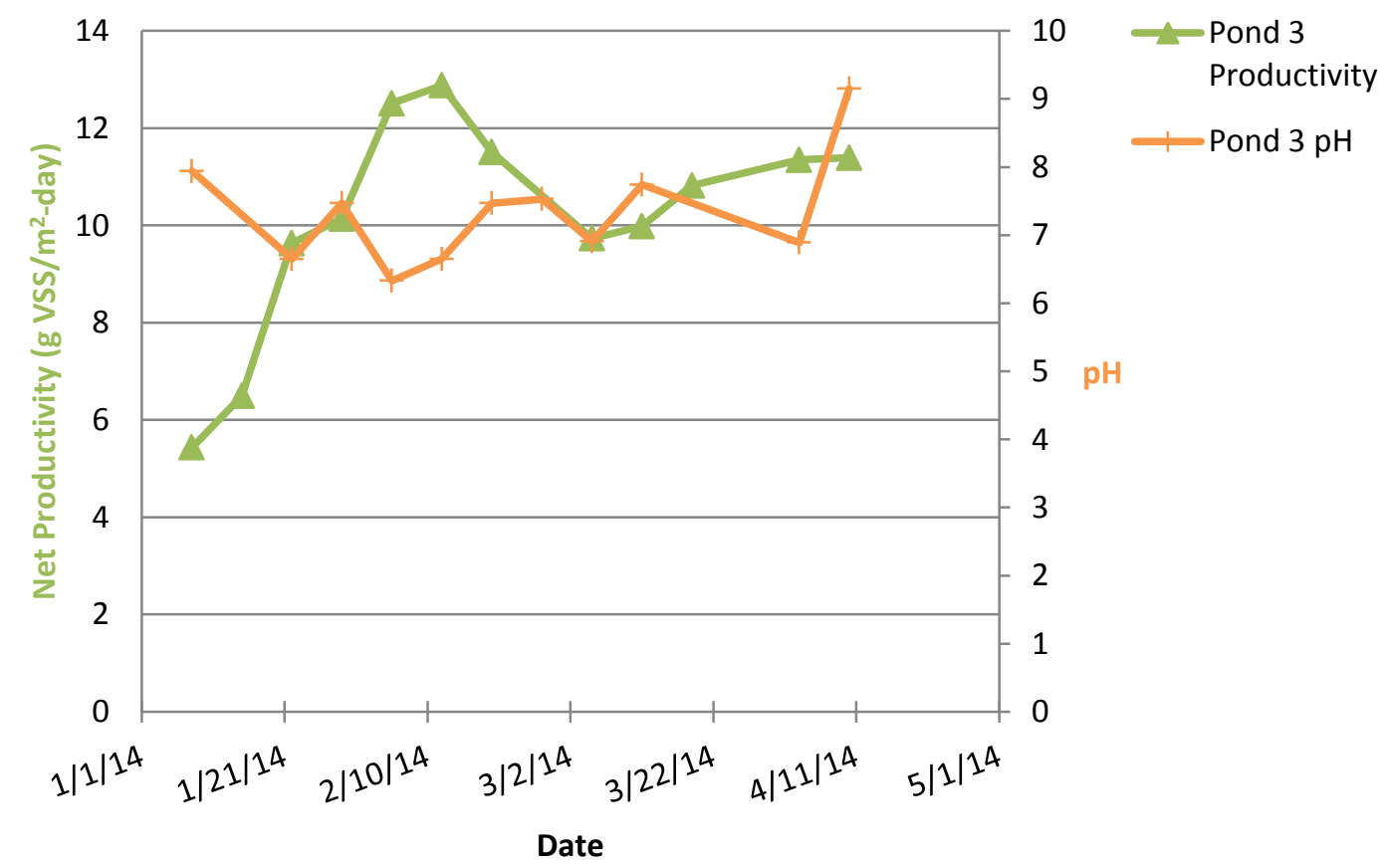

Figure 4-22: Net Productivity and pH in Pond 3. The pH data is taken from alkalinity data collected on the samples once transported back to the laboratory 
The Beta set ponds followed the same inverse correlation between productivity and nutrient concentrations as the Alpha ponds (Figure 4-23 and Figure 4-24). Unlike the Alpha ponds, nutrient concentrations in Beta remained above $10 \mathrm{mg} / \mathrm{L}$.

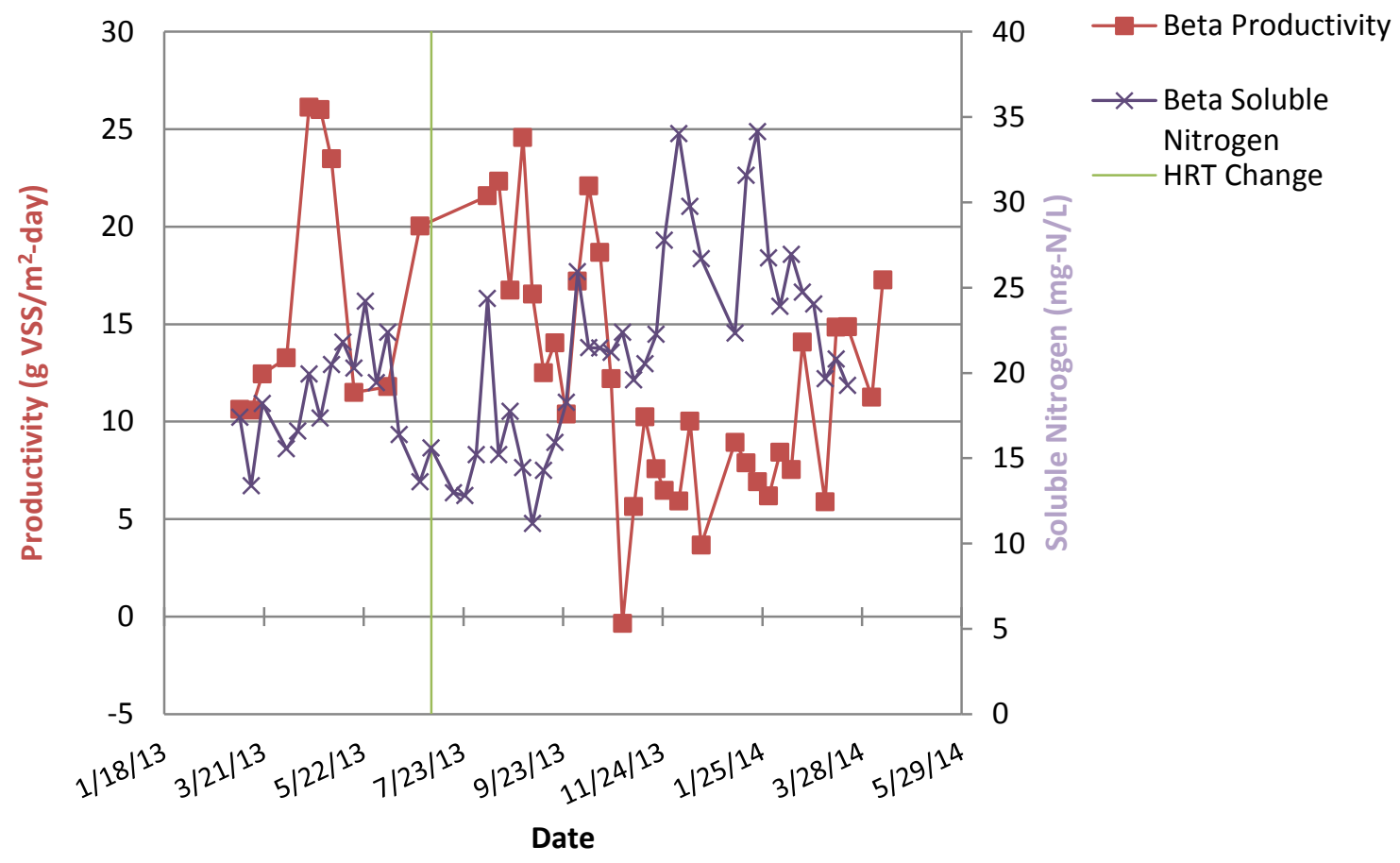

Figure 4-23: Beta productivity and soluble nitrogen concentrations. Error bars excluded for clarity. The green line represents the change from a 4 day HRT to a 3 day HRT in Alpha 


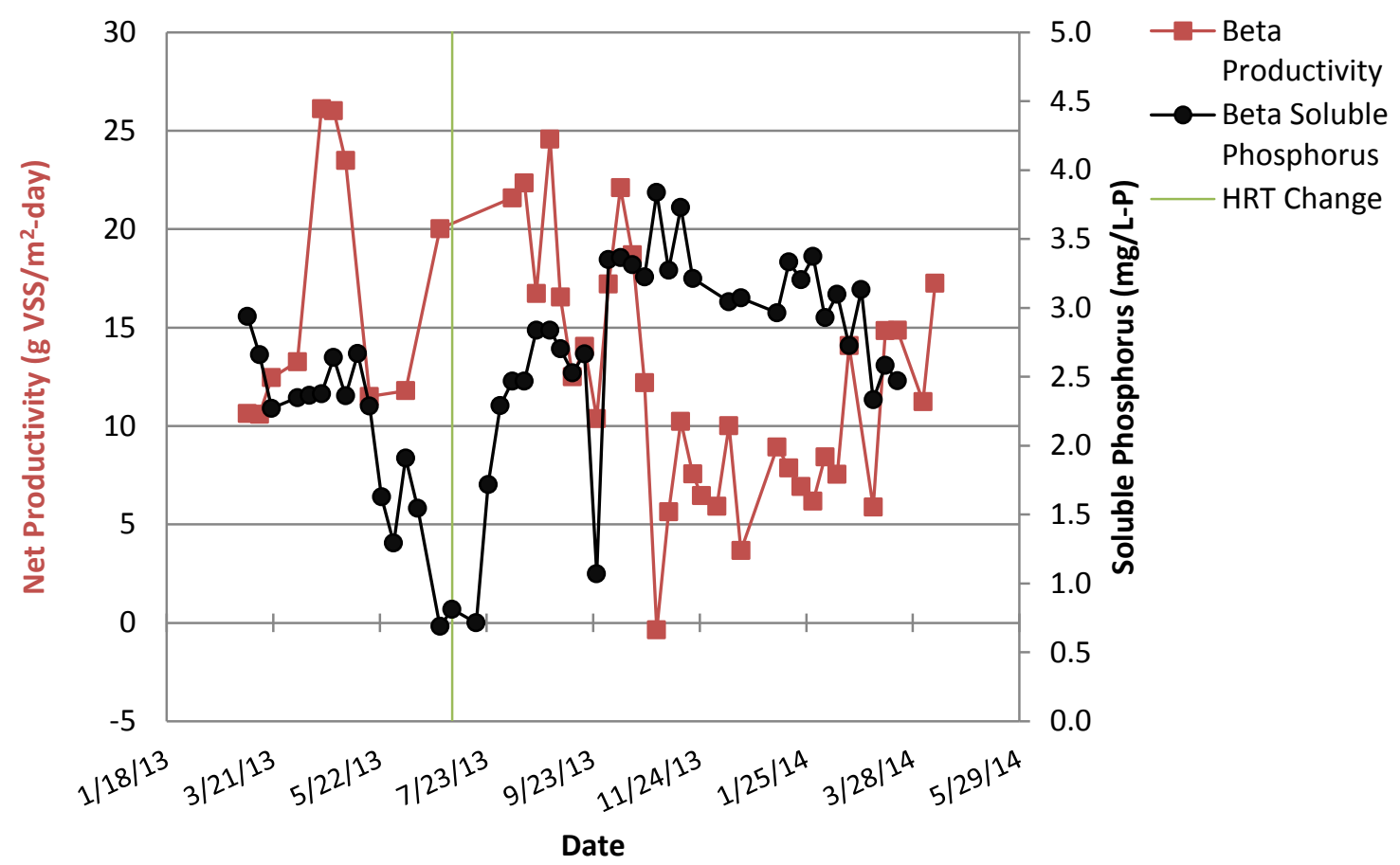

Figure 4-24: Beta productivity and soluble Phosphorus concentrations. Error bars excluded for clarity. The green line represents the change from a 4 day HRT to a 3 day HRT in Alpha.

Unlike Alpha, Beta did not have a decline of productivity from January to March 2014.

The continuous upward trend in the data indicates proper $\mathrm{CO}_{2}$ additions. Several differences between the conditions of the ponds could explain the lower productivity in Alpha. In Beta, the nutrient concentrations were not reduced as much as they were in Alpha.

\subsection{Settling results}

2 and 24-hour settling data were collected to evaluate the settling performance of the ponds. Gravitational settling was the main method of biomass separation. Characterizing the settling performance of the ponds was important for determining the effectiveness of 
gravitational settling. 2-hour settling data was also used as possible evidence that there was solids accumulation in the ponds.

\subsubsection{2-Hour Settling}

Settling for all of the ponds remained high throughout the year. All ponds averaged at least $80 \%$ removal in summer, and at least $60 \%$ in winter. The settling performance was slightly higher in the summer than in the winter (Table 4-6). Alpha settling was similar to Beta and Gamma during the summer, but was less than the other two pond sets during the winter (Figure 4-25,).

Percent removal was calculated using the following equation,

Equation 3: 2-hour percent removal

$$
\text { Percent Removal }=\frac{0 \text { Hour TSS }-2 \text { Hour TSS }}{0 \text { Hour TSS }}
$$

Where the variables having the following units:

Percent removal: \%

0-hour TSS: mg/L

2-Hour TSS: mg/L 


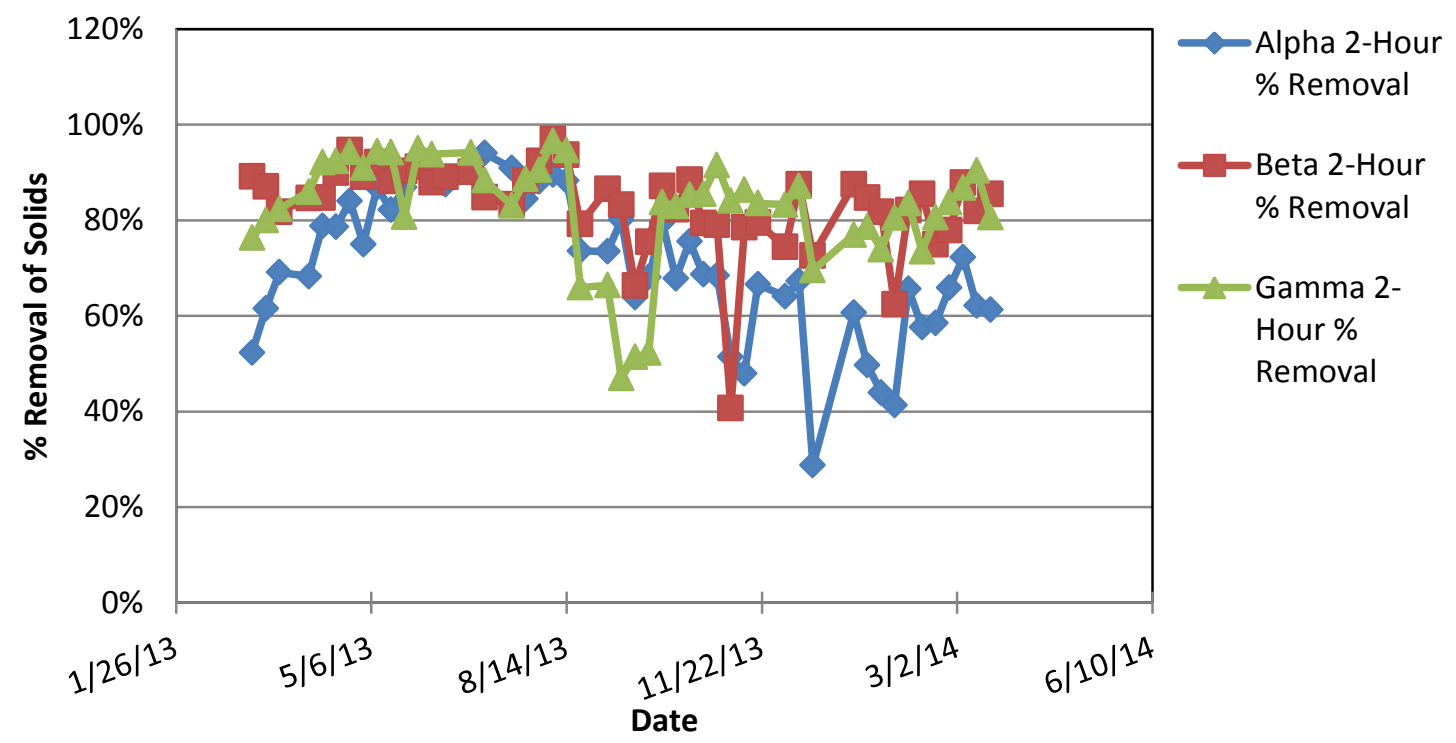

Figure 4-25: 2-hour settling for all pond sets from March 6, 2013 to March 19, 2014

Table 4-6: Summer and winter 2-hour solids percent removal. Summer was from March 6 to August $29,2013$. Winter was from Sept 4, 2013 to February 26, 2014

\begin{tabular}{rcccccc} 
& \multicolumn{6}{c}{ 2-Hour \% Removal } \\
\cline { 2 - 7 } Max \% Removal & $94 \%$ & $80 \%$ & $97 \%$ & $88 \%$ & $97 \%$ & $92 \%$ \\
\cline { 2 - 7 } Min \% Removal & $52 \%$ & $29 \%$ & $79 \%$ & $41 \%$ & $66 \%$ & $47 \%$ \\
Average \% Removal & $81 \%$ & $62 \%$ & $89 \%$ & $78 \%$ & $88 \%$ & $77 \%$ \\
Standard Deviation & $11 \%$ & $13 \%$ & $4 \%$ & $11 \%$ & $8 \%$ & $12 \%$ \\
Number of Data Points & 22 & 24 & 22 & 23 & 21 & 23 \\
\hline
\end{tabular}

\subsubsection{4-Hour Settling}

24-hour settling for all of the ponds remained high throughout the year. All ponds averaged at least $90 \%$ removal throughout the year There was only a slight decrease in percent removal from summer to winter (Figure 4-26, Table 4-7). All of the ponds 
performed nearly identically, with no pond set settling much better or worse than any other (Figure 4-26).

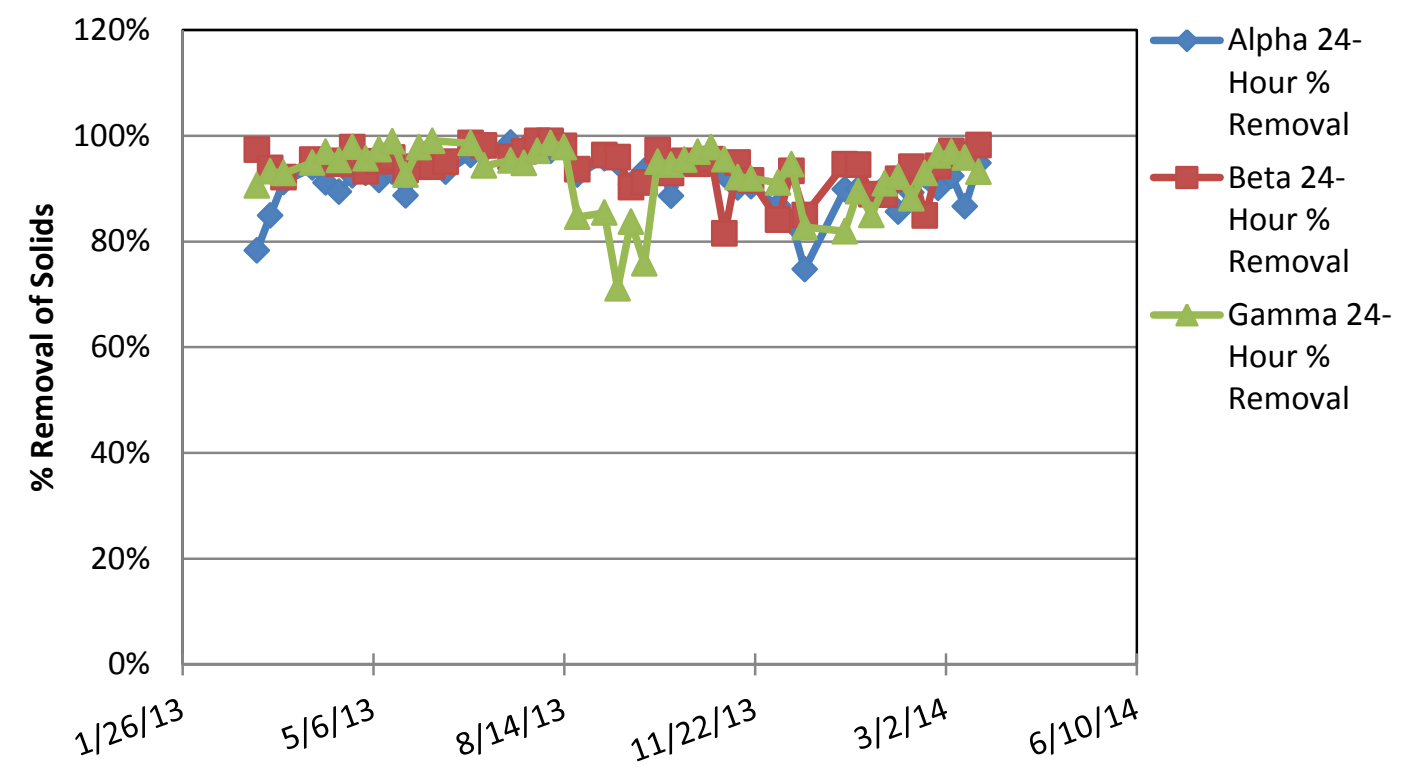

Figure 4-26: 24-hour settling for all pond sets from March 6, 2013 to March 19, 2014

Table 4-7: Summer and winter 24-hour solids percent removal. Summer was from March 6 to August 29, 2013. Winter was from Sept 4, 2013 to February 26, 2014

24-Hour \% Removal

\begin{tabular}{rcccccc} 
& \multicolumn{2}{c}{ Alpha } & \multicolumn{2}{c}{ Beta } & \multicolumn{2}{c}{ Gamma } \\
\cline { 2 - 7 } Max \% Removal & $99 \%$ & $96 \%$ & $99 \%$ & $97 \%$ & $99 \%$ & $98 \%$ \\
Summer & Winter & Summer & Winter & Summer & Winter \\
Min \% Removal & $78 \%$ & $75 \%$ & $92 \%$ & $81 \%$ & $85 \%$ & $71 \%$ \\
Average \% Removal & $93 \%$ & $90 \%$ & $95 \%$ & $92 \%$ & $95 \%$ & $90 \%$ \\
Standard Deviation & $5 \%$ & $5 \%$ & $2 \%$ & $4 \%$ & $3 \%$ & $7 \%$ \\
Number of Data Points & 22 & 23 & 22 & 23 & 21 & 23 \\
\hline
\end{tabular}




\subsection{Standpipe performance results}

TSS collected by the ramped standpipes was compared to that collected by the 4-inch standpipes. In each pond set, one pond had the 4-inch standpipe, and the other two had ramp standpipes installed. The ponds with the 4-inch standpipes were Ponds 3, 6 and 7. The ramp standpipe was installed in pond 7 on November 1, 2013, and in pond 3, and 6 on November 8, 2013. The period from October 2, 2013, to November 1, 2013 was included on Figures 4-27, 4-28, and 4-29 for comparison.

Gamma was the only pond set that showed any significant difference between the 4-inch and ramp standpipes (Figure 4-27, Error! Reference source not found.). There was no difference between the 4-inch and the ramp standpipe in Alpha and Beta (Error!

Reference source not found., Figure 4-29).

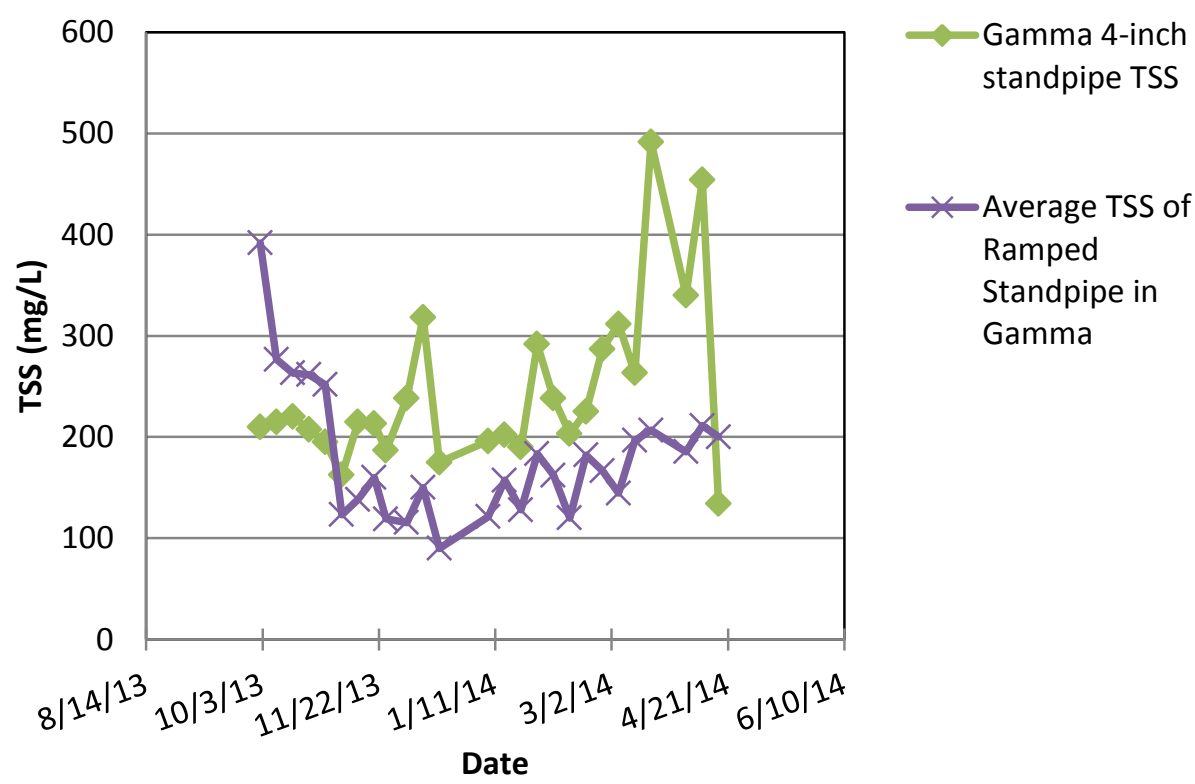

Figure 4-27: TSS of ramped and 4-inch standpipes for Gamma from October 2, 2013 to April 17, 2014 

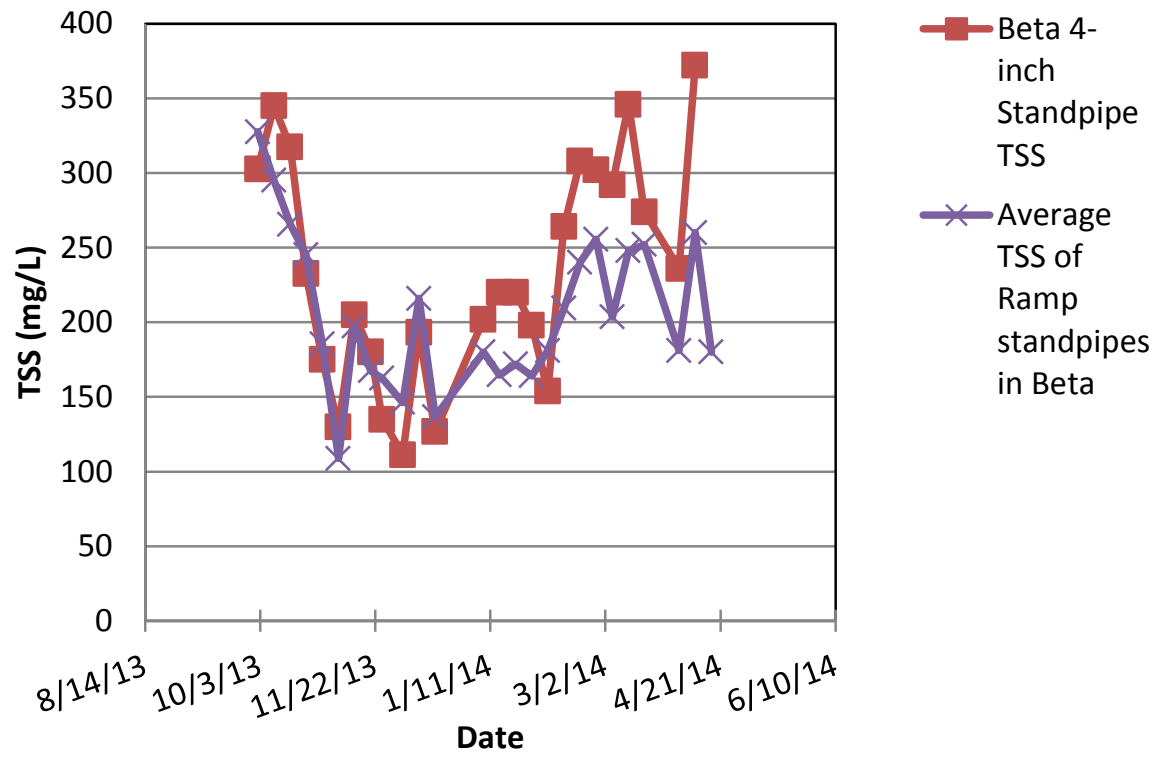

Figure 4-28: TSS of ramped and 4-inch standpipes for Beta from October 2, 2013 to April 17, 2014
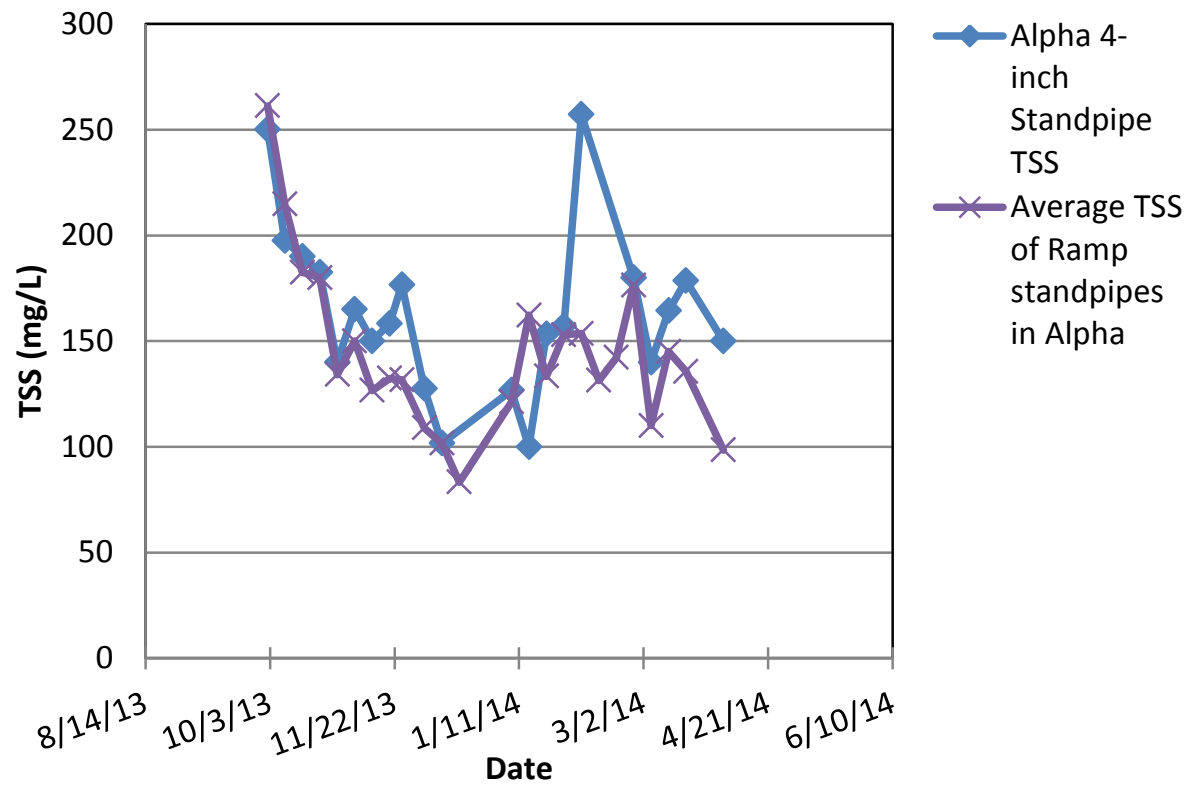

Figure 4-29: TSS of ramped and 4-inch standpipes for Alpha from October 2, 2013 to April 17, 2014 
Error! Reference source not found. shows the difference between the 4-inch and ramped standpipe better than the time series graph show in Figure 4-27. For 20 out of the 26 weeks of the experiment the TSS in the ponds with the 4-inch standpipe was significantly higher TSS than the ramped standpipe ponds. For all cases significantly higher TSS was considered a difference of $50 \mathrm{mg} / \mathrm{L}$ or more.

Figure 4-31, and Figure 4-32 shows how similar the 4-inch and ramped standpipes performed for Beta and Alpha respectively. In Beta, TSS in the ponds with the 4-inch standpipe was significantly higher than the ramped for 17 out of the 26 weeks of the experiment.

In Alpha, the number of weeks that the TSS in the ponds with the 4-inch standpipe was significantly higher than the ramped was only three out of the 26 weeks of the experiment. The TSS concentrations were similar for the 4-inch and ramped standpipes for the other 23 week. 


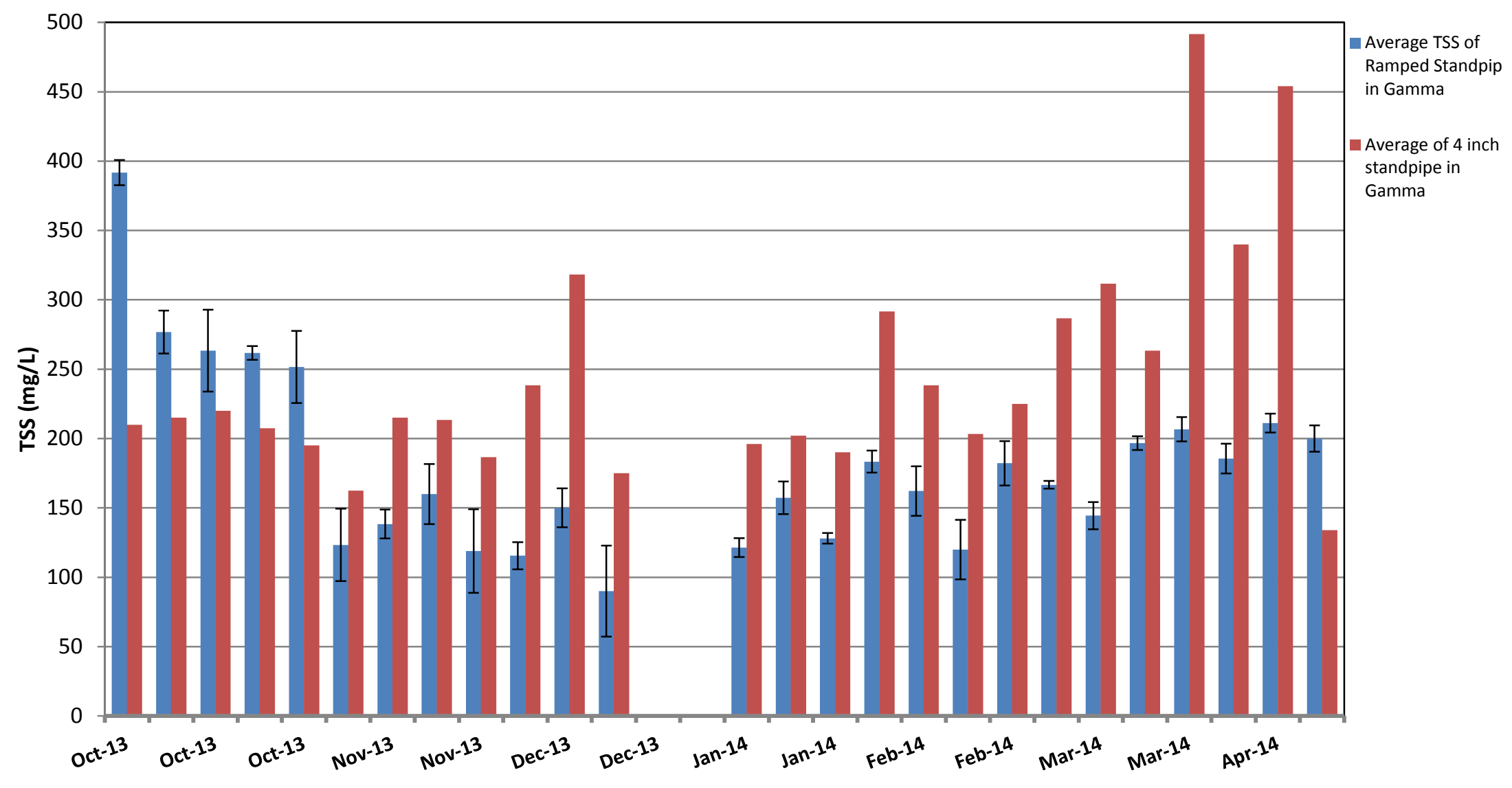

Figure 4-30: Weekly average TSS for Gamma set ponds with ramped and 4-inch standpipe from October 2013 to April 2014. Error bars are one standard deviation in positive and negative direction. 


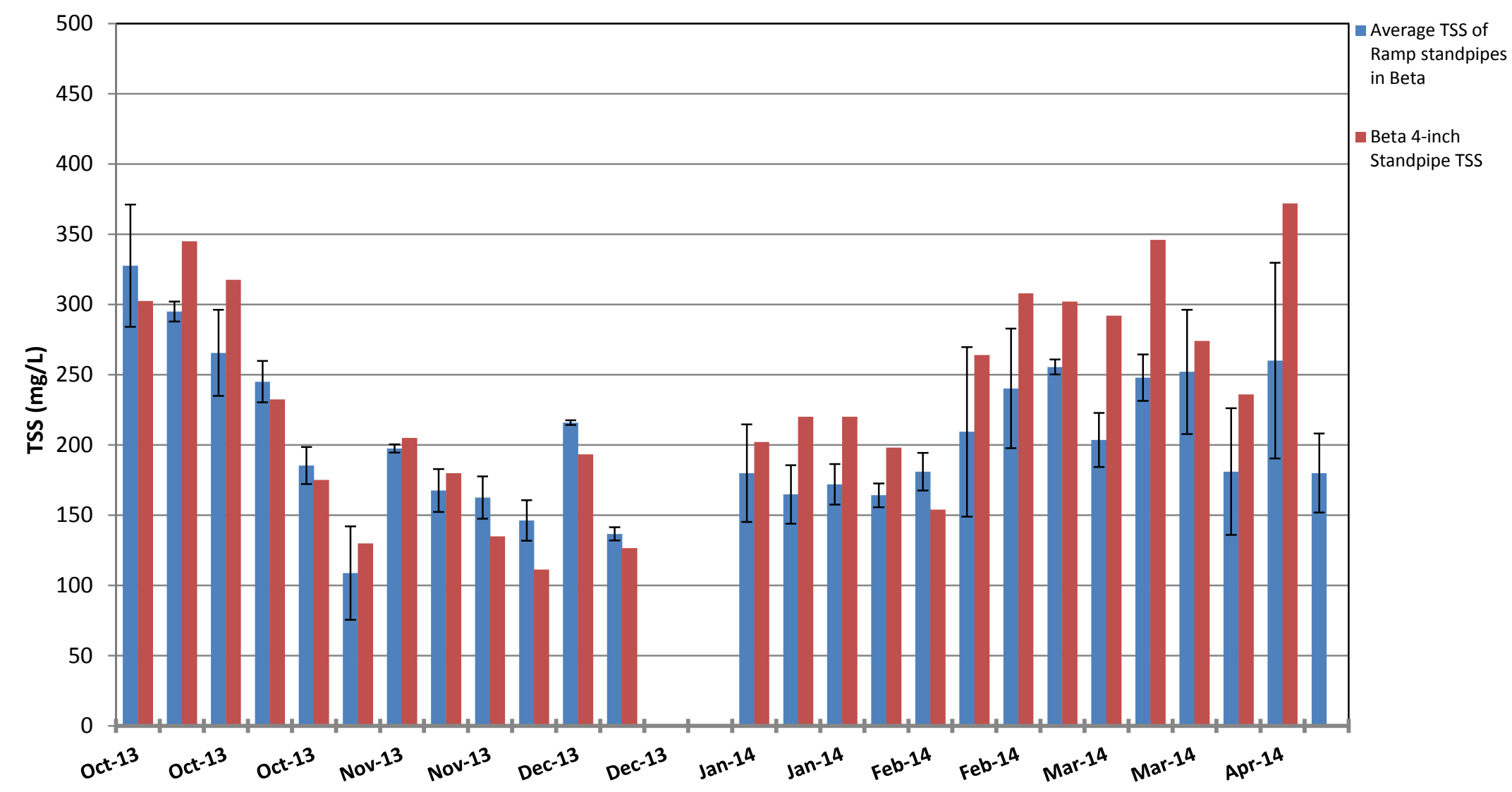

Figure 4-31: Weekly average TSS for Beta set ponds with ramped and 4-inch standpipe from October 2013 to April 2014 . Error bars are one standard deviation in positive and negative direction. 


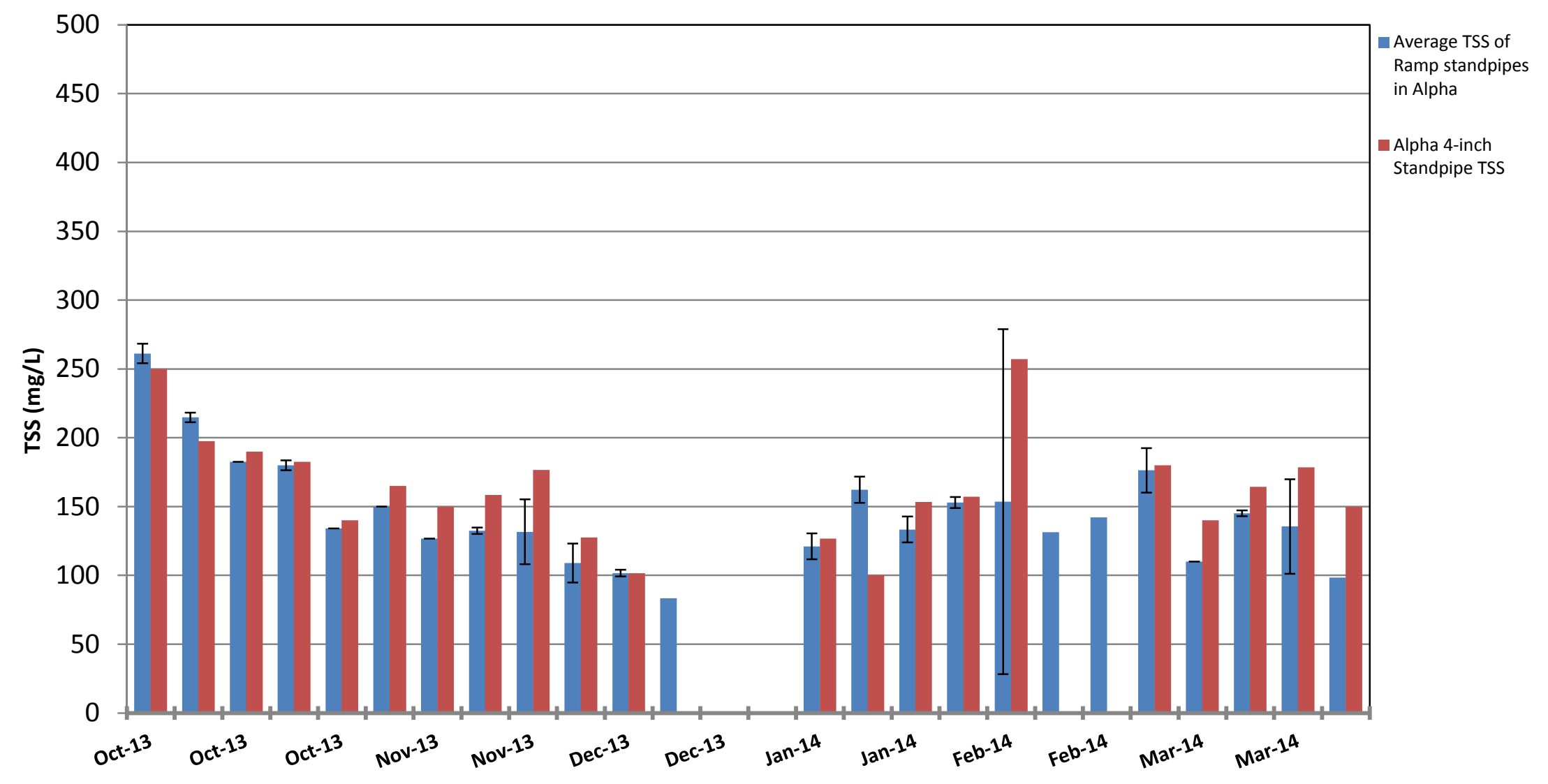

Figure 4-32: Weekly average TSS for Alpha set ponds with ramped and 4-inch standpipe from October 2013 to April 2014 . Error bars are one standard deviation in positive and negative direction. 
One possible reason for the lack of accumulation in the Alpha ponds was that they had consistently lower 2-hour settling efficiency than Gamma (4.6.1) from October 2013 to March 2014. The lower settling efficiency in Alpha meant that solids in the Alpha set ponds stayed suspended for a longer time than in the Gamma ponds. Alpha flocs were smaller than the other two pond sets (Figure 4-33) and stayed suspended as they overflowed the 4-inch standpipe, preventing solids from being retained (3.2.6.3).

Figure 4-31 showed that from January 2014 to April 2014 the TSS in the 4-inch standpipe Beta ponds was consistently higher than in the ramp standpipe ponds. This was most likely due to seasonal floc differences between colder months and warmer months (Figure 4-33). The floc characteristics of Beta changed from December 2013 (winter) to April 2014 (spring). The amount of colloidal algae in the ponds remained the same however the amount of flocculated algae increased from winter to spring. During spring, when there was more flocculated biomass, it is possible that more of the biomass was strained in the 4-standpipe. This could be the reason for the increase in the difference between the 4-inch and ramped standpipe seen in the Beta ponds.
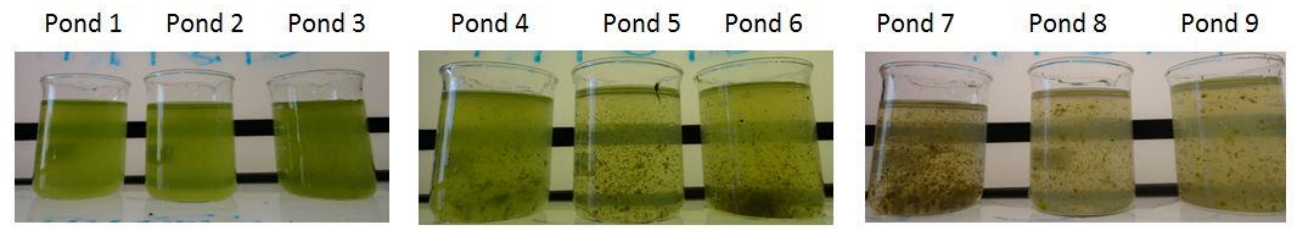

December 4th 2013
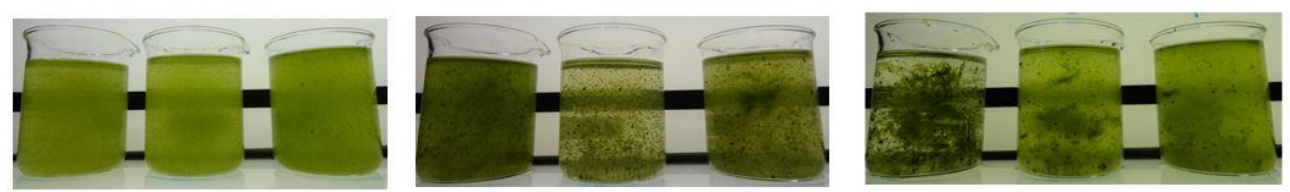

April 24th, 2014

Figure 4-33: Seasonal floc size variation in all ponds. 
Gamma had large flocs throughout the year and minimal colloidal algae in the winter which most likely led to the solids accumulation seen in Ponds 7.

\subsection{Aeration results}

Sonication and homogenization were used to pretreat anaerobically digested sludge before being transferred to aerobic reactors. These results were to demonstrate how nutrients would be released from the biomass of the sludge if introduced into ponds. These experiments were performed to determine the total amounts of nutrients that can be made available for nutrient recycling. Pretreatments were used in an attempt to increase the extent of nutrient release.

\subsubsection{Results of the Aerobic Degradation of Sonicated-Digested Algae Experiment}

The sonication experiments were run from August 20 to September 20, 2013. Because anaerobically digested sludge placed in the reactors was diluted with reverse osmosis water, there may have been a trace metal limitation. 


\subsubsection{Temperature, $\mathrm{pH}$, Dissolved Oxygen}

Temperature (Figure 4-34), pH (Figure 4-35), and dissolved oxygen (Figure 4-36) were monitored for all reactors.

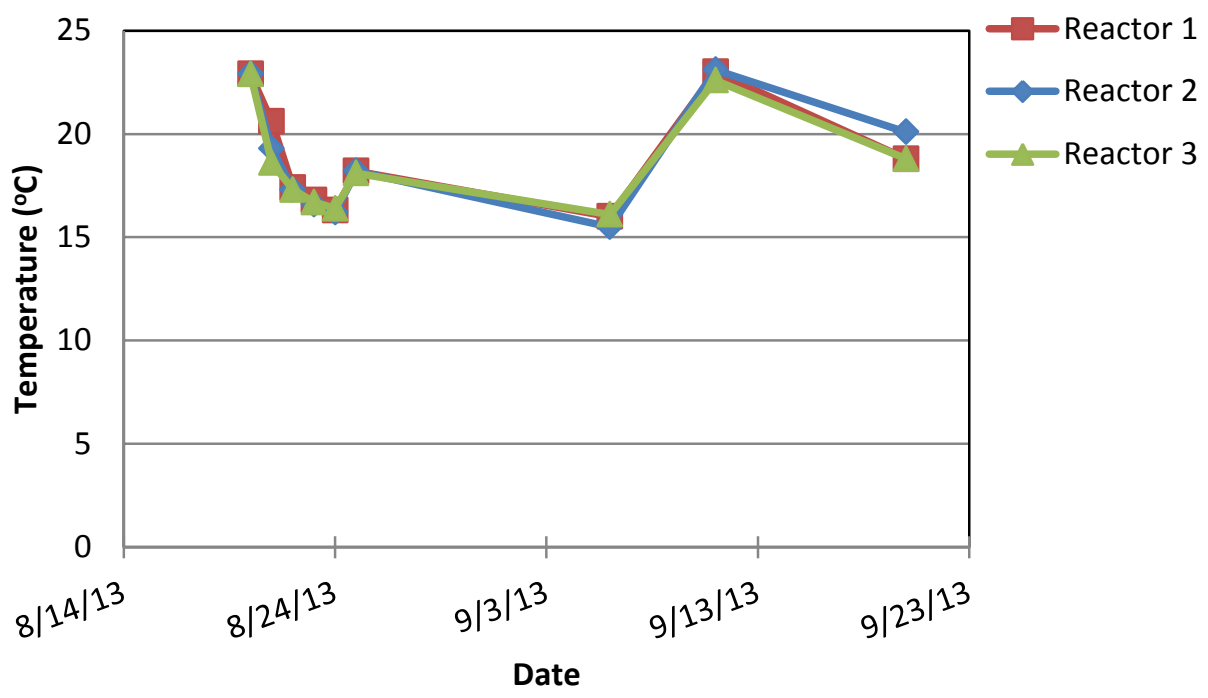

Figure 4-34: Temperature of the reactors for the sonicated algae aeration experiment.

The reactors were placed in an unheated water bath in an attempt to dampen changes in temperature, which did not prevent temperature fluctuations of at least $6.5^{\circ} \mathrm{C}$ (Figure 4-34). Evaporative cooling was thought to be the cause of the drop in temperature at the beginning of the experiment. Polystyrene packaging peanuts were placed in the water in an attempt to reduce evaporation. This did little to prevent evaporation based on the continued drop in temperature. During the course of the experiment, the air conditioning system in the building failed and there were several days when the temperature in the room reached $25^{\circ} \mathrm{C}$, as was apparent in the spike in temperature near the end of the experiment. 
The $\mathrm{pH}$ was similar in Reactors 1,2, and 3 (Figure 4-35). The $\mathrm{pH}$ spiked at the very beginning of the experiment perhaps due to carbon dioxide and ammonia stripping. After August 25, 2013, nearly all the ammonia was gone from the reactors, and the $\mathrm{pH}$ stabilized to $7.7 \pm 0.08$. No attempt was made to control $\mathrm{pH}$ in the system, it was only monitored. The stabilized $\mathrm{pH}$ in the reactors was just outside of the optimum $\mathrm{pH}$ range (6.5-7.5) for typical aerobic bacterial growth in wastewater treatment (Metcalf \&Eddy, Inc., 2003).

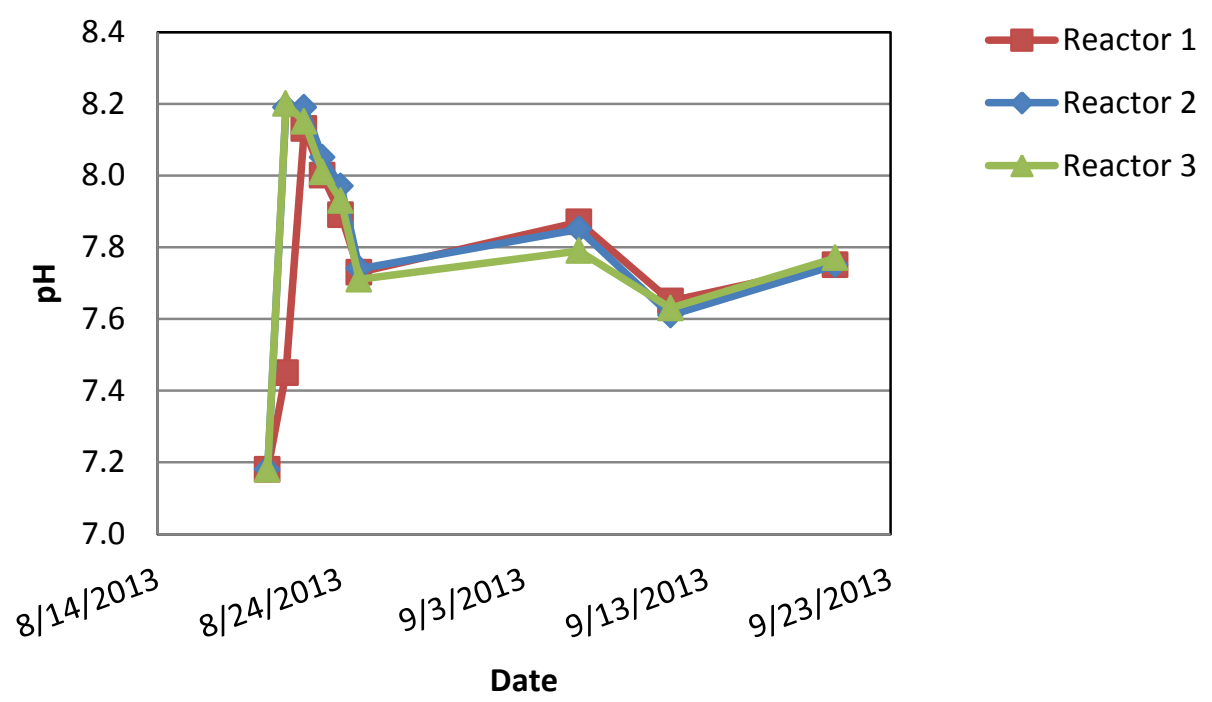

Figure 4-35: pH data for sonication aeration experiment.

It was important to keep the reactors aerobic to ensure that the degrading population of bacteria was well supplied with oxygen. The dissolved oxygen stayed near saturation $\left(9 \mathrm{mg} / \mathrm{L}\right.$ at $\left.20^{\circ} \mathrm{C}\right)$ throughout the experiment (Figure 4-36). The first value was taken just after dilution and before aeration was started. 


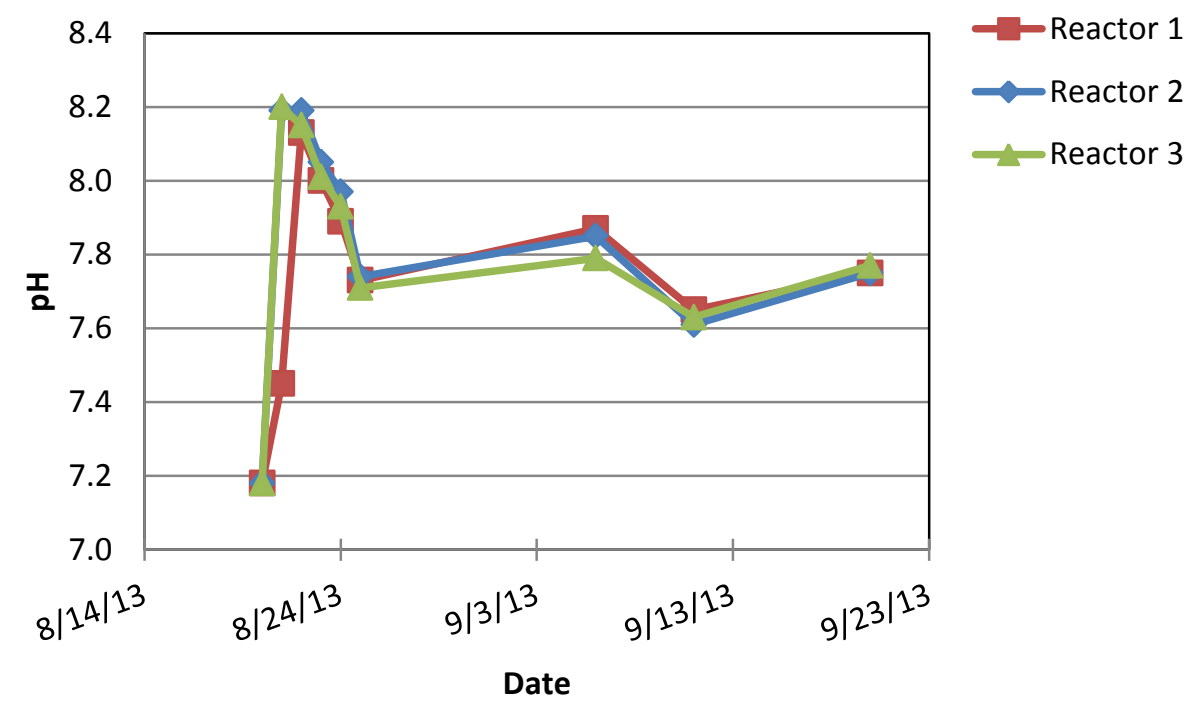

Figure 4-36: Dissolved oxygen concentration for the sonication aeration experiment.

\subsubsection{Solids}

The VSS in the reactors fluctuated throughout the experiment, which is contrary to the expectation that VSS would decline due to degradation. Unrepresentative sampling was likely an explanation for the increases in VSS. It is likely that anaerobic digestion nearly completed VSS destruction, and that only recalcitrant VSS remained at the start of the aerobic degradation experiment. 


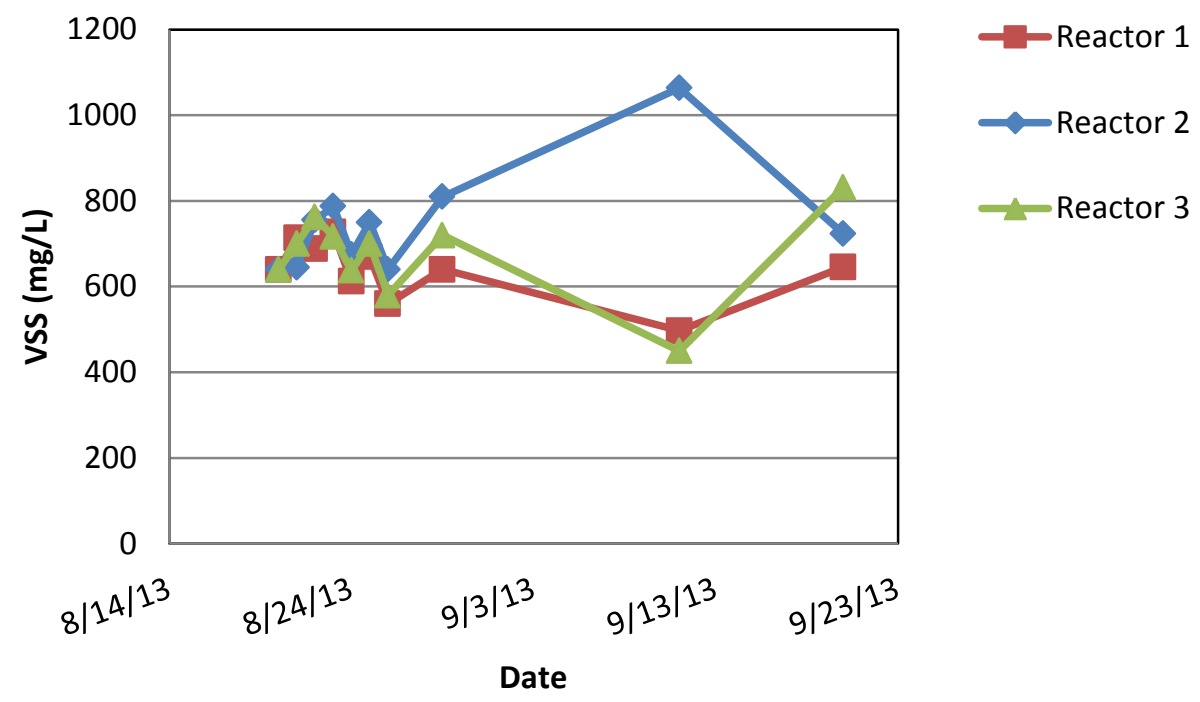

Figure 4-37: VSS concentration data for the sonication aeration experiment. 


\subsubsection{Nitrogen}

Due to QA/QC issues and delays in sample processing, TKN and organic nitrogen could not be presented in this thesis.

The TAN in the reactors was depleted within five days of starting the experiment (Figure 4-38).

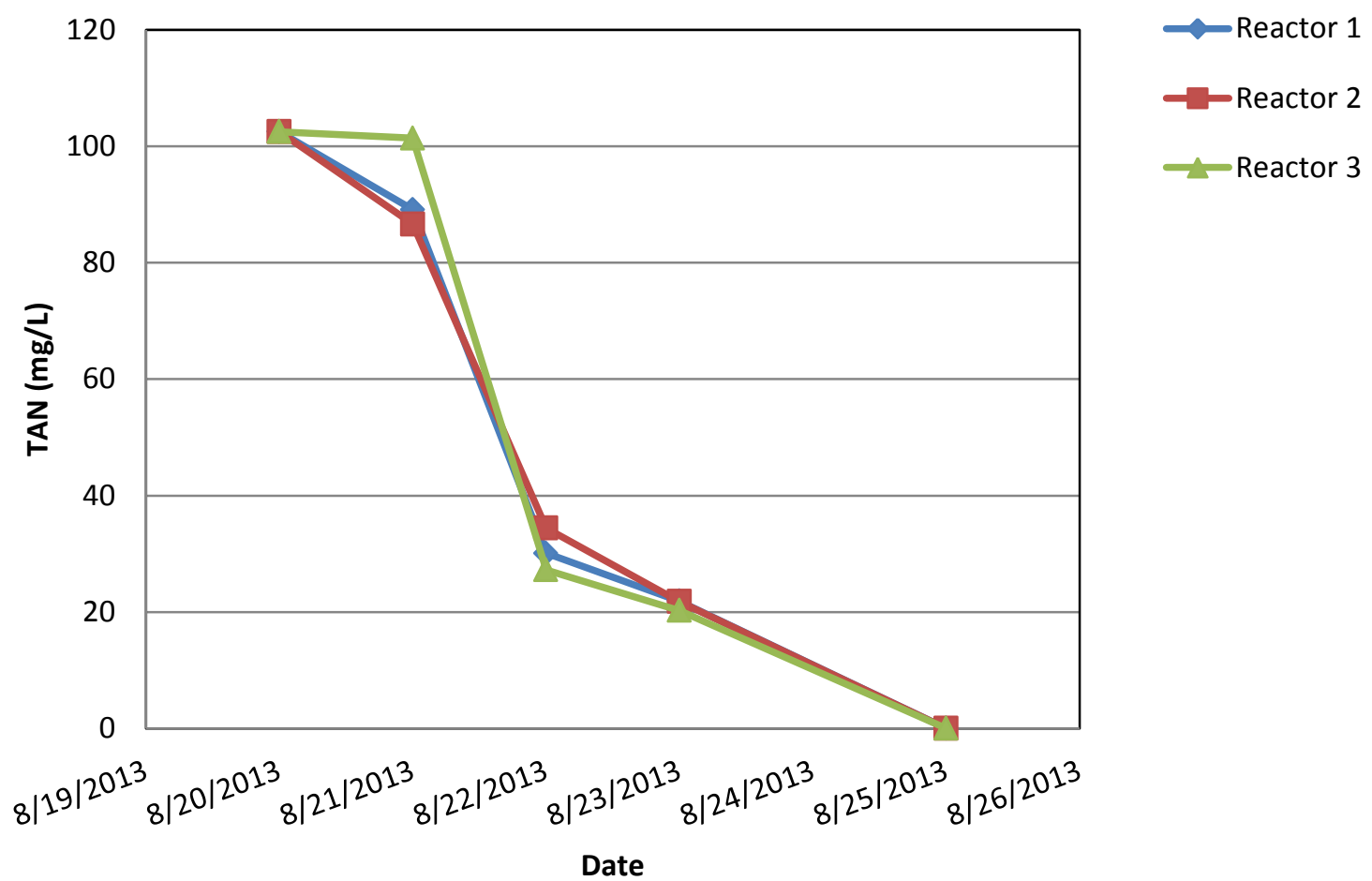

Figure 4-38: TAN data for the sonication aeration experiment. This graph shows up until the point when the TAN concentrations reached zero. The concentration remained at zero until the end of the experiment on September 20,2013

The $\mathrm{pH}$ during this time was between 8.2 and 7.7. In this $\mathrm{pH}$ range, 5\% of TAN is in the form of $\mathrm{NH}_{3}$. Even at low concentration, there could still have been considerable ammonia volatilization, due to the large volume of air being bubbled through the reactors. 


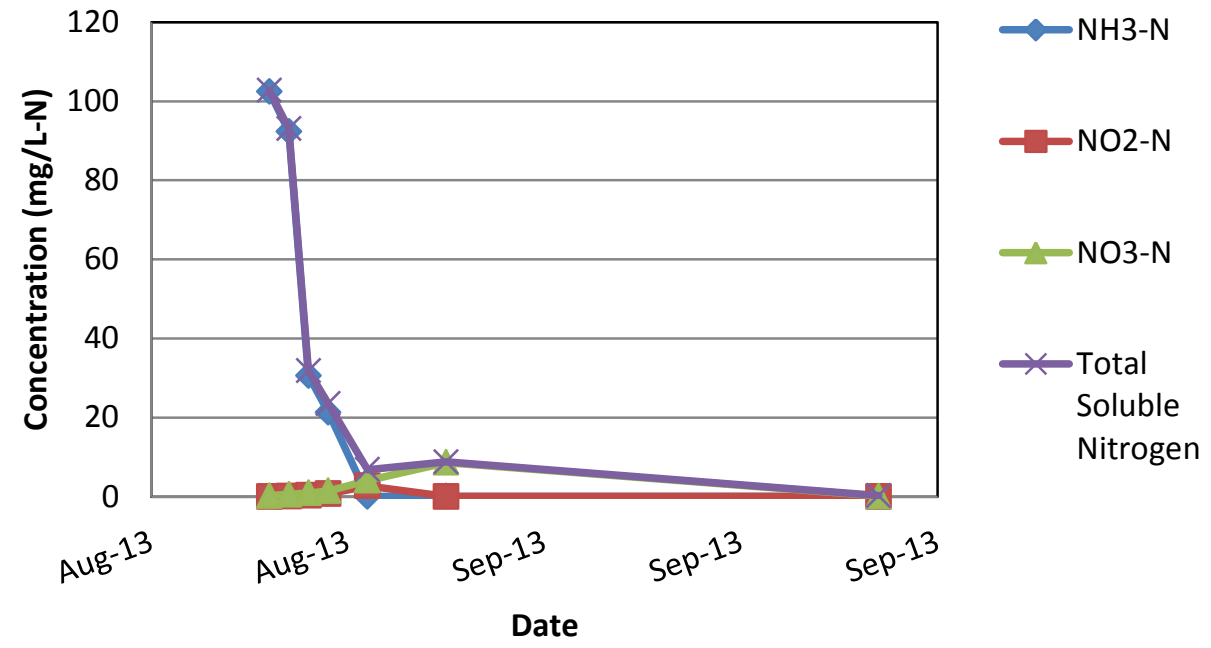

Figure 4-39: Total soluble nitrogen for the sonication aeration experiment. Error bars were omitted from this graph because the standard deviations were too small to be visible.

Ammonium was the dominant species of soluble nitrogen in the reactors. Nitrite was the first oxidized nitrogen species to be formed, peaking at Day 5 with a concentration of $2.70 \pm 0.21 \mathrm{mg} / \mathrm{L}$. Nitrate was formed after nitrite. The nitrate concentration peaked on day 9 with a concentration $8.63 \pm 0.30$. By the end of the experiment, almost all of the soluble nitrogen was gone from solution. By day 30, there was only $0.21 \mathrm{mg} / \mathrm{L}-\mathrm{N}$ of soluble nitrogen in the reactors. 


\subsubsection{Phosphorus}

Due to delays in sample processing there was no available data as time of writing for total phosphorus. Because of the lack of total phosphorus data particulate phosphorus was not calculated.

Rather than increasing quantitatively with decreasing particulate phosphorus, the dissolved phosphorus in the reactors decreased over time (Figure 4-40). The apparent loss of dissolved phosphorus might have been due to analytical errors or precipitation.

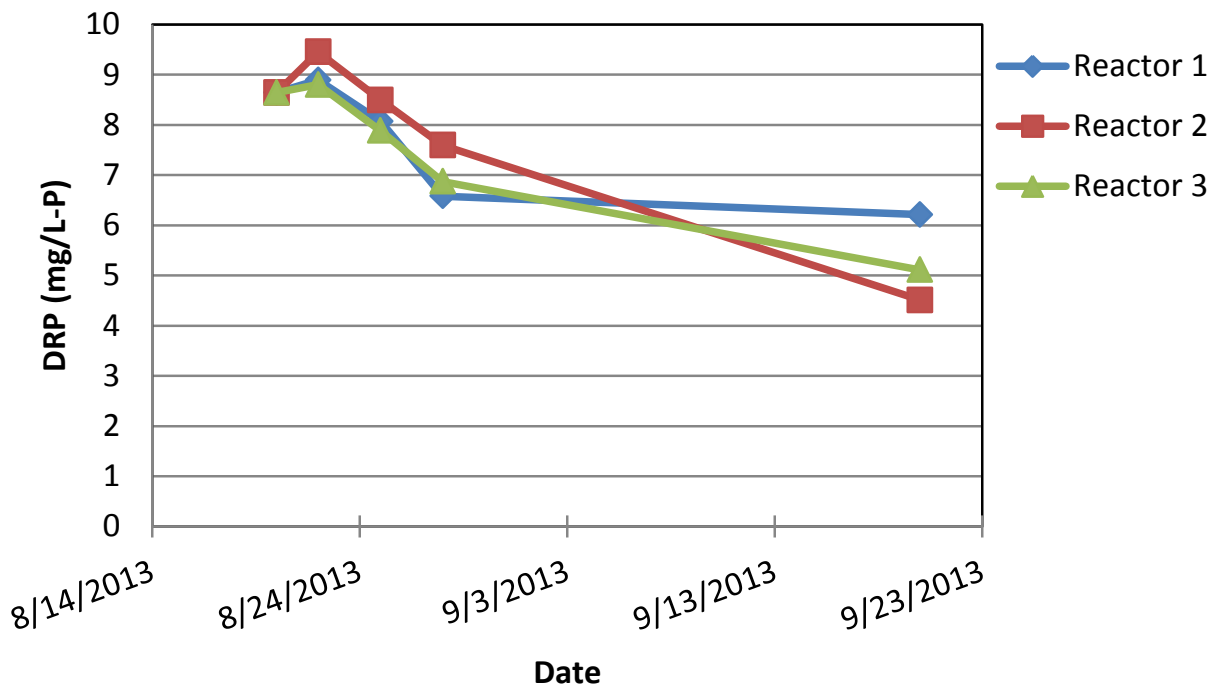

Figure 4-40: Dissolved reactive phosphorus graph for the sonicated aeration experiment

\subsubsection{Results of the Aerobic Degradation of Homogenized-Digested Algae Experiment}

The homogenization aeration experiment was similar to the sonication experiment with the exception of the pretreatment method. The results of both experiments were compared 
to determine the difference between pretreatment methods. Standard deviations were calculated from triplicate reactors.

\subsubsection{Temperature, $\mathrm{pH}$, and Dissolved Oxygen}

As with the sonication experiment, the reactors were placed in water-filled fish tanks. For this experiment, fish tank heaters were used to keep the temperature constant around $20^{\circ} \mathrm{C}$. The addition of the fish tank heater greatly improved temperature stability (Figure 4-41,Error! Reference source not found.). The average temperature for the unhomogenized samples was $20.2 \pm 0.97^{\circ} \mathrm{C}$, and $19.8 \pm 0.70^{\circ} \mathrm{C}$ for the homogenized samples.

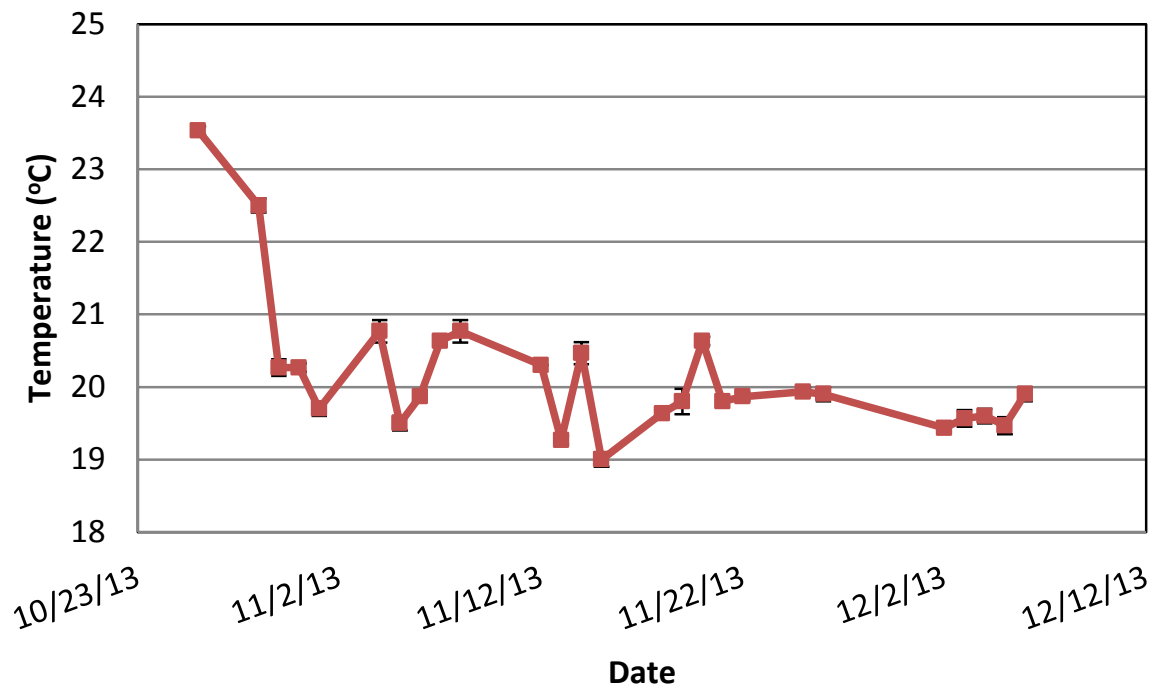

Figure 4-41: Temperature for the unhomogenized control samples in the homogenized aeration experiment. Error bars are one standard deviation in the positive and negative direction but are obscured by data points. 


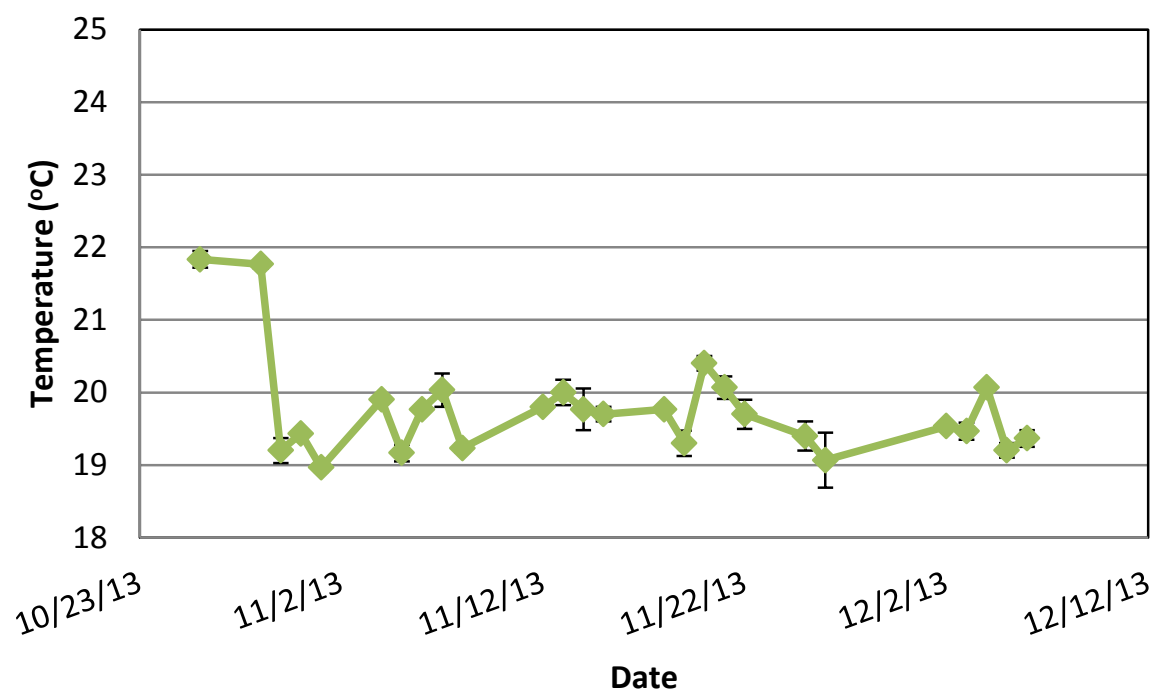

Figure 4-42: Temperature for the homogenized samples in the homogenized aeration experiment. Error bars are one standard deviation in the positive and negative direction but are obscured by data points

The $\mathrm{pH}$ of the reactors started higher than the $\mathrm{pH}$ of the sonication experiment. The maximum $\mathrm{pH}$ was around 8.5 in both the homogenized and control reactors. This experiment had a similar trend in $\mathrm{pH}$ to that of the sonication experiment. The $\mathrm{pH}$ in the reactors was high initially and slowly decreased (Figure 4-43, Figure 4-44). The pH eventually stabilized to $6.45 \pm 0.12$ for the unhomogenized and to $6.77 \pm 0.13$ for the homogenized. This was about one $\mathrm{pH}$ lower than the sonication experiment. 


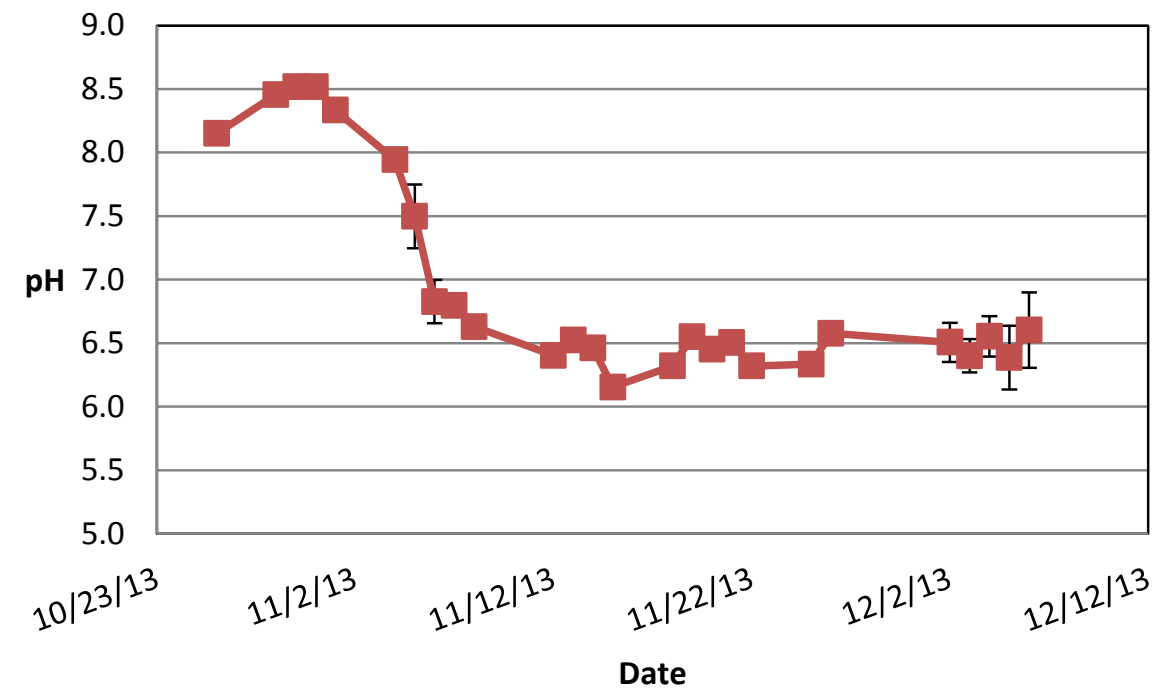

Figure 4-43: pH for the unhomogenized control samples of the homogenized aeration experiment. Error bars are one standard deviation in the positive and negative direction.

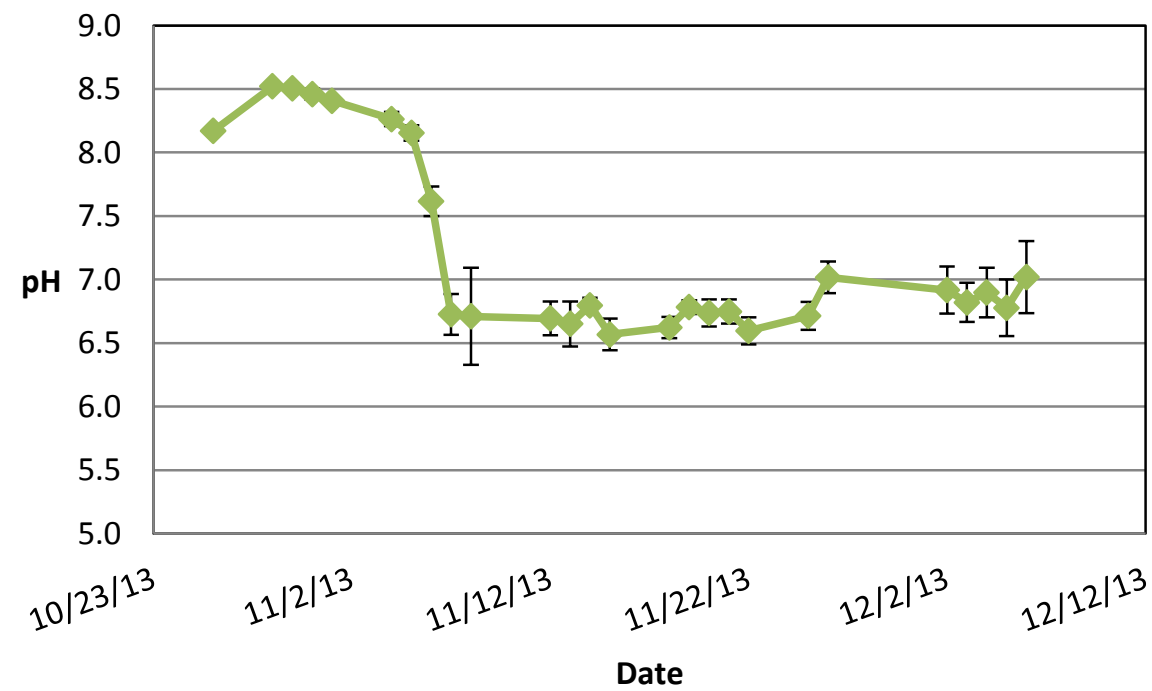

Figure 4-44: $\mathrm{pH}$ for the homogenized samples of the homogenized aeration experiment. Error bars are one standard deviation in the positive and negative direction.

The dissolved oxygen of the reactors was maintained at levels high enough for bacterial metabolism (Figure 4-45, Figure 4-46). The DO in activated sludge aeration tanks is usually around 1.5-2 mg/L (Metcalf \&Eddy, Inc., 2003). The DO in the reactors was 
roughly four times that of activated sludge basins, which was assumed to be adequate to provide the bacterial populations with enough oxygen.

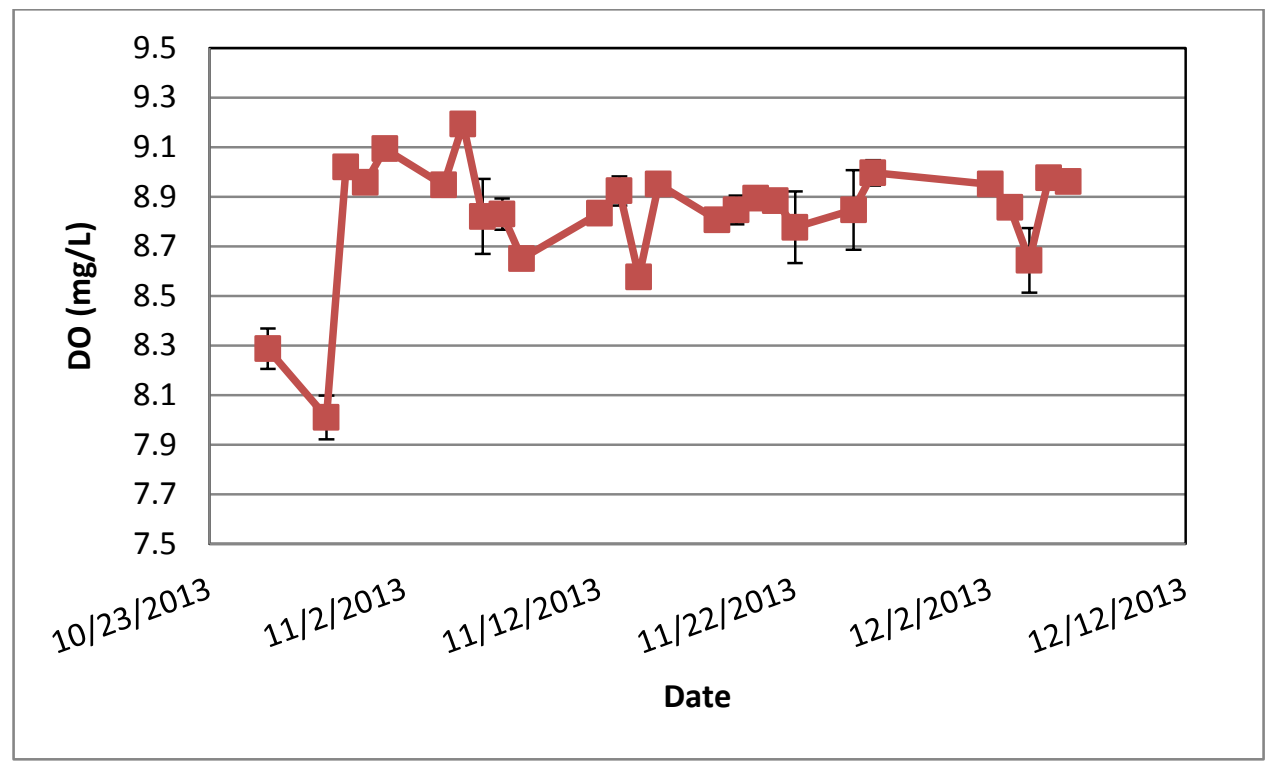

Figure 4-45: Dissolved oxygen graphs for the unhomogenized samples of the homogenized aeration experiment. Error bars are one standard deviation in the positive and negative direction.

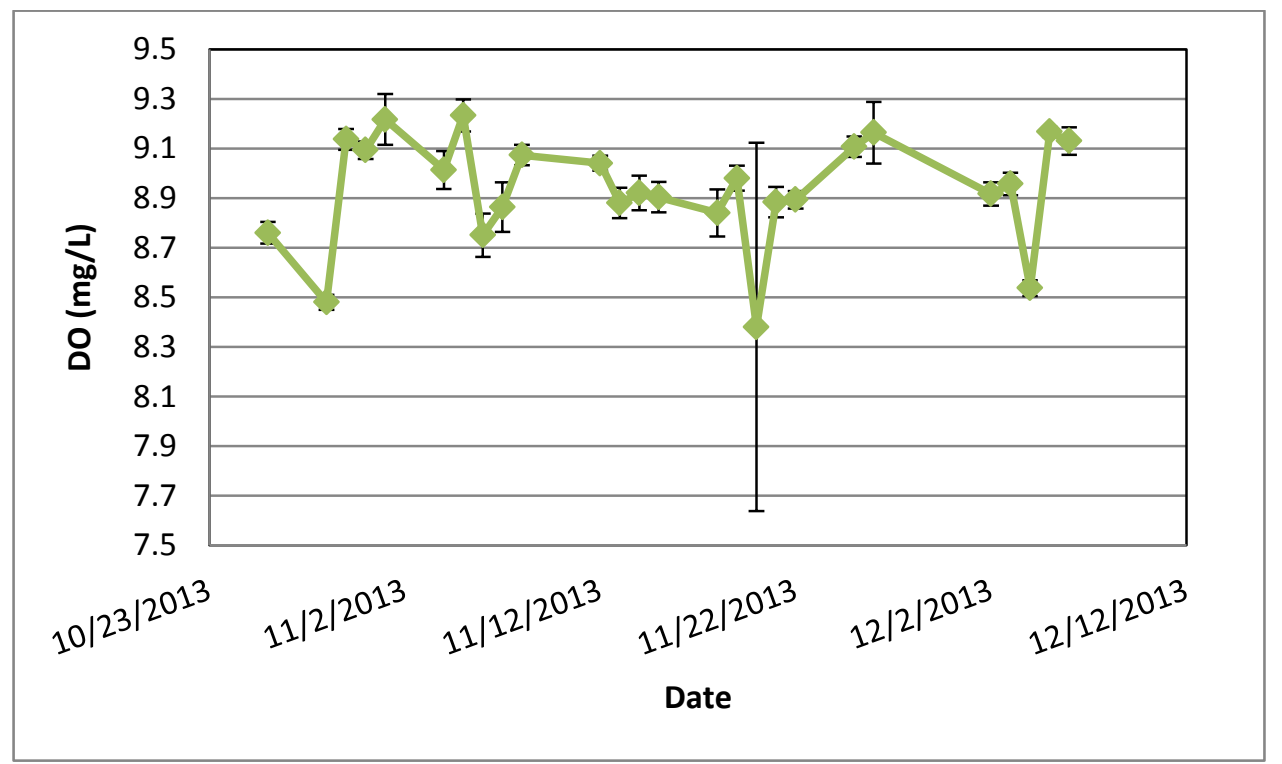

Figure 4-46: Dissolved oxygen graphs for the homogenized samples of the homogenized aeration experiment. Error bars are one standard deviation in the positive and negative direction. 


\subsubsection{Solids}

The VSS of this experiment decayed as expected (Figure 4-47). The difference between the homogenized and unhomogenized VSS concentrations was due the difference in initial dilutions.

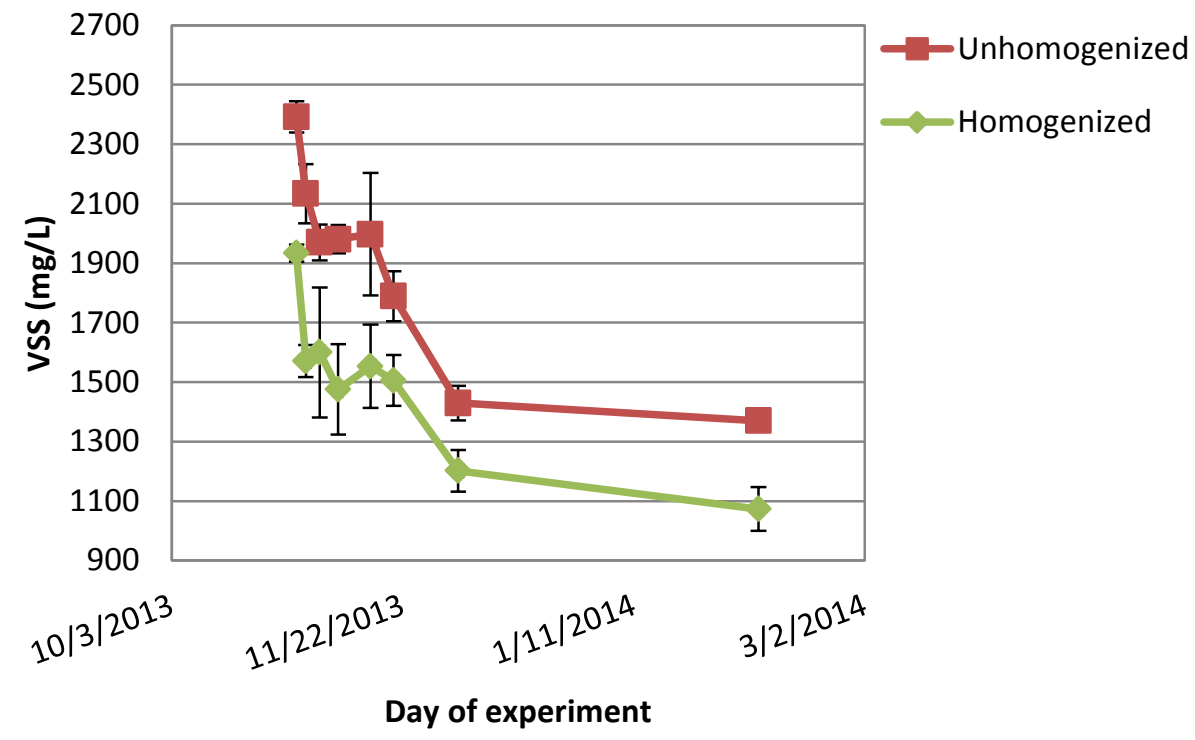

Figure 4-47: VSS graph of both the homogenized and unhomogenized samples from the homogenized experiment. Error bars are one standard deviation in the positive and negative direction

The VSS was normalized by the initial VSS to show that the relative solids degradation in both the homogenized and unhomogenized was essentially identical (Figure 4-48). 


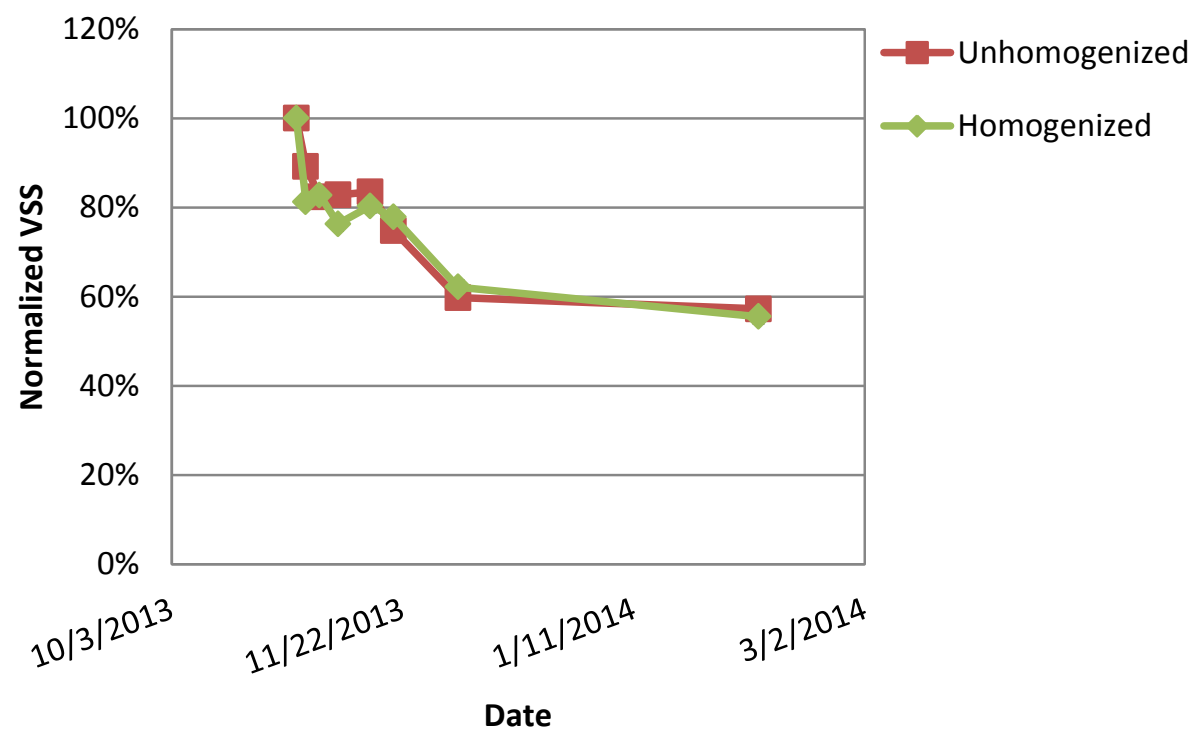

Figure 4-48: Normalized VSS for both the homogenized and unhomogenized samples of the homogenization experiment. Values were normalized by the initial VSS concentration of the samples. Error bars removed for clarity.

The inert fraction of the homogenized and unhomogenized samples is outlined in Table 4-8. Homogenization had no effect on the inert fraction of biomass present in the samples. The inert fraction seen in this experiment was slightly higher than the $40 \%$ from Jewell and McCarty (1971).

Table 4-8: summary of VSS results for the homogenization aeration experiment.

\begin{tabular}{cccc} 
Pretreatment & $\begin{array}{c}\text { Initial } \\
\text { VSS }\end{array}$ & Final VSS & Inert \\
Type & $(\mathrm{mg} / \mathrm{L})$ & $(\mathrm{mg} / \mathrm{L})$ & Fraction \\
\hline Homogenized & $1933 \pm 29$ & $1073 \pm 74$ & $55 \% \pm 4 \%$ \\
Unhomogenized & $2391 \pm 52$ & $1370 \pm 26$ & $57 \% \pm 0.2 \%$ \\
\hline
\end{tabular}




\subsubsection{Nitrogen}

Figure 4-49 and Figure 4-50 show the change in concentrations of various nitrogen species for both unhomogenized and homogenized samples in the homogenization aeration experiment.

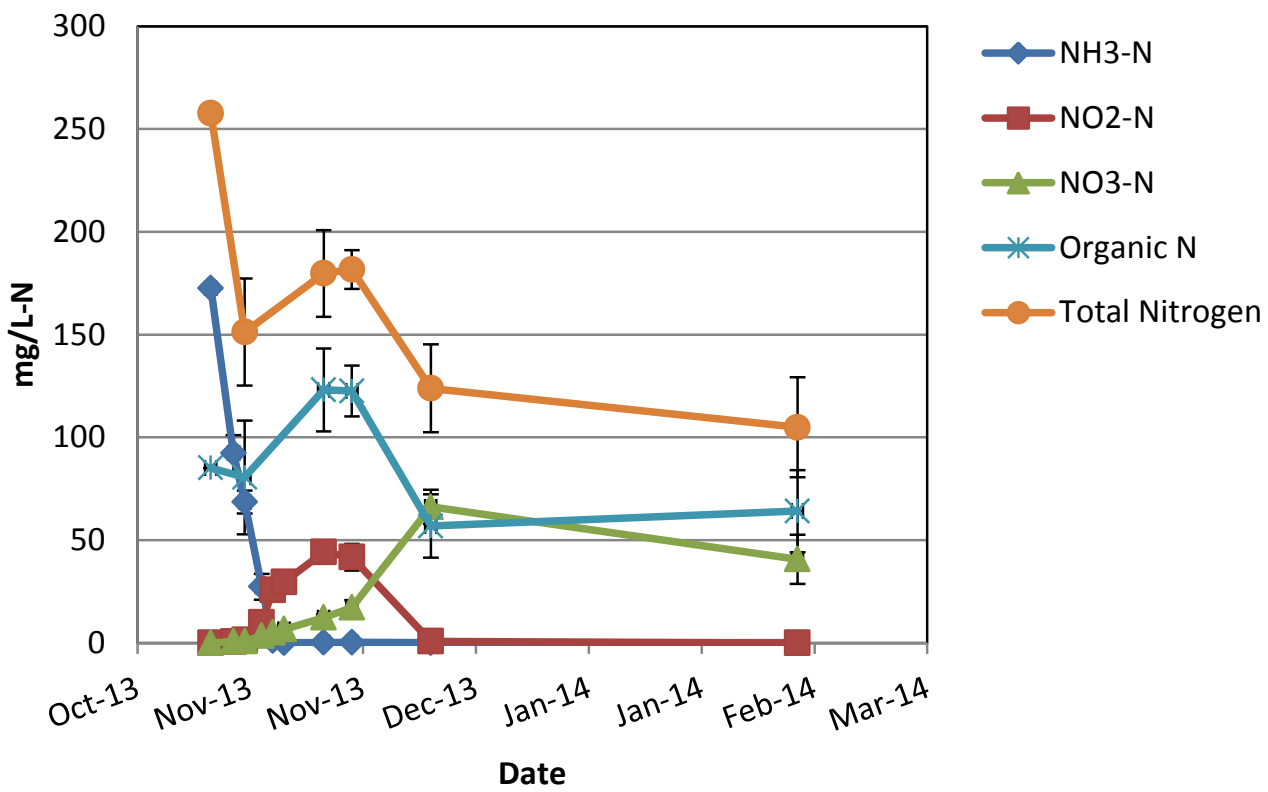

Figure 4-49: Nitrogen evolution graph for unhomogenized samples from homogenization aeration experiment. Error bars are one standard deviation in the positive and negative directions. Data points are the mean values of triplicate reactors. 


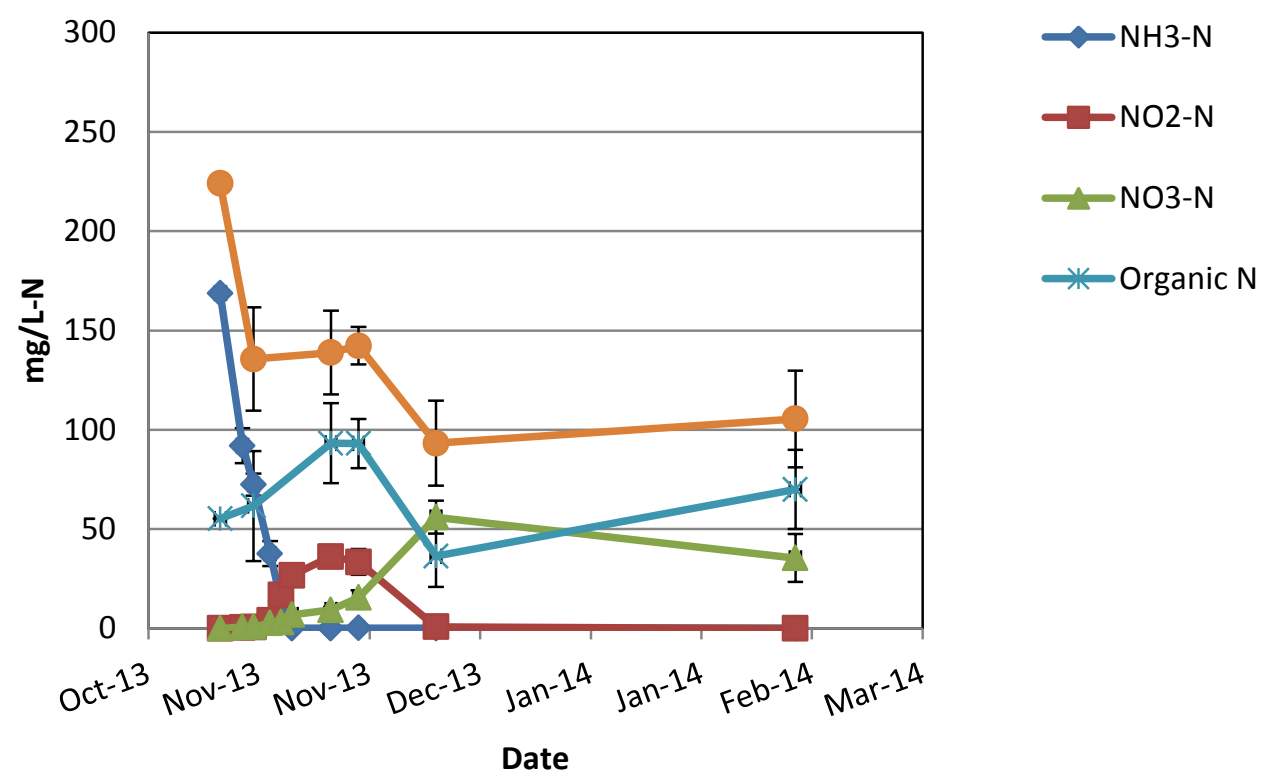

Figure 4-50: Nitrogen evolution graph for homogenized samples from homogenization aeration experiment. Error bars are one standard deviation in the positive and negative directions. Data points are mean values from triplicate reactors.

The organic nitrogen concentration increased slightly indicating analytical or sampling error. Organic nitrogen was expected to decrease due to the decay of biomass. This graph is similar to what was observed in the sonication experiment but to a much greater extent. The peak concentrations for nitrate and nitrite were much higher for both the homogenized and unhomogenized samples than for the sonication experiment. The decrease in total nitrogen is most likely due to ammonia volatilization. As stated earlier, the $\mathrm{pH}$ at the beginning of the experiment averaged around 8.5 for all the reactors. At this $\mathrm{pH}$ around $20 \%$ of the TAN is in the volatile form of $\mathrm{NH}_{3}$. All of the TAN in both the homogenized and unhomogenized reactors was fully striped from the reactors within 11 days. Similar to the sonication experiment, the oxidized forms of nitrogen did not appear in the reactors until all of the ammonia was gone (Table 4-9). 
Table 4-9: Summary results of oxidized nitrogen for the homogenization aeration experiment.

\begin{tabular}{ccccc} 
& Peak & \multicolumn{3}{c}{ Peak } \\
& Nitrite & Time to & Nitrate & Time to \\
Pretreatment & Concentration & Peak & Concentration & Peak \\
Type & $(\mathrm{mg} / \mathrm{L}-\mathrm{N})$ & $($ Days $)$ & $(\mathrm{mg} / \mathrm{L}-\mathrm{N})$ & (Days) \\
\hline Homogenized & $36 \pm 3.2$ & 18 & $56 \pm 1.1$ & 37 \\
Unhomogenized & $44 \pm 0.3$ & 18 & $66 \pm 8.3$ & 37 \\
\hline
\end{tabular}

\subsubsection{Phosphorus}

Due to QA/QC failures total phosphorus data was not available at the time of writing this thesis.

Unlike the sonication experiment, DRP increased from the beginning to the end of the homogenization experiment (Figure 4-51Table 4-10). There was a rapid initial decrease in DRP at the beginning of the experiment followed by a rapid re-release of DRP, which eventually leveled off. The unhomogenized samples reached a higher overall DRP, but by the end of the experiment both homogenized and unhomogenized had similar DRP concentrations. 


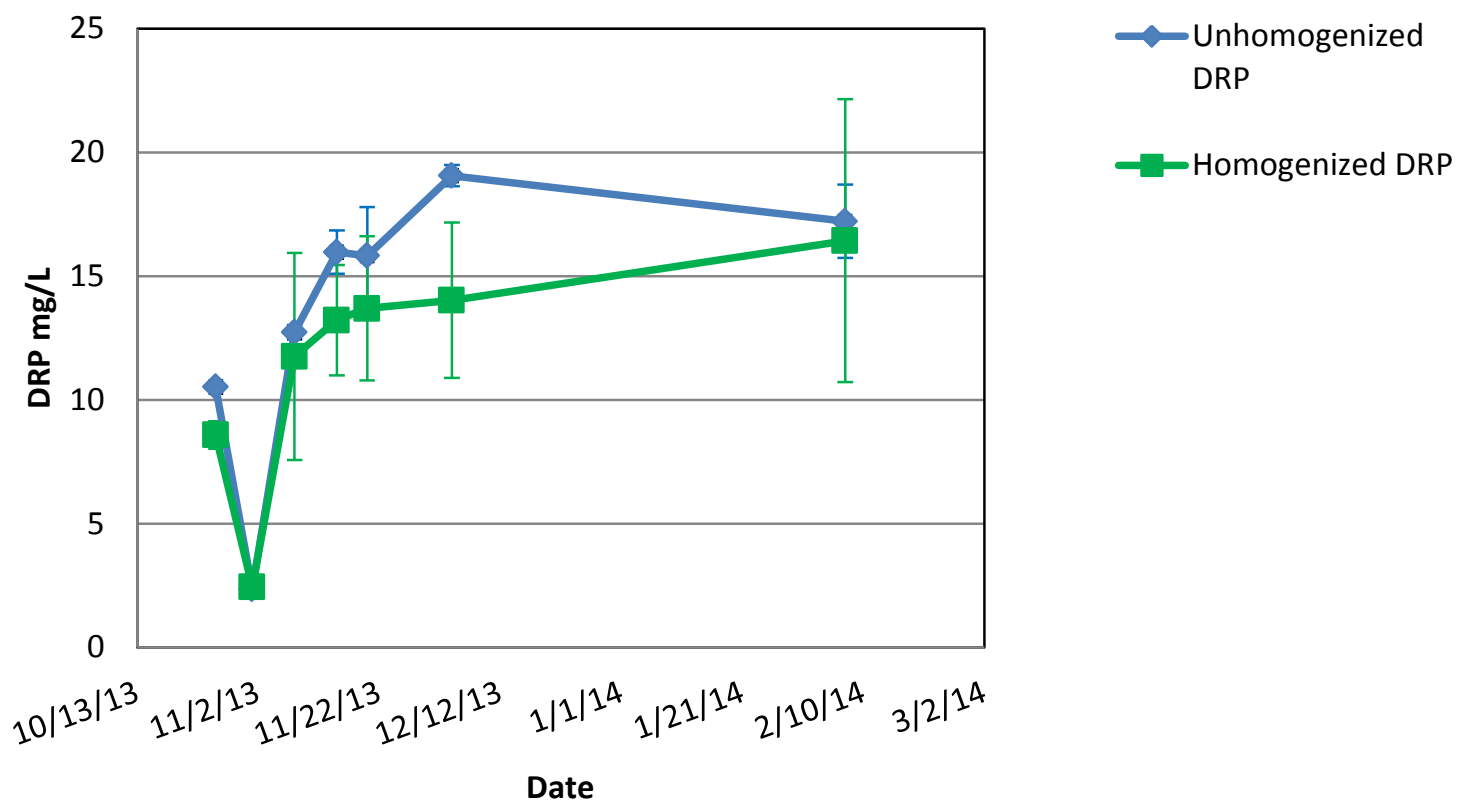

Figure 4-51: DRP for the homogenized aeration experiment.

Table 4-10: DRP released during homogenization experiment.

\begin{tabular}{rccc} 
Pretreatment Type & $\begin{array}{c}\text { Initial } \\
\text { DRP }\end{array}$ & Final DRP & $\begin{array}{c}\text { DRP } \\
\text { Released }\end{array}$ \\
\hline Homogenized & $10.52 \pm 0.02$ & $17.21 \pm 1.48$ & $6.69 \pm 1.51$ \\
Unhomogenized & $8.59 \pm 0.56$ & $16.43 \pm 5.72$ & $7.84 \pm 6.27$
\end{tabular}

The VSS decreased roughly $900 \mathrm{mg} / \mathrm{L}$ in the homogenized samples. Assuming that phosphorus made up $1 \%$ of the biomass, this would lead to an expected release of $9 \mathrm{mg} / \mathrm{L}$ of DRP. The difference between the starting and ending concentrations of DRP was roughly $8 \mathrm{mg} / \mathrm{L}$ which agrees with the expected value of $9 \mathrm{mg} / \mathrm{L}$. 

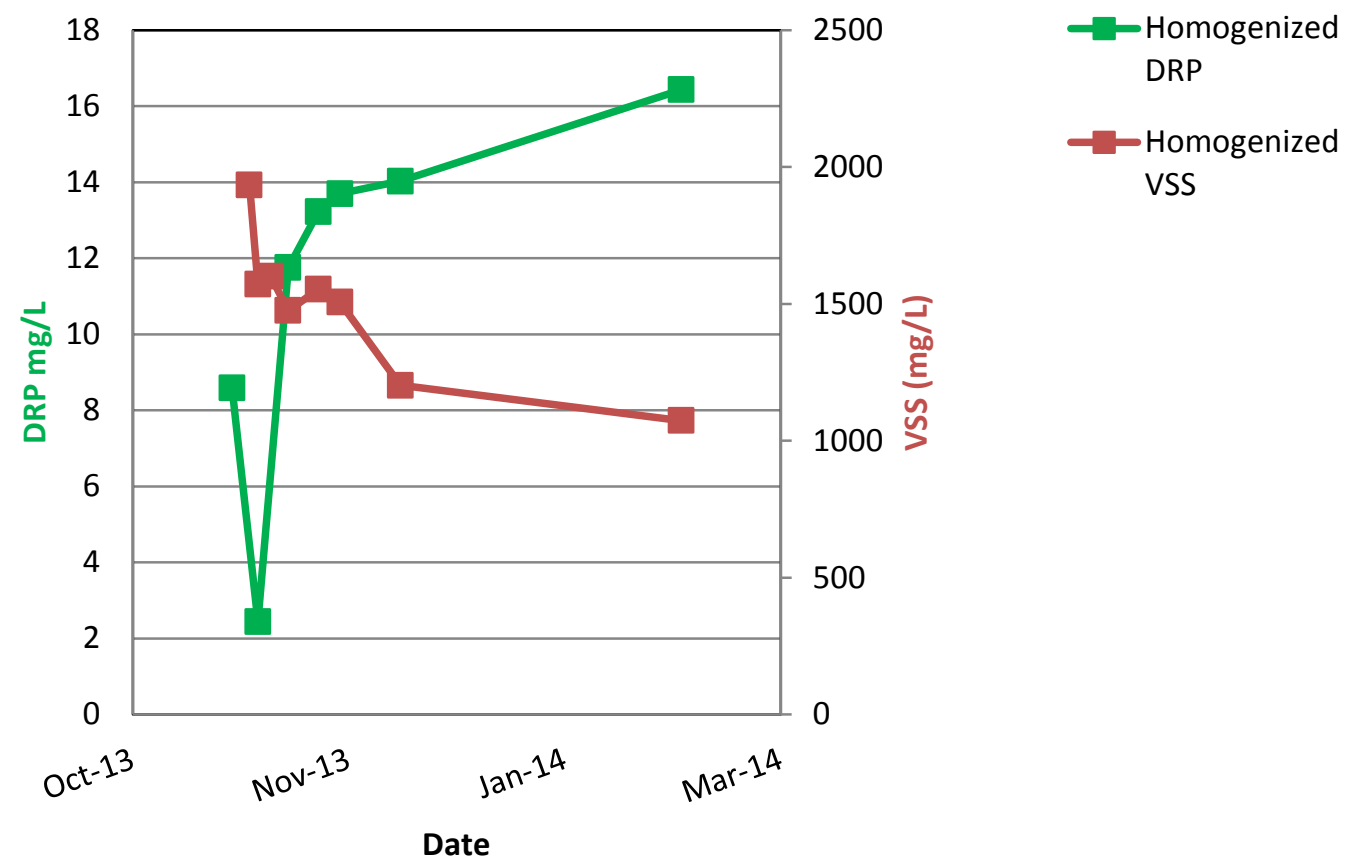

Figure 4-52: Homogenized DRP graphed with VSS degradation. Error bars were excluded for clarity.

The VSS decreased roughly $1000 \mathrm{mg} / \mathrm{L}$ in the unhomogenized samples. Assuming that phosphorus made up $1 \%$ of the biomass, this would lead to an expected release of $10 \mathrm{mg} / \mathrm{L}$ of DRP. The difference between the starting and ending concentrations of DRP was roughly $6 \mathrm{mg} / \mathrm{L}$ which does not completely agree with the expected value of $10 \mathrm{mg} / \mathrm{L}$ but without reliable values for the true percent phosphorus content of the cells it is impossible to know if the expected value was correct. 


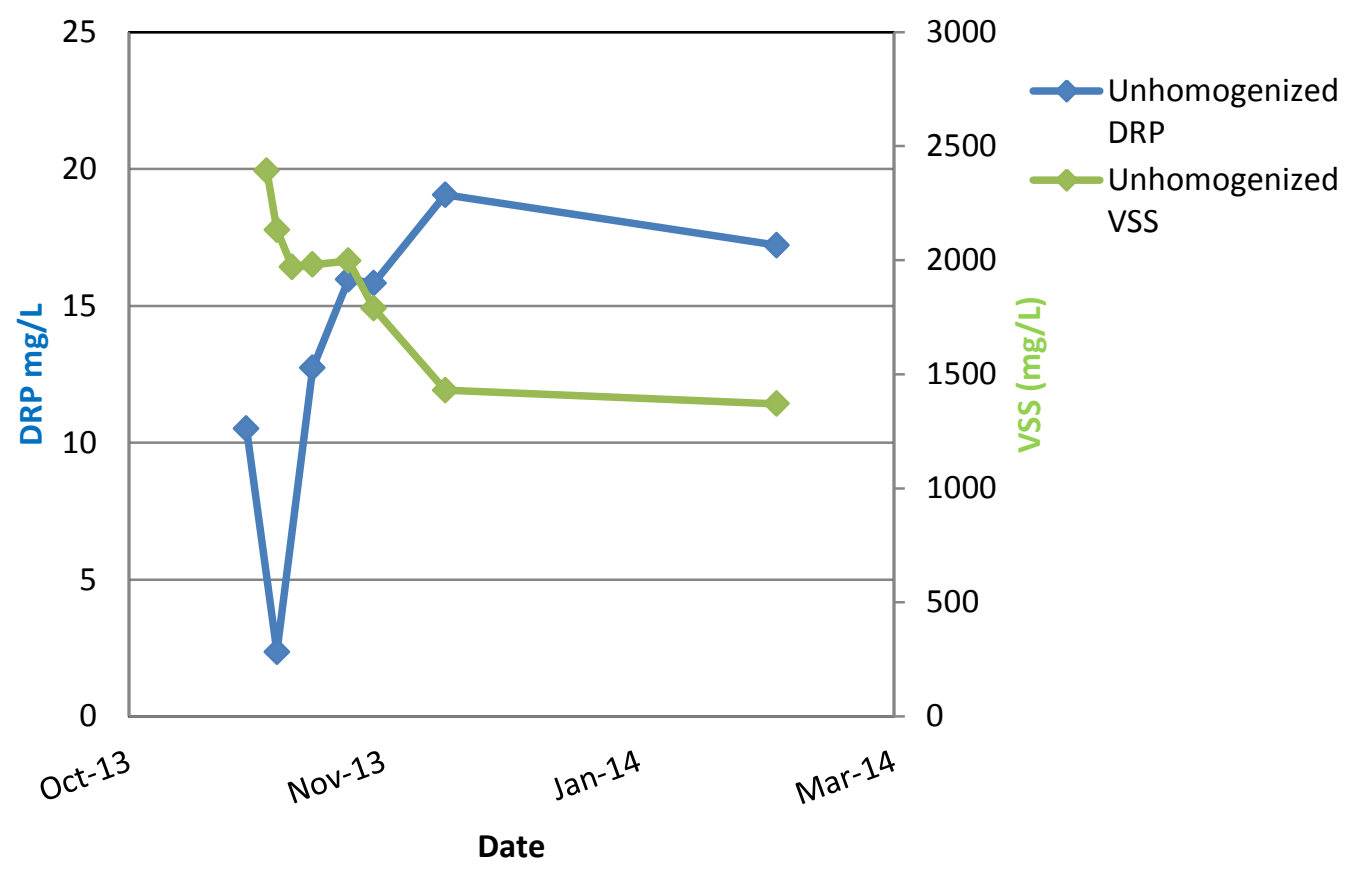

Figure 4-53: Unhomogenized DRP graphed with VSS degradation. Error bars were excluded for clarity.

\subsubsection{Statistical Results}

The results from a series of t-tests performed to compare the homogenized and unhomogenized samples from the homogenization aeration experiment are summarized in Error! Reference source not found.. T-tests were run for each sample day. The null hypothesis of the t-tests was that there was no difference between the homogenized and untreated samples. This was done in lieu of a statistical time series comparison due to the small sample size of each data set. The overall significance level was set at a p-value of 0.1 , instead of the normal 0.05 , to balance type 1 and type 2 errors. Because multiple comparisons were performed on the same data sets a Bonferonni correction was applied to 
the p-value cutoff to reduce the likelihood of determining significance when there was

none.

\begin{tabular}{|c|c|c|c|c|c|c|}
\hline & VSS p-values & NHx p-value & NO3 p-value & NO2 p-value & DRP p-value & $\begin{array}{c}\text { Organic Nitrogen } \\
\text { p-value }\end{array}$ \\
\hline Sample Day 1 & & $\underline{0.0002}$ & 1 & 1 & 0.8206 & $\underline{0.0006}$ \\
\hline Sample Day 2 & 1 & 0.0524 & 0.0315 & 0.0483 & & \\
\hline Sample Day 3 & 0.079 & 0.0161 & 0.0541 & 0.0445 & 0.0366 & 0.8377 \\
\hline Sample Day 4 & 0.961 & 0.0151 & 0.4064 & 0.0443 & & \\
\hline Sample Day 5 & & 0.0277 & 0.0432 & 0.017 & & \\
\hline Sample Day 6 & 0.3125 & 0.3868 & 0.7921 & 0.1927 & 0.6023 & \\
\hline Sample Day 7 & 0.687 & 0.7607 & 0.361 & 0.3545 & 0.8265 & 0.5932 \\
\hline Sample Day 8 & 0.4599 & 0.3939 & 0.9004 & 0.5313 & 0.664 & 0.3512 \\
\hline Sample Day 9 & 0.447 & 0.2322 & 0.5804 & 0.0128 & 0.5473 & 0.2918 \\
\hline Sample Day 10 & 0.5406 & 0.2254 & 0.8078 & 0.39 & 0.5269 & 0.1847 \\
\hline Individual p-value cutoff & 0.0125 & 0.01 & 0.01 & 0.01 & 0.0143 & 0.0167 \\
\hline
\end{tabular}

The vast majority of the values in Table 4-11 indicate no significant difference between the homogenized and untreated samples. 


\section{Conclusions}

The main objective of this thesis was to determine how water and nutrients could be recycled in large scale algae production facilities to increase the sustainability of these sorts of systems in the future.

\subsection{Experimental Conclusions}

The 2-day HRT conclusions will be discussed first, then the ponds-in-series experiment, then the standpipe experiments, and lastly the aeration experiments. It should be noted that the summer productivity values were for a time period prior to the installation of the ramped standpipes, and may be artificially high for the 2-day HRT ponds.

\subsubsection{2-Day HRT Productivity}

The productivity of the 2-day HRT ponds was consistently higher than for the 3-day HRT ponds (Figure 5-1). On average the productivity of the 2-day HRT ponds was $48 \%$ higher in the summer and 37\% higher in the winter (Table 5-1). 


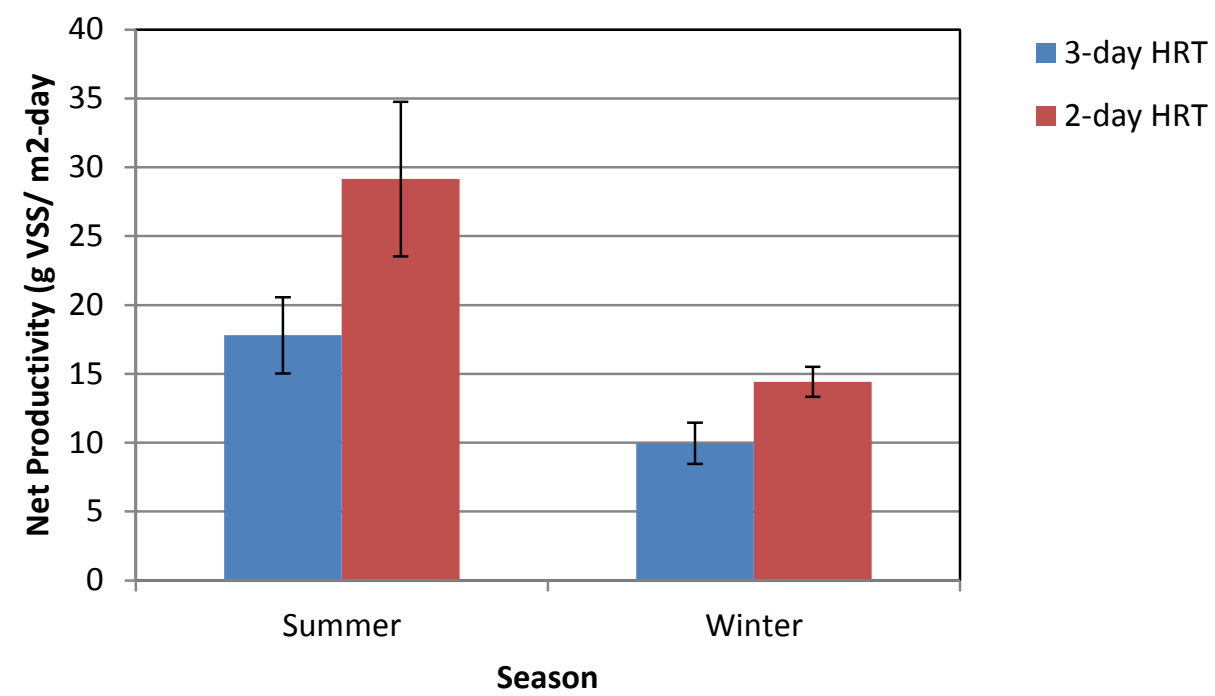

Figure 5-1: Summer and winter average productivity for the 2 and 3-day HRT ponds.

Table 5-1: Summer and winter average productivity and percent difference for the 2 and 3-day HRT ponds.

\begin{tabular}{lccccc} 
& & Standard & & Standard & \\
& 3-day HRT & Deviation & 2-day HRT & Deviation & \% Difference \\
\cline { 2 - 6 } Summer & 17.79 & 2.77 & 29.14 & 5.62 & $48 \%$ \\
Winter & 9.96 & 1.49 & 14.42 & 1.08 & $37 \%$ \\
\hline
\end{tabular}

In a large scale continuous flow system to achieve the maximum productivity, a 2-day HRT would be better than a 3-day HRT.

\subsubsection{Ponds-in-Series}

From here on in the Beta and Alpha ponds will be referred to as Round 1 and Round 2 respectively. Round 1 meaning the ponds that used primary clarifier effluent and Round 3 meaning the ponds that used settled algae pond effluent. Productivity in the Round 1 ponds was consistently higher than in Round 2 (Figure 5-2, Table 5-2). 


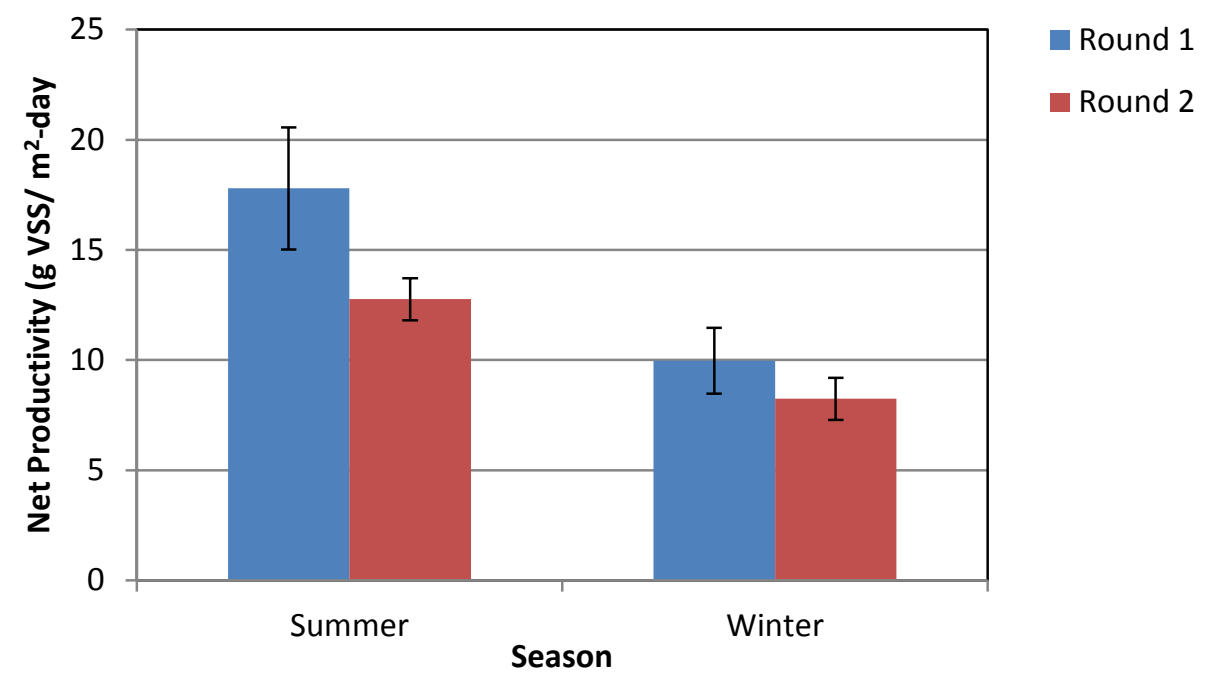

Figure 5-2: Seasonal productivity for Round 1 and Round 2 ponds.

Table 5-2: Average seasonal productivity for Round 1 and Round 2 ponds.

$\begin{array}{llll}\text { Round } & \text { Standard } & \text { Round } & \text { Standard } \\ 1 & \text { Deviation } & 2 & \text { Deviation } \% \text { difference }\end{array}$

\begin{tabular}{lrrrrr} 
Summer & 17.79 & 2.77 & 12.76 & 0.96 & $33 \%$ \\
Winter & 9.96 & 1.49 & 8.24 & 0.96 & $19 \%$ \\
\hline
\end{tabular}

In the summer productivity in Round 1 ponds was 33\% higher than Round 2, and in winter the Round 1 ponds were 19\% higher than Round 2. The reduced productivity in Round 2 could not be explained by nitrogen or phosphorus limitation. The lowest concentrations of soluble nitrogen and phosphorus in Round 2 never fell below the half saturation constants for algae, $0.0784 \mathrm{mg} / \mathrm{L}-\mathrm{N}$ and $0.0062 \mathrm{mg} / \mathrm{L}-\mathrm{P}$ (Fulton, 2009). Due to the unreliable nature of the Neptune $\mathrm{CO}_{2}$ system, carbon may have been limiting in Round 2 from January to April 2014. There may have also been trace metal limitations or allelopathic compounds present in Round 2 which caused productivity to be lower than Round 1. 
Despite low nutrient concentrations, the productivity in Round 2 was never more than one third less than that of the first round. During summer, the productivity in Round 2 reached as high as roughly $20 \mathrm{~g} \mathrm{VSS} / \mathrm{m}^{2}$-day. While this was lower than the productivity of Round 1at an identical time, it may be high enough to grow algae on used media without nutrient addition.

One major issue seen in the Round 2 ponds was poor settling performance (4.6). Flocs in the Round 2 ponds were small in comparison to the Round 1 ponds. The small floc size was most likely due to the low organic loading rate (Frost, 2008) into the pond. To achieve better settling flocs, and maximize biomass yield, nutrients should be supplemented into the ponds.

Biomass production could be accomplished in a two pond unit (Figure 5-3). 


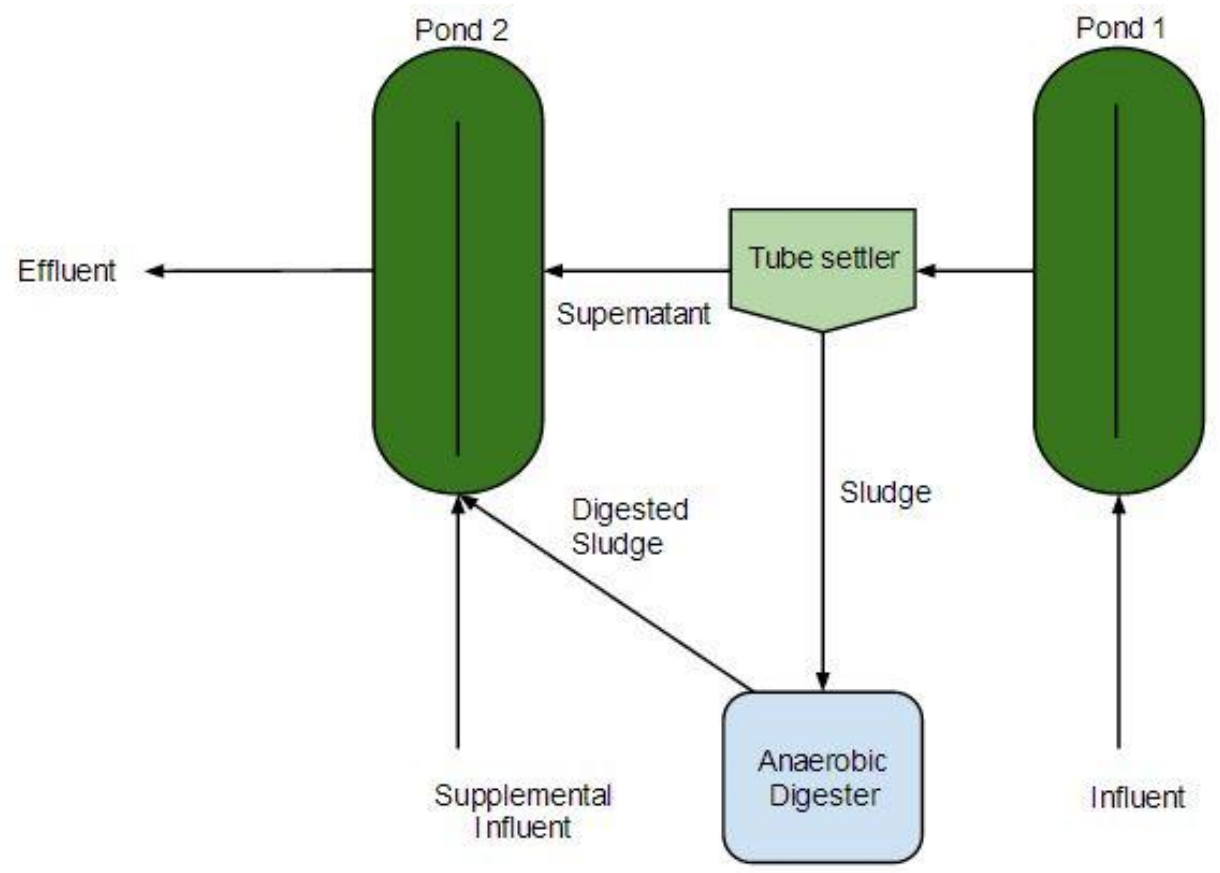

Figure 5-3: Possible two pond production schematic

The two pond configuration would allow algae to be grown in a series of ponds which uses nutrients and water more efficiently than a single pond. The second pond could have nutrients supplemented by the addition of digested sludge. Figure 5-3 shows a possible pond flow diagram for the minimum number of ponds needed to achieve recycling. More ponds, tube settlers, and anaerobic digesters could be put in place downstream of the second pond to grow additional biomass. Eventually nitrogen would become limiting due to ammonia volatilization. A multi-pond system would be more efficient than a single pond system because it would allow for a higher percent of total nutrients to be used. 


\subsubsection{Standpipe Performance}

The 3-day HRT ponds had no significant difference in TSS between the ponds with ramped standpipes and those with the 4-inch standpipe. This was most likely due to the small floc size in the 3-day HRT ponds. Small flocs stayed suspended in the water and were more easily washed out of the ponds regardless of standpipe design. The 2-day HRT

ponds had much larger flocs than the 3-day HRT ponds which caused a significant mass of algae to be retained in the ponds. In the 2-day HRT ponds from October 2, 2014 to April $17,2014, \mathrm{TSS}$ in the 4 -inch standpipe ponds was on average $35 \%$ higher than the ramped standpipes. For ponds with large floc characteristics (2-day HRT) ramped standpipe could prevent solids retention and accumulation.

\subsubsection{Aeration Experiments}

Pretreatment of algae sludge to lyse cells made no statistical difference in terms of solids degradation or nutrient release. The treated algae was $56 \% \pm 0.5 \%$ inert VSS, the untreated algae was $57 \% \pm 4.1 \%$ inert VSS.

Because pretreatment did not increase nutrient release, it would not be needed for a large scale production system. Lyseing of cells is an incredibly energy intensive process (Hill, 2014). To achieve nutrient solubilization and recycling without the need for lyseing represents a significant energy savings verses requiring cell lyseing. 


\subsection{Limitations of the Study}

The limitations of this study were as follows:

Pond operational limitations

1. All samples were taken as grab samples which only give a concentration at one point in time of the day.

2. Intermittent failure of tube settler pumps cause inconsistent feed to the Alpha ponds.

3. Neptune SCADA system malfunctioned from January to March 2014

Laboratory limitations

1. The method of determining organic nitrogen of the ponds was occasionally unreliable.

2. Possible trace metal limitations due to reverse osmosis dilution water

Experimental limitations

1. Algal and bacterial biomass were not differentiated in productivity calculations

2. Lack of control samples for the sonication aeration experiment.

3. Grab samples are only representative of the ponds at one time during the day. 


\subsection{Further research}

The research done for this thesis raised as many questions as it answered. Some areas requiring additional research include the following:

1. Set the ponds up for full scale water and nutrient recycling using a field anaerobic digestion to supplement nutrients. Full scale recycling would shed light on how efficiently water and nutrients could be used on a large scale. Sludge addition could have the added benefit of selecting for better settling algae in the ponds which may further increase nutrient and water recycling efficiency. (Ripley, 2013).

2. Determine the amount of sludge to supplement into the recycled ponds to make up the correct amount of nutrients.

3. Determine the number of ponds that can be operated in series to optimize nutrient use, and productivity. Because of ammonia volatilization, or the production of inhibitory compounds, the number of ponds that are possible to be effectively run in series is limited. The optimum number would allow for a system to be designed that would effectively use nutrients and produce the most biomass from the least amount of water.

4. Install ramped standpipes in all the Gamma ponds to see if the pond TSS converges to similar values. This would confirm that it was the 4-inch standpipes were the cause of the solids accumulation in the ponds.

5. Determine the effects solids retention has on removal of BOD, nitrogen, and phosphorus. This could be achieved by recycling settled solids into the ponds to control the solids retention time of the ponds. 


\section{Bibliography}

Boggess, C. (2014). Optimization of Growth Parameters for Algal Regrowth Potential Studies.

Cellana Inc. (2013). Technology: The ReNew Algae ${ }^{\mathrm{TM}}$ Solution. Retrieved April 9, 2014, from Cellana.com: http://cellana.com/technology/the-algae-solution/

DePinto, J. V., \& Verhoff, F. H. (1977). Nutrient Regeneration from Aerobic Decomposition of Green Algae. Environmental Science \& Technology, 11(4), 317377.

Eaton, A. D., Clesceri, L. S., \& Greenberg, A. E. (1995). Standard Methods for the Examination of Water and Wastewater. American Public Health Association.

EPA. (2012, 6 27). Ag 101: Phosphorus. Retrieved 5 28, 2014, from Environmental Protection Agency: http://www.epa.gov/oecaagct/ag101/impactphosphorus.html

Frost, D. T. (2008). Bioflocculation For Control of Wastewater Pond Microalgae.

Fulton, L. (2009). Nutrient Removal by Algae Grown in CO2-ENriched Wastewater over a Range of Nitrogen-to-Phosphorus Ratios.

Golueke, C., \& Oswald, W. J. (1965, April). Harvesting and PRocessing Sewage-Grown Planktonic Algae. Water Pollution Control Federation, 37(4), 471-489.

Hill, A. S. (2014). The Effect of Pretreatment Methods on Methane Yield and Nutrient Solubilization During Anaerobic Digestion of Microalgae.

Hugdahl, M. (2012, June 20). Ammonia: All You've Ever Wanted To Know. Retrieved May 2, 2014, from Lab Science News: http://www.labsciencenews.com/ammonia-allyouve-ever-wanted-to-know/ 
Huntley, M. E., \& G.Redalje, D. (2007, May). CO2 Mitigation and Renewable Oil from Photosynthetic Microbes: A New Appraisal. Mitigation and Adaptation Stratagies for Global Change, 12(4), 573-608.

Jewell, W. J., \& McCarty, P. L. (1971). Aerobic Decompostiton of Algae. Environmental Science and Technology, 5(10), 1023-1031.

Kelley, J. E. (2013). Lipid Production By Microalgae Treating Municipal Wastewater.

Kristiensen, E., Ahmend, S. I., \& Devol H, A. (1995). Aerobic and Anaerobic Decomposition of Organic Matter in Marine Sediment: Which is Faster? American Society of Limnology and Oceanography, 1430-1437.

Lefebvre, L. C. (2012). Bioflocculation of Wastewater Treatment Pond Suspended Solids.

Lundquist, T., Woertz, I., Quinn, N., \& Benemann, J. (2010). A Realistic Technology and Engineering Assessment of Algae Biofuel Production.

Metcalf \&Eddy, Inc. (2003). Wastewater Engineering Treatment and Reuse. New York: McGraw-Hill Companies, Inc.

Munoz, R., \& Guieysse, B. (2006, August). Algal-bacterial processes for treatment of hazardous contaminants: A review. Water Research, 40(15), 2799-2815.

National Renewable Energy Laboratory. (2014, Jan 22). Learning about Renewable Energy: Biofuel Basics. Retrieved April 9, 2014, from National Renewable Energy Laboratory: http://www.nrel.gov/learning/re_biofuels.html

NREL. (2008). Solar Maps. Retrieved April 22, 2014, from National Renewable Energy Laboratory: http://www.nrel.gov/gis/images/map_pv_us_annual10km_dec2008.jpg 
Oswald, W. J. (1990). Advanced Integrated Wastewater Pond System. 1990 ASCE Convention (pp. 73-81). San Francisco: ASCE.

Ripley, E. B. (2013). Settling Performance in Wastewater Fed High Rate Algae Ponds.

Robarts, R., \& Wetzel, R. (2002, 11 10). The Global Water and Nitrogen Cycles. Retrieved 5 9, 2014, from University of Michigan: http://www.globalchange.umich.edu/globalchange1/current/lectures/kling/water_ni tro/water_nitro.html

U.S. Department of Energy. (2012). Advancements in Sustainable Algal Production Funding Oppertunity Announcement. Washington D.C.: Department of Energy. Venteris, E. R., Skaggs, R. L., Coleman, A. M., \& Wignosta, M. S. (2013). A GIS Cost Model to Assess the vailability of Freshwater, Seawater, and Saline Groundwater for Algal Biofuel Production in the United States. Environmental Science and Technology, 4840-4849. 


\section{Appendix A.}

This appendix presented the standpipe trials which lead up to the final design of the ramped standpipe. These trials were necessary due to the discovery of solids accumulation in the ponds due to the 4-inch standpipe design (Ripley, 2013).

Several standpipe designs were tested to investigate discrepancies between pond water and effluent water.

First, a modification of the existing, conventional standpipes was tested. Four evenly spaced holes were drilled into the sides, roughly two inches below the water surface, and oriented in the direction of flow. Large flocs of algae clogged the holes shortly after inserting the standpipe preventing water from leaving the ponds through the holes.

Next a slanted, metallic fin was affixed to a one inch standpipe (Figure A-1).

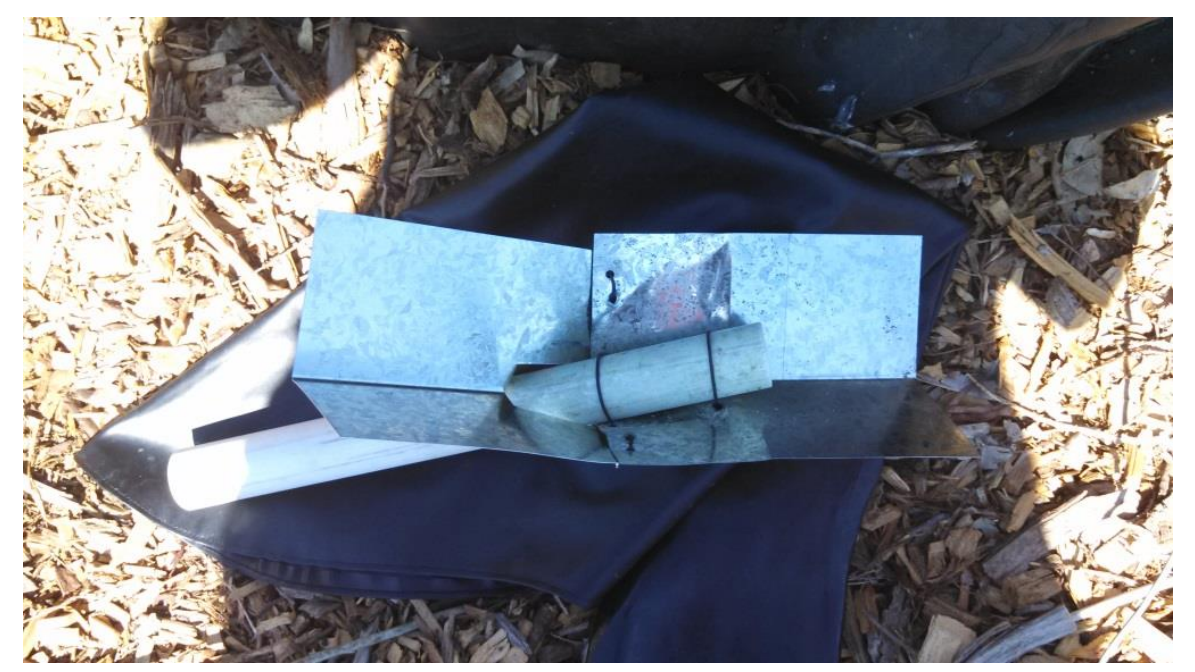

Figure A-1: Finned standpipe design, the fins were meant to allow the water to well up behind the standpipe and create a deeper wave. 
The fin was designed to increase the height of the standing wave overflowing into the standpipe. Two fin designs were tested. One design had a single fin behind the standpipe, extending from beneath the water level to several inches above the water level. The second design had a fin like the first, and also an additional fin extending deeper under the water surface ahead of the standpipe. The design was intended to not only increase the height of the standing wave overflowing the standpipe but also to retrieve solids from lower in the ponds that would otherwise be retained. Because this design used a small diameter opening it became clogged with duck feathers or algae flocs. The clogging would cause the ponds to periodically overflow if left unchecked for several hours.

Sampling of the 1-inch standpipes was done with a standard 70-mL screw cap test tube. The test tubes were placed in the standpipe and allowed to fill with water.

Error! Reference source not found.and show the results for solids testing of samples taken from the ponds and standpipes. The results show the 1 inch standpipes solids concentration of the water exiting the pond was not representative of the water in the ponds. Standpipe concentrations varied from that of the ponds, in both the positive and negative direction. All 1 inch stand pipes performed inconsistently between pond of the same set and different sets. This is most likely due to the different floc characteristics of the pond sets. Because this design was inconsistent another design had to be tested. 
Table A-1: Summation of results of grab samples and 1 inch standpipe samples for testing the 1 inch standpipe design, samples taken on August 9th, 2013

\begin{tabular}{|c|c|c|c|}
\hline Pond & $\begin{array}{c}\text { Sample } \\
\text { Type }\end{array}$ & $\begin{array}{c}\mathrm{TSS} \\
(\mathrm{mg} / \mathrm{L})\end{array}$ & $\begin{array}{c}\% \\
\text { Difference }\end{array}$ \\
\hline \multirow{3}{*}{ Pond 4} & $1 "$ & & \multirow{3}{*}{$-3 \%$} \\
\hline & Standpipe & 379.5 & \\
\hline & Grab & 370.0 & \\
\hline \multirow{3}{*}{ Pond 7} & $1 "$ & & \multirow{3}{*}{$11 \%$} \\
\hline & Standpipe & 309.4 & \\
\hline & Grab & 348.4 & \\
\hline \multirow{3}{*}{ Pond 8} & $1 "$ & & \multirow{3}{*}{$50 \%$} \\
\hline & Standpipe & 268.3 & \\
\hline & Grab & 534.4 & \\
\hline \multirow[t]{2}{*}{ Pond 9} & $\begin{array}{l}1 " \\
\text { Standpipe }\end{array}$ & 260.9 & \multirow[t]{2}{*}{$51 \%$} \\
\hline & Grab & 535.0 & \\
\hline
\end{tabular}


Table A-2: Summary of results of grab and standpipe samples for samples taken on August 16th, 2013

\begin{tabular}{cccc} 
Pond & Sample Type & $\begin{array}{c}\text { TSS } \\
(\mathrm{mg} / \mathrm{L})\end{array}$ & \% Difference \\
\hline \multirow{2}{*}{ Pond 1 } & 1" Standpipe & 265.25 & \multirow{2}{*}{ Grab } \\
& 253.52 & \\
Pond 4 & 1" Standpipe & 240.58 & \multirow{2}{*}{$18.4 \%$} \\
& Grab & 196.20 & \\
Pond 5 & 1" Standpipe & 237.40 & $15.3 \%$ \\
& Grab & 201.02 & \\
Pond 6 & 1" Standpipe & 230.27 & $-0.3 \%$ \\
& Grab & 230.95 & \\
Pond 7 & Single Fin & 219.28 & $0.1 \%$ \\
& Grab & 218.98 & \\
Pond 7 & Double Fin & 226.54 & $8.8 \%$ \\
& Grab & 248.36 & \\
Pond 8 & Single Fin & 188.30 & \multirow{2}{*}{$1.5 \%$} \\
& Grab & 185.42 & \\
Pond 9 & 1" Standpipe & 204.59 & $21.9 \%$ \\
\hline
\end{tabular}

shows the solids data for the ramped standpipe. One sample from each pond set was taken for this analysis. The ramped standpipe had over flow solids concentrations similar to that of the ponds regardless of pond set. Because of the greater consistency and reduced likely hood of clogging, the ramped standpipe design was chosen to be installed in the ponds for further evaluation. 
Table A-3: Summation of results of grab samples and trough samples for testing the ramped standpipe for samples taken on September 4, 2013.

\begin{tabular}{cccc} 
Pond & $\begin{array}{c}\text { Sample } \\
\text { Type }\end{array}$ & $\begin{array}{c}\text { TSS } \\
(\mathrm{mg} / \mathrm{L})\end{array}$ & \% Difference \\
\hline \multirow{2}{*}{ Pond 1 } & Ramp & 271.25 & $0.9 \%$ \\
& Grab & 273.75 & \\
\multirow{2}{*}{ Pond 4 } & Ramp & 410 & $0.3 \%$ \\
& Grab & 411.25 & \\
\multirow{2}{*}{ Pond 7 } & Ramp & 275 & \multirow{2}{*}{$1.4 \%$} \\
& Grab & 279 & \\
\hline
\end{tabular}




\section{Appendix B.}

This appendix outlined the nitrate interference suppressor solution (ISS) preparation procedure.

Into a 500-mL volumetric flask, fill about half way with DI water, add the following chemicals and shake to dissolve.

3.33 g Aluminum sulfate, $\mathrm{Al}_{2}\left(\mathrm{SO}_{4}\right) * 18 \mathrm{H}_{2} \mathrm{O}$

1.56 g Silver sulfate, $\mathrm{AgSO}_{4}$

$0.62 \mathrm{~g}$ Boric acid, $\mathrm{H}_{3} \mathrm{BO}_{3}$

0.96 g Sulfamic Acid, $\mathrm{NH}_{3} \mathrm{SO}_{3}$

Adjust the $\mathrm{pH}$ to 3 by adding $0.1 \mathrm{~N} \mathrm{NaOH}$. Dilute to $500 \mathrm{~mL}$ with DI water. 


\section{Appendix C.}

This appendix showed the raw solids data analyzed for this thesis. These data were used

for calculating net productivity, determining the presence or absence of solids accumulation in the ponds, and evaluation of settling performance of the ponds. 
Table C-1: 0-Hour TSS values for the influent and ponds.

Initial TSS

\begin{tabular}{|c|c|c|c|c|c|c|c|c|c|c|}
\hline Date & INF TSS & P1 TSS & P2 TSS & P3 TSS & P4 TSS & P5 TSS & P6 TSS & P7 TSS & P8 TSS & P9 TSS \\
\hline 2013/03/06 & 64.72 & 166.11 & 164.73 & 121.93 & 185.33 & 233.97 & 201.90 & 267.79 & 137.10 & 219.26 \\
\hline 2013/03/13 & 53.39 & 170.05 & 197.02 & 123.63 & 212.84 & 202.42 & 185.79 & 159.37 & 166.97 & 256.82 \\
\hline $2013 / 03 / 20$ & 32.83 & 138.64 & 227.27 & 120.45 & 215.91 & 220.45 & 188.64 & 209.09 & 132.35 & 267.65 \\
\hline \multicolumn{11}{|l|}{$2013 / 03 / 27$} \\
\hline 2013/04/04 & 65.35 & 272.85 & 260.62 & 181.13 & 249.62 & 296.14 & 165.83 & 187.53 & 201.59 & 287.06 \\
\hline 2013/04/11 & 58.02 & 264.06 & 409.95 & 204.50 & 251.35 & 315.10 & 255.98 & 526.26 & 223.22 & 216.56 \\
\hline 2013/04/18 & 62.01 & 267.01 & 299.91 & 261.66 & 356.18 & 455.04 & 411.97 & 239.46 & 214.26 & 286.90 \\
\hline $2013 / 04 / 25$ & 65.20 & 163.92 & 227.28 & 165.98 & 444.09 & 468.70 & 402.84 & 317.41 & 948.73 & 554.55 \\
\hline 2013/05/02 & 67.61 & 167.13 & 232.73 & 203.69 & 402.16 & 418.32 & 322.59 & 381.15 & & 470.50 \\
\hline 2013/05/09 & 58.72 & 351.69 & 310.84 & 126.61 & 308.64 & 325.39 & 326.69 & 410.24 & 936.35 & 325.15 \\
\hline 2013/05/16 & 57.09 & 224.58 & 218.12 & 213.36 & 189.25 & 216.37 & 256.43 & 250.00 & 313.98 & 190.75 \\
\hline $2013 / 05 / 23$ & 46.01 & 215.82 & 204.93 & 162.11 & 254.10 & 297.67 & 246.58 & 124.29 & 345.75 & 251.28 \\
\hline 2013/05/30 & 50.69 & 267.62 & 191.08 & 216.64 & 269.98 & 278.51 & 256.21 & 232.37 & 336.29 & 246.70 \\
\hline 2013/06/06 & 138.72 & 278.87 & 222.46 & 265.42 & 252.97 & 332.93 & 275.87 & 271.65 & 320.52 & 271.70 \\
\hline 2013/06/13 & 69.87 & 244.22 & 222.61 & 279.64 & 246.56 & 297.21 & 291.23 & & & \\
\hline \multicolumn{11}{|l|}{$2013 / 06 / 20$} \\
\hline $2013 / 06 / 26$ & 45.56 & 386.36 & 243.18 & 193.18 & 325.00 & 353.13 & 293.18 & 308.00 & 263.16 & 302.17 \\
\hline 2013/07/03 & 75.56 & 245.45 & 163.64 & 229.55 & 290.00 & 190.00 & 254.55 & 281.25 & 177.78 & 215.22 \\
\hline \multicolumn{11}{|l|}{ 2013/07/10 } \\
\hline 2013/07/17 & 46.67 & 281.82 & 229.55 & 231.82 & 315.91 & 425.00 & 247.73 & 220.00 & 284.21 & 206.52 \\
\hline $2013 / 07 / 24$ & 44.44 & 259.09 & 286.36 & 309.09 & 300.00 & 346.87 & 279.55 & 314.00 & 313.16 & 291.30 \\
\hline 2013/07/31 & 54.00 & 240.91 & 284.09 & 272.73 & 428.57 & 373.33 & 252.27 & 340.91 & 365.79 & 276.09 \\
\hline 2013/08/07 & 65.81 & 215.91 & 270.45 & 188.64 & 269.05 & 293.33 & 402.27 & 282.41 & 481.58 & 497.73 \\
\hline 2013/08/14 & 51.00 & 269.57 & 265.91 & 240.48 & 321.74 & 286.91 & 300.00 & 273.68 & 252.63 & 287.57 \\
\hline 2013/08/21 & 43.00 & 206.52 & 213.64 & 209.52 & 239.13 & 225.00 & 209.37 & 107.89 & 92.11 & 50.00 \\
\hline 2013/08/29 & 50.71 & 331.54 & 310.88 & 302.63 & 386.84 & 316.76 & 422.50 & 302.08 & 191.01 & 135.00 \\
\hline 2013/09/04 & 55.71 & 228.48 & 268.18 & 261.90 & 367.39 & 335.00 & 281.25 & 228.95 & 142.11 & 110.00 \\
\hline 2013/09/11 & 47.86 & 325.83 & 232.61 & 259.51 & 180.71 & 215.00 & 261.76 & 252.27 & 81.58 & 130.00 \\
\hline 2013/09/18 & 53.00 & 226.32 & 227.50 & 254.76 & 215.22 & 252.50 & 223.68 & 407.89 & 158.33 & 163.16 \\
\hline 2013/09/25 & 64.29 & 265.79 & 227.49 & 252.50 & 200.00 & 267.50 & 160.00 & 192.50 & 187.50 & 195.00 \\
\hline 2013/10/02 & 82.14 & 240.00 & 282.50 & 250.00 & 290.00 & 365.00 & 302.50 & 210.00 & 390.00 & 390.00 \\
\hline 2013/10/09 & 47.86 & 214.76 & 87.86 & 197.50 & 295.00 & 57.50 & 345.00 & 215.00 & 287.50 & 265.00 \\
\hline 2013/10/16 & 43.57 & 200.12 & 165.00 & 190.00 & 278.57 & 252.50 & 317.50 & 220.00 & 282.50 & 232.50 \\
\hline $2013 / 10 / 23$ & 55.71 & 195.00 & 165.00 & 182.50 & 235.00 & 255.00 & 232.50 & 207.50 & 260.00 & 265.00 \\
\hline 2013/10/30 & 182.50 & 147.50 & 141.74 & 140.00 & 175.00 & 195.83 & 175.00 & 195.00 & 267.50 & 227.50 \\
\hline 2013/11/06 & 43.57 & 150.00 & 150.00 & 165.00 & 80.00 & 137.50 & 120.00 & 162.50 & 107.50 & 152.50 \\
\hline $2013 / 11 / 13$ & 62.86 & 107.50 & 137.50 & 150.00 & 200.00 & 195.00 & 205.00 & 215.00 & 135.00 & 150.00 \\
\hline $2013 / 11 / 20$ & 61.33 & 131.43 & 133.33 & 158.33 & 155.00 & 180.00 & 180.00 & 213.33 & 148.33 & 185.00 \\
\hline $2013 / 11 / 25$ & 71.87 & 125.00 & 138.33 & 176.67 & 173.33 & 151.67 & 135.00 & 186.67 & 101.67 & 153.33 \\
\hline 2013/12/04 & 60.00 & 110.00 & 107.92 & 127.50 & 158.75 & 133.75 & 111.25 & 238.33 & 121.67 & 105.00 \\
\hline 2013/12/11 & 70.71 & 91.67 & 111.67 & 101.67 & 216.67 & 215.00 & 193.33 & 318.33 & 155.00 & 135.00 \\
\hline $2013 / 12 / 18$ & 77.14 & 83.33 & 85.00 & 88.33 & 70.00 & 136.67 & 126.67 & 175.00 & 61.67 & 116.67 \\
\hline \multicolumn{11}{|l|}{$2013 / 12 / 25$} \\
\hline \multicolumn{11}{|l|}{$2014 / 01 / 01$} \\
\hline 2014/01/08 & 68.57 & 123.33 & 118.33 & 126.67 & 150.00 & 210.00 & 202.00 & 196.00 & 124.00 & 114.00 \\
\hline 2014/01/15 & 60.71 & 170.00 & 121.67 & 100.00 & 182.00 & 147.50 & 220.00 & 202.00 & 150.00 & 162.00 \\
\hline $2014 / 01 / 22$ & 73.57 & 125.00 & 141.67 & 153.33 & 184.00 & 160.00 & 220.00 & 190.00 & 126.00 & 132.00 \\
\hline $2014 / 01 / 29$ & 84.00 & 151.67 & 154.29 & 157.14 & 158.33 & 170.00 & 198.00 & 291.67 & 178.33 & 191.67 \\
\hline 2014/02/05 & 71.33 & 160.00 & 147.14 & 257.14 & 170.00 & 192.00 & 154.00 & 238.33 & 151.67 & 181.67 \\
\hline $2014 / 02 / 12$ & 54.67 & 138.33 & 125.71 & 162.86 & 171.67 & & 258.00 & 203.33 & 120.00 & 161.67 \\
\hline 2014/02/19 & 62.00 & 143.33 & 140.00 & 175.71 & 218.33 & 220.00 & 306.00 & 225.00 & 175.00 & 201.67 \\
\hline $2014 / 02 / 26$ & 111.33 & 178.33 & 174.29 & 180.00 & 255.00 & 256.00 & 302.00 & 286.67 & 165.00 & 168.33 \\
\hline $2014 / 03 / 05$ & 140.00 & 110.00 & 110.00 & 140.00 & 215.00 & 192.00 & 292.00 & 311.67 & 138.33 & 155.00 \\
\hline 2014/03/12 & 66.00 & 141.67 & 148.57 & 164.29 & 261.67 & 234.00 & 346.00 & 263.33 & 196.67 & 201.67 \\
\hline 2014/03/19 & 63.33 & 128.33 & 142.86 & 178.57 & 290.00 & 214.00 & 274.00 & 491.67 & 211.67 & 196.67 \\
\hline $2014 / 04 / 03$ & 52.86 & 98.33 & 98.57 & 153.33 & 220.00 & 142.00 & 236.00 & 340.00 & 191.67 & 173.33 \\
\hline $2014 / 04 / 10$ & 62.14 & 853.33 & 524.29 & 182.00 & 320.00 & 200.00 & 372.00 & 454.00 & 206.67 & 218.33 \\
\hline $2014 / 04 / 17$ & 62.14 & 853.33 & 524.29 & 182.00 & 320.00 & 200.00 & 372.00 & 454.00 & 206.67 & 218.33 \\
\hline
\end{tabular}


Table C-2: 0-Hour VSS values for influent and the ponds.

Initial VSS

\begin{tabular}{|c|c|c|c|c|c|c|c|c|c|c|}
\hline Date & NF VSS & $\mathrm{P} 1$ & P2 VSS & VSS & VSS & P5 VSS & P6 VSS & P7 VSS & P8 VSS & $\mathrm{P} 9 \mathrm{~V}$ \\
\hline 2013/03/06 & 61.90 & 160.48 & 151.29 & 118.92 & 177.61 & 208.46 & 186.40 & 238.52 & 125.00 & 184.54 \\
\hline $2013 / 03 / 13$ & 51.28 & 159.21 & 175.36 & 86.39 & 194.41 & 174.08 & 161.38 & 134.02 & 140.52 & 225.16 \\
\hline $2013 / 03 / 20$ & 28.83 & 120.45 & 193.18 & 104.55 & 179.55 & 190.91 & 163.64 & 170.45 & 105.88 & 229.41 \\
\hline \multicolumn{11}{|l|}{$2013 / 03 / 27$} \\
\hline $2013 / 04 / 04$ & 55.64 & 255.94 & 240.76 & 165.50 & 232.70 & 262.30 & 143.46 & 171.43 & 175.34 & 247.43 \\
\hline $2013 / 04 / 11$ & & & 376.33 & & 251.87 & 304.10 & 246.37 & 518.49 & 206.31 & 206.35 \\
\hline 2013/04/18 & 54.47 & 266.59 & 295.54 & 250.60 & 327.34 & 418.46 & 371.24 & 226.17 & 209.97 & 266.67 \\
\hline $2013 / 04 / 25$ & 64.10 & 159.81 & 223.35 & 163.86 & 371.00 & 410.09 & 349.39 & 273.89 & 835.56 & 509.17 \\
\hline $2013 / 05 / 02$ & 67.61 & 140.28 & 225.08 & 190.91 & 367.42 & 368.86 & 305.70 & 333.32 & & 432.65 \\
\hline $2013 / 05 / 09$ & & 312.56 & 300.21 & & 282.26 & 289.52 & 300.08 & 387.87 & 842.30 & 297.38 \\
\hline 2013/05/16 & 52.88 & 196.84 & 188.65 & 187.53 & 166.77 & 194.16 & 219.76 & 220.45 & 308.29 & 169.03 \\
\hline $2013 / 05 / 23$ & 54.56 & 234.20 & 208.74 & 173.84 & 263.89 & 284.40 & 237.43 & 147.62 & 333.96 & 264.15 \\
\hline $2013 / 05 / 30$ & 60.81 & 297.25 & 183.96 & 205.61 & 265.22 & 276.32 & 236.84 & 226.85 & 321.06 & 255.59 \\
\hline 2013/06/06 & 121.82 & 250.40 & 207.41 & 246.56 & 246.37 & 301.79 & 247.35 & 246.39 & 287.54 & 240.66 \\
\hline 2013/06/13 & & & 218.18 & & 236.36 & & 282.16 & & & \\
\hline \multicolumn{11}{|l|}{$2013 / 06 / 20$} \\
\hline $2013 / 06 / 26$ & 48.89 & 318.18 & 227.27 & 184.09 & 295.45 & 306.25 & 263.64 & 272.00 & 228.95 & 265.22 \\
\hline 2013/07/03 & & 222.73 & 147.73 & 206.82 & 260.00 & 173.33 & & 243.75 & 152.78 & 189.13 \\
\hline \multicolumn{11}{|l|}{$2013 / 07 / 10$} \\
\hline 2013/07/17 & 65.56 & 286.36 & 209.09 & 227.27 & 309.09 & 453.12 & 220.45 & 186.00 & 234.21 & 167.39 \\
\hline $2013 / 07 / 24$ & & 245.45 & 254.55 & 286.36 & 277.27 & 337.50 & & 264.40 & 257.89 & 258.70 \\
\hline $2013 / 07 / 31$ & & & & & 411.90 & 362.67 & & 336.36 & 360.53 & 269.57 \\
\hline 2013/08/07 & & & 261.36 & 175.00 & 254.76 & & 370.45 & 273.12 & 447.37 & 442.59 \\
\hline 2013/08/14 & 23.00 & 245.65 & 247.73 & 228.57 & 302.17 & 267.35 & 300.00 & & 242.11 & 260.23 \\
\hline $2013 / 08 / 21$ & 42.00 & 193.48 & 202.27 & 192.86 & 241.30 & 222.50 & & & & 51.00 \\
\hline $2013 / 08 / 29$ & 47.14 & 305.72 & 284.12 & 283.28 & 352.63 & 284.48 & 385.00 & 274.46 & 177.77 & 132.50 \\
\hline $2013 / 09 / 04$ & 53.57 & 206.74 & 240.91 & 242.86 & & 295.00 & 253.12 & 215.79 & 123.68 & 107.50 \\
\hline 2013/09/11 & 45.00 & 223.46 & 208.70 & 238.22 & 163.45 & 197.74 & 234.45 & 216.82 & 62.03 & 115.00 \\
\hline $2013 / 09 / 18$ & 51.00 & 205.26 & 205.00 & 252.38 & 208.70 & 240.00 & 213.16 & 371.05 & 172.22 & 165.79 \\
\hline $2013 / 09 / 25$ & 62.86 & 252.63 & 226.32 & 240.00 & 194.74 & 210.00 & 155.00 & 187.50 & 175.00 & 212.50 \\
\hline 2013/10/02 & 73.57 & 225.00 & 210.00 & 237.50 & 257.50 & 322.50 & 267.50 & 192.50 & 337.50 & 345.00 \\
\hline 2013/10/09 & 45.71 & 205.00 & 107.26 & 192.50 & 280.00 & 75.00 & 322.50 & 222.50 & 275.00 & 242.50 \\
\hline 2013/10/16 & 28.57 & 183.10 & 140.00 & 170.00 & 247.62 & 225.00 & 287.50 & 200.00 & 257.50 & 217.50 \\
\hline $2013 / 10 / 23$ & 51.43 & 180.00 & 145.00 & 157.50 & 192.50 & 217.50 & 185.00 & 172.50 & 215.00 & 227.50 \\
\hline $2013 / 10 / 30$ & 172.50 & 140.00 & 125.00 & 140.00 & 162.50 & 181.67 & 162.50 & 170.00 & 235.00 & 195.00 \\
\hline 2013/11/06 & 41.43 & 140.00 & 137.50 & 160.00 & 85.00 & 135.00 & 115.00 & 150.00 & 100.00 & 145.00 \\
\hline 2013/11/13 & 61.43 & 112.50 & 130.00 & 155.00 & 185.00 & 177.50 & 190.00 & 185.00 & 122.50 & 137.50 \\
\hline $2013 / 11 / 20$ & 57.33 & 114.29 & 118.33 & 150.00 & 136.67 & 155.00 & 156.67 & 180.00 & 126.67 & 158.33 \\
\hline $2013 / 11 / 25$ & 65.00 & 116.67 & 123.33 & 163.33 & 160.00 & 136.67 & 125.00 & 163.33 & 88.33 & 131.67 \\
\hline 2013/12/04 & 56.87 & 110.00 & 105.42 & 125.00 & 150.00 & 121.25 & 105.00 & 213.33 & 110.00 & 98.33 \\
\hline 2013/12/11 & 62.86 & 86.67 & 103.33 & 91.67 & 195.00 & 183.33 & 166.67 & 265.00 & 131.67 & 123.33 \\
\hline $2013 / 12 / 18$ & 73.57 & 81.67 & & & & 126.67 & 118.33 & 158.33 & 61.67 & 110.00 \\
\hline \multicolumn{11}{|l|}{$2013 / 12 / 25$} \\
\hline \multicolumn{11}{|l|}{ 2014/01/01 } \\
\hline 2014/01/08 & 63.57 & 118.33 & 116.67 & 113.33 & 142.00 & 196.00 & 184.00 & 178.00 & 116.00 & 108.00 \\
\hline 2014/01/15 & 55.00 & 145.00 & 113.33 & 93.33 & 158.00 & 125.00 & 162.50 & 174.00 & 134.00 & 136.00 \\
\hline $2014 / 01 / 22$ & 68.57 & 118.33 & 133.33 & 133.33 & 152.00 & 122.50 & 180.00 & 174.00 & 112.00 & 112.00 \\
\hline $2014 / 01 / 29$ & 73.33 & 133.33 & 135.71 & 141.43 & 131.67 & 146.00 & 170.00 & 241.67 & 155.00 & 161.67 \\
\hline $2014 / 02 / 05$ & 60.67 & 156.67 & 142.86 & 170.00 & 160.00 & 178.00 & 148.00 & 208.33 & 143.33 & 171.67 \\
\hline $2014 / 02 / 12$ & 50.00 & 161.67 & 128.57 & 184.29 & 165.00 & & 248.00 & 201.67 & 113.33 & 160.00 \\
\hline $2014 / 02 / 19$ & 60.00 & 146.67 & 140.00 & 182.86 & 203.33 & 212.00 & 280.00 & 203.33 & 160.00 & 180.00 \\
\hline $2014 / 02 / 26$ & & & & & 241.67 & 236.00 & 282.00 & 261.67 & 160.00 & 165.00 \\
\hline $2014 / 03 / 05$ & 133.33 & 101.67 & 100.00 & 134.29 & 191.67 & 172.00 & 252.00 & 265.00 & 128.33 & 135.00 \\
\hline $2014 / 03 / 12$ & 60.00 & 125.00 & 130.00 & 152.86 & 225.00 & 200.00 & 294.00 & 220.00 & 160.00 & 165.00 \\
\hline $2014 / 03 / 19$ & 59.33 & 118.33 & 128.57 & 161.43 & 258.33 & 198.00 & 250.00 & 431.67 & 193.33 & 178.33 \\
\hline 2014/04/03 & 50.71 & 93.33 & 90.00 & 153.33 & 200.00 & 138.00 & 214.00 & 298.00 & 168.33 & 158.33 \\
\hline & & 116.67 & 112.86 & 170.00 & 282.00 & 178.00 & 322.00 & 370.00 & 183.33 & 190.00 \\
\hline 2014/04/17 & 55.71 & 116.67 & 112.86 & 170.00 & 282.00 & 178.00 & 322.00 & 370.00 & 183.33 & 190.00 \\
\hline
\end{tabular}


Table C-3: 2-Hour supernatant solids for all ponds.

2 HR

\begin{tabular}{|c|c|c|c|c|c|c|c|c|c|}
\hline Date & P1 2hr TSS & P2 2hr TSS & P3 2hr TSS & P4 2hr TSS & P5 2hr TSS & P6 2hr TSS & P7 2hr TSS & P8 2hr TSS & P9 2hr TSS \\
\hline $2013 / 03 / 06$ & 102.00 & 48.00 & 64.00 & 11.33 & 29.00 & 28.00 & 84.62 & 44.00 & 16.00 \\
\hline 2013/03/13 & 94.00 & 58.00 & 38.00 & 25.00 & 35.00 & 18.00 & 46.00 & 44.00 & 12.00 \\
\hline $2013 / 03 / 20$ & 52.00 & 48.00 & 41.00 & 46.00 & 56.00 & 15.00 & 46.00 & 24.00 & 34.00 \\
\hline \multicolumn{10}{|l|}{ 2013/03/27 } \\
\hline 2013/04/04 & 152.00 & 64.00 & 27.00 & 56.00 & 51.00 & 10.67 & 36.00 & 34.00 & 17.33 \\
\hline 2013/04/11 & 84.00 & 82.00 & 24.00 & 66.00 & 48.00 & 11.00 & 76.00 & 14.00 & 6.00 \\
\hline $2013 / 04 / 18$ & 48.00 & 102.00 & 32.00 & 60.00 & 29.00 & 28.00 & 39.00 & 8.00 & 8.00 \\
\hline $2013 / 04 / 25$ & 30.00 & 40.00 & 20.00 & 24.00 & 12.00 & 32.00 & 38.00 & 20.00 & 16.00 \\
\hline 2013/05/02 & 38.00 & 59.00 & 55.00 & 36.00 & 32.00 & 52.00 & 38.00 & & 38.00 \\
\hline 2013/05/09 & 22.00 & 17.00 & 35.00 & 17.00 & 21.00 & 38.00 & 32.00 & 1.33 & 29.00 \\
\hline $2013 / 05 / 16$ & 37.33 & 37.00 & 42.00 & 12.00 & 22.00 & 48.00 & 20.00 & 8.00 & 13.00 \\
\hline $2013 / 05 / 23$ & 17.00 & 25.00 & 31.00 & 12.00 & 13.00 & 49.00 & 60.00 & 10.00 & 17.00 \\
\hline 2013/05/30 & 16.00 & 14.67 & 24.00 & 19.00 & 13.00 & 38.00 & 20.00 & 7.33 & 10.00 \\
\hline 2013/06/06 & 11.93 & 13.07 & 50.10 & 17.00 & 32.80 & 53.60 & 23.40 & 12.27 & 16.50 \\
\hline 2013/06/13 & 14.67 & 20.00 & 63.00 & 4.67 & 47.00 & 44.00 & & & \\
\hline \multicolumn{10}{|l|}{$2013 / 06 / 20$} \\
\hline 2013/06/26 & 16.00 & 14.67 & 37.33 & 24.00 & 56.00 & 18.67 & 25.50 & 24.67 & 24.67 \\
\hline 2013/07/03 & 10.00 & 10.67 & 16.67 & 6.67 & 33.00 & 66.00 & 30.00 & 32.00 & 13.33 \\
\hline \multicolumn{10}{|l|}{ 2013/07/10 } \\
\hline 2013/07/17 & 24.00 & 19.33 & 24.00 & 18.00 & 17.00 & 100.00 & 75.00 & 7.33 & 29.00 \\
\hline $2013 / 07 / 24$ & 54.00 & 36.00 & 41.00 & 26.67 & 59.00 & 26.00 & 50.00 & 22.67 & 32.00 \\
\hline 2013/07/31 & 42.67 & 26.00 & 24.00 & 18.67 & 27.00 & 28.00 & 61.00 & 14.00 & 18.00 \\
\hline 2013/08/07 & 40.00 & 19.33 & 11.00 & 6.67 & 12.67 & 9.00 & 16.00 & 8.67 & 13.33 \\
\hline 2013/08/14 & 48.00 & 31.33 & 13.33 & 13.33 & 19.33 & 24.00 & 18.00 & 10.00 & 15.33 \\
\hline 2013/08/21 & 68.00 & 58.00 & 40.00 & 46.00 & 21.33 & 70.00 & 24.00 & 33.00 & 22.00 \\
\hline 2013/08/29 & 59.00 & 72.00 & 58.00 & 74.00 & 15.00 & 41.00 & 39.00 & 37.00 & 42.00 \\
\hline 2013/09/04 & 75.00 & 63.00 & 61.00 & 54.00 & 47.00 & 32.67 & 44.00 & 54.00 & 48.00 \\
\hline 2013/09/11 & 74.00 & 45.00 & 46.00 & 29.00 & 49.00 & 30.00 & 21.33 & 77.00 & 73.00 \\
\hline 2013/09/18 & 86.00 & 76.00 & 94.00 & 106.00 & 80.00 & 115.00 & 52.00 & 98.00 & 116.00 \\
\hline $2013 / 09 / 25$ & 90.00 & 78.00 & 70.00 & 76.00 & 49.00 & 27.33 & 34.00 & 118.00 & 122.00 \\
\hline 2013/10/02 & 63.00 & 50.00 & 44.00 & 56.00 & 34.00 & 30.00 & 44.00 & 38.00 & 70.00 \\
\hline 2013/10/09 & 50.00 & 43.00 & 48.00 & 38.00 & 15.33 & 47.00 & 74.00 & 15.33 & 30.00 \\
\hline 2013/10/16 & 45.00 & 43.00 & 47.00 & 32.67 & 29.00 & 36.00 & 46.00 & 20.00 & 37.33 \\
\hline $2013 / 10 / 23$ & 63.00 & 44.00 & 64.00 & 54.00 & 55.00 & 40.00 & 62.00 & 17.33 & 18.00 \\
\hline 2013/10/30 & 39.00 & 37.00 & 59.00 & 32.67 & 53.00 & 30.00 & 26.67 & 14.00 & 14.67 \\
\hline 2013/11/06 & 65.00 & 61.00 & 102.00 & 59.00 & 64.00 & 69.00 & 42.00 & 8.00 & 22.00 \\
\hline 2013/11/13 & 75.00 & 45.33 & 80.00 & 37.33 & 40.67 & 51.00 & 46.00 & 8.67 & 19.33 \\
\hline $2013 / 11 / 20$ & 49.00 & 36.00 & 57.00 & 42.67 & 30.67 & 30.67 & 37.00 & 15.33 & 40.00 \\
\hline \multicolumn{10}{|l|}{$2013 / 11 / 25$} \\
\hline $2013 / 12 / 04$ & 37.00 & 41.00 & 46.00 & 66.00 & 13.33 & 28.00 & 31.33 & 18.00 & 23.33 \\
\hline 2013/12/11 & 28.00 & 36.00 & 36.00 & 46.00 & 11.33 & 21.00 & 22.00 & 18.00 & 27.00 \\
\hline $2013 / 12 / 18$ & 65.00 & 50.00 & 68.00 & 48.00 & 11.33 & 6.67 & 24.00 & 34.67 & 25.00 \\
\hline \multicolumn{10}{|l|}{$2013 / 12 / 25$} \\
\hline \multicolumn{10}{|l|}{ 2014/01/01 } \\
\hline 2014/01/08 & 51.00 & 44.00 & 50.00 & 9.33 & 54.00 & 11.33 & 20.00 & 25.00 & 44.00 \\
\hline $2014 / 01 / 15$ & 68.00 & 62.00 & 60.00 & 37.00 & 23.00 & 22.00 & 30.00 & 22.00 & 56.00 \\
\hline $2014 / 01 / 22$ & 58.00 & 82.00 & 98.00 & 44.00 & 23.00 & 36.00 & 50.00 & 32.00 & 35.00 \\
\hline $2014 / 01 / 29$ & 91.00 & 69.00 & 112.00 & 48.00 & 94.00 & 54.00 & 24.00 & 54.00 & 38.00 \\
\hline $2014 / 02 / 05$ & 49.00 & 55.00 & 90.00 & 41.00 & 16.67 & 32.00 & 21.00 & 38.00 & 28.00 \\
\hline $2014 / 02 / 12$ & 34.00 & 61.00 & 88.00 & 38.00 & 22.00 & 48.00 & 30.67 & 49.00 & 38.00 \\
\hline 2014/02/19 & 54.00 & 53.00 & 86.00 & 84.00 & 42.00 & 54.00 & 27.00 & 44.00 & 42.00 \\
\hline $2014 / 02 / 26$ & 54.00 & 48.00 & 80.00 & 88.00 & 47.00 & 40.00 & 14.00 & 31.00 & 42.00 \\
\hline 2014/03/05 & 24.00 & 36.00 & 40.00 & 44.00 & 24.00 & 10.00 & 14.00 & 20.00 & 32.00 \\
\hline 2014/03/12 & 48.00 & 46.00 & 80.00 & 84.00 & 40.00 & 17.00 & 8.67 & 15.00 & 36.00 \\
\hline 2014/03/19 & 80.00 & 41.00 & 45.00 & 67.00 & 24.00 & 24.67 & 27.00 & 66.00 & 42.00 \\
\hline 2014/04/03 & \multicolumn{9}{|c|}{2 hours solids not run this week } \\
\hline $2014 / 04 / 10$ & 24.00 & 24.00 & 66.00 & 47.00 & 8.00 & 11.33 & 16.67 & 50.00 & 65.00 \\
\hline $2014 / 04 / 17$ & 24.00 & 24.00 & 66.00 & 47.00 & 8.00 & 11.33 & 16.67 & 50.00 & 65.00 \\
\hline
\end{tabular}


Table C-4: 24-Hour supernatant solids for all ponds.

$24 \mathrm{HR}$

\begin{tabular}{|c|c|c|c|c|c|c|c|c|c|}
\hline Date & P1 24hr TSS & P2 24hr TSS & P3 24hr TSS & P4 24hr TSS & P5 24hr TSS & P6 24hr TSS & P7 24hr TSS & P8 24hr TSS & P9 24hr TSS \\
\hline 2013/03/06 & 38.67 & 18.67 & 37.33 & 4.67 & 7.33 & 4.67 & 27.33 & 17.33 & 12.00 \\
\hline 2013/03/13 & 36.00 & 28.67 & 12.00 & 7.33 & 13.33 & 15.33 & 11.33 & 16.67 & 8.00 \\
\hline $2013 / 03 / 20$ & 12.67 & 12.67 & 14.00 & 24.00 & 23.33 & 3.33 & 19.33 & 9.33 & 13.33 \\
\hline \multicolumn{10}{|l|}{$2013 / 03 / 27$} \\
\hline 2013/04/04 & 26.00 & 14.00 & 6.00 & 12.00 & 20.00 & 3.33 & 16.67 & 9.33 & 5.33 \\
\hline 2013/04/11 & 26.00 & 33.00 & 18.00 & 18.67 & 14.67 & 6.00 & 18.67 & 4.67 & 7.33 \\
\hline 2013/04/18 & 30.67 & 39.33 & 18.67 & 30.67 & 19.33 & 13.33 & 18.67 & 8.00 & 6.67 \\
\hline $2013 / 04 / 25$ & 10.00 & 16.67 & 15.33 & 9.33 & 9.33 & 10.00 & 14.00 & 7.33 & 6.00 \\
\hline $2013 / 05 / 02$ & 16.67 & 14.67 & 10.00 & 23.33 & 0.00 & 24.67 & 26.67 & 36.00 & 20.67 \\
\hline 2013/05/09 & 12.67 & 10.00 & 23.33 & 16.00 & 11.33 & 19.33 & 16.67 & 5.33 & 10.00 \\
\hline 2013/05/16 & 8.00 & 17.33 & 19.33 & 5.33 & 7.33 & 16.00 & 2.67 & 4.67 & 1.33 \\
\hline $2013 / 05 / 23$ & 7.33 & 24.00 & 30.67 & 10.00 & 15.33 & 26.00 & 22.00 & 7.33 & 6.00 \\
\hline $2013 / 05 / 30$ & 6.67 & 4.67 & 22.67 & 16.00 & 2.67 & 27.33 & 8.67 & 2.00 & 5.33 \\
\hline 2013/06/06 & 7.20 & 5.67 & 22.80 & 6.40 & 20.27 & 25.00 & 4.33 & 2.53 & 1.60 \\
\hline 2013/06/13 & 7.33 & 10.00 & 36.67 & 3.33 & 22.00 & 17.33 & & & \\
\hline \multicolumn{10}{|l|}{$2013 / 06 / 20$} \\
\hline $2013 / 06 / 26$ & 3.33 & 6.00 & 14.67 & 2.00 & 8.00 & 4.00 & 8.67 & 6.67 & 5.33 \\
\hline 2013/07/03 & 6.67 & 5.33 & 6.00 & 0.00 & 2.00 & 13.00 & 8.00 & 18.00 & 8.67 \\
\hline \multicolumn{10}{|l|}{ 2013/07/10 } \\
\hline 2013/07/17 & 5.33 & 2.67 & 2.00 & 1.33 & 0.67 & 28.00 & 26.00 & 0.00 & 4.67 \\
\hline $2013 / 07 / 24$ & 8.00 & 2.67 & 10.00 & 5.33 & 9.00 & 12.67 & 22.00 & 6.67 & 18.67 \\
\hline $2013 / 07 / 31$ & 4.00 & 2.67 & 1.33 & 2.67 & 3.33 & 4.00 & 17.00 & 0.00 & 10.00 \\
\hline 2013/08/07 & 8.67 & 5.33 & 5.00 & 2.00 & 2.67 & 5.00 & 4.00 & 3.33 & 10.00 \\
\hline 2013/08/14 & 10.00 & 6.00 & 2.00 & 4.00 & 6.00 & 7.33 & 7.33 & 4.00 & 6.67 \\
\hline 2013/08/21 & 20.67 & 16.67 & 9.33 & 13.33 & 6.67 & 22.00 & 7.33 & 15.33 & 11.33 \\
\hline $2013 / 08 / 29$ & 15.33 & 18.00 & 19.33 & 18.00 & 9.33 & 13.33 & 8.00 & 21.33 & 16.67 \\
\hline 2013/09/04 & 11.33 & 13.33 & 8.00 & 12.67 & 13.33 & & 12.67 & 20.67 & 26.00 \\
\hline 2013/09/11 & 18.67 & 11.33 & 12.00 & 5.33 & 13.33 & 8.00 & 9.33 & 47.00 & 33.00 \\
\hline 2013/09/18 & 25.00 & 20.67 & 19.33 & 26.00 & 200.00 & 16.67 & 9.33 & 29.00 & 46.00 \\
\hline $2013 / 09 / 25$ & 23.33 & 16.00 & 10.67 & 37.00 & 16.00 & 3.33 & 10.00 & 58.00 & 71.00 \\
\hline 2013/10/02 & 10.00 & 11.33 & 6.67 & 12.00 & 5.33 & 8.00 & 9.33 & 13.33 & 26.67 \\
\hline \multicolumn{10}{|l|}{ 2013/10/09 } \\
\hline 2013/10/16 & 12.00 & 6.67 & 10.00 & 9.33 & 18.67 & 11.33 & 13.33 & 5.33 & 13.33 \\
\hline $2013 / 10 / 23$ & 10.00 & 8.00 & 10.00 & 13.33 & 20.00 & 6.00 & 12.67 & 4.00 & 4.00 \\
\hline $2013 / 10 / 30$ & 7.33 & 6.67 & 8.67 & 6.67 & 12.00 & 6.00 & 6.67 & 5.33 & 2.67 \\
\hline \multicolumn{10}{|l|}{ 2013/11/06 } \\
\hline $2013 / 11 / 13$ & 245.33 & 8.67 & 20.00 & 7.33 & 6.00 & 17.33 & 16.00 & 6.67 & 16.67 \\
\hline \multicolumn{10}{|l|}{$2013 / 11 / 20$} \\
\hline \multicolumn{10}{|l|}{$2013 / 11 / 25$} \\
\hline 2013/12/04 & 17.33 & 10.67 & 18.00 & 46.00 & 2.67 & 18.67 & 8.00 & 15.33 & 11.33 \\
\hline 2013/12/11 & 14.67 & 16.00 & 19.00 & 31.00 & 2.67 & 8.67 & 13.33 & 9.33 & 8.00 \\
\hline 2013/12/18 & 18.67 & 21.33 & 25.00 & 29.00 & 2.00 & 2.67 & 7.33 & 21.33 & 15.33 \\
\hline \multicolumn{10}{|l|}{$2013 / 12 / 25$} \\
\hline \multicolumn{10}{|l|}{ 2014/01/01 } \\
\hline $2014 / 01 / 08$ & 12.67 & 14.00 & 10.67 & 2.67 & 26.00 & 4.00 & 22.00 & 24.00 & 27.00 \\
\hline 2014/01/15 & 10.00 & 12.00 & 14.67 & 8.67 & 10.00 & 10.67 & 14.67 & 10.67 & 28.00 \\
\hline $2014 / 01 / 22$ & 11.33 & 15.33 & 22.00 & 29.00 & 15.33 & 17.33 & 26.67 & 22.00 & 18.00 \\
\hline $2014 / 01 / 29$ & 15.33 & 7.33 & 22.67 & 18.00 & 15.33 & 26.00 & 8.00 & 28.00 & 16.67 \\
\hline $2014 / 02 / 05$ & 9.33 & 16.00 & 68.00 & 20.67 & 5.33 & 14.67 & 8.00 & 18.00 & 14.67 \\
\hline $2014 / 02 / 12$ & 12.67 & 12.00 & 22.00 & 19.33 & 16.67 & 11.33 & 8.67 & 25.33 & 16.67 \\
\hline 2014/02/19 & 13.33 & 8.00 & 13.33 & 58.00 & 22.00 & 27.00 & 12.00 & 14.67 & 15.33 \\
\hline $2014 / 02 / 26$ & 14.00 & 10.00 & 29.00 & 24.00 & 7.33 & 14.67 & 4.00 & 6.00 & 10.67 \\
\hline 2014/03/05 & 8.67 & 4.00 & 16.00 & 10.67 & 2.67 & 6.67 & 0.67 & 4.67 & 8.67 \\
\hline 2014/03/12 & 14.00 & 8.67 & 40.00 & 12.00 & 9.33 & 7.33 & 2.00 & 4.67 & 18.67 \\
\hline 2014/03/19 & 4.00 & 9.33 & 10.67 & 6.67 & 2.00 & 6.00 & 10.00 & 21.00 & 16.67 \\
\hline $2014 / 04 / 03$ & 14.67 & 14.00 & 15.33 & 10.00 & 7.33 & 4.67 & 4.67 & 18.00 & 26.67 \\
\hline $2014 / 04 / 10$ & 14.00 & 14.67 & 14.00 & 12.67 & 4.00 & 3.33 & 4.67 & 26.00 & 26.67 \\
\hline $2014 / 04 / 17$ & 14.00 & 14.67 & 14.00 & 12.67 & 4.00 & 3.33 & 4.67 & 26.00 & 26.67 \\
\hline
\end{tabular}


Table C-5: Tube settler supernatant TSS for all ponds.

\begin{tabular}{|c|c|c|c|c|c|c|c|c|c|}
\hline \multirow[b]{2}{*}{ Date } & \multicolumn{9}{|c|}{ Tube Settlers } \\
\hline & TS1 & TS2 & TS3 & TS4 & TS5 & TS6 & TS7 & TS8 & TS9 \\
\hline $2013 / 03 / 06$ & 130.00 & 29.59 & 88.89 & 28.00 & 46.48 & 48.78 & & 59.72 & 47.14 \\
\hline 2013/03/13 & 150.00 & 31.63 & 50.00 & 32.97 & 50.00 & 51.16 & & 34.85 & 39.80 \\
\hline $2013 / 03 / 20$ & 57.00 & 38.61 & 45.00 & 51.58 & 100.00 & 28.26 & & 25.51 & 20.65 \\
\hline \multicolumn{10}{|l|}{$2013 / 03 / 27$} \\
\hline 2013/04/04 & 168.57 & 58.82 & 12.37 & 56.79 & 107.87 & 22.00 & 66.67 & 69.23 & 64.81 \\
\hline 2013/04/11 & 139.71 & 97.01 & 21.88 & 128.57 & 92.31 & 58.16 & 38.89 & 25.32 & 23.53 \\
\hline 2013/04/18 & 138.81 & 136.07 & 37.82 & 122.45 & 118.18 & 87.78 & 57.81 & 30.00 & 29.79 \\
\hline $2013 / 04 / 25$ & 66.33 & 16.67 & 58.54 & 159.32 & 5.88 & 116.67 & 39.51 & 34.15 & 65.69 \\
\hline 2013/05/02 & 93.41 & 36.25 & 258.82 & 171.67 & 66.39 & 104.11 & 63.75 & 82.81 & 242.86 \\
\hline 2013/05/09 & 88.92 & 91.63 & 46.57 & 75.13 & 59.02 & 76.70 & 88.36 & 72.82 & 86.53 \\
\hline $2013 / 05 / 16$ & 87.11 & 87.92 & 77.58 & 83.65 & 83.77 & 56.67 & 63.77 & & 76.58 \\
\hline $2013 / 05 / 23$ & & 95.56 & 78.83 & 90.76 & 82.35 & 67.32 & & & 76.79 \\
\hline $2013 / 05 / 30$ & 92.32 & 89.53 & 79.18 & 86.45 & 66.56 & 56.19 & 73.01 & 80.46 & 85.60 \\
\hline 2013/06/06 & 92.79 & 93.14 & 76.44 & 84.88 & 75.05 & 52.10 & 85.46 & 27.52 & 65.71 \\
\hline 2013/06/13 & 96.16 & 94.85 & 67.72 & 83.70 & 77.10 & 46.04 & & & \\
\hline \multicolumn{10}{|l|}{$2013 / 06 / 20$} \\
\hline $2013 / 06 / 26$ & & & & 8.85 & 46.53 & 36.43 & & & \\
\hline 2013/07/03 & & & & 25.00 & 36.99 & 144.29 & & & \\
\hline \multicolumn{10}{|l|}{ 2013/07/10 } \\
\hline 2013/07/17 & 19.00 & 2.00 & 21.43 & 15.00 & 33.23 & 160.00 & & & \\
\hline $2013 / 07 / 24$ & 61.43 & 21.00 & 11.00 & 44.00 & 68.82 & 166.71 & & & \\
\hline 2013/07/31 & 27.00 & 14.00 & 14.00 & 33.00 & 157.58 & 64.82 & & & \\
\hline 2013/08/07 & 35.71 & 13.00 & 15.00 & 27.50 & 50.00 & 40.48 & & & \\
\hline $2013 / 08 / 14$ & 55.15 & 32.00 & 42.64 & & & & & & \\
\hline 2013/08/21 & 66.67 & 64.00 & 49.24 & & & & & & \\
\hline $2013 / 08 / 29$ & 128.00 & 123.38 & 77.42 & & & & & & \\
\hline 2013/09/04 & 94.29 & 83.57 & 65.00 & & & & & & \\
\hline 2013/09/11 & 68.12 & 108.62 & 95.71 & & & & & & \\
\hline 2013/09/18 & 100.00 & 100.00 & 110.71 & 121.10 & 119.87 & 94.96 & & & \\
\hline $2013 / 09 / 25$ & 173.23 & 138.12 & 115.62 & 136.08 & 91.15 & 54.88 & & & \\
\hline 2013/10/02 & 155.17 & 136.66 & 101.71 & 71.75 & 72.51 & 107.14 & & & \\
\hline 2013/10/09 & 54.05 & 108.57 & 77.61 & 69.20 & 67.11 & 134.71 & & & \\
\hline 2013/10/16 & 54.36 & 56.39 & 57.59 & 47.18 & 87.07 & 57.35 & & & \\
\hline $2013 / 10 / 23$ & 67.33 & 82.92 & 78.39 & 84.76 & 108.82 & 79.71 & & & \\
\hline $2013 / 10 / 30$ & 50.23 & 67.76 & 92.71 & 82.05 & 110.00 & 52.38 & & & \\
\hline \multicolumn{10}{|l|}{ 2013/11/06 } \\
\hline 2013/11/13 & 43.74 & 36.26 & 114.02 & 39.67 & 61.66 & 85.45 & & & \\
\hline $2013 / 11 / 20$ & 56.72 & 41.79 & 93.98 & 43.03 & 39.98 & 52.83 & & & \\
\hline $2013 / 11 / 25$ & 47.17 & 29.35 & 88.02 & 68.63 & 28.77 & 92.28 & & & \\
\hline 2013/12/04 & 61.32 & 62.34 & 80.83 & 76.27 & 24.40 & 36.59 & & & \\
\hline 2013/12/11 & 61.52 & 68.75 & 76.93 & 72.75 & 29.17 & 32.02 & & & \\
\hline 2013/12/18 & 76.40 & 61.50 & 75.40 & 71.23 & 17.69 & 18.16 & & & \\
\hline \multicolumn{10}{|l|}{$2013 / 12 / 25$} \\
\hline \multicolumn{10}{|l|}{ 2014/01/01 } \\
\hline 2014/01/08 & & & & 15.86 & 65.15 & 112.39 & & & \\
\hline 2014/01/15 & & 64.37 & 78.20 & 30.31 & 31.19 & 57.00 & & & \\
\hline $2014 / 01 / 22$ & & & & 53.55 & 31.71 & 32.42 & & & \\
\hline $2014 / 01 / 29$ & & & & 46.43 & 34.48 & & & & \\
\hline 2014/02/05 & & 90.41 & 115.95 & 67.30 & 41.67 & & & & \\
\hline $2014 / 02 / 12$ & & & & 84.83 & 41.80 & 189.47 & & & \\
\hline 2014/02/19 & & & & 90.35 & 56.32 & 48.33 & & & \\
\hline $2014 / 02 / 26$ & & & & & 47.44 & 52.59 & & & \\
\hline 2014/03/05 & & & & 64.31 & 30.25 & 16.09 & & & \\
\hline 2014/03/12 & & & & 115.13 & 57.63 & 33.55 & & & \\
\hline \multicolumn{10}{|l|}{ 2014/03/19 } \\
\hline 2014/04/03 & & & & 76.43 & 23.03 & 23.16 & & & \\
\hline $2014 / 04 / 10$ & & & & 114.09 & 11.88 & 38.23 & & & \\
\hline $2014 / 04 / 17$ & & & & 114.09 & 11.88 & 38.23 & & & \\
\hline
\end{tabular}




\section{Appendix D.}

This appendix showed the data for comparing the ramp to the 4-inch standpipe design for the Alpha, Beta, and Gamma set ponds.

Table D-1: Standpipe comparison for the Alpha ponds.

\begin{tabular}{|c|c|c|c|c|c|c|c|c|c|c|c|c|c|c|}
\hline \multicolumn{15}{|c|}{ Alpha } \\
\hline Date & Influent & P1 Ramp A & P1 Ramp B & P2 Ramp A & P2 Ramp B & P3 4-inch A & P3 4-inch B & $\begin{array}{c}\text { Average TSS } \\
\text { of Ramp }\end{array}$ & $\begin{array}{c}\text { Average TSS } \\
\text { of 4-inch }\end{array}$ & $\begin{array}{c}\text { Standard } \\
\text { Deviation } \\
\text { Ramp }\end{array}$ & $\begin{array}{c}\text { Standard } \\
\text { Deviation 4- } \\
\text { inch }\end{array}$ & $\begin{array}{c}\% \text { Difference of } 4 \\
\text { inch and Ramp }\end{array}$ & $\begin{array}{l}\text { Average } \% \\
\text { Difference }\end{array}$ & $\begin{array}{c}\text { Standard } \\
\text { Deviation of \% } \\
\text { Difference }\end{array}$ \\
\hline & & P1 TSS & P1 TSS & P2 TSS & P2 TSS & P3 TSS & P3 TSS & & & & & & & \\
\hline 2013-10-02 & 82.14 & 230.00 & 250.00 & 325.00 & 240.00 & 245.00 & 255.00 & 261.25 & 250.00 & 43.28 & 7.07 & $-4 \%$ & $10 \%$ & $20 \%$ \\
\hline 2013-10-09 & 47.86 & 220.00 & 209.52 & & & 200.00 & 195.00 & 214.76 & 197.50 & 7.41 & 3.54 & $-8 \%$ & & \\
\hline $2013-10-16$ & 43.57 & 205.00 & 195.24 & 170.00 & 160.00 & 190.00 & 190.00 & 182.56 & 190.00 & 21.06 & 0.00 & $4 \%$ & & \\
\hline $2013-10-23$ & 55.71 & 195.00 & 195.00 & 170.00 & 160.00 & 180.00 & 185.00 & 180.00 & 182.50 & 17.80 & 3.54 & $1 \%$ & & \\
\hline 2013-10-30 & 182.50 & 150.00 & 145.00 & 140.00 & 101.54 & 140.00 & 140.00 & 134.13 & 140.00 & 22.11 & 0.00 & $4 \%$ & & \\
\hline 2013-11-06 & 43.57 & 145.00 & 155.00 & 150.00 & 150.00 & 165.00 & 165.00 & 150.00 & 165.00 & 4.08 & 0.00 & $10 \%$ & & \\
\hline 2013-11-13 & 62.86 & & 105.00 & 135.00 & 140.00 & 150.00 & 150.00 & 126.67 & 150.00 & 18.93 & 0.00 & $17 \%$ & & \\
\hline $2013-11-20$ & 61.33 & 122.86 & 140.00 & 133.33 & 133.33 & 156.67 & 160.00 & 132.38 & 158.33 & 7.08 & 2.36 & $18 \%$ & & \\
\hline $2013-11-25$ & 71.87 & 126.67 & 123.33 & 143.33 & 133.33 & 160.00 & 193.33 & 131.67 & 176.67 & 8.82 & 23.57 & $31 \%$ & & \\
\hline 2013-12-04 & 60.00 & 113.33 & 106.67 & 112.50 & 103.33 & 117.50 & 137.50 & 108.96 & 127.50 & 4.78 & 14.14 & $16 \%$ & & \\
\hline $2013-12-11$ & 70.71 & 96.67 & 86.67 & 110.00 & 113.33 & 103.33 & 100.00 & 101.67 & 101.67 & 12.32 & 2.36 & $0 \%$ & & \\
\hline $2013-12-18$ & 77.14 & 83.33 & 83.33 & & & & & 83.33 & & 0.00 & & & & \\
\hline \multicolumn{15}{|l|}{$2013-12-25$} \\
\hline 2014-01-01 & & & & & & & & & & & & & & \\
\hline 2014-01-08 & 68.57 & 126.67 & 120.00 & & 116.67 & 120.00 & 133.33 & 121.11 & 126.67 & 5.09 & 9.43 & $5 \%$ & & \\
\hline 2014-01-15 & 60.71 & 243.33 & & 120.00 & 123.33 & 106.67 & 93.33 & 162.22 & 100.00 & 70.26 & 9.43 & $-44 \%$ & & \\
\hline 2014-01-22 & 73.57 & 126.67 & 123.33 & 143.33 & 140.00 & 160.00 & 146.67 & 133.33 & 153.33 & 9.81 & 9.43 & $14 \%$ & & \\
\hline 2014-01-29 & 84.00 & 153.33 & 150.00 & 154.29 & 154.29 & 154.29 & 160.00 & 152.98 & 157.14 & 2.03 & 4.04 & $3 \%$ & & \\
\hline 2014-02-05 & 71.33 & 160.00 & 160.00 & 145.71 & 148.57 & 168.57 & 345.71 & 153.57 & 257.14 & 7.51 & 125.26 & $55 \%$ & & \\
\hline 2014-02-12 & 54.67 & & 131.43 & & & & & 131.43 & & & & & & \\
\hline 2014-02-19 & 62.00 & & 146.67 & 137.14 & 142.86 & & & 142.22 & & 4.79 & & & & \\
\hline $2014-02-26$ & 111.33 & 180.00 & 176.67 & 177.14 & 171.43 & 191.43 & 168.57 & 176.31 & 180.00 & 3.57 & 16.16 & $2 \%$ & & \\
\hline 2014-03-05 & 140.00 & 110.00 & 110.00 & 111.43 & 108.57 & 140.00 & 140.00 & 110.00 & 140.00 & 1.17 & 0.00 & $25 \%$ & & \\
\hline 2014-03-12 & 66.00 & 140.00 & 143.33 & 148.57 & 148.57 & 165.71 & 162.86 & 145.12 & 164.29 & 4.21 & 2.02 & $13 \%$ & & \\
\hline 2014-03-19 & 63.33 & 126.67 & 130.00 & 142.86 & 142.86 & 154.29 & 202.86 & 135.60 & 178.57 & 8.50 & 34.35 & $29 \%$ & & \\
\hline 2014-04-03 & 52.86 & 100.00 & 96.67 & 100.00 & 97.14 & 150.00 & & 98.45 & 150.00 & 1.80 & & $45 \%$ & & \\
\hline 2014-04-10 & 62.14 & & & 234.29 & & 184.00 & 180.00 & & 182.00 & & 2.83 & & & \\
\hline 2014-04-17 & 62.14 & 170.00 & 166.67 & 154.29 & 154.29 & 143.33 & 156.67 & 161.31 & 150.00 & 8.22 & 9.43 & $-7 \%$ & & \\
\hline
\end{tabular}


Table D-2: Standpipe comparison for the Beta ponds.

\begin{tabular}{|c|c|c|c|c|c|c|c|c|c|c|c|c|c|}
\hline \multicolumn{14}{|c|}{ Beta } \\
\hline Date & P4 Ramp A & P4 Ramp B & P5 Ramp A & P5 Ramp B & P6 4-inch A & P6 4-inch B & $\begin{array}{c}\text { Average TSS } \\
\text { of Ramp }\end{array}$ & $\begin{array}{c}\text { Average TSS of } \\
\text { 4-inch }\end{array}$ & $\begin{array}{c}\text { Standard } \\
\text { Deviation } \\
\text { Ramp } \\
\end{array}$ & $\begin{array}{c}\text { Standard } \\
\text { Deviation } 4 \text { - } \\
\text { inch }\end{array}$ & $\begin{array}{c}\% \text { Difference of } 4- \\
\text { inch and Ramp }\end{array}$ & $\begin{array}{c}\text { Average } \% \\
\text { Difference } \\
\end{array}$ & $\begin{array}{c}\text { Standard } \\
\text { Deviation of } \% \\
\text { Difference } \\
\end{array}$ \\
\hline & P4 TSS & P4 TSS & P5 TSS & P5 TSS & P6 TSS & P6 TSS & & & & & & & \\
\hline 2013-10-02 & 290.00 & 290.00 & 360.00 & 370.00 & 315.00 & 290.00 & 327.50 & 302.50 & 43.49 & 17.68 & $-8 \%$ & $11 \%$ & $18 \%$ \\
\hline 2013-10-09 & 290.00 & 300.00 & & & 340.00 & 350.00 & 295.00 & 345.00 & 7.07 & 7.07 & $16 \%$ & & \\
\hline 2013-10-16 & 280.95 & 276.19 & 285.00 & 220.00 & 320.00 & 315.00 & 265.54 & 317.50 & 30.57 & 3.54 & $18 \%$ & & \\
\hline $2013-10-23$ & 240.00 & 230.00 & 245.00 & 265.00 & 245.00 & 220.00 & 245.00 & 232.50 & 14.72 & 17.68 & $-5 \%$ & & \\
\hline 2013-10-30 & 170.00 & 180.00 & 191.67 & 200.00 & 175.00 & 175.00 & 185.42 & 175.00 & 13.15 & 0.00 & $-6 \%$ & & \\
\hline 2013-11-06 & 80.00 & 80.00 & 140.00 & 135.00 & & 130.00 & 108.75 & 130.00 & 33.26 & & $18 \%$ & & \\
\hline $2013-11-13$ & 200.00 & 200.00 & 195.00 & 195.00 & 210.00 & 200.00 & 197.50 & 205.00 & 2.89 & 7.07 & $4 \%$ & & \\
\hline $2013-11-20$ & 150.00 & 160.00 & 183.33 & 176.67 & 176.67 & 183.33 & 167.50 & 180.00 & 15.24 & 4.71 & $7 \%$ & & \\
\hline $2013-11-25$ & 163.33 & 183.33 & 153.33 & 150.00 & 133.33 & 136.67 & 162.50 & 135.00 & 15.00 & 2.36 & $-18 \%$ & & \\
\hline 2013-12-04 & 157.50 & 160.00 & 132.50 & 135.00 & 112.50 & 110.00 & 146.25 & 111.25 & 14.51 & 1.77 & $-26 \%$ & & \\
\hline 2013-12-11 & 216.67 & 216.67 & 213.33 & 216.67 & 196.67 & 190.00 & 215.83 & 193.33 & 1.67 & 4.71 & $-11 \%$ & & \\
\hline $2013-12-18$ & & & 140.00 & 133.33 & 126.67 & 126.67 & 136.67 & 126.67 & 4.71 & 0.00 & $-7 \%$ & & \\
\hline \multicolumn{14}{|l|}{$2013-12-25$} \\
\hline 2014-01-01 & & & & & & & & & & & & & \\
\hline $2014-01-08$ & 148.00 & 152.00 & 208.00 & 212.00 & 200.00 & 204.00 & 180.00 & 202.00 & 34.72 & 2.83 & $12 \%$ & & \\
\hline 2014-01-15 & 184.00 & 180.00 & 155.00 & 140.00 & 215.00 & 225.00 & 164.75 & 220.00 & 20.90 & 7.07 & $30 \%$ & & \\
\hline 2014-01-22 & 184.00 & 184.00 & 155.00 & 165.00 & 225.00 & 215.00 & 172.00 & 220.00 & 14.45 & 7.07 & $26 \%$ & & \\
\hline $2014-01-29$ & 156.67 & 160.00 & 164.00 & 176.00 & 200.00 & 196.00 & 164.17 & 198.00 & 8.44 & 2.83 & $19 \%$ & & \\
\hline 2014-02-05 & 166.67 & 173.33 & 188.00 & 196.00 & 156.00 & 152.00 & 181.00 & 154.00 & 13.39 & 2.83 & $-16 \%$ & & \\
\hline $2014-02-12$ & 166.67 & & & 252.00 & 264.00 & & 209.33 & 264.00 & 60.34 & & $24 \%$ & & \\
\hline $2014-02-19$ & 216.67 & 220.00 & 220.00 & 304.00 & 308.00 & & 240.17 & 308.00 & 42.58 & & $26 \%$ & & \\
\hline $2014-02-26$ & 260.00 & 250.00 & 252.00 & 260.00 & 300.00 & 304.00 & 255.50 & 302.00 & 5.26 & 2.83 & $17 \%$ & & \\
\hline 2014-03-05 & 200.00 & 230.00 & 184.00 & 200.00 & 268.00 & 316.00 & 203.50 & 292.00 & 19.21 & 33.94 & $38 \%$ & & \\
\hline $2014-03-12$ & 256.67 & 266.67 & 236.00 & 232.00 & 344.00 & 348.00 & 247.83 & 346.00 & 16.57 & 2.83 & $35 \%$ & & \\
\hline 2014-03-19 & 296.67 & 283.33 & 216.00 & 212.00 & 280.00 & 268.00 & 252.00 & 274.00 & 44.25 & 8.49 & $8 \%$ & & \\
\hline 2014-04-03 & 220.00 & 220.00 & 144.00 & 140.00 & 240.00 & 232.00 & 181.00 & 236.00 & 45.06 & 5.66 & $28 \%$ & & \\
\hline 2014-04-10 & 312.00 & 328.00 & 200.00 & 200.00 & 368.00 & 376.00 & 260.00 & 372.00 & 69.59 & 5.66 & $38 \%$ & & \\
\hline 2014-04-17 & 200.00 & 208.00 & 152.00 & 160.00 & & & 180.00 & & 28.10 & & & & \\
\hline
\end{tabular}


Table D-3: Standpipe comparison for the Gamma ponds.

\begin{tabular}{|c|c|c|c|c|c|c|c|c|c|c|c|c|c|}
\hline \multicolumn{14}{|c|}{ Gamma } \\
\hline Date & P7 4-inch A & P7 4-inch B & P8 Ramp A & P8 Ramp B & P9 Ramp A & P9 Ramp B & $\begin{array}{c}\text { Average TSS of } \\
\text { 4-inch }\end{array}$ & $\begin{array}{c}\text { Average TSS } \\
\text { of Ramp }\end{array}$ & $\begin{array}{c}\text { Standard } \\
\text { Deviation 4- } \\
\text { inch } \\
\end{array}$ & $\begin{array}{c}\text { Standard } \\
\text { Deviation } \\
\text { Ramp } \\
\end{array}$ & $\begin{array}{c}\% \text { Difference of } \\
\text { 4-inch and } \\
\text { Ramp } \\
\end{array}$ & $\begin{array}{c}\text { Average } \% \\
\text { Difference }\end{array}$ & $\begin{array}{c}\text { Standard } \\
\text { Deviation of } \\
\text { \% Difference } \\
\end{array}$ \\
\hline & P7 TSS & P7 TSS & P8 TSS & P8 TSS & P9 TSS & P9 TSS & & & & & & & \\
\hline $2013-10-02$ & 210.00 & 210.00 & 380.00 & 400.00 & 395.00 & 385.00 & 210.00 & 391.67 & 0.00 & 9.13 & $-55 \%$ & $35 \%$ & $41 \%$ \\
\hline 2013-10-09 & 210.00 & 220.00 & 285.00 & 290.00 & 255.00 & 275.00 & 215.00 & 276.67 & 7.07 & 15.48 & $-24 \%$ & & \\
\hline $2013-10-16$ & 200.00 & 240.00 & 285.00 & 280.00 & 225.00 & 240.00 & 220.00 & 263.33 & 28.28 & 29.58 & $-17 \%$ & & \\
\hline $2013-10-23$ & 210.00 & 205.00 & 265.00 & 255.00 & 265.00 & 265.00 & 207.50 & 261.67 & 3.54 & 5.00 & $-22 \%$ & & \\
\hline 2013-10-30 & 195.00 & 195.00 & 280.00 & 255.00 & 220.00 & 235.00 & 195.00 & 251.67 & 0.00 & 25.98 & $-24 \%$ & & \\
\hline 2013-11-06 & 160.00 & 165.00 & 105.00 & 110.00 & 155.00 & 150.00 & 162.50 & 123.33 & 3.54 & 26.14 & $29 \%$ & & \\
\hline $2013-11-13$ & 215.00 & 215.00 & 140.00 & 130.00 & 145.00 & 155.00 & 215.00 & 138.33 & 0.00 & 10.41 & $47 \%$ & & \\
\hline $2013-11-20$ & 213.33 & 213.33 & 143.33 & 153.33 & 183.33 & 186.67 & 213.33 & 160.00 & 0.00 & 21.60 & $30 \%$ & & \\
\hline $2013-11-25$ & 190.00 & 183.33 & 96.67 & 106.67 & 153.33 & 153.33 & 186.67 & 118.89 & 4.71 & 30.11 & $48 \%$ & & \\
\hline 2013-12-04 & 246.67 & 230.00 & 120.00 & 123.33 & 103.33 & 106.67 & 238.33 & 115.56 & 11.79 & 9.81 & $78 \%$ & & \\
\hline $2013-12-11$ & 323.33 & 313.33 & 146.67 & 163.33 & 140.00 & 130.00 & 318.33 & 150.00 & 7.07 & 14.01 & $82 \%$ & & \\
\hline $2013-12-18$ & 176.67 & 173.33 & & 60.00 & 120.00 & 113.33 & 175.00 & 90.00 & 2.36 & 32.89 & $72 \%$ & & \\
\hline \multicolumn{14}{|l|}{$2013-12-25$} \\
\hline \multicolumn{14}{|l|}{ 2014-01-01 } \\
\hline 2014-01-08 & 196.00 & 196.00 & 120.00 & 128.00 & 116.00 & 112.00 & 196.00 & 121.33 & 0.00 & 6.83 & $51 \%$ & & \\
\hline 2014-01-15 & 188.00 & 216.00 & 144.00 & 156.00 & 172.00 & 152.00 & 202.00 & 157.33 & 19.80 & 11.78 & $26 \%$ & & \\
\hline 2014-01-22 & 180.00 & 200.00 & 124.00 & 128.00 & 132.00 & 132.00 & 190.00 & 128.00 & 14.14 & 3.83 & $42 \%$ & & \\
\hline $2014-01-29$ & 300.00 & 283.33 & 176.67 & 180.00 & 193.33 & 190.00 & 291.67 & 183.33 & 11.79 & 7.93 & $49 \%$ & & \\
\hline $2014-02-05$ & 236.67 & 240.00 & 146.67 & 156.67 & 183.33 & 180.00 & 238.33 & 162.22 & 2.36 & 17.85 & $41 \%$ & & \\
\hline 2014-02-12 & 203.33 & 203.33 & 123.33 & 116.67 & & 156.67 & 203.33 & 120.00 & 0.00 & 21.43 & $56 \%$ & & \\
\hline $2014-02-19$ & 226.67 & 223.33 & 176.67 & 173.33 & 196.67 & 206.67 & 225.00 & 182.22 & 2.36 & 15.99 & $22 \%$ & & \\
\hline $2014-02-26$ & 276.67 & 296.67 & 163.33 & 166.67 & 170.00 & 166.67 & 286.67 & 166.67 & 14.14 & 2.72 & $58 \%$ & & \\
\hline 2014-03-05 & 306.67 & 316.67 & 136.67 & 140.00 & 156.67 & 153.33 & 311.67 & 144.44 & 7.07 & 9.81 & $84 \%$ & & \\
\hline $2014-03-12$ & 266.67 & 260.00 & 196.67 & 196.67 & 196.67 & 206.67 & 263.33 & 196.67 & 4.71 & 5.00 & $30 \%$ & & \\
\hline 2014-03-19 & 500.00 & 483.33 & 210.00 & 213.33 & 196.67 & 196.67 & 491.67 & 206.67 & 11.79 & 8.77 & $94 \%$ & & \\
\hline 2014-04-03 & 360.00 & 320.00 & 193.33 & 190.00 & 173.33 & 173.33 & 340.00 & 185.56 & 28.28 & 10.67 & $65 \%$ & & \\
\hline $2014-04-10$ & 468.00 & 440.00 & 206.67 & 206.67 & 220.00 & 216.67 & 454.00 & 211.11 & 19.80 & 6.87 & $83 \%$ & & \\
\hline 2014-04-17 & 136.00 & 132.00 & 206.67 & & 193.33 & & 134.00 & 200.00 & 2.83 & 9.43 & $-37 \%$ & & \\
\hline
\end{tabular}




\section{Appendix E.}

The sonication experimental data was presented first followed by the data for the homogenization experiment. For the homogenization experiment "UH" was used in place of unhomogenized, and " $\mathrm{H}$ " was used in place of homogenized

Table E-1: Sonication experiment pH, temperature, and dissolved oxygen

\begin{tabular}{cccccccccc} 
& \multicolumn{3}{c}{ Reactor 1 } & \multicolumn{3}{c}{ Reactor 2 } & \multicolumn{3}{c}{ Reactor 3 } \\
\cline { 2 - 9 } Date & Temp & pH & DO & Temp & pH & DO & Temp & pH & DO \\
\hline $8 / 20 / 2013$ & 22.9 & 7.18 & 6.65 & 22.9 & 7.18 & 6.65 & 22.9 & 7.18 & 6.65 \\
$8 / 21 / 2013$ & 20.6 & 7.45 & 9.44 & 19.3 & 8.19 & 9.35 & 18.6 & 8.2 & 9.45 \\
$8 / 22 / 2013$ & 17.4 & 8.13 & 9.37 & 17.3 & 8.19 & 9.43 & 17.3 & 8.15 & 9.43 \\
$8 / 23 / 2013$ & 16.8 & 8 & 9.56 & 16.6 & 8.05 & 9.56 & 16.7 & 8.01 & 9.54 \\
$8 / 24 / 2013$ & 16.3 & 7.89 & 9.6 & 16.2 & 7.97 & 9.6 & 16.4 & 7.93 & 9.57 \\
$8 / 25 / 2013$ & 18.2 & 7.73 & 9.29 & 18.2 & 7.74 & 9.29 & 18.1 & 7.71 & 9.27 \\
$9 / 6 / 2013$ & 16.0 & 7.87 & 9.56 & 15.5 & 7.85 & 9.58 & 16.1 & 7.79 & 9.4 \\
$9 / 11 / 2013$ & 23 & 7.65 & 8.2 & 23.1 & 7.61 & 8.07 & 22.6 & 7.63 & 8.34 \\
$9 / 20 / 2013$ & 18.8 & 7.75 & 8.58 & 20.1 & 7.75 & 8.68 & 18.8 & 7.77 & 8.89 \\
\hline
\end{tabular}

Table E-2: Sonication experiment VSS

\begin{tabular}{cccc} 
& \multicolumn{3}{c}{ VSS } \\
\cline { 2 - 4 } Date & Reactor & Reactor & Reactor \\
\hline $8 / 20 / 2013$ & 639.7 & 639.7 & 639.7 \\
$8 / 21 / 2013$ & 713.3 & 644.4 & 700.0 \\
$8 / 22 / 2013$ & 688.3 & 755.6 & 762.5 \\
$8 / 23 / 2013$ & 727.8 & 787.5 & 716.7 \\
$8 / 24 / 2013$ & 612.5 & 675.0 & 637.5 \\
$8 / 25 / 2013$ & 670.0 & 750.0 & 700.0 \\
$8 / 26 / 2013$ & 560.0 & 640.0 & 580.0 \\
$8 / 29 / 2013$ & 640.0 & 810.0 & 720.0 \\
$9 / 11 / 2013$ & 497.0 & 1063.6 & 450.0 \\
$9 / 20 / 2013$ & 645.2 & 723.6 & 831.2 \\
\hline
\end{tabular}


Table E-3: Sonication experiment TAN

\section{TAN}

\begin{tabular}{cccc} 
& \multicolumn{3}{c}{ TAN } \\
\cline { 2 - 4 } & Reactor 1 & Reactor 2 & Reactor 3 \\
\hline $8 / 20 / 2013$ & 102.49 & 102.49 & 102.49 \\
$8 / 21 / 2013$ & 89.09 & 86.63 & 101.38 \\
$8 / 22 / 2013$ & 30.11 & 34.41 & 27.23 \\
$8 / 23 / 2013$ & 21.89 & 21.8 & 20.26 \\
$8 / 24 / 2013$ & & & \\
$8 / 25 / 2013$ & 0.01 & 0.03 & 0.03 \\
$9 / 6 / 2013$ & & & \\
$9 / 11 / 2013$ & & & \\
$9 / 20 / 2013$ & 0.06 & 0.04 & 0.02 \\
\hline
\end{tabular}

Table E-4 Sonication experiment nitrate

$\mathrm{NO}_{2}$

\begin{tabular}{cccc} 
& Reactor & Reactor & Reactor \\
& 1 & 2 & 3 \\
\hline $8 / 20 / 2013$ & 0.002 & 0.004 & 0.003 \\
$8 / 21 / 2013$ & 0.147 & 0.157 & 0.162 \\
$8 / 22 / 2013$ & 0.340 & 0.326 & 0.312 \\
$8 / 23 / 2013$ & 0.705 & 0.689 & 0.740 \\
$8 / 25 / 2013$ & 2.53 & 2.94 & 2.63 \\
$8 / 29 / 2013$ & 0.07 & 0.03 & 0.03 \\
$9 / 20 / 2013$ & 0.02 & 0.01 & 0.02 \\
\hline
\end{tabular}


Table E-5: Sonication experiment nitrate

\begin{tabular}{cccc} 
& \multicolumn{3}{c}{$\mathrm{NO}_{3}$} \\
\cline { 2 - 4 } Date & Reactor & Reactor & Reactor \\
\hline $8 / 20 / 2013$ & 0.24 & 0.24 & 0.24 \\
$8 / 21 / 2013$ & 0.64 & 0.53 & 0.57 \\
$8 / 22 / 2013$ & 0.88 & 0.98 & 0.91 \\
$8 / 23 / 2013$ & 1.35 & 1.5 & 1.5 \\
$8 / 25 / 2013$ & 3.99 & 4.27 & 4.03 \\
$8 / 29 / 2013$ & 8.51 & 8.41 & 8.97 \\
$9 / 20 / 2013$ & 0.11 & 0.22 & 0.14 \\
\hline
\end{tabular}

Table E-6: Sonication experiment dissolved reactive phosphorus

\begin{tabular}{cccc} 
& \multicolumn{3}{c}{ DRP } \\
\cline { 2 - 4 } Date & Reactor & Reactor & Reactor \\
\hline $8 / 20 / 2013$ & 8.64 & 8.64 & 8.64 \\
$8 / 21 / 2013$ & & & \\
$8 / 22 / 2013$ & 8.89 & 9.45 & 8.80 \\
$8 / 23 / 2013$ & & & \\
$8 / 25 / 2013$ & 8.07 & 8.49 & 7.88 \\
$8 / 29 / 2013$ & 6.58 & 7.59 & 6.87 \\
$9 / 20 / 2013$ & 6.21 & 4.51 & 5.11 \\
\hline
\end{tabular}


Table E-7: Homogenization experiment pH, dissolved oxygen, and temperature

\begin{tabular}{|c|c|c|c|c|c|c|c|c|c|c|c|c|c|c|c|c|c|c|}
\hline \multirow[b]{2}{*}{ Date } & \multicolumn{6}{|c|}{$\mathrm{pH}$} & \multicolumn{6}{|c|}{$\mathrm{DO}$} & \multicolumn{6}{|c|}{ Temp } \\
\hline & UH 1 & $\mathrm{UH} 2$ & UH 3 & $\mathrm{H} 1$ & $\mathrm{H} 2$ & $\mathrm{H} 3$ & UH 1 & $\mathrm{UH} 2$ & $\mathrm{UH} 3$ & $\mathrm{H} 1$ & $\mathrm{H} 2$ & $\mathrm{H} 3$ & UH 1 & $\mathrm{UH} 2$ & UH 3 & $\mathrm{H} 1$ & $\mathrm{H} 2$ & $\mathrm{H} 3$ \\
\hline $10 / 26 / 2013$ & 8.16 & 8.12 & 8.17 & 8.15 & 8.19 & 8.17 & 8.25 & 8.23 & 8.38 & 8.71 & 8.79 & 8.78 & 23.5 & 23.5 & 23.6 & 21.9 & 21.7 & 21.9 \\
\hline 10/29/2013 & 8.48 & 8.46 & 8.43 & 8.52 & 8.5 & 8.54 & 7.98 & 7.94 & 8.11 & 8.48 & 8.45 & 8.51 & 22.4 & 22.6 & 22.5 & 21.7 & 21.8 & 21.8 \\
\hline $10 / 30 / 2013$ & 8.55 & 8.53 & 8.47 & 8.49 & 9 & 8.51 & 9.01 & 9.01 & 9.04 & 9.17 & 9.15 & 9.09 & 20.4 & 20.2 & 20.2 & 19 & 19.3 & 19.3 \\
\hline $10 / 31 / 2013$ & 8.48 & 8.57 & 8.5 & 8.48 & 8.49 & 8.41 & 8.97 & 8.97 & 8.93 & 9.09 & 9.13 & 9.06 & 20.3 & 20.3 & 20.2 & 19.5 & 19.4 & 19.4 \\
\hline $11 / 1 / 2013$ & & 8.29 & 8.31 & 8.39 & .44 & 39 & & 9.05 & 9.1 & 9.26 & 9.29 & .1 & 19.8 & 19.7 & 19.6 & 18.9 & 19 & 19 \\
\hline $11 / 4 / 2013$ & .02 & 7.96 & 7.85 & 8.2 & 8.29 & 8.3 & & 8.93 & 8.97 & 8.93 & 9.08 & 9.03 & 20.9 & & 20.6 & 19.9 & 19.9 & 19.9 \\
\hline $11 / 5 / 2013$ & 7.68 & 7.6 & 7.21 & 8.09 & 8.16 & 8.21 & 9.19 & 9.18 & 9.21 & 9.26 & 9.28 & 9.16 & 19.6 & & ; 19.4 & 19.1 & 19.1 & 19.3 \\
\hline $11 / 6 / 2013$ & 6.8 & 6.67 & 7.01 & 7.53 & 7.57 & 7.75 & 8.65 & 8.94 & 8.87 & 8.8 & 8.8 & 38.65 & 19.9 & 19.9 & 19.8 & 19.7 & 19.8 & 19.8 \\
\hline $11 / 7 / 2013$ & 6.78 & 6.76 & 6.85 & 6.91 & 6.66 & 6.61 & 8.85 & 8.88 & 8.76 & 8.94 & 8.9 & 8.75 & 20.6 & 20.6 & 20.7 & 19.9 & 19.9 & 20.3 \\
\hline $11 / 8 / 2013$ & 6.65 & 6.57 & 6.67 & 6.96 & 6.9 & 6.27 & 8.64 & 8.65 & 8.66 & 9.08 & 9.11 & 9.03 & 20.9 & 20.8 & 20.6 & 19.3 & 19.2 & 19.2 \\
\hline $11 / 12 / 2013$ & 6.45 & 6.34 & 6.42 & 6.78 & 6.76 & 6.54 & 8.83 & 8.81 & 8.86 & 9.01 & 9.07 & 9.04 & 20.3 & 20.3 & 20.3 & 19.8 & 19.8 & 19.8 \\
\hline $11 / 13 / 2013$ & 6.55 & 6.47 & 6.55 & 6.78 & 6.72 & 6.45 & 8.99 & 8.9 & 8.88 & 8.84 & 8.85 & 8.95 & 19.3 & 19.2 & 19.3 & 19.9 & 19.9 & 20.2 \\
\hline $11 / 14 / 2013$ & 6.48 & 6.41 & 6.49 & 6.79 & 6.74 & 6.86 & 8.61 & 8.55 & 8.57 & 8.95 & 8.97 & 8.84 & 20.6 & 20.5 & 20.3 & 19.6 & 19.6 & 20.1 \\
\hline $11 / 15 / 2013$ & 6.14 & 6.08 & 6.24 & 6.51 & 6.48 & 6.71 & 8.96 & 8.95 & 8.94 & 8.89 & 8.85 & 8.97 & 19 & 19.1 & 18.9 & 19.6 & 19.8 & 19.7 \\
\hline $11 / 18 / 2013$ & 6.33 & 6.27 & 6.36 & 6.58 & 6.57 & 6.72 & 8.8 & 8.85 & 8.77 & 8.79 & 8.78 & 38.95 & 19.6 & 19.7 & 19.6 & 19.8 & 19.7 & 19.8 \\
\hline $11 / 19 / 2013$ & 6.58 & 6.49 & 6.58 & 6.81 & .72 & 6.8 & & 8.89 & 8.87 & 8.98 & & & 20 & & 19.7 & 19.1 & 19.4 & \\
\hline $11 / 20 / 2013$ & 6.47 & 6.41 & 6.47 & 6.74 & 6.63 & 6.84 & 8.92 & 8.87 & 8.89 & 8.95 & 8.65 & 7.54 & 20.6 & & 20.6 & 20.3 & 20.4 & \\
\hline $11 / 21 / 2013$ & 6.52 & 6.45 & 6.54 & 6.84 & 6.75 & 6.65 & 8.88 & 8.91 & 8.86 & 8.83 & 8.87 & 8.95 & 19.8 & 19.8 & 19.8 & 20.1 & 19.9 & 20.2 \\
\hline $11 / 22 / 2013$ & 6.34 & 6.27 & 6.35 & 6.72 & 6.53 & 6.54 & 8.61 & 8.87 & 8.85 & 8.89 & 8.86 & 8.93 & 19.9 & 19.9 & 19.8 & 19.5 & 19.7 & 19.9 \\
\hline $11 / 25 / 2013$ & 6.34 & 6.3 & 6.36 & 6.84 & 6.65 & 6.65 & 8.69 & 8.84 & 9.01 & 9.14 & 9.12 & 9.06 & 19.9 & 20 & 19.9 & 19.4 & 19.2 & 19.6 \\
\hline $11 / 26 / 2013$ & 6.57 & 6.54 & 6.62 & 7.14 & 6.89 & 7.02 & 8.94 & 9.01 & - 9.04 & 9.23 & 9.24 & 9.02 & 20 & 19.9 & 19.8 & 18.9 & 18.8 & 19.5 \\
\hline $12 / 2 / 2013$ & 6.61 & 6.33 & 6.58 & 7.07 & 6.71 & 6.97 & 8.94 & 8.98 & 8.93 & 8.97 & 8.88 & 8.9 & 19.4 & 19.4 & 19.5 & 19.5 & 19.5 & 19.6 \\
\hline $12 / 3 / 2013$ & 6.52 & 6.26 & 6.42 & 6.95 & 6.65 & 6.86 & 8.81 & 8.9 & 8.86 & 8.91 & 8.96 & 9 & 19.7 & 19.5 & 19.5 & 19.4 & . 19.4 & 19.6 \\
\hline $12 / 4 / 2013$ & 6.71 & 6.39 & 6.56 & 7.09 & 6.7 & 6.9 & 8.63 & 8.78 & 8.52 & 8.55 & 8.5 & 8.56 & 19.6 & 19.5 & 19.7 & 20.1 & 20 & 20.1 \\
\hline $12 / 5 / 2013$ & 6.65 & 6.15 & 6.36 & 6.89 & 6.52 & 6.92 & 8.97 & 9 & 8.96 & 9.16 & 9.15 & 9.19 & 19.6 & 19.4 & 19.4 & 19.1 & 19.3 & 19.2 \\
\hline $12 / 6 / 2013$ & 6.93 & 6.35 & 6.53 & 7.12 & 6.7 & 7.24 & 8.92 & 8.99 & 8.97 & 9.08 & 9.19 & 9.12 & 20 & 19.9 & 19.8 & 19.3 & 19.3 & 19.5 \\
\hline
\end{tabular}

Table E-8: Homogenization experiment VSS

\begin{tabular}{ccccccc} 
& \multicolumn{7}{c}{ VSS } \\
\cline { 2 - 7 } Date & UH 1 & UH 2 & UH 3 & H 1 & H 2 & H 3 \\
\hline $10 / 26 / 2013$ & & & & & & \\
$10 / 30 / 2013$ & 2375 & 2350 & 2450 & 1950 & 1900 & 1950 \\
$11 / 1 / 2013$ & 2233.3 & 2033.3 & 2133.3 & 1533.3 & 1633.3 & 1546.7 \\
$11 / 4 / 2013$ & 2008.3 & 2000.0 & 1900.0 & 1800.0 & 1633.3 & 1366.7 \\
$11 / 8 / 2013$ & 1941.67 & 1966.67 & 2033.33 & 1575.00 & 1550.00 & 1300.00 \\
$11 / 15 / 2013$ & 1858.33 & 2233.33 & 1900.00 & 1583.33 & 1675.00 & 1400.00 \\
$11 / 20 / 2013$ & 1800.00 & 1866.67 & 1700.00 & 1483.33 & 1433.33 & 1600.00 \\
$12 / 4 / 2013$ & 1379.17 & 1492.86 & 1416.67 & 1273.33 & 1200.00 & 1133.33 \\
$2 / 7 / 2014$ & 1350 & 1360 & 1400 & 1130 & 1100 & 990 \\
\hline
\end{tabular}


Table E-9: Homogenization experiment TAN

TAN

\begin{tabular}{ccccccc}
\cline { 2 - 6 } Date & UH 1 & UH 2 & UH 3 & H 1 & H 2 & H 3 \\
\hline $2013-10-26$ & 172.52 & 172.52 & 172.52 & 168.78 & 168.78 & 168.78 \\
$2013-10-30$ & 99.07 & 95.54 & 82.32 & 87.09 & 94.40 & 94.02 \\
$2013-11-01$ & 71.72 & 71.82 & 62.13 & 68.43 & 74.47 & 74.47 \\
$11 / 4 / 2013$ & 32.57 & 29.09 & 20.40 & 35.12 & 38.84 & 45.54 \\
$11 / 6 / 2013$ & 2.73 & 0.22 & 0.05 & 11.57 & 14.85 & 21.40 \\
$11 / 8 / 2013$ & 0.07 & 0.04 & 0.03 & 0.03 & 0.02 & 0.03 \\
$11 / 15 / 2013$ & 0.22 & 0.09 & 0.10 & 0.10 & 0.13 & 0.05 \\
$11 / 20 / 2013$ & 0.23 & 0.25 & 0.21 & 0.18 & 0.24 & 0.22 \\
$12 / 4 / 2013$ & 0.11 & 0.06 & 0.13 & 0.06 & 0.05 & 0.04 \\
$2 / 7 / 2014$ & 0.039 & 0.071 & 0.034 & 0.025 & 0.024 & 0.023 \\
\hline
\end{tabular}

Table E-10: Homogenization experiment nitrite

\begin{tabular}{ccccccc} 
& \multicolumn{7}{c}{$\mathrm{NO}_{2}$} \\
\cline { 2 - 7 } Date & UH 1 & UH 2 & UH 3 & H 1 & H 2 & H 3 \\
\hline $10 / 26 / 2013$ & 0 & 0 & 0 & 0 & 0 & 0 \\
$10 / 30 / 2013$ & 0.56 & 0.66 & 0.63 & 0.44 & 0.34 & 0.32 \\
$11 / 1 / 2013$ & 1.14 & 1.44 & 1.57 & 0.69 & 0.66 & 0.68 \\
$11 / 4 / 2013$ & 7.72 & 9.90 & 12.51 & 4.79 & 3.76 & 3.44 \\
$11 / 6 / 2013$ & 26.65 & 26.01 & 24.54 & 17.28 & 16.45 & 16.18 \\
$11 / 8 / 2013$ & 29.37 & 29.70 & 30.04 & 27.35 & 26.34 & 36.76 \\
$11 / 15 / 2013$ & 47.81 & 42.18 & 42.44 & 36.54 & 35.95 & 43.72 \\
$11 / 20 / 2013$ & 47.34 & 43.26 & 34.62 & 30.83 & 34.71 & 49.67 \\
$12 / 4 / 2013$ & 0.70 & 0.78 & 0.78 & 0.78 & 0.86 & 0.78 \\
$2 / 7 / 2014$ & 0.01 & 0.01 & 0.01 & 0.01 & 0.01 & 0.02 \\
\hline
\end{tabular}


Table E-11: Homogenization experiment nitrate

\begin{tabular}{ccccccc} 
& \multicolumn{7}{c}{$\mathrm{NO}_{3}$} \\
\cline { 2 - 7 } Date & $\mathrm{UH} 1$ & $\mathrm{UH} 2$ & $\mathrm{UH} 3$ & $\mathrm{H} 1$ & $\mathrm{H} 2$ & $\mathrm{H} \mathrm{3}$ \\
\hline $10 / 26 / 2013$ & 0 & 0 & 0 & 0 & 0 & 0 \\
$10 / 30 / 2013$ & 0.71 & 0.76 & 0.71 & 0.77 & 0.74 & 0.67 \\
$11 / 1 / 2013$ & 0.84 & 0.62 & 0.84 & 0.82 & 0.84 & 0.79 \\
$11 / 4 / 2013$ & 3.75 & 3.03 & 3.67 & 2.67 & 2.67 & 2.57 \\
$11 / 6 / 2013$ & 5.30 & 5.28 & 4.43 & 3.11 & 3.10 & 2.74 \\
$11 / 8 / 2013$ & 7.15 & 7.15 & 5.79 & 3.44 & 8.67 & 5.53 \\
$11 / 15 / 2013$ & 11.31 & 11.76 & 14.06 & 8.34 & 9.84 & 9.42 \\
$11 / 20 / 2013$ & 15.26 & 14.81 & 21.44 & 16.99 & 14.81 & 8.46 \\
$12 / 4 / 2013$ & 57.16 & 73.70 & 67.62 & 54.74 & 56.66 & 57.16 \\
$2 / 7 / 2014$ & 28.44 & 52.41 & 41.30 & 25.08 & 31.12 & 50.11 \\
\hline
\end{tabular}

Table E-12: Homogenization experiment dissolved reactive phosphorus

\begin{tabular}{ccccccc} 
& \multicolumn{7}{c}{ DRP } \\
\cline { 2 - 7 } Date & UH 1 & UH 2 & UH 3 & H 1 & H 2 & H 3 \\
\hline $10 / 26 / 2013$ & 10.49 & 10.53 & 10.53 & 9.21 & 8.40 & 8.15 \\
$11 / 1 / 2013$ & 2.03 & 2.37 & 2.68 & 2.65 & 2.28 & 2.40 \\
$11 / 8 / 2013$ & 12.94 & 12.39 & 12.85 & 7.93 & 11.12 & 16.22 \\
$11 / 15 / 2013$ & 15.46 & 15.46 & 16.98 & 10.82 & 13.62 & 15.22 \\
$11 / 20 / 2013$ & 18.01 & 14.23 & 15.23 & 15.13 & 10.34 & 15.62 \\
$12 / 4 / 2013$ & 19.25 & 18.56 & 19.35 & 15.21 & 16.39 & 10.47 \\
$2 / 7 / 2014$ & 15.54 & 18.37 & 17.72 & 10.20 & 17.64 & 21.44 \\
\hline
\end{tabular}


Table E-13: Homogenization experiment TKN

TKN

\begin{tabular}{|c|c|c|c|c|c|c|}
\hline \multirow[b]{2}{*}{ Date } & \\
\hline & UH 1 & UH 2 & UH 3 & $\mathrm{H} 1$ & $\mathrm{H} 2$ & $\mathrm{H} 3$ \\
\hline $10 / 26 / 2013$ & 257.6 & 257.6 & 257.6 & 224 & 224 & 224 \\
\hline \multicolumn{7}{|l|}{$10 / 30 / 2013$} \\
\hline $11 / 1 / 2013$ & 120.4 & 170.8 & 156 & 126 & 148.4 & 128 \\
\hline \multicolumn{7}{|l|}{$11 / 4 / 2013$} \\
\hline \multicolumn{7}{|l|}{$11 / 6 / 2013$} \\
\hline \multicolumn{7}{|l|}{$11 / 8 / 2013$} \\
\hline $11 / 15 / 2013$ & 117.60 & 106.40 & 145.60 & 84.00 & 89.60 & 106.40 \\
\hline $11 / 20 / 2013$ & 112 & 120 & 136.3 & 92 & 96 & 92 \\
\hline $12 / 4 / 2013$ & 42.00 & 56 & 72.8 & 33.6 & 36.4 & 39.2 \\
\hline $2 / 7 / 2014$ & 72.80 & 78.4 & 70 & 61.6 & 78.4 & 70 \\
\hline
\end{tabular}




\section{Appendix F.}

This appendix presented the soluble nitrogen and phosphorus data for the ponds.

Table F-1: Soluble nitrogen data for influent and all ponds

\begin{tabular}{|c|c|c|c|c|c|c|c|c|c|c|}
\hline \multirow[b]{2}{*}{ Date } & \multirow[b]{2}{*}{ Influent } & \multicolumn{3}{|c|}{ Alpha } & \multicolumn{3}{|c|}{ Beta } & \multicolumn{3}{|c|}{ Gamma } \\
\hline & & Pond 1 & Pond 2 & Pond 3 & Pond 4 & Pond 5 & Pond 6 & Pond 7 & Pond 8 & Pond 9 \\
\hline $3 / 6 / 2013$ & 37.45 & 7.05 & 12.89 & 10.81 & 16.71 & 19.80 & 15.68 & 19.83 & 29.52 & 22.89 \\
\hline $3 / 13 / 2013$ & 50.00 & 6.43 & 11.89 & 11.29 & 12.78 & 14.70 & 12.64 & 15.40 & 23.42 & 15.23 \\
\hline $3 / 20 / 2013$ & 36.80 & 11.98 & 12.11 & 10.80 & 17.25 & 18.42 & 18.92 & 21.83 & 23.25 & 21.01 \\
\hline \multicolumn{11}{|l|}{$3 / 27 / 2013$} \\
\hline 4/4/2013 & 50.89 & 2.97 & 6.75 & 3.68 & 14.44 & 17.26 & 14.93 & 15.57 & 16.91 & 12.01 \\
\hline $4 / 11 / 2013$ & 43.25 & 6.46 & 6.62 & 7.21 & 16.76 & 18.41 & 14.61 & 18.22 & 16.82 & 15.52 \\
\hline $4 / 18 / 2013$ & 36.99 & 11.21 & 9.27 & 10.73 & 19.90 & 21.81 & 18.09 & 20.35 & 19.00 & 15.73 \\
\hline $4 / 25 / 2013$ & 37.37 & 17.10 & 9.49 & 11.38 & 18.48 & 17.27 & 16.31 & 14.25 & 15.05 & 14.77 \\
\hline $5 / 2 / 2013$ & 37.62 & 19.02 & 9.54 & 14.54 & 21.84 & 19.00 & 20.59 & 14.65 & 9.63 & 11.69 \\
\hline $5 / 9 / 2013$ & 44.47 & 12.90 & 10.00 & 13.32 & 23.93 & 20.76 & 20.73 & 15.16 & 15.91 & 15.02 \\
\hline $5 / 16 / 2013$ & 43.71 & 11.16 & 10.48 & 11.00 & 20.96 & 20.22 & 19.67 & 13.92 & 17.29 & 15.98 \\
\hline $5 / 23 / 2013$ & 41.23 & 9.68 & 11.63 & 14.15 & 24.71 & 23.61 & 24.27 & 17.56 & 21.43 & 19.20 \\
\hline $5 / 30 / 2013$ & 32.90 & 4.53 & 8.29 & 11.33 & 19.41 & 18.47 & 20.36 & 13.60 & 16.05 & 16.34 \\
\hline $6 / 6 / 2013$ & 43.87 & 9.54 & 13.53 & 18.94 & 20.71 & 22.16 & 24.25 & 14.34 & 17.53 & 16.08 \\
\hline $6 / 13 / 2013$ & 35.17 & 7.76 & 10.63 & 13.89 & 15.37 & 16.47 & 17.28 & 12.16 & 14.30 & 10.66 \\
\hline $6 / 26 / 2013$ & 35.62 & 1.96 & 2.79 & 6.01 & 12.71 & 11.40 & 16.74 & 13.60 & 15.81 & 12.05 \\
\hline $7 / 3 / 2013$ & 54.23 & 3.71 & 6.99 & 2.94 & 16.46 & 14.10 & 16.20 & 12.12 & 10.63 & 9.92 \\
\hline $7 / 17 / 2013$ & 42.34 & 3.03 & 2.38 & 2.43 & 15.19 & 11.05 & 12.68 & 11.41 & 13.69 & 10.37 \\
\hline $7 / 24 / 2013$ & 30.13 & 2.69 & 2.56 & 2.69 & 12.06 & 12.79 & 13.54 & 8.79 & 9.57 & 7.03 \\
\hline $7 / 31 / 2013$ & 53.05 & 5.12 & 1.37 & 1.28 & 12.95 & 17.10 & 15.57 & 13.27 & 14.08 & 12.43 \\
\hline $8 / 7 / 2013$ & 37.77 & 3.09 & 2.45 & 4.02 & 22.70 & 23.43 & 26.97 & 22.99 & 24.33 & 28.94 \\
\hline $8 / 14 / 2013$ & 31.32 & 1.09 & 1.23 & 3.42 & 15.07 & 15.90 & 14.67 & 15.02 & 18.64 & 14.59 \\
\hline $8 / 21 / 2013$ & 53.83 & 1.41 & 1.87 & 2.85 & 17.20 & 19.33 & 16.71 & 19.61 & 18.97 & 16.93 \\
\hline $8 / 29 / 2013$ & 36.26 & 0.78 & 0.66 & 0.67 & 13.82 & 13.12 & 16.38 & 14.95 & 16.29 & 18.17 \\
\hline $9 / 4 / 2013$ & 27.45 & 4.54 & 5.51 & 2.54 & 9.84 & 11.76 & 11.91 & 11.35 & 8.74 & 7.44 \\
\hline $9 / 11 / 2013$ & 38.56 & 18.46 & 7.30 & 3.91 & 14.68 & 14.20 & 13.96 & 12.90 & 18.69 & 9.94 \\
\hline $9 / 18 / 2013$ & 40.26 & 8.02 & 8.22 & 4.20 & 17.29 & 16.43 & 14.00 & 17.55 & 17.25 & 15.16 \\
\hline $9 / 25 / 2013$ & 44.11 & 6.28 & 7.53 & 5.56 & 18.49 & 19.50 & 16.82 & 23.41 & 17.62 & 18.17 \\
\hline $10 / 2 / 2013$ & 45.47 & 14.49 & 20.01 & 13.04 & 26.29 & 28.10 & 23.40 & 22.03 & 20.86 & 19.92 \\
\hline $10 / 9 / 2013$ & 40.34 & 10.36 & 14.08 & 12.28 & 21.00 & 21.95 & 21.51 & 22.19 & 22.24 & 20.53 \\
\hline $10 / 16 / 2013$ & 35.78 & 12.88 & 15.35 & 13.35 & 20.65 & 21.75 & 21.94 & 23.53 & 21.54 & 20.86 \\
\hline $10 / 23 / 2013$ & 33.88 & 12.87 & 15.90 & 12.99 & 20.49 & 21.30 & 21.78 & 19.39 & 19.86 & 18.78 \\
\hline $10 / 30 / 2013$ & 35.79 & 13.02 & 15.97 & 13.58 & 21.59 & 22.32 & 23.20 & 22.87 & 23.97 & 24.54 \\
\hline $11 / 6 / 2013$ & 33.81 & 15.94 & 12.78 & 11.04 & 18.13 & 19.83 & 20.78 & 20.60 & 24.29 & 23.97 \\
\hline $11 / 13 / 2013$ & 32.84 & 11.68 & 13.42 & 13.76 & 18.89 & 21.48 & 21.26 & 17.45 & 22.72 & 21.87 \\
\hline $11 / 20 / 2013$ & 29.70 & 15.37 & 15.61 & 13.16 & 21.97 & 22.79 & 21.99 & 16.98 & 23.19 & 23.18 \\
\hline $11 / 25 / 2013$ & 27.78 & 15.44 & 14.88 & 17.14 & 30.19 & 27.40 & 25.69 & 26.81 & 24.14 & 32.53 \\
\hline $12 / 4 / 2013$ & 36.80 & 17.27 & 17.13 & 18.30 & 43.90 & 30.80 & 27.37 & 27.31 & 32.15 & 32.79 \\
\hline $12 / 11 / 2013$ & 35.37 & 20.30 & 21.77 & 21.04 & 28.56 & 31.64 & 29.07 & 30.71 & 33.73 & 34.87 \\
\hline $12 / 18 / 2013$ & 29.66 & 19.86 & 18.19 & 20.20 & 27.50 & 26.83 & 25.76 & 27.88 & 31.97 & 26.68 \\
\hline $1 / 8 / 2014$ & 31.01 & 5.48 & 8.73 & 10.57 & 20.92 & 21.38 & 24.72 & 28.97 & 34.66 & 32.13 \\
\hline $1 / 15 / 2014$ & 34.53 & 3.30 & 5.07 & 7.04 & 29.22 & 33.38 & 32.13 & 41.28 & 44.40 & 44.04 \\
\hline $1 / 22 / 2014$ & 37.43 & 2.15 & 3.82 & 4.50 & 32.48 & 35.86 & 34.10 & 44.56 & 48.41 & 47.41 \\
\hline $1 / 29 / 2014$ & 34.39 & 1.13 & 1.81 & 1.45 & 29.02 & 27.07 & 24.09 & 37.63 & 38.27 & 37.14 \\
\hline $2 / 5 / 2014$ & 34.03 & 1.88 & 2.60 & 2.73 & 26.95 & 24.42 & 20.33 & 37.48 & 37.75 & 39.01 \\
\hline $2 / 12 / 2014$ & 43.29 & 20.43 & 20.27 & 19.42 & 29.59 & 28.49 & 22.75 & 39.12 & 38.60 & 38.57 \\
\hline $2 / 19 / 2014$ & 39.77 & 15.24 & 14.20 & 14.93 & 28.71 & 26.07 & 19.42 & 36.78 & 36.31 & 35.87 \\
\hline $2 / 26 / 2014$ & 38.76 & 12.35 & 15.15 & 13.91 & 27.53 & 24.76 & 19.81 & 33.88 & 31.81 & 32.09 \\
\hline $3 / 5 / 2014$ & 39.59 & 11.63 & 11.26 & 10.48 & 22.31 & 19.91 & 16.72 & 22.47 & 23.41 & 23.09 \\
\hline $3 / 12 / 2014$ & 35.54 & 11.57 & 11.17 & 8.30 & 24.68 & 20.46 & 17.30 & 20.63 & 26.11 & 22.90 \\
\hline $3 / 19 / 2014$ & 42.09 & 12.57 & 11.86 & 9.04 & 17.50 & 20.85 & 19.41 & 21.56 & 21.57 & 21.70 \\
\hline
\end{tabular}


Table F-2: Dissolved reactive phosphorus data for influent and all ponds

Dissolved Reactive Phosphorus (mg/L-P)

\begin{tabular}{|c|c|c|c|c|c|c|c|c|c|c|}
\hline \multirow[b]{2}{*}{ Date } & \multirow[b]{2}{*}{ Influent } & \multicolumn{3}{|c|}{ Alpha } & \multicolumn{3}{|c|}{ Beta } & \multicolumn{3}{|c|}{ Gamma } \\
\hline & & Pond 1 & Pond 2 & Pond 3 & Pond 4 & Pond 5 & Pond 6 & Pond 7 & Pond 8 & Pond 9 \\
\hline $3 / 6 / 2013$ & 3.68 & 1.95 & 2.15 & 1.18 & 2.65 & 2.94 & 2.70 & 2.71 & 3.38 & 2.90 \\
\hline $3 / 13 / 2013$ & 3.41 & 1.68 & 1.83 & 2.21 & 2.74 & 2.66 & 2.95 & 2.92 & 3.29 & 2.68 \\
\hline $3 / 20 / 2013$ & 3.23 & 2.43 & 1.82 & 2.05 & 2.76 & 2.27 & 2.92 & 2.84 & 2.72 & 2.78 \\
\hline \multicolumn{11}{|l|}{$3 / 27 / 2013$} \\
\hline 4/4/2013 & 3.87 & 1.51 & 1.66 & 1.69 & 2.69 & 2.35 & 3.18 & 2.62 & 2.90 & 2.80 \\
\hline $4 / 11 / 2013$ & 3.44 & 0.94 & 0.12 & 0.39 & 2.76 & 2.36 & 2.87 & 2.82 & 4.53 & 2.15 \\
\hline $4 / 18 / 2013$ & 3.41 & 0.59 & 0.63 & 0.63 & 2.49 & 2.38 & 2.50 & 2.43 & 2.79 & 2.65 \\
\hline $4 / 25 / 2013$ & 3.41 & 2.83 & 1.48 & 2.83 & 2.91 & 2.64 & 3.13 & 2.89 & 3.30 & 3.16 \\
\hline $5 / 2 / 2013$ & 3.60 & 0.93 & 0.19 & 0.50 & 2.37 & 2.36 & 3.16 & 2.80 & 3.61 & 2.81 \\
\hline $5 / 9 / 2013$ & 3.67 & 1.28 & 1.44 & 2.73 & 2.09 & 2.67 & 3.10 & 2.92 & 3.29 & 3.08 \\
\hline $5 / 16 / 2013$ & 3.50 & 0.30 & 0.39 & 0.39 & 2.44 & 2.29 & 2.80 & 2.75 & 3.10 & 3.16 \\
\hline $5 / 23 / 2013$ & 3.57 & 0.22 & 0.36 & 0.90 & 2.14 & 1.63 & 2.44 & 2.56 & 2.94 & 2.86 \\
\hline $5 / 30 / 2013$ & 3.60 & 0.03 & 0.07 & 1.49 & 1.79 & 1.29 & 2.28 & 2.62 & 2.57 & 2.74 \\
\hline $6 / 6 / 2013$ & 4.13 & 0.16 & 0.35 & 1.81 & 2.14 & 1.91 & 2.32 & 2.92 & 2.99 & 3.24 \\
\hline $6 / 13 / 2013$ & 3.59 & 0.29 & 0.42 & 1.60 & 1.33 & 1.54 & 2.14 & 2.34 & 2.67 & 2.90 \\
\hline $6 / 26 / 2013$ & 2.79 & 0.00 & 0.00 & 0.11 & 1.03 & 0.69 & 1.67 & 2.13 & 2.07 & 2.75 \\
\hline $7 / 3 / 2013$ & 3.28 & 0.00 & 0.01 & 0.00 & 1.31 & 0.81 & 1.70 & 1.95 & 1.74 & 2.37 \\
\hline $7 / 17 / 2013$ & 3.92 & 0.03 & 0.05 & 0.00 & 2.24 & 0.71 & 1.54 & 2.06 & 2.36 & 2.30 \\
\hline $7 / 24 / 2013$ & 3.33 & 0.39 & 0.22 & 0.20 & 2.16 & 1.72 & 1.89 & 2.46 & 4.09 & 2.81 \\
\hline $7 / 31 / 2013$ & 4.45 & 0.32 & 0.51 & 0.57 & 2.77 & 2.29 & 2.35 & 2.65 & 3.48 & 3.35 \\
\hline 8/7/2013 & 3.40 & 0.90 & 0.42 & 0.99 & 2.98 & 2.47 & 2.48 & 2.93 & 3.27 & 3.39 \\
\hline $8 / 14 / 2013$ & 3.78 & 0.99 & 1.04 & 1.34 & 2.64 & 2.47 & 2.44 & 2.39 & 2.41 & 3.29 \\
\hline $8 / 21 / 2013$ & 3.62 & 0.83 & 0.97 & 1.01 & 2.28 & 2.84 & 2.31 & 2.18 & 2.21 & 2.63 \\
\hline $8 / 29 / 2013$ & 3.62 & 0.83 & 0.97 & 1.01 & 2.28 & 2.84 & 2.31 & 2.18 & 2.21 & 2.63 \\
\hline $9 / 4 / 2013$ & 3.68 & 0.59 & 0.50 & 1.79 & 2.75 & 2.70 & 2.71 & 2.68 & 2.82 & 3.00 \\
\hline $9 / 11 / 2013$ & 2.93 & 0.54 & 0.47 & 0.51 & 2.59 & 2.53 & 3.03 & 2.88 & 3.03 & 2.91 \\
\hline $9 / 18 / 2013$ & 4.04 & 0.60 & 0.55 & 2.20 & 2.63 & 2.67 & 3.16 & 2.99 & 3.01 & 2.79 \\
\hline $9 / 25 / 2013$ & 1.78 & 0.75 & 0.70 & 0.63 & 0.78 & 1.07 & 1.28 & 1.27 & 1.17 & 1.48 \\
\hline $10 / 2 / 2013$ & 4.28 & 3.08 & 0.62 & 2.92 & 3.13 & 3.35 & 3.73 & 2.94 & 3.33 & 3.27 \\
\hline $10 / 9 / 2013$ & 3.85 & 0.81 & 0.58 & 0.93 & 2.89 & 3.36 & 3.30 & 3.10 & 3.24 & 3.01 \\
\hline $10 / 16 / 2013$ & 4.20 & 2.65 & 0.79 & 2.50 & 2.75 & 3.31 & 2.54 & 3.51 & 3.11 & 2.96 \\
\hline $10 / 23 / 2013$ & 4.18 & 2.46 & 0.87 & 2.40 & 2.78 & 3.22 & 2.79 & 3.33 & 3.41 & 3.60 \\
\hline $10 / 30 / 2013$ & 4.52 & 2.82 & 1.03 & 2.78 & 3.31 & 3.84 & 3.34 & 3.83 & 3.51 & 3.88 \\
\hline $11 / 6 / 2013$ & 3.81 & 0.95 & 0.80 & 2.60 & 3.40 & 3.27 & 2.84 & 3.34 & 3.23 & 3.02 \\
\hline $11 / 13 / 2013$ & 3.83 & 1.55 & 1.46 & 2.81 & 3.66 & 3.73 & 3.02 & 3.20 & 3.47 & 3.15 \\
\hline $11 / 20 / 2013$ & 3.93 & 1.43 & 1.25 & 2.68 & 3.44 & 3.21 & 3.01 & 3.37 & 3.46 & 3.03 \\
\hline \multicolumn{11}{|l|}{$11 / 25 / 2013$} \\
\hline \multicolumn{11}{|l|}{$12 / 4 / 2013$} \\
\hline $12 / 11 / 2013$ & 3.84 & 2.68 & 2.80 & 2.71 & 3.20 & 3.04 & 3.08 & 3.36 & 3.58 & 3.24 \\
\hline $12 / 18 / 2013$ & 4.15 & 2.78 & 2.77 & 2.55 & 3.21 & 3.07 & 3.21 & 3.16 & 3.44 & 3.06 \\
\hline $1 / 8 / 2014$ & 3.40 & 2.62 & 2.79 & 2.95 & 3.05 & 2.96 & 3.02 & 3.08 & 3.42 & 3.07 \\
\hline $1 / 15 / 2014$ & 3.40 & 3.10 & 3.10 & 2.94 & 3.46 & 3.33 & 3.06 & 3.05 & 3.45 & 3.22 \\
\hline $1 / 22 / 2014$ & 3.60 & 3.04 & 2.94 & 2.58 & 3.48 & 3.20 & 3.26 & 3.53 & 3.92 & 3.82 \\
\hline $1 / 29 / 2014$ & 3.54 & 1.80 & 2.32 & 2.50 & 3.56 & 3.37 & 3.39 & 3.85 & 3.76 & 3.64 \\
\hline 2/5/2014 & 3.68 & 2.21 & 2.13 & 2.36 & 3.32 & 2.93 & 3.10 & 3.44 & 3.40 & 3.62 \\
\hline $2 / 12 / 2014$ & 3.66 & 1.98 & 2.03 & 2.43 & 2.92 & 3.10 & 3.04 & 3.42 & 3.37 & 3.34 \\
\hline $2 / 19 / 2014$ & 3.39 & 1.97 & 2.05 & 2.07 & 2.67 & 2.72 & 2.83 & 2.88 & 2.94 & 2.90 \\
\hline $2 / 26 / 2014$ & 3.69 & 1.37 & 1.58 & 2.28 & 3.01 & 3.13 & 3.40 & 3.92 & 3.98 & 3.78 \\
\hline $3 / 5 / 2014$ & 3.17 & 0.85 & 0.87 & 1.73 & 2.28 & 2.33 & 2.67 & 2.76 & 2.51 & 2.55 \\
\hline $3 / 12 / 2014$ & 3.41 & 0.53 & 0.55 & 1.57 & 1.90 & 2.58 & 3.25 & 2.94 & 3.13 & 2.85 \\
\hline $3 / 19 / 2014$ & 3.50 & 0.40 & 0.43 & 1.75 & 1.92 & 2.47 & 3.30 & 2.73 & 3.02 & 2.74 \\
\hline
\end{tabular}

